INSTITUTO DE PESQUISAS ENERGÉTICAS E NUCLEARES

Autarquia Associada à Universidade de São Paulo

\author{
PREPARAÇÃO E CARACTERIZAÇÃO DE NANOPARTíCULAS DE \\ MOLIBDATOS DE TERRAS RARAS PARA DETECÇÃO DO ANTÍGENO \\ ESPECÍFICO DA PRÓSTATA (PSA)
}

CLARISSA LOMBARDI DIAS

Dissertação apresentada como parte dos requisitos para a obtenção do Grau de Mestre em Ciências na Área de Tecnologia Nuclear - Materiais.

Orientador:

Dra. Maria Claudia F. C. Felinto 
À minha querida mãe por vivenciar minhas conquistas e me amar incondicionalmente.

Ao meu pai por todo apoio, suporte e amor. 


\section{AGRADECIMENTOS}

À Deus por sempre abrir meus caminhos.

Aos meus pais por possibilitarem que eu realizasse meus sonhos e ao meu amado irmão pela cumplicidade.

Aos meus queridos familiares: tia Lourdes, tio Tadeu, Gabriele, Fábio, Luan, Cauê, Davi, tia Cleide, Ana Paula e Raitan por todo apoio, amor e carinho.

À minha querida avó Olinda por entender, apoiar, me ensinar, por ter vivido essa fase comigo e preparado minhas refeições com tanto carinho.

Ao Luis por todo incentivo, positividade, pelos momentos de distração, cumplicidade, pela paciência imensurável e por todo amor.

À Dra. Maria Claudia F. C. Felinto pela orientação, ensinamentos e amizade.

Ao Instituto de Pesquisas Energéticas e Nucleares (IPEN/CNEN - SP) pela oportunidade de desenvolver este trabalho em suas dependências. Ao Conselho Nacional de Energia Nuclear (CNEN) pela bolsa concedida.

À Comissão de pós-graduação do Instituto de Pesquisas Energéticas e Nucleares (IPEN/CNEN - SP) pelos esclarecimentos de dúvidas e por serem sempre prestativos.

Ao professor Hermi Felinto de Brito por ceder equipamentos para realização desse trabalho, pelos ensinamentos e convivência. Aos seus alunos, Cássio, José, Tiago, Ivan, Israel, Lucas, César, Helliomar, Latif e Danilo por me ajudarem com a parte experimental do trabalho, pela ótima convivência e amizade. 
À Claudia Akemi Kodaira e Ana Valéria Lourenço pelos ensinamentos e auxílios com a parte biológica desse trabalho.

Ao querido professor Oscar por todos os ensinamentos, conversas e amizade.

Às grandes amigas que a vida me trouxe durante o mestrado Liana, Débora e Elen, pela ótima convivência, momentos de descontração, risadas, ajudas imensuráveis e ensinamentos diários.

Aos colegas de trabalho do laboratório: Eduardo, Vitor, Heloísa, Thelma, Everton, Klauss, Paula, Edson e Edison por todo apoio diário.

Aos colegas do CQMA: João, Takeshi, Valdelei e Brandão pela amizade e apoio técnico.

A todos os colegas do Centro de Química e Meio Ambiente do IPEN/CNEN - SP pelo apoio durante o desenvolvimento deste trabalho.

Aos irmãos que a vida me trouxe: Débora, Natália, Fernanda, Bruna, Caio, Gustavo C., Bruno, Gustavo F. e seus familiares por todos ótimos momentos que tivemos, pelo apoio, compreensão e amizade nesses anos.

Às amigas do coração: Karina, Amanda, Ana Ferrari, Juliana e Camila pelos ótimos momentos de descontração e amizade.

Aos amigos de graduação, Tayrine, Marina Guerreiro, Ana Carolina, Elen Dias, Pérola, Nadin, Renata, Alessandro, Fernando, Laura e aos professores Mércia, Heitor, Suzana, Débora e Eliana. 
"O sábio não entesoura. Quanto mais dá aos outros, tanto mais tem." Lao-Tsé

"Morre lentamente quem se transforma em escravo do hábito; repetindo todos os dias os mesmos trajetos."

Pablo Neruda 


\title{
PREPARAÇÃO E CARACTERIZAÇÃO DE NANOPARTÍCULAS DE MOLIBDATOS DE TERRAS RARAS PARA DETECÇÃO DO ANTÍGENO ESPECÍFICO DA PRÓSTATA (PSA)
}

\author{
Clarissa Lombardi Dias
}

\section{RESUMO}

O interesse em utilizar terras raras para investigar propriedades e funções de sistemas bioquímicos tanto quanto de determinar substâncias biológicas tem crescido em diferentes áreas, incluindo biomarcadores em imunologia (fluoroimunoensaios). Atualmente, o uso de terras raras no diagnóstico de diversas doenças tem se tornado muito importante com o desenvolvimento de kits de diagnóstico. Como característica principal, as terras raras podem apresentar longo tempo de vida, fotoestabilidade e bandas de emissão finas e bem definidas na região do visível, demonstrando vantagens únicas quando comparadas a outras espécies luminescentes. $O$ presente trabalho teve como objetivo sintetizar molibdatos de terras raras pelo método de coprecipitação, assim como caracterizá-los através de técnicas como: difração de raios $\mathrm{X}$, espectroscopia do infravermelho, análise termogravimétrica, microscopia eletrônica de varredura, microscopia eletrônica de transmissão e estudos de luminescência. Nesse trabalho foram desenvolvidos três diferentes estudos de síntese: a influência da variação da velocidade do dispersor no momento da precipitação; a influência do tratamento térmico na estrutura, morfologia e propriedades luminescentes; e a influência da concentração do íon dopante nas propriedades estruturais e espectroscópicas. Outro passo importante desse trabalho foi o de aminofuncionalizar as nanopartículas utilizando um organosilano (APTES) para recobrir e estabelecer pontos para que essas partículas pudessem se ligar a espécies biológicas. Foi comprovado pelos resultados das caracterizações que esse processo foi eficiente e a incorporação da sílica foi bem sucedida. O Antígeno Específico da Próstata (PSA) foi então ligado às nanopartículas funcionalizadas para possibilitar o diagnóstico de câncer de 
próstata através de fluoroimunoensaios e dessa forma, níveis de detecção foram estabelecidos. 


\title{
SYNTHESIS AND CHARACTERIZATION OF RARE EARTH MOLIBDATES NANOPARTICLES FOR DETECTION OF SPECIFIC PROSTATIC CANCER (PSA)
}

\author{
Clarissa Lombardi Dias
}

\begin{abstract}
The interest in using rare earths to investigate the properties and functions of biochemical systems as well as to determinate biological substances has increased in several fields, including biomarkers in immunology (fluoroimmunoassays). Nowadays the use of lanthanides in the diagnosis of various diseases have become more important through the development of commercial diagnostic kits. As main feature, these rare earths can show a long lifetime, photostability and emission bands of atomic like behavior and well defined, in the visible region, demonstrating unique advantages when compared to other luminescent species. The present work had as its goal to synthesize rare earth molybdates by the co-precipitation method as well as to characterize these materials by X-ray diffraction, near infrared spectroscopy, thermogravimetric analysis, scanning electronic microscopy, transmission electronic microscopy and luminescent studies. In this work, three different studied were developed: the influence of the vortex speed variation during co-precipitation in the structure of the final product, morphology and luminescence properties; the influence of the annealing temperature also in the structure, morphology and luminescence properties; and the influence of concentration of the doping in the luminescence properties. Another important step of this work was the functionalization of nanoparticles using an organosilane (APTES) to coat and establish points for binding the particles to biological species. It was proved that this process was very efficient by the characterization results and the silica incorporation was well succeeded. Specific prostatic cancer (PSA) was then linked to the functionalized nanoparticles to diagnostic prostatic cancer by fluoroimmunoassay and levels for detection were established.
\end{abstract}




\section{SUMÁRIO}

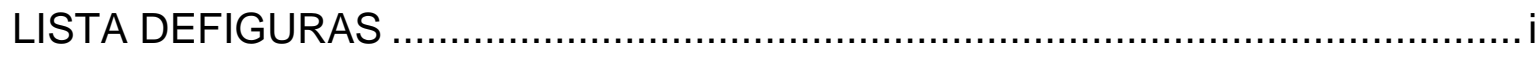

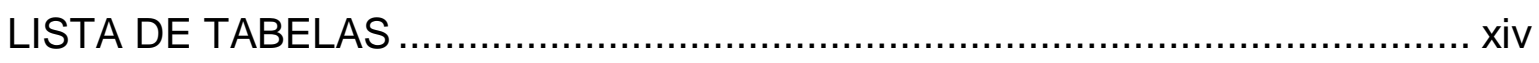

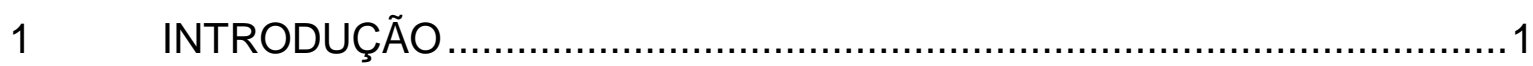

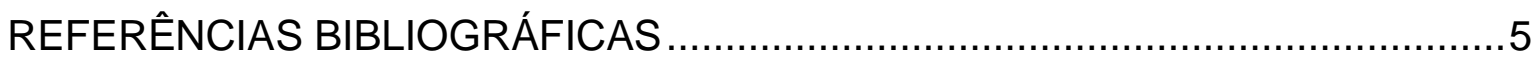

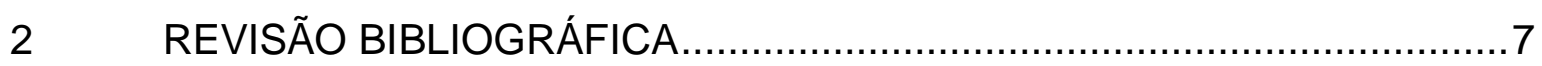

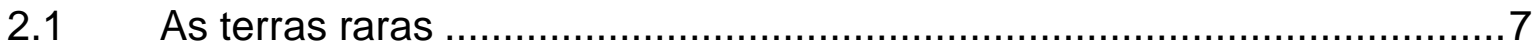

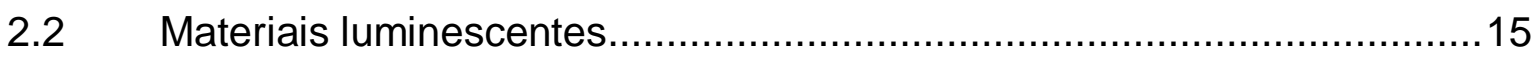

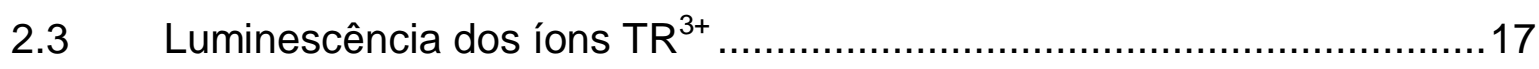

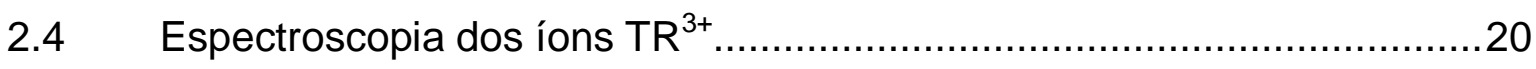

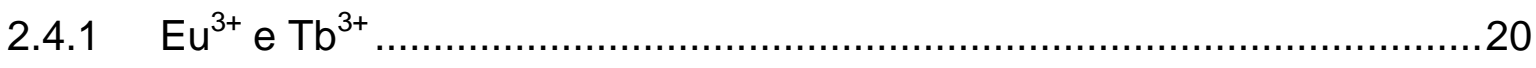

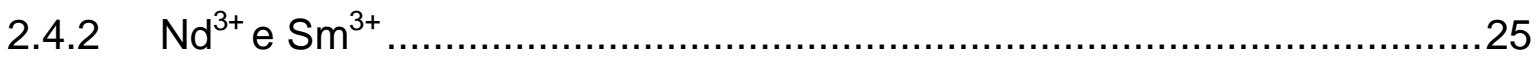

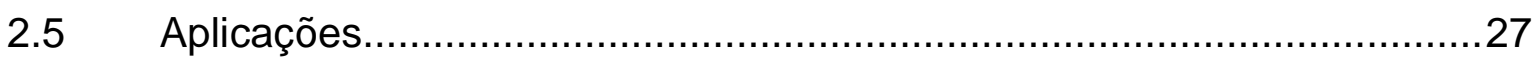

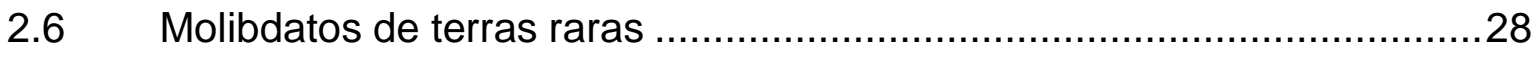

2.6.1 As terras raras como sondas biológicas ........................................ 30

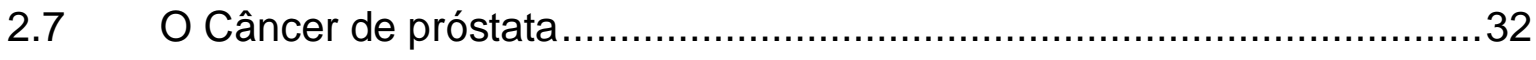

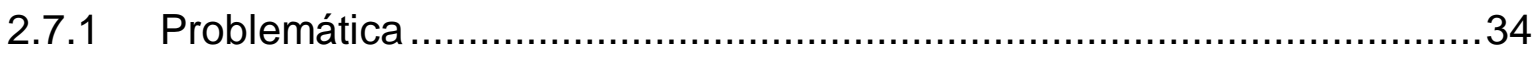

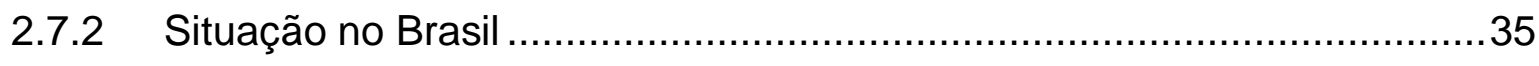


2.7.4 O uso da nanotecnologia para o diagnóstico de doenças.

2.7.5 Ensaios biológicos por fluorimetria

REFERÊNCIAS BIBLIOGRÁFICAS

4.1 Reagentes e solventes

4.1 Sínteses

4.1.1 Síntese dos cloretos de terras raras

4.1.2 Obtenção das nanopartículas de molibdato de terras raras - Via método coprecipitação

4.1.3 Estudo da influência da velocidade de dispersão na precipitação no tamanho da partícula e nas propriedades espectroscópicas de $\mathrm{Eu}_{2}\left(\mathrm{MoO}_{4}\right)_{3}$ 55

4.1.4 Estudo da influência do tratamento térmico (Annealing) à $120^{\circ} \mathrm{C}, 300^{\circ} \mathrm{C}$, $500^{\circ} \mathrm{C}, 700^{\circ} \mathrm{C}$ e $1.000^{\circ} \mathrm{C}$ nas propriedades espectroscópicas e estruturais. 56

4.1.5 Síntese das nanopartículas de ítrio dopadas com terras raras 57

4.2 Caracterização dos molibdatos de terras raras e das nanopartículas funcionalizadas de molibdatos de terras raras .58

4.2.1 Espectroscopia de Absorção no Infravermelho por Transformada de Fourier (FTIR) .58 
4.2.4 Microscopia Eletrônica de Varredura (MEV) ……................................59

4.2.5 Microscopia Eletrônica de Transmissão (TEM) .....................................60

4.2.6 Estudos de Fotoluminescência ...........................................................60

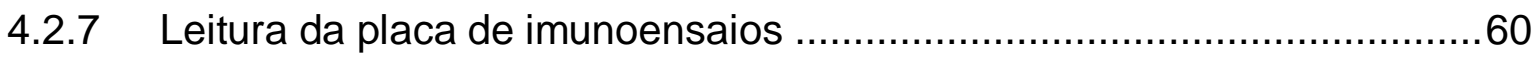

4.3 Funcionalização das nanopartículas dopadas com Terras Raras............61

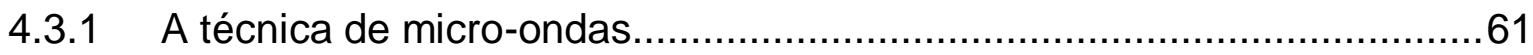

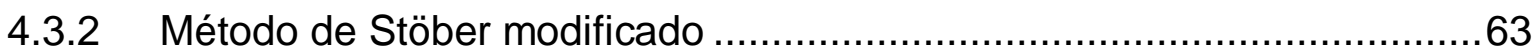

4.3.3 Determinação de aminas primárias - método da ninidrina ........................65

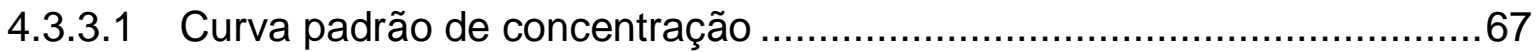

4.3.3.2 Quantificação de aminas nas partículas................................................

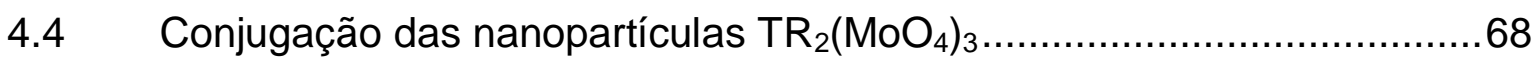

4.4.1 Reação das entidades $\mathrm{TR}_{2}\left(\mathrm{MoO}_{4}\right)_{3} @$ Si com o espaçador glutaraldeído.68

4.4.2 Reação das nanopartículas $\mathrm{TR}_{2}\left(\mathrm{MoO}_{4}\right)_{3} @$ Si-Glu com a Albumina Sérica Bovina (BSA) 69

4.4.3 Reação das nanopartículas $\mathrm{Eu}_{2}\left(\mathrm{MoO}_{4}\right)_{3} @ \mathrm{Si}$-Glu com o anticorpo de marcação para o antígeno específico da próstata (PSA) ....................................70

4.4.4 Método de Bradford para deteç̧ão de proteínas ...................................71 
4.4.5 Sensibilização da placa com o anticorpo de captura H11P8 para PSA ...72

4.5 Desenvolvimento do imunoensaio para determinar o antígeno específico da próstata PSA .73

4.6 Teste de Hemocompatibilidade 74

4.6.1 Preparação dos filmes de quitosana 74

4.6.2 Método de Hemocompatibilidade 75

REFERÊNCIAS BIBLIOGRÁFICAS 76

5 RESULTADOS E DISCUSSÃO - Sínteses e Caracterizações. .78

5.1 Síntese dos molibdatos de terras raras $\mathrm{TR}_{2}\left(\mathrm{MoO}_{4}\right)_{3}\left(\mathrm{TR}=\mathrm{Y}^{3+}, \mathrm{Nd}^{3+}, \mathrm{Sm}^{3+}\right.$, $\mathrm{Eu}^{3+}, \mathrm{Gd}^{3+}$ e $\left.\mathrm{Tb}^{3+}\right)$ 78

5.2 Caracterizações dos molibdatos de terras raras $\mathrm{TR}_{2}\left(\mathrm{MoO}_{4}\right)_{3}$ 84

5.2.1 Espectroscopia de absorção no infravermelho com transformada de Fourrier (FTIR) dos molibdatos de terras raras $\mathrm{TR}_{2}\left(\mathrm{MoO}_{4}\right)_{3}$ .84

5.2.2 Análise Termogravimétrica (TG/DTG) .88

5.2.3 Difração de raios $X$ - método do pó (DRX) .93

5.2.4 Microscopia eletrônica de varredura (MEV) .97

5.2.5 Estudo fotoluminescente dos $\mathrm{TR}_{2}\left(\mathrm{MoO}_{4}\right)_{3}$ .98

5.2.6 Comportamento espectroscópico do íon $\mathrm{Gd}^{3+}$ na matriz $\mathrm{Gd}_{2}\left(\mathrm{MoO}_{4) 3} \ldots . .99\right.$

5.2.7 Comportamento espectroscópico do íon $\mathrm{Y}^{3+}$ na matriz $\mathrm{Y}_{2}\left(\mathrm{MoO}_{4}\right)_{3}$ 101 
5.2.8 Comportamento espectroscópico do íon $\mathrm{Eu}^{3+}$ na matriz $\mathrm{Eu}_{2}\left(\mathrm{MoO}_{4}\right)_{3} \ldots 103$

5.2.9 Parâmetros de intensidade 107

5.2.10 Comportamento espectroscópico do íon $\mathrm{Sm}^{3+}$ na matriz $\mathrm{Sm}_{2}\left(\mathrm{MoO}_{4}\right)_{3}$ 110

5.2.11 Comportamento espectroscópico do íon $\mathrm{Tb}^{3+}$ na matriz $\mathrm{Tb}_{2}\left(\mathrm{MoO}_{4}\right)_{3} . .113$

5.2.12 Comportamento espectroscópico do íon $\mathrm{Nd}^{3+}$ na matriz $\mathrm{Nd}_{2}\left(\mathrm{MoO}_{4}\right)_{3} .116$

5.3 Estudo da influência da velocidade de dispersão usada para precipitação dos molibdatos no tamanho da partícula e nas propriedades espectroscópicas de $\mathrm{Eu}_{2}\left(\mathrm{MoO}_{4}\right)_{3}$ 119

5.3.1 Características qualitativas 119

5.3.2 Espectroscopia de infravermelho com transformada de Fourrier (FTIR) 120

5.3.3 Análise Termogravimétrica (TG/DTG). 121

5.3.4 Difração de raio-X (DRX) 124

5.3.5 Microscopia eletrônica de varredura (MEV) 125

5.3.6 Propriedades espectroscópicas luminescentes 126

5.4 Dopagens das nanopartículas de molibdato de ítrio com elementos de terras raras. 130

5.4.1 Espectroscopia de infravermelho com transformada de Fourrier (FTIR)132

5.4.2 Difração de raio X (DRX) 133 
5.4.4 Estudo das propriedades luminescentes

5.5 Estudo de Influência do tratamento térmico (Annealing) nas propriedades estruturais e luminescentes do luminóforo $\mathrm{Eu}_{2}\left(\mathrm{MoO}_{4}\right)_{3}, \mathrm{Sm}_{2}\left(\mathrm{MoO}_{4}\right)_{3}, \mathrm{~Tb}_{2}\left(\mathrm{MoO}_{4}\right)_{3} \mathrm{e}$ $\mathrm{Nd}_{2}\left(\mathrm{MoO}_{4}\right)_{3}$ 142

5.5.1 Características qualitativas dos materiais tratados termicamente. 143

5.5.2 Caracterização das matrizes termicamente tratadas por Espectroscopia de infravermelho com transformada de Fourrier (FTIR) 145

5.5.3 Difração de raio X (DRX) 146

5.5.4 Estudo do tamanho do cristalito em relação ao aumento da temperatura 151

5.5.5 Microscopia eletrônica de varredura (MEV) 152

5.5.6 Estudo de luminescência das matrizes $\mathrm{Eu}_{2}\left(\mathrm{MoO}_{4}\right)_{3}, \quad \mathrm{~Tb}_{2}\left(\mathrm{MoO}_{4}\right)_{3}$, $\mathrm{Sm}_{2}\left(\mathrm{MoO}_{4}\right)_{3}$ e $\mathrm{Nd}_{2}\left(\mathrm{MoO}_{4}\right)_{3}$ termicamente tratadas 156

5.6 Funcionalização das nanopartículas dopadas com Terras Raras. 168

5.6.1 Preparação das partículas contendo os fósforos $\left(\mathrm{Eu}_{2}\left(\mathrm{MoO}_{4}\right)_{3}\right.$, $\mathrm{Y}\left(5 \% \mathrm{Eu}_{2}\left(\mathrm{MoO}_{4}\right)_{3}, \mathrm{~Tb}_{2}\left(\mathrm{MoO}_{4}\right)_{3}, \mathrm{Sm}_{2}\left(\mathrm{MoO}_{4}\right)_{3}, \mathrm{Nd}_{2}\left(\mathrm{MoO}_{4}\right)_{3}\right)$ incorporados na sílica aminofuncionalizada: método micro-ondas 169

5.6.2 Partículas de sílica contendo os fósforos $\left(\mathrm{Eu}_{2}\left(\mathrm{MoO}_{4}\right)_{3}, \mathrm{Y}\left(5 \% \mathrm{Eu}_{2}\left(\mathrm{MoO}_{4}\right)_{3}\right.\right.$, $\left.\mathrm{Tb}_{2}\left(\mathrm{MoO}_{4}\right)_{3}, \mathrm{Sm}_{2}\left(\mathrm{MoO}_{4}\right)_{3}, \mathrm{Nd}_{2}\left(\mathrm{MoO}_{4}\right)_{3}\right)$ incorporado na sílica aminofuncionalizada: método Stöber 
5.6.3.1 Espectroscopia de absorção na região do infravermelho com transformada de Fourrier (FTIR) dos fósforos $\mathrm{TR}_{2}\left(\mathrm{MoO}_{4}\right)_{3}$

5.6.3.2 Difração de raio $X(\mathrm{DRX})$ dos molibdatos de $\mathrm{TR}^{3+}\left(\mathrm{TR}=\mathrm{Eu}_{2}\left(\mathrm{MoO}_{4}\right)_{3}\right.$, $\mathrm{Y}\left(5 \% \mathrm{Eu}_{2}\left(\mathrm{MoO}_{4}\right)_{3}, \mathrm{Sm}_{2}\left(\mathrm{MoO}_{4}\right)_{3}, \mathrm{~Tb}_{2}\left(\mathrm{MoO}_{4}\right)_{3}\right.$ e $\mathrm{Nd}_{2}\left(\mathrm{MoO}_{4}\right)_{3}$ funcionalizados

5.6.3.3 Microscopia eletrônica de varredura (MEV) das nanopartículas de neodímio aminofuncionalizadas $\left(\mathrm{Nd}_{2}\left(\mathrm{MoO}_{4}\right)_{3} @ \mathrm{Si}\right)$ 180

5.6.3.4 Espectroscopia por dispersão de energia (EDS) das nanopartículas de neodímio aminofuncionalizadas $\left(\mathrm{Nd}_{2}\left(\mathrm{MoO}_{4}\right)_{3} @ S i\right)$

5.6.3.5 Microscopia eletrônica de transmissão (TEM) das nanopartículas de neodímio aminofuncionalizadas $\left(\mathrm{Nd}_{2}\left(\mathrm{MoO}_{4}\right)_{3} @ S i\right)$ 183

5.6.3.6 Estudo das propriedades luminescentes das partículas de $\mathrm{TR}_{2}\left(\mathrm{MoO}_{4}\right)_{3}$ $@ \mathrm{Si}$

5.6.4 Determinação das aminas primárias 194

5.6.4.1 Curva de calibração 194

5.6.4.2 Quantificação de aminas nas partículas silanizadas 196

REFERÊNCIAS BIBLIOGRÁFICAS 198

6 RESULTADOS E DISCUSSÕES - CONJUGAÇÃO BIOLÓGICA 207

6.1 Quantificação e eletroforese dos anticorpos 207

6.1.1 Quantificação dos anticorpos monoclonais 207

6.1.2 Eletroforese das proteínas 208 
6.2 Conjugação das nanopartículas de $\mathrm{TR}_{2}\left(\mathrm{MoO}_{4}\right)_{3}$ com a parte

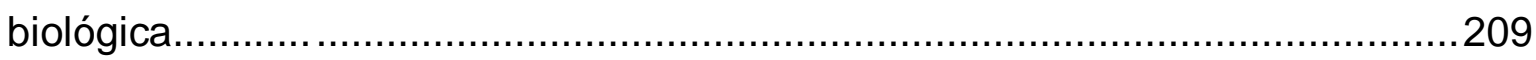

6.2.1 Detecção de BSA conjugada com a partícula luminescente $\mathrm{TR}_{2}\left(\mathrm{MoO}_{4}\right)_{3} @ S i$ $\left(\mathrm{TR}=\mathrm{Nd}^{3+}\right)$ utilizando o método de Bradford .................................................209

6.2.2 Detecção de PSA conjugada com a partícula luminescente $\mathrm{TR}_{2}\left(\mathrm{MoO}_{4}\right)_{3} @ \mathrm{Si}\left(\mathrm{TR}=\mathrm{Nd}^{3+} \mathrm{e} \mathrm{Eu}^{3+}\right)$ utilizando o método de Bradford ....................216

6.2.3 Estudo da conjugação entre os sistemas $\mathrm{Y}_{2}-\mathrm{xEu_{x+0,05 }}\left(\mathrm{MoO}_{4}\right)_{3} @ S i-G l u t-$ H11P8 e antígeno em função da concentração dos anticorpos do PSA ............220

6.3 Teste de Hemocompatibilidade .......................................................225

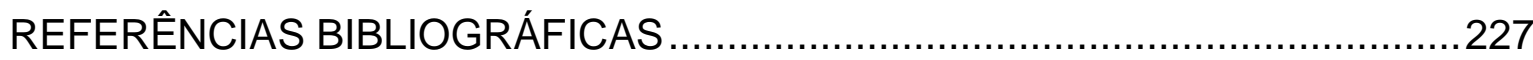

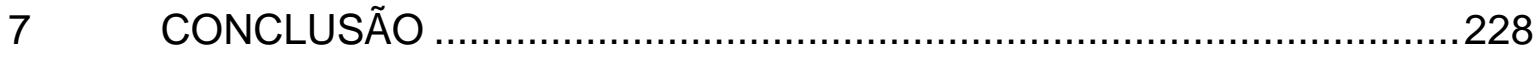

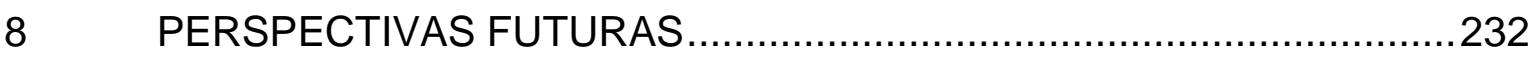




\section{LISTA DEFIGURAS}

FIGURA 1.1. Ilustração das nanopartículas em ação. Conjugação e reconhecimento de espécies de proteínas específicas, respectivamente. 4

FIGURA 2.1. As quatro primeiras energias de ionização dos elementos terras $\operatorname{raras}(A)^{3}$ e distribuição radial da densidade eletrônica dos orbitais $4 f, 5 s$ e $5 p$ em um íon $\mathrm{TR}^{3+}$

FIGURA 2.2. Representação da contração lantanídica dos íons $\mathrm{TR}^{3+}$.

FIGURA 2.3. Diagrama dos níveis de energia da configuração $4 f^{N}$ dos íons $T R^{3+}$ dopados na matriz de $\mathrm{LaF}_{3}$ calculados a partir dos parâmetros reportados por Carnall e reeditados.

FIGURA 2.4. Processo de absorção e emissão da luz no diagrama de Jablonski.

FIGURA 2.5. Diagrama esquemático dosníveis de energia envolvidos no processo de luminescência dos íons terras raras a) $\mathrm{Eu}^{3+}$ e b) $\mathrm{Tb}^{3+}$ e energias das principais transições no processo de luminescência.

FIGURA 2.6. Uso das transições ${ }^{5} \mathrm{D}_{0} \rightarrow{ }^{7} \mathrm{~F}_{\mathrm{J}}$ do íon $\mathrm{Eu}^{3+}$ como sonda de sítios de simetria em cristais. As transições ${ }^{5} D_{0} \rightarrow{ }^{7} F_{3},{ }^{7} F_{5}$ são proibidas sob as regras de seleção de Judd e são usualmente muito fracas, portanto, não estão incluídas. $O$ esquema refere-se às transições permitidas por dipolo elétrico, exceto o caso da transição ${ }^{5} \mathrm{D}_{0} \rightarrow{ }^{7} \mathrm{~F}_{1}$, que é permitida pelo mecanismo de dipolo magnético. 22 
FIGURA 2.7. a) Processo da luminescência de um ativador (A) dopado em uma matriz $(H)$ e b) Transferência de energia de um sensibilizador $S$ para um ativador A.

FIGURA 2.8. Processo de funcionalização das nanopartículas para bioconjugação.

FIGURA 2.9. Localização da próstata. 32

FIGURA 2.10. llustração da próstata normal e próstata aumentada, respectivamente.

FIGURA 2.11. Ilustração das taxas de incidências de câncer de próstata no mundo.

FIGURA 4.1. Fluxograma da rota de síntese dos cloretos de terras raras $\left(\mathrm{TR}(\mathrm{Cl})_{3} \cdot 6 \mathrm{H}_{2} \mathrm{O}\right)$. .53

FIGURA 4.2. Fluxograma da síntese de nanopartículas de molibdatos dopadas com terras raras pelo método de coprecipitação.

FIGURA 4.3. Fluxograma sobre o estudo da influência da velocidade de dispersão da precipitação no tamanho da partícula.

FIGURA 4.4. Fluxograma demonstrando a metodologia utilizada para proceder ao tratamento térmico (annealing) com as amostras de molibdato de terras raras....57

FIGURA 4.5. Fluxograma da síntese do molibdato de ítrio dopado com európio e térbio. .58

FIGURA 4.6. Esquema da silanização do $\mathrm{TR}_{2}\left(\mathrm{MoO}_{4}\right)_{3}$ utilizando o 3aminopropiltrietoxisilano 
FIGURA 4.8. llustração do método de Stöber .65

FIGURA 4.9. Estrutura da ninidrina. 66

FIGURA 4.10. Representação química do teste de ninidrina. 66

FIGURA 4.11. Esquema representativo da reação do marcador luminescente com o glutaraldeído 69

FIGURA 4.12. Esquema representativo da reação do marcador luminescente com a proteína BSA. .70

FIGURA 4.13. Representação química do corante Coomassie Brilliant Blue G-250.

FIGURA 4.14. Estrutura cristalina do antígeno específico da próstata humano complexado a um anticorpo anti-PSA e esquema do imonoensaio para detecção do mesmo. .73

FIGURA 4.15. Esquema ilustrativo do método de preparação para o teste de hemocompatibilidade. .75

FIGURA 5.1. Fotografias do molibdato de európio: a) sob luz ambiente e b) sob irradiação ultravioleta $\left(\lambda_{\mathrm{ex}}=366 \mathrm{~nm}\right)$.

FIGURA 5.2. Fotografias do molibdato de európio a) sob luz ambiente e b) sob irradiação ultravioleta $\left(\lambda_{\mathrm{ex}}=366 \mathrm{~nm}\right)$. .83

FIGURA 5.3. Fotografias do molibdato de gadolínio sob luz ambiente. .83

FIGURA 5.4. Fotografias do molibdato de neodímio sob luz ambiente. 83

FIGURA 5.5.Espectros de infravermelho dos molibdatos de terras raras. 87 
FIGURA 5.6. Curva TGA/DTG registradas no intervalo de 0 a $1000^{\circ} \mathrm{C}$, sob atmosfera dinâmica de $\mathrm{N}_{2}$ do $\mathrm{Eu}_{2}\left(\mathrm{MoO}_{4}\right)_{3}$ .90

FIGURA 5.7. Curvas TGA/DTG registradas no intervalo de 0 a $1000{ }^{\circ} \mathrm{C}$, sob atmosfera dinâmica de $\mathrm{N}_{2}$ do $\mathrm{Sm}_{2}\left(\mathrm{MoO}_{4}\right)_{3}$ .90

FIGURA 5.8. Curvas TGA/DTG registradas no intervalo de 0 a $1000 \stackrel{\circ}{\circ}$, sob atmosfera dinâmica de $\mathrm{N}_{2}$ do $\mathrm{Tb}_{2}\left(\mathrm{MoO}_{4}\right)_{3}$

FIGURA 5.9. Curvas TGA/DTG registradas no intervalo de 0 a $1000 \stackrel{\circ}{\circ}$, sob atmosfera dinâmica de $\mathrm{N}_{2}$ do $\mathrm{Gd}_{2}\left(\mathrm{MoO}_{4}\right)_{3}$.

FIGURA 5.10. Curvas TGA/DTG registradas no intervalo de 0 a $1000 \stackrel{\circ}{ } \mathrm{C}$, sob atmosfera dinâmica de $\mathrm{N}_{2}$ do $\mathrm{Nd}_{2}\left(\mathrm{MoO}_{4}\right)_{3}$. .92

FIGURA 5.11. Curvas TGA/DTG registradas no intervalo de 0 a $1000^{\circ} \mathrm{C}$, sob atmosfera dinâmica de $\mathrm{N}_{2}$ do $\mathrm{Y}_{2}\left(\mathrm{MoO}_{4}\right)_{3}$ .92

FIGURA 5.12. Estrutura ortorrômbica dos $\mathrm{TR}_{2}\left(\mathrm{MoO}_{4}\right)_{3}$. .94

FIGURA 5.13. Poliedro formado pela estrutura cristalina $\mathrm{REO}_{7}$. .95

FIGURA 5.14. Difratograma de raios $X$ - método do pó dos $\mathrm{TR}_{2}\left(\mathrm{MoO}_{4}\right)_{3}$. .96

FIGURA 5.15. Micrografias dos molibdatos de terras raras. .98

FIGURA 5.16. Espectro de emissão do $\mathrm{Gd}_{2}\left(\mathrm{MoO}_{4}\right)_{3}$. 100

FIGURA 5.17. Espectro de excitação do $\mathrm{Y}_{2}\left(\mathrm{MoO}_{4}\right)_{3}$. 102

FIGURA 5.18. Espectro de emissão do $\mathrm{Y}_{2}\left(\mathrm{MoO}_{4}\right)_{3}$ 102

FIGURA 5.19. Espectro de excitação do $\mathrm{Eu}_{2}\left(\mathrm{MoO}_{4}\right)_{3}$. 106 
FIGURA 5.20. Espectro de emissão do $\mathrm{Eu}_{2}\left(\mathrm{MoO}_{4}\right)_{3}$ 106

FIGURA 5.21. Espectro de excitação do $\mathrm{Sm}_{2}\left(\mathrm{MoO}_{4}\right)_{3}$. 112

FIGURA 5.22. Espectro de emissão do $\mathrm{Sm}_{2}\left(\mathrm{MoO}_{4}\right)_{3}$ 112

FIGURA 5.23. Estado fundamental e os primeiros estados emissores do térbio 113 FIGURA 5.24. Espectro de excitação do $\mathrm{Tb}_{2}\left(\mathrm{MoO}_{4}\right)_{3}$

FIGURA 5.25. Espectro de emissão do $\mathrm{Tb}_{2}\left(\mathrm{MoO}_{4}\right)_{3}$ 116

FIGURA 5.26. Diagrama parcial de nível de energia para o íon $\mathrm{Nd}^{3+}$

FIGURA 5.27. Espectro de emissão do $\mathrm{Nd}_{2}\left(\mathrm{MoO}_{4}\right)_{3}$

FIGURA 5.28. Fotografias do molibdato de európio com velocidade de dispersão a) 2500, b) $8000 \mathrm{rpm}, \mathrm{c}) 16000 \mathrm{rpm}$ e d) $24000 \mathrm{rpm}$ sob irradiação ultravioleta ( $\lambda_{\text {ex }}$ $=366 \mathrm{~nm}$ ). 120

FIGURA 5.29. Espectro de infravermelho do $\mathrm{Eu}_{2}\left(\mathrm{MoO}_{4}\right)_{3}$ : com a velocidades de dispersão em 2.500 rpm, 8.000 rpm, 16.000 rpm e 24.000 rpm. 121

FIGURA 5.30. Curvas TGA/DTG registradas no intervalo de 0 a $1000{ }^{\circ} \mathrm{C}$, sob atmosfera dinâmica de $\mathrm{N}_{2}$, do $\mathrm{Eu}_{2}\left(\mathrm{MoO}_{4}\right)_{3}-8.000$ rpm. 122

FIGURA 5.31. Curvas TGA/DTG registradas no intervalo de 0 a $1000{ }^{\circ} \mathrm{C}$, sob atmosfera dinâmica de $\mathrm{N}_{2}$, do $\mathrm{Eu}_{2}\left(\mathrm{MoO}_{4}\right)_{3}-8.000 \mathrm{rpm}$. 122

FIGURA 5.32. Curvas TGA/DTG registradas no intervalo de 0 a $1000{ }^{\circ} \mathrm{C}$, sob atmosfera dinâmica de $\mathrm{N}_{2}$, do $\mathrm{Eu}_{2}\left(\mathrm{MoO}_{4}\right)_{3}-16.000 \mathrm{rpm}$. 123

FIGURA 5.33. Curvas TGA/DTG registradas no intervalo de 0 a $1000{ }^{\circ} \mathrm{C}$, sob atmosfera dinâmica de $\mathrm{N}_{2}$, do $\mathrm{Eu}_{2}\left(\mathrm{MoO}_{4}\right)_{3}-24.000 \mathrm{rpm}$. 123 
FIGURA 5.34. Difratograma de $\mathrm{Eu}_{2}\left(\mathrm{MoO}_{4}\right)_{3}$ nas diferentes velocidades de dispersão da nanopartícula deEu $\left(\mathrm{MoO}_{4}\right)_{3}$ 124

FIGURA 5.35. Micrografias de $\mathrm{Eu}_{2}\left(\mathrm{MoO}_{4}\right)_{3}$ : a) com velocidade de dispersão de: a) 8000 rpm; b) 16000 rpm e c) 24000 rpm. 126

FIGURA 5.36. Espectros de excitação do luminóforo $\mathrm{Eu}_{2}\left(\mathrm{MoO}_{4}\right)_{3}$ obtidos em diferentes velocidades de dispersão (8000 rpm, 16000 rpm e 24000 rpm)em temperatura ambiente.

FIGURA 5.37. Espectros de excitação do luminóforo $\mathrm{Eu}_{2}\left(\mathrm{MoO}_{4}\right)_{3}$ obtidos em diferentes velocidades de dispersão (8000 rpm, 16000 rpm e 24000 rpm) em N 2 líquido. 127

FIGURA 5.38. Espectros de emissão do luminóforo $\mathrm{Eu}_{2}\left(\mathrm{MoO}_{4}\right)_{3}$ obtidos em diferentes velocidades de dispersão (8000 rpm, 16000 rpm e 24000 rpm) em temperatura ambiente. 128

FIGURA 5.39. Espectros de emissão do luminóforo $\mathrm{Eu}_{2}\left(\mathrm{MoO}_{4}\right)_{3}$ obtidos em diferentes velocidades de dispersão (8000 rpm, 16000 rpm e 24000 rpm) em temperatura ambiente em $\mathrm{N}_{2}$ líquido. 129

FIGURA 5.40. Imagem da emissão do sistema $Y_{2-x}\left(M_{0 O}\right)_{3} \% E u(x=0,01,0,03$, $0,05$ e 0,1$)$ e excitados com luz ambiente e com irradiação ultravioleta (366nm) emitindo cor avermelhada intensa e do sistema $\mathrm{Y}_{2-\mathrm{x}}\left(\mathrm{MoO}_{4}\right)_{3} \% \mathrm{~Tb}$ ( $\mathrm{x}=0,01,0,03$, $0,05$ e 0,1$)$ excitados com luz ambiente e com irradiação ultravioleta (366nm) não emitindo cor 131

FIGURA 5.41. Espectros de Infravermelho dos do sistema $\mathrm{Y}_{2-\mathrm{x}}\left(\mathrm{MoO}_{4}\right)_{3} \% \mathrm{Eu}$ $(x=0,01 ; 0,03 ; 0,05,0,1$ e 2.0$)$.

FIGURA 5.42. Difratograma das amostras de $\mathrm{Y}_{2-\mathrm{x}}\left(\mathrm{MoO}_{4}\right)_{3} \% \mathrm{Eu}(\mathrm{x}=0,01,0,03,0,05$ e 0,1$)$ 
FIGURA 5.43. Difratograma das amostras de $\mathrm{Y}_{2-\mathrm{x}}\left(\mathrm{MoO}_{4}\right)_{3} \% \mathrm{~Tb}(\mathrm{x}=0,01,0,03,0,05$ e 0,1$)$.

FIGURA 5.44. Micrografias de nanopartículas de $\mathrm{Y}_{2}-\mathrm{X}\left(\mathrm{MoO}_{4}\right)_{3} \% \mathrm{Eu}(\mathrm{X}=0,01,0,03$, $0,05$ e 0,1$)$.

FIGURA 5.45. Micrografias de nanopartículas de $\mathrm{Y}_{2}-\mathrm{x}\left(\mathrm{MoO}_{4}\right)_{3} \% \mathrm{~Tb}(\mathrm{X}=0,01,0,03$, $0,05$ e 0,1$)$.

FIGURA 5.46. Espectros de excitação das amostras de $\mathrm{Y}_{2}-\mathrm{x}\left(\mathrm{MoO}_{4}\right)_{3} \% \mathrm{Eu}(\mathrm{x}=0,01$, $0,03,0,05$ e 0,1$)$. 138

FIGURA 5.47. Espectros de emissão das nanopartículas de $\mathrm{Y}_{2}\left(\mathrm{MoO}_{4}\right)_{3}$ $\left(1 \%, 3 \%, 5 \%\right.$ e $\left.10 \% \mathrm{Eu}^{3+}\right)$. 139

FIGURA 5.48. Espectros de excitação das nanopartículas deY $\operatorname{dex}_{2}\left(\mathrm{MoO}_{4}\right)_{3} \% \mathrm{~Tb}$ $(x=0,01,0,03,0,05$ e 0,1$)$.

FIGURA 5.49. Espectros de emissão das nanopartículas de $\mathrm{Y}_{2}-\mathrm{x}\left(\mathrm{MoO}_{4}\right)_{3}$ $\% \operatorname{Tb}(x=0,01,0,03,0,05$ e 0,1$)$.

FIGURA 5.50. Amostras submetidas ao tratamento térmico sob luz ambiente e irradiação ultravioleta (366nm).

FIGURA 5.51. Espectros de infravermelho das amostras de $\mathrm{Nd}_{2}\left(\mathrm{MoO}_{4}\right)_{3}$. 146

FIGURA 5.52. Temperaturas de fusão e de transição e tipos de estruturas ocorrendo na família de compostos a) $\mathrm{TR}_{2}\left(\mathrm{MoO}_{4}\right)_{3}$ e b) $\mathrm{TR}_{2}\left(\mathrm{WO}_{4}\right)_{3}$..... 148

FIGURA 5.53. Difratogramas de raios $\mathrm{X}$ do $\mathrm{Eu}_{2}\left(\mathrm{MoO}_{4}\right)_{3}$ submetidos ao tratamento térmico.

FIGURA 5.54 Difratogramas de raios $\mathrm{X}$ do $\mathrm{Tb}_{2}\left(\mathrm{MoO}_{4}\right)_{3}$ submetidos ao tratamento térmico. 
FIGURA 5.55. Difratogramas de raios $\mathrm{X}$ do $\mathrm{Sm}_{2}\left(\mathrm{MoO}_{4}\right)_{3}$ submetidos ao tratamento térmico. 150

FIGURA 5.56. Difratogramas de raios $X$ de $\mathrm{Nd}_{2}\left(\mathrm{MoO}_{4}\right)_{3}$ submetidas a tratamento térmico.

FIGURA 5.57. Difratograma de raio $X$ do estudo do tamanho do cristalito em relação ao aumento da temperatura para as amostras de $\mathrm{Eu}_{2}\left(\mathrm{MoO}_{4}\right)_{3}, \mathrm{~Tb}_{2}\left(\mathrm{MoO}_{4}\right)_{3}$ , $\mathrm{Sm}_{2}\left(\mathrm{MoO}_{4}\right)_{3}$ e $\mathrm{Nd}_{2}\left(\mathrm{MoO}_{4}\right)_{3}$.

FIGURA 5.58. Micrografias de $\mathrm{Nd}_{2}\left(\mathrm{MoO}_{4}\right)_{3}$ submetidas ao tratamento térmico.. 154

FIGURA 5.59. Micrografias de $\mathrm{Eu}_{2}\left(\mathrm{MoO}_{4}\right)_{3}$ submetidas ao tratamento térmico.. 155

FIGURA 5.60. Espectros de excitação das nanopartículas de $\mathrm{Eu}_{2}\left(\mathrm{MoO}_{4}\right)_{3}$ 157

FIGURA 5.61. Espectro de emissão das nanopartículas de $\mathrm{Eu}_{2}\left(\mathrm{MoO}_{4}\right)_{3}$ submetidas ao tratamento térmico. 158

FIGURA 5.62. Espectro de excitação das nanopartículas de $\mathrm{Tb}_{2}\left(\mathrm{MoO}_{4}\right)_{3}$ submetidas ao tratamento térmico. 160

FIGURA 5.63. Espectro de emissão das nanopartículas de $\mathrm{Tb}_{2}\left(\mathrm{MoO}_{4}\right)_{3}$ submetidas ao tratamento térmico. 162

FIGURA 5.64. Espectro de excitação das nanopartículas de $\mathrm{Sm}_{2}\left(\mathrm{MoO}_{4}\right)_{3}$ submetidas ao tratamento térmico. 164

FIGURA 5.65. Espectro de emissão das nanopartículas de $\mathrm{Sm}_{2}\left(\mathrm{MoO}_{4}\right)_{3}$ submetidas ao tratamento térmico com $\lambda_{\text {exc }}=405 \mathrm{~nm}$ e temperatura ambiente.... 165

FIGURA 5.66. Espectro de emissão das nanopartículas de $\mathrm{Nd}_{2}\left(\mathrm{MoO}_{4}\right)_{3}$ submetidas ao tratamento térmico com excitação monitorada em $250 \mathrm{~nm}$. 167 
FIGURA 5.67 Espectro de emissão das nanopartículas de $\mathrm{Nd}_{2}\left(\mathrm{MoO}_{4}\right)_{3}$ submetidas ao tratamento térmico com excitação monitorada em $810 \mathrm{~nm}$. 168

FIGURA 5.68 Representação esquemática de uma nanopartícula de $\mathrm{TR}_{2}\left(\mathrm{MoO}_{4}\right)_{3}$ funcionalizada (adaptação de Giaume et al. ${ }^{82}$ ) 170

FIGURA 5.69. Representação esquemática do processo para a preparação de partículas de sílica aminofuncionalizadas incorporando o luminóforo $\mathrm{TR}_{2}\left(\mathrm{MoO}_{4}\right)_{3}$ utilizando o método por micro-ondas.

FIGURA 5.70. Representação esquemática do processo para a preparação de partículas de sílica incorporando os fósforos $\left(\mathrm{Eu}_{2}\left(\mathrm{MoO}_{4}\right)_{3}\right.$,pelo o método Stöber.

FIGURA 5.71. Representação esquemática da aminofuncionalização das partículas de sílica contendo os fósforosTR $\left(\mathrm{MoO}_{4}\right)_{3}$,utilizando o método Stöber. 172

FIGURA 5.72. Espectro de infravermelho das partículas de $\mathrm{Eu}_{2}\left(\mathrm{MoO}_{4}\right)_{3}$ aminofuncionalizadas pelo método de Stöber e pelo método de micro-ondas. 175

FIGURA 5.73.Espectro de infravermelho das partículas de $\mathrm{Sm}_{2}\left(\mathrm{MoO}_{4}\right)_{3}$ aminofuncionalizadas pelo método de Stöber e pelo método de micro-ondas. 175

FIGURA 5.74. Espectro de infravermelho das partículas de $\mathrm{Tb}_{2}\left(\mathrm{MoO}_{4}\right)_{3}$ aminofuncionalizadas pelo método de Stöber e pelo método de micro-ondas. 176

FIGURA 5.75.Espectro de infravermelho das partículas de $\mathrm{Y}\left(5 \% \mathrm{Eu}_{2}\left(\mathrm{MoO}_{4}\right)_{3}\right.$ amino-funcionalizadas pelo método de Stöber e pelo método de micro-ondas. . 176

FIGURA 5.76. Espectro de infravermelho das partículas de $\mathrm{Nd}_{2}\left(\mathrm{MoO}_{4}\right)_{3}$ aminofuncionalizadas pelo método de Stöber e pelo método de micro-ondas. 177 
FIGURA 5.77.Difratogramas do $\mathrm{Eu}_{2}\left(\mathrm{MoO}_{4}\right)_{3}$ e $\mathrm{Eu}_{2}\left(\mathrm{MoO}_{4}\right)_{3} @ S i$ funcionalizados pelo método de Stöber e micro-ondas.

FIGURA 5.78. Difratogramas do $\mathrm{Y}\left(5 \% \mathrm{Eu}\left(\mathrm{MoO}_{4}\right)_{3}\right.$ funcionalizados pelo método de Stöber e micro-ondas.

FIGURA 5.79.Difratogramas do $\mathrm{Sm}_{2}\left(\mathrm{MoO}_{4}\right)_{3}$ funcionalizados pelo método de Stöber e micro-ondas.

FIGURA 5.80. Difratogramas do $\mathrm{Tb}_{2}\left(\mathrm{MoO}_{4}\right)_{3}$ funcionalizados pelo método de Stöber e micro-ondas.

FIGURA 5.81. Micrografias de $\mathrm{Nd}_{2}\left(\mathrm{MoO}_{4}\right)_{3}$ a) não funcionalizada; b) funcionalizada pelo método de Stöber e c) funcionalizada pelo método de micro-ondas.

FIGURA 5.82. Imagens obtidas por EDS das amostras de $\mathrm{Nd}_{2}\left(\mathrm{MoO}_{4}\right)_{3}$ Stöber.. 182

FIGURA 5.83. Imagens obtidas por EDS das amostras de $\mathrm{Nd}_{2}\left(\mathrm{MoO}_{4}\right)_{3}$ microondas.

FIGURA 5.84. Micrografias de microscopia eletrônica de transmissão (TEM) das nanopartículas de A) $\mathrm{Nd}_{2}\left(\mathrm{MoO}_{4}\right)_{3}$, B) $\mathrm{Nd}_{2}\left(\mathrm{MoO}_{4}\right)_{3} @ S i-m i c$ e $\mathrm{Nd}_{2}\left(\mathrm{MoO}_{4}\right)_{3} @ S i-$ Stöber 184

FIGURA 5.85. Espectro de excitação de $\mathrm{Eu}_{2}\left(\mathrm{MoO}_{4}\right)_{3}$ amino-funcionalizadas através do método de micro-ondas e Stöber. 185

FIGURA 5.86. Espectro emissão das nanopartículas de $\mathrm{Eu}_{2}\left(\mathrm{MoO}_{4}\right)_{3}$ aminofuncionalizadas através do método de micro-ondas e Stöber. 186

FIGURA 5.87. Espectro de excitação de $\mathrm{Y}_{2.995} \mathrm{Eu}_{0,005}\left(\mathrm{MoO}_{4}\right)_{3}$ aminofuncionalizadas através do método de micro-ondas e Stöber. 188 
FIGURA 5.88. Espectros de emissão das nanopartículas de $\mathrm{Y}\left(5 \% \mathrm{Eu}_{2}\left(\mathrm{MoO}_{4}\right)_{3}\right.$ amino-funcionalizadas através do método de micro-ondas 189

FIGURA 5.89. Espectros de excitação das nanopartículas de $\mathrm{Tb}_{2}\left(\mathrm{MoO}_{4}\right)_{3}$ e $\mathrm{Tb}_{2}\left(\mathrm{MoO}_{4}\right)_{3}$ amino-funcionalizadas pelos métodos de micro-ondas e Stöber.....191

FIGURA 5.90. Espectros de emissão das nanopartículas de $\mathrm{Tb}_{2}\left(\mathrm{MoO}_{4}\right)_{3}$ e $\mathrm{Tb}_{2}\left(\mathrm{MoO}_{4}\right)_{3}$ amino-funcionalizadas pelos métodos de micro-ondas e Stöber.....191

FIGURA 5.91. Espectros de excitação das nanopartículas de $\mathrm{Sm}_{2}\left(\mathrm{MoO}_{4}\right)_{3}$ e $\mathrm{Sm}_{2}\left(\mathrm{MoO}_{4}\right)_{3}$ amino-funcionalizadas pelos métodos de micro-ondas e Stöber....193

FIGURA 5.92. Espectros de emissão das nanopartículas de $\mathrm{Sm}_{2}\left(\mathrm{MoO}_{4}\right)_{3}$ aminofuncionalizadas pelo método de micro-ondas. 193

FIGURA 5.93. Espectro de absorção da glicina. 194

FIGURA 5.94. Foto das diluições de glicina usadas para construir a curva de calibração. 195

FIGURA 5.95. Curva de calibração da glicina para determinação de grupos aminas primarias 196

FIGURA 6.1. Curva de calibração da albumina bovina sérica utilizada para quantificação dos anticorpos monoclonais (método de Bradford). 207

FIGURA 6.2. Foto do gel de eletroforese após todas as etapas de tratamento..209 FIGURA 6.3. Estrutura da albumina sérica bovina (BSA). 210

FIGURA 6.4.Esquema representativo da imobilização da proteína BSA na partícula $\mathrm{Nd}_{2}\left(\mathrm{MoO}_{4) 3} @\right.$ Si utilizando glutaraldeído como espaçador. ${ }^{8}$. 213 
FIGURA 6.5. Esquema da reação para a identificação de proteínas, com a formação do complexo Proteína - corante de coloração azul. a) cubetas com material para análise no espectrofotômetro; b) reação da proteína com o reagente de Comassei; c) Espectros de absorção da proteína-corante; e d)perfil as curvas absorbância versus concentração da proteína em vários comprimentos de onda. ${ }^{7}$

FIGURA 6.6. Fotografia da placa de poliestireno de 96 poços do ensaio para identificação da proteína BSA. Os sobrenadantes são identificados em vermelho, as $1^{\underline{a}}$ águas de lavagem são identificadas em azul, as $4^{\underline{a}}$ águas de lavagem são identificadas em lilás, as dispersões de partículas são identificados em preto e o em laranja é o reagente colorimétrico. 215

FIGURA 6.7. Espectros de emissão obtidos da nanopartículas de $\mathrm{Nd}_{2}\left(\mathrm{MoO}_{4}\right)_{3} @ \mathrm{Si}$ ligadas ao BSA

FIGURA 6.8. Esquema representativo da imobilização do anticorpo anti-PSA H11P8 na partícula TR ${ }_{2}\left(\mathrm{MoO}_{4}\right)_{3} @ S i$ utilizando glutaraldeído como espaçador. 217

FIGURA 6.9. Fotografia do fluorímetro Victor ${ }^{2} D$ da Perkin Elmer. 222

FIGURA 6.10. Perfil da variação da concentração de H11P8(anticorpo de marcação) em função da densidade de contagens em várias concentrações de H2P8(anticorpo de captura). 223

FIGURA 6.11. Perfil da variação da concentração de H2P8(anticorpo de captura) em função da densidade de contagens, em várias concentrações de H11P8(anticorpo de marcação). .224

FIGURA 6.12. Intensidade do sinal luminescente com a concentração da partícula

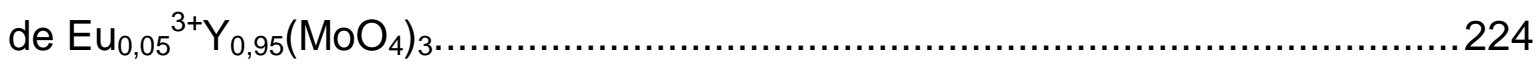


FIGURA 6.13. Micrografias dos filmes de quitosana contendo nanopartículas de $\mathrm{Eu}_{2}\left(\mathrm{MoO}_{4}\right)_{3}$ .226 


\section{LISTA DE TABELAS}

TABELA 2.1. Configurações eletrônicas e níveis espectroscópicos fundamentais dos elementos TR, de seus íons $\mathrm{TR}^{3+} \mathrm{e}$ valores dos raios iônicos dos íons $\mathrm{TR}^{3+} .11$

TABELA 4.1. Lista de reagentes e solventes utilizados nos experimentos. .51

TABELA 5.1. Carta de correlação dos modos vibracionais do $\mathrm{RE}_{2}\left(\mathrm{MoO}_{4}\right)_{3}{ }^{15}$..... .86

TABELA 5.2. Principais frequências dos modos vibracionais do molibdato de terra rara. .87

TABELA 5.3. Diâmetro do cristalito calculados pela formula de Scherrer. .97

TABELA 5.4. Parâmetros de intensidade experimentais $\left(\Omega_{\lambda}\right)^{46}$, taxas não radiativas $\left(A_{\text {nrad }}\right)$, radiativas $\left(A_{\text {rad }}\right)$ e totais $\left(A_{\text {total }}\right)$, tempo de vida $(\tau)$, eficiência

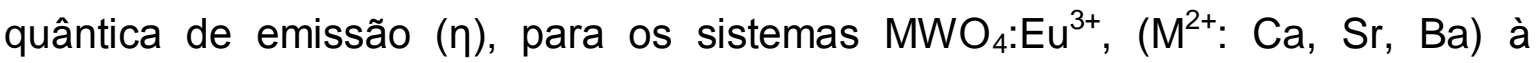
temperatura ambiente. 109

TABELA 5.5. Diâmetro do cristalito calculado pelo método de Sherrer, 125

TABELA 5.6. Tempos de vida $(\tau)$, parâmetros de intensidade $\left(\Omega_{\lambda}\right)$, taxa radiativa $\left(A_{\text {rad }}\right)$, taxa não-radiativa $\left(A_{\text {nrad }}\right)$ e eficiência quântica $(\eta)$ de emissão do nível emissor ${ }^{5} \mathrm{D}_{0}$ determinado para o luminóforo dopado com európio em $298 \mathrm{~K}$......130

TABELA 5.7. Diâmetro do cristalito calculado pelo método de Sherrer ,para $Y_{2^{-}}$ $x\left(\mathrm{MoO}_{4}\right)_{3} \% \mathrm{Eu}(\mathrm{x}=0,01,0,03,0,05$ e 0,1$)$ e $\mathrm{Y}_{2}-\mathrm{x}\left(\mathrm{MoO}_{4}\right)_{3} \% \mathrm{~Tb}(\mathrm{x}=0,01,0,03,0,05$ e 0,1$)$. 
TABELA 5.8. Tempos de vida $(\tau)$, parâmetros de intensidade $\left(\Omega_{\lambda}\right)$, taxa radiativa $\left(A_{\text {rad }}\right)$, taxa não-radiativa $\left(A_{\text {nrad }}\right)$ e eficiência quântica $(\eta)$ de emissão do nível emissor ${ }^{5} \mathrm{D}_{0}$ determinado para os fósforos dopados com európio em $298 \mathrm{~K}$......140

TABELA 5.9. Dados de temperaturas de derretimento, transição e estruturas dos molibdatos de terras raras. 145

TABELA 5.10. Parâmetros de intensidade $\left(\Omega_{\lambda}\right)$, taxa radiativa $\left(A_{\text {rad }}\right)$, em $298 \mathrm{~K}$, determinado para o luminóforo $\mathrm{Eu}_{2}\left(\mathrm{MoO}_{4}\right)_{3}$ para diferentes temperaturas de annealing. 159

TABELA 5.11. Parâmetros de intensidade experimentais $\eta_{\mathrm{Sm}}$ da matriz de $\mathrm{Sm}_{2}\left(\mathrm{MoO}_{4}\right)_{3}$ e $\eta_{\mathrm{Eu}}$ da matriz de $\mathrm{Sm}_{2}\left(\mathrm{MoO}_{4}\right)_{3}$. 166

TABELA 6.1. Ensaio de identificação da presença de proteína BSA método de Bradford. A presença de BSA foi confirmada pelo desenvolvimento da cor azul nas amostras. 214

TABELA 6.2. Relação da quantidade de proteína encontrada na solução sobrenadante e ligadas ao anticorpo H11P8 nas diversas condições de reações estudadas. Concentração da proteína PSA $26 \mu \mathrm{g} \mathrm{mL}^{-1}$. 


\section{INTRODUÇÃO}

O câncer de próstata é um problema de saúde pública mundial, acometendo populações tanto de países em desenvolvimento quanto de países desenvolvidos. ${ }^{1}$ De acordo com a Organização Mundial da Saúde (OMS), a doença é considerada a neoplasia maligna mais frequente, que mais aumenta nos homens e a segunda maior causadora de mortes no Brasil. Nos EUA, o câncer de próstata ocorre em 1 a cada 6 homens, sendo que 200.000 novos casos são diagnosticados por ano, com mortalidade anual de cerca de 38.000 indivíduos. $^{2}$

A partir da década de 1990 observou-se uma maior incidência da doença na população masculina, fato esse que pode ser explicado pela maior realização dos testes do Antígeno Prostático Específico (PSA) e também pelo aumento da longevidade pela influência de fatores ambientais, por fatores dietéticos ou outras origens ainda não identificadas. ${ }^{1}$ A glicoproteína produzida por células da glândula prostática, conhecida por PSA, é secretada no plasma seminal em concentrações altas e seu valor pode estar aumentado na presença de doenças inflamatórias da glândula, como nas neoplasias da próstata. ${ }^{2,3}$

A obtenção de um diagnóstico precoce realizado através da dosagem do Antígeno Prostático Específico (PSA) visa um processo curativo e atua como um melhor sinalizador do câncer, aumentando dessa forma, as chances de tratamento, uma vez que a patologia pode ser curável em até $80 \%$ dos casos. ${ }^{2} \mathrm{O}$ principal objetivo na descoberta e desenvolvimento do exame de PSA era o de detectar os tumores, em uma fase inicial para se obter melhores resultados na terapia. .

Em paralelo, o desenvolvimento e utilização de nanopartículas de íons terras raras como marcadores luminescentes biológicos ao longo dos anos apresentaram inúmeras vantagens que estão resumidas como segue: ser um 
Introdução

método seguro, de baixo custo, apresentar maior especificidade (demonstrando que os ensaios são mais sensíveis quando comparados aos radioimunoensaios) e a luminescência pode ser medida rapidamente (com alto grau de sensibilidade e exatidão). ${ }^{4}$

Para facilitar a designação dos elementos do grupo 3 da tabela periódica, a Comissão de Nomenclatura em Química Inorgânica da IUPAC (International Union of Pure and Applied Chemistry) recomenda usar a expressão "metais de terras raras" para os elementos de La à Lu, incluindo o Sc e Y. O termo "série do lantânio" é reservado aos elementos que compreendem do La ao Lu, e o termo "lantanídeos" é ainda mais restrito, pela exclusão do lantânio, portanto deve-se considerar apenas os elementos do Ce ao Lu. ${ }^{5}$

A característica mais importante dos metais de terras raras (TR) é que os elétrons opticamente ativos encontram-se na camada $4 \mathrm{f}$ que tem menor extensão espacial do que a camada fechada $\left(5 s^{2} 5 p^{6}\right)$. Quando esses elementos fazem parte de complexos, os elétrons $4 \mathrm{f}$, que pertencem aos orbitais mais internos, são protegidos da interação com o campo ligante pelas camadas mais externas totalmente preenchidas $\left(5 s^{2} 5 p^{6}\right)$. Consequentemente, os elétrons $4 f$ interagem fracamente com os elétrons dos átomos, molécula ou íons vizinhos e as propriedades eletrônicas são pouco afetadas pelo ambiente químico. Em particular, os espectros dos compostos contendo íons $4 \mathrm{f}$ no estado sólido retêm suas características atômicas, as quais facilitam a interpretação das estruturas dos seus níveis de energia. Devido a esta pequena perturbação, a espectroscopia eletrônica (absorção e emissão) pode ser usada como uma técnica em potencial para investigar o ambiente químico ao redor do íon atuando como sonda espectroscópica. Consequentemente, os espectros dos íons $\mathrm{TR}^{3+}$ apresentam transições ópticas bastante finas sugerindo que a interação entre estes íons e a circunvizinhança química é relativamente fraca. Estas características tornam os íons $\mathrm{TR}^{3+}$ promissores no estudo espectroscópico na química do estado sólido.Os fósforos derivados de terras raras (TR) apresentam diversas características importantes: tempo de vida longo, um deslocamento entre os máximos das bandas de absorção e emissão grande, além de fotoestabilidade. Dentre as 


\section{Introdução}

vantagens da utilização desses fósforos, uma das mais importantes é demonstrada por seu comportamento atômico, oriundo da blindagem efetiva do ambiente químico sobre os elétrons $4 \mathrm{f}$ exercida pelos elétrons das subcamadas preenchidas $5 s^{2}$ e $5 p^{6}$ da configuração do xenônio. Consequentemente, esse efeito de blindagem faz com que as bandas de emissão sejam extremamente finas e bem definidas na região do visível ou seja tenham comportamento atômico. ${ }^{6}$

Sobre um ponto de vista atual este trabalho também enfoca a nanotecnologia onde partículas menores do que 100nm atuam como fósforos e conjugam-se a parte biológica para sinalização das mesmas.

O tamanho destas nanopartículas é um dos parâmetros importantes que influenciam diretamente na obtenção de excelentes resultados no meio biológico, como por exemplo, na detecção de tumores, pois é possível sintetizar compostos luminescentes a base de terras raras com dimensões que se aproximam às glicoproteínas ( $5 \mathrm{~nm}$ ), como é o caso do PSA. ${ }^{7}$

Quando o foco é a interação das nanopartículas de terras raras com o meio biológico, fatores como a funcionalização da superfície dessas partículas se torna um passo crucial. ${ }^{8}$ Nesse processo, dentre as diversas fontes de encapsulamento, a sílica pode ser utilizada para recobrir as partículas devido às suas propriedades de alta resistência, fácil dispersão em água, biocompatibilidade e atoxicidade. Além dessas características, a superfície da sílica pode ser facilmente modificada para que ocorra 0 acoplamento de biomoléculas de interesse como, por exemplo, anticorpos, proteínas, peptídeos, entre outros ${ }^{9,8}$, possibilitando o reconhecimento de algum material biológico (proteína, peptídeo anticorpo) para diagnóstico de doenças específicas.

A utilização do molibdato como matriz tem sido muito estudado por serem compostos inorgânicos que apresentam excelente desempenho em áreas de estudo como catálise, lasers, condutores iônicos, fósforos, imãs e cintiladores. $^{10,11}$ Diversos estudos têm sido realizados utilizando molibdatos 
Introdução

dopados com terras raras devido a suas ótimas propriedades ópticas e, além disso, molibdatos podem existir em diferentes fases cristalinas (que pode depender de fatores como a forma de preparação, o valor de $\mathrm{pH}$, tratamento térmico, entre outros) compostas de valências iguais ou diferentes do elemento molibdênio. ${ }^{10}$

O foco deste trabalho foi sintetizar nanopartículas de molibdatos de terras raras recobertas com sílica para atuarem como marcadores biológicos enfocando a possibilidade de facilitar o possível diagnóstico do PSA (FIG.1.1).
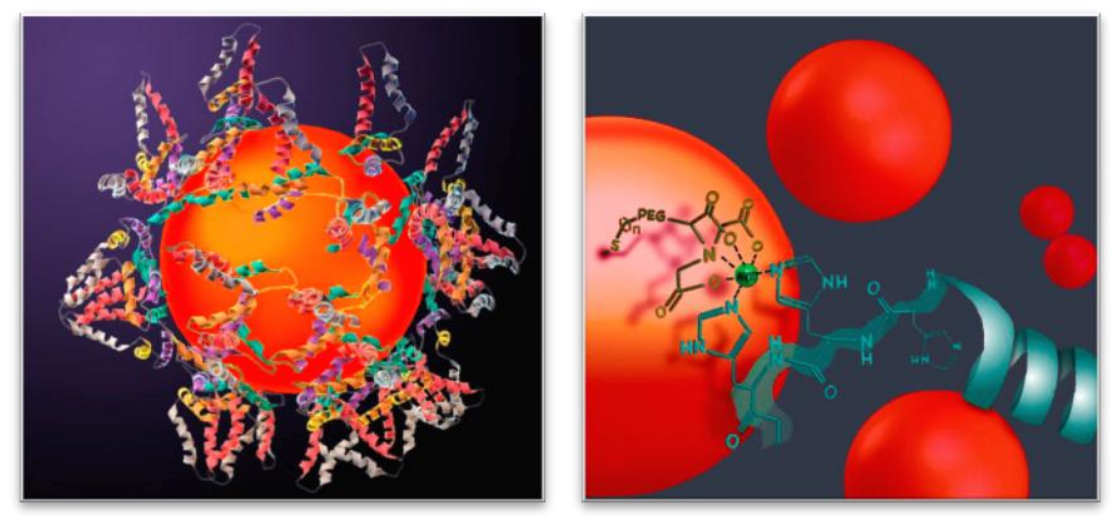

FIGURA 1.1. llustração das nanopartículas em ação. Conjugação e reconhecimento de espécies de proteínas específicas, respectivamente. 
Introdução

\section{REFERÊNCIAS BIBLIOGRÁFICAS}

01. GUERRA, M. R.; GALLO, C. V. M; MENDONÇA, G. A. S. Risco de câncer no Brasil: tendências e estudos epidemiológicos mais recentes. Revista Brasileira de Cancerologia, v.51, n.3, p.227-234, 2005.

02.TONON, T. C. A.; SCHOFFEN, J. P. F. Câncer de próstata: uma revisão da literatura. Revista Saúde e Pesquisa, v.2, n.3, p.403-410, 2009.

03. GRAZZIOTIN, T.; MARQUES, J. A.; DA ROS, C. T.; MOREIRA, B. S.; ZELMANOWICZ, A. M.; PIONER, G. T.; CARVALHAL, E.; NETO, B. Screening and diagnosis of prostate cancer. Revista da AMRIGS, n. 53, v.2, p.179-183, 2009.

04. MARTINS, T. S.; ISOLANI, P. C. Terras raras: aplicações industriais e biológicas. Química Nova, v.28, n.1, p.111-117, 2005.

05. KENYON, A.J. Review Recent developments in rare-earth doped materials for optoelectronics. Progress in Quantum Electronics, v.26, p.225-284, 2002.

06. KODAIRA, C. A.; TOMIYAMA, C. S.; FELINTO, M. C. F. C. et al. Nanopartículas de $\mathrm{Y}_{2} \mathrm{O}_{3}: \mathrm{Eu}^{3+}$ funcionalizadas para atuarem como marcadores luminescentes em imunoensaio para a LDL. REUNIÃO ANUAL DA SOCIEDADE BRASILEIRA DE QUÍMICA, 31 maio a 03 junho, 2007, Água de Lindóia. Livro de resumos. São Paulo: Sociedade Brasileira de Química, 2007.

07. SALATA, O.V. Applications of nanoparticles in biology and medicine. Journal of Nanobiotechnology, v.2:3p.1-6, 2004.

08. BOUZIGUES, C.; GACOIN, T.; ALEXANDROU, A. Biological Applications of Rare-Earth Based Nanoparticles. ACS Nano, v.5, n.11, 8488-8505, 2011.

09. LOURENÇO, A. L. Partículas de sílica funcionalizadas contendo complexos de $T R^{3+}$ para aplicação como marcadores biológicos.2010. Tese (Doutorado). Instituto de Química - Universidade de São Paulo.

10. TIAN, Y.; QI, X.; WU, X.; HUA, R.; CHEN, B. Luminescent Properties of $\mathrm{Y}_{2}\left(\mathrm{MoO}_{4}\right)_{3}: \mathrm{Eu}^{3+} \mathrm{Red}$ Phosphors with Flowerlike Shape Prepared via 
Introdução

Coprecipitation Method. Journal of Physic and Chemistry, v.113, p.1076710772, 2009. 


\section{REVISÃo BIBLIOGRÁFICA}

\section{$2.1 \quad$ As terras raras}

Segundo a IUPAC (International Union of Pure and Applied Chemistry), os termos padronizados para os elementos do grupo 3 da tabela periódica são: "metais de terras raras" para elementos da série do La a Lu e o Sc e o Y. Para designação "série do lantânio" deve ser reservado aos elementos que compreendem do La ao Lu e o termo "lantanídeos" do Ce ao Lu. ${ }^{1}$

O termo terras raras foi designado porque esses elementos foram inicialmente conhecidos em forma de seus óxidos, que se assemelham aos materiais conhecidos como terras. Hoje, sabe-se que esse termo não é considerado apropriado porque além da expressão "terras" não ser adequada à denominação de tais elementos, a expressão "raras" também não está de acordo, pois os lantanídeos são mais abundantes do que muitos outros elementos na natureza (com exceção do promécio). Por exemplo, os elementos túlio (0,5ppm) e lutécio $(0,8 \mathrm{ppm})$ que são as terras raras menos abundantes na crosta terrestre, são mais abundantes que a prata $(0,07 \mathrm{ppm})$ e o bismuto $(0,008 \mathrm{ppm}){ }^{2}$

O Cério foi o primeiro elemento de terras raras descoberto em $1751^{2}$ mas foi só em 1794 que iniciou-se a química das terras raras, quando Johann Gadolin conseguiu obter o óxido de um mineral preto posteriormente conhecido como gadolinite que ele o chamou de terra ytria. Os demais elementos foram descobertos ao longo dos anos através de obtenções de seus óxidos. Como todos os elementos possuíam propriedades físicas e químicas semelhantes e, além disso, apresentavam grande desafio em seu processo de separação e classificação, foram nomeados como terras raras e só após muito tempo foram de fato explorados. ${ }^{3}$ 
As terras raras (TR) são elementos que apresentam configuração eletrônica $[X e] 4 f^{N} 5 s^{2} 5 p^{6} 6 s^{2}$. Porém alguns elementos de terras raras como o Gd apresentam configuração eletrônica $4 f^{7} 5 d^{1} 6 s^{2}$ com ocupação de orbitais $5 d^{4}$, pois as subcamadas preenchidas e semipreenchidas apresentam energias mais baixas. Os íons TR podem se apresentar em três estados de oxidação diferentes (divalente, trivalente e tetravalente), entretanto o estado mais estável é o trivalente. Contudo, quando os íons $\mathrm{TR}^{2+}$ e $\mathrm{TR}^{4+}$ apresentam subcamada $4 \mathrm{f}$ vazia, semipreenchida e totalmente preenchida, tornam-se íons estáveis. ${ }^{4,5}$

Os íons $\mathrm{TR}^{3+}$ são considerados "ácidos duros" e têm preferência por se ligar a "bases duras" em uma molécula orgânica ou em sistemas inorgânicos, como moléculas de água, carboxilatos, dicetonatos, fosfinóxidos, sulfóxidos, aminas aromáticas bidentadas e derivados de $\mathrm{N}$-óxidos entre outros. Essas ligações são preferencialmente feitas através de átomos de oxigênio negativamente carregados e de coordenantes neutros que possuam grande momento dipolar ("bases duras"). É importante lembrar que devido à facilidade de interação entre o íon e a água, isto pode dificultar na coordenação de ligantes monodentados como alcoóis, esteres e cetonas. Para contornar esse fenômeno, deve-se utilizar um solvente com fraca habilidade coordenante. ${ }^{5,6,7}$

Nos compostos de terras raras trivalentes os átomos coordenantes apresentam a seguinte ordem de preferência de ligação: $\mathrm{F}>\mathrm{O}>\mathrm{N}>\mathrm{S}$. Por exemplo: nos molibdatos de terras raras $\left[\mathrm{TR}_{2}\left(\mathrm{MoO}_{4}\right)_{3}\right]$, os íons $\mathrm{TR}^{3+}$ se ligam aos grupos molibdatos pelos oxigênios negativamente carregados.

Os elétrons de valência dos íons lantanídeos estão situados no subnível $4 f$ e estão blindados pelos subníveis $5 s$ e $5 p$ que são totalmente preenchidos, portanto os elétrons $4 f$ sofrem pouca influência do ambiente químico. A sobreposição dos orbitais $4 f$ dos íons $T^{3+}$ com os orbitais dos ligantes é pequena, que ocorre devido a essa proteção da interação do campo ligante pelas subcamadas $5 s 5 p$ preenchidas. Ademais, a habilidade de polarização dos íns $\mathrm{TR}^{3+}$ é fraca por apresentarem raios iônicos grandes. ${ }^{4,8}$ 
O estudo das variações de energias dos orbitais em função do aumento do número atômico dos íons terras raras pode ser realizado através da energia de ionização. As duas primeiras energias de ionização da série lantanídica apresentam pouca variação ao longo de toda a série. Em contrapartida, há uma forte variação nas energias dos processos $T R^{2+} \rightarrow T R^{3+} e$ $\mathrm{TR}^{3+} \rightarrow \mathrm{TR}^{\mathrm{IV}}$, como ilustrado na FIG.2.1. O estudo das energias de ionização desses íons pode explicar a estabilidade dos íons $\mathrm{TR}^{2+/ 3+/ \mathrm{IV}}$ (FIG.2.1a). ${ }^{3}$

Por exemplo, o processo de ionização do $\mathrm{La}^{3+} \rightarrow \mathrm{La}^{4+}$ apresenta energia relativamente alta, considerando que há a quebra da estabilidade gerada pela configuração do gás nobre $\mathrm{Xe}$, enquanto que a baixa energia do processo $\mathrm{Ce}^{3+}\left(4 f^{1}\right) \rightarrow \mathrm{Ce}^{4+}\left(4 f^{0}\right)$ é explicada por gerar a subcamada $4 \mathrm{f}$ vazia. Por outro lado, uma maior energia de ionização para $\mathrm{Gd}^{3+}\left(4 f^{7}\right) \rightarrow \mathrm{Gd}^{4+}\left(4 f^{6}\right)$ é observada devido à estabilidade gerada pela configuração semipreenchida $4 f^{75}$.
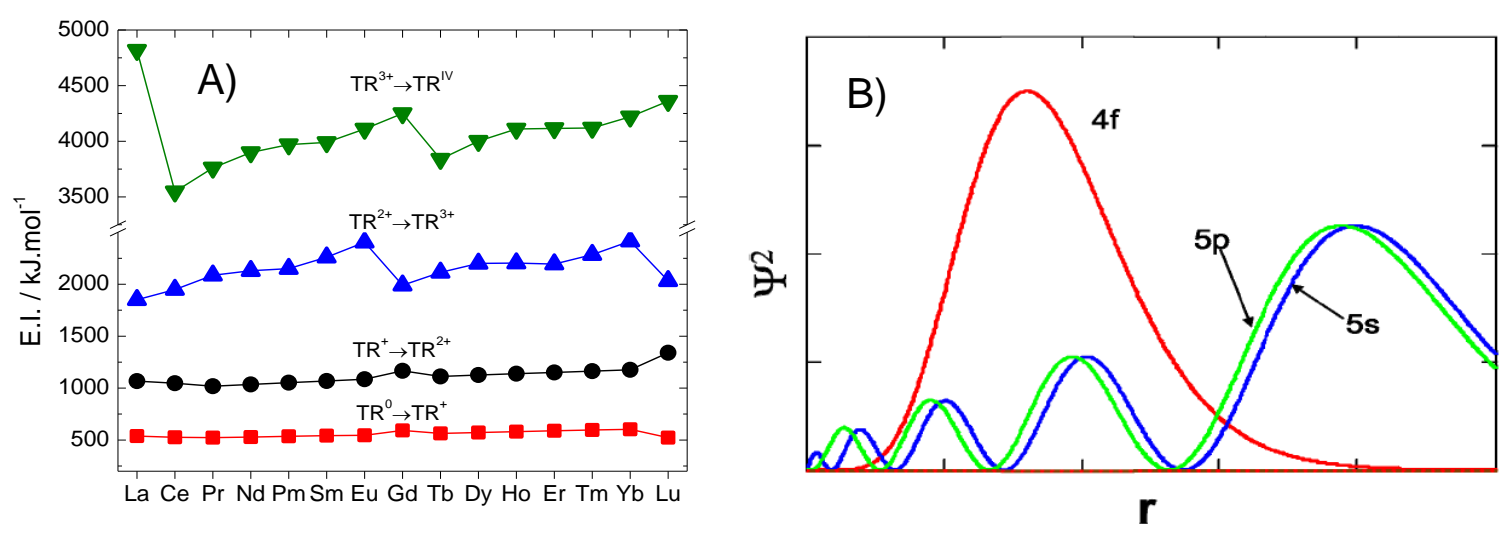

FIGURA 2.1. As quatro primeiras energias de ionização dos elementos terras $\operatorname{raras}(A)^{3}$ e distribuição radial da densidade eletrônica dos orbitais 4 f, $5 \mathrm{~s}$ e $5 p$ em um íon $\mathrm{TR}^{3+}$.

Analogicamente, a menor energia do processo $\mathrm{Eu}^{2+}\left(4 \mathrm{f}^{7}\right) \rightarrow \mathrm{Eu}^{3+}\left(4 \mathrm{f}^{6}\right)$ confere certa estabilidade ao íon $\mathrm{Eu}^{2+}\left(4 \mathrm{f}^{7}\right)$, mesmo em solução aquosa. A estabilidade da configuração totalmente preenchida $4 f^{14}$ é evidenciada pelo 
aumento da energia de ionização $L u^{3+}\left(4 f^{14}\right) \rightarrow L u^{4+}\left(4 f^{13}\right)$ em comparação com as demais ionizações da série lantanídica. ${ }^{9}$

$\mathrm{Na}$ FIG.2.1b, pode-se observar que os orbitais $5 \mathrm{~s}^{2}$ e $5 p^{6}$ apresentam distribuição radial mais extensa que a dos orbitais $4 \mathrm{f}^{\mathrm{N}}$, sendo portanto os mais externos nestes íons. Desta forma, como foi mencionado anteriormente, os elétrons $4 f^{N}$ se encontram protegidos do ambiente químico devido ao eficiente efeito de blindagem exercido pelas subcamadas $5 s^{2}$ e $5 p^{6}$, interagindo fracamente com os elétrons dos átomos circundantes. Como resultado, as propriedades eletrônicas são ligeiramente afetadas pelo ambiente químico ao redor do íon metálico central.

Os elétrons da mesma subcamada se encontram na mesma distância do núcleo, exercendo um fraco efeito de blindagem um sobre o outro. Há um crescimento gradual no preenchimento eletrônico dos orbitais $4 f$ na série lantanídica, ou seja, a carga nuclear efetiva tende a aumentar numa razão maior que a repulsão intereletrônica. ${ }^{3,9}$ Como consequência, há a diminuição do raio iônico conforme o aumento do número atômico, conforme TAB. 2.1. Este efeito é conhecido como contração lantanídica e é responsável pela diminuição de aproximadamente $20 \%$ do raio iônico na série do $\mathrm{La}^{3+}$ ao $\mathrm{Lu}^{3+}$. 
TABELA 2.1. Configurações eletrônicas e níveis espectroscópicos fundamentais dos elementos TR, de seus íons $\mathrm{TR}^{3+}$ e valores dos raios iônicos dos íons $\mathrm{TR}^{3+}$.

\begin{tabular}{l|l|l|l}
\hline $\begin{array}{l}\text { Elemento } \\
\text { TR }\end{array}$ & $\begin{array}{l}\text { Configuração } \\
\text { fundamental }\end{array}$ & $\begin{array}{l}\text { Configuração } \\
\text { do íon TR }\end{array}$ & $\begin{array}{l}\text { Raio iônico } \\
(\AA)\end{array}$
\end{tabular}




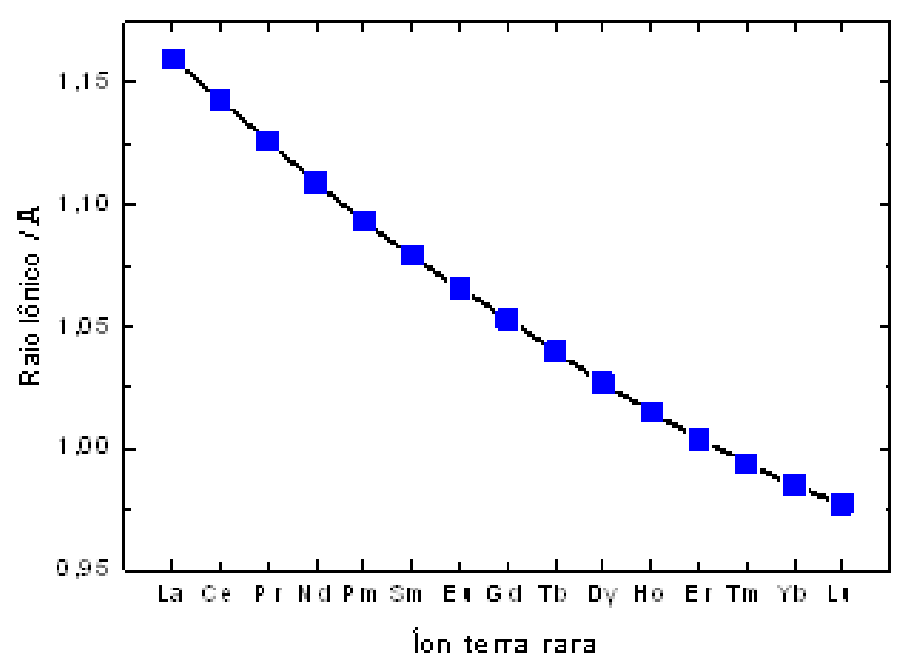

FIGURA 2.2. Representação da contração lantanídica dos íons $T^{3+}{ }^{3}$.

O tamanho do raio iônico e seus orbitais externos influenciam no número de coordenação dos íons de $\mathrm{TR}^{3+}$, desta forma estes íons podem apresentar número de coordenação até doze na primeira esfera de coordenação. ${ }^{8}$ Um forte caráter iônico está presente na interação química dos sistemas contendo íons $\mathrm{TR}^{3+}$ devido à formação de ligações não direcionais. ${ }^{10}$

A blindagem das subcamadas $5 s^{2}$ e $5 p^{6}$ sobre os orbitais $4 \mathrm{f}^{\mathrm{N}}$ têm um efeito direto sobre a estrutura dos níveis de energia dos íons terras raras. Nos lantanídeos, as repulsões intereletrônicas $\left(\sim 10^{4} \mathrm{~cm}^{-1}\right)$ são maiores do que o acoplamento spin-órbita $\left(\sim 10^{3} \mathrm{~cm}^{-1}\right)$ que, por sua vez, é maior do que o efeito do campo cristalino $\left(\sim 10^{2} \mathrm{~cm}^{-1}\right)$. Esta ordem significa que o campo cristalino nos íons lantanídeos está atuando no sentido de remover alguma degenerescência contida nos valores individuais do número quântico $\mathrm{J}$ em $\mathrm{M}_{\mathrm{J}}$. Portanto, este desdobramento adicional é geralmente da ordem de algumas centenas de $\mathrm{cm}^{-1}$ que é consideravelmente menor que a diferença de energia entre os níveis com diferentes valores de $\mathrm{J}$ associado ao acoplamento spin-órbita. ${ }^{5,11}$

O pequeno efeito do campo ligante, causado pela fraca perturbação do ambiente químico sobre os elétrons $4 f$ dos íons $\mathrm{TR}^{3+}$ implica em bandas de 
absorção e de emissão estreitas ${ }^{12,13,14}$, características de seus níveis de energia, visto que as transições intraconfiguracionais $4 \mathrm{f}^{\mathrm{N}}-4 \mathrm{f}^{\mathrm{N}}$ se comportam como raias que são parecidas às observadas em espectros atômicos. Este efeito é evidenciado pelas transições eletrônicas intraconfiguracionais $4 f-4 f$, que são estreitas e praticamente não se deslocam em função do ambiente químico. ${ }^{5}$

A partir dos dados espectrais de compostos contendo íons $\mathrm{TR}^{3+}$ é possível determinar as energias dos níveis do estado fundamental e dos estados excitados destes íons (FIG.2.3). Desta forma, podem se projetar compostos e materiais que apresentam altas intensidades de luminescência, levando em consideração as diferenças entre as energias dos níveis excitados dos íons $\operatorname{TR}^{3+}$ e dos estados excitados dos ligantes. ${ }^{5,15}$ 


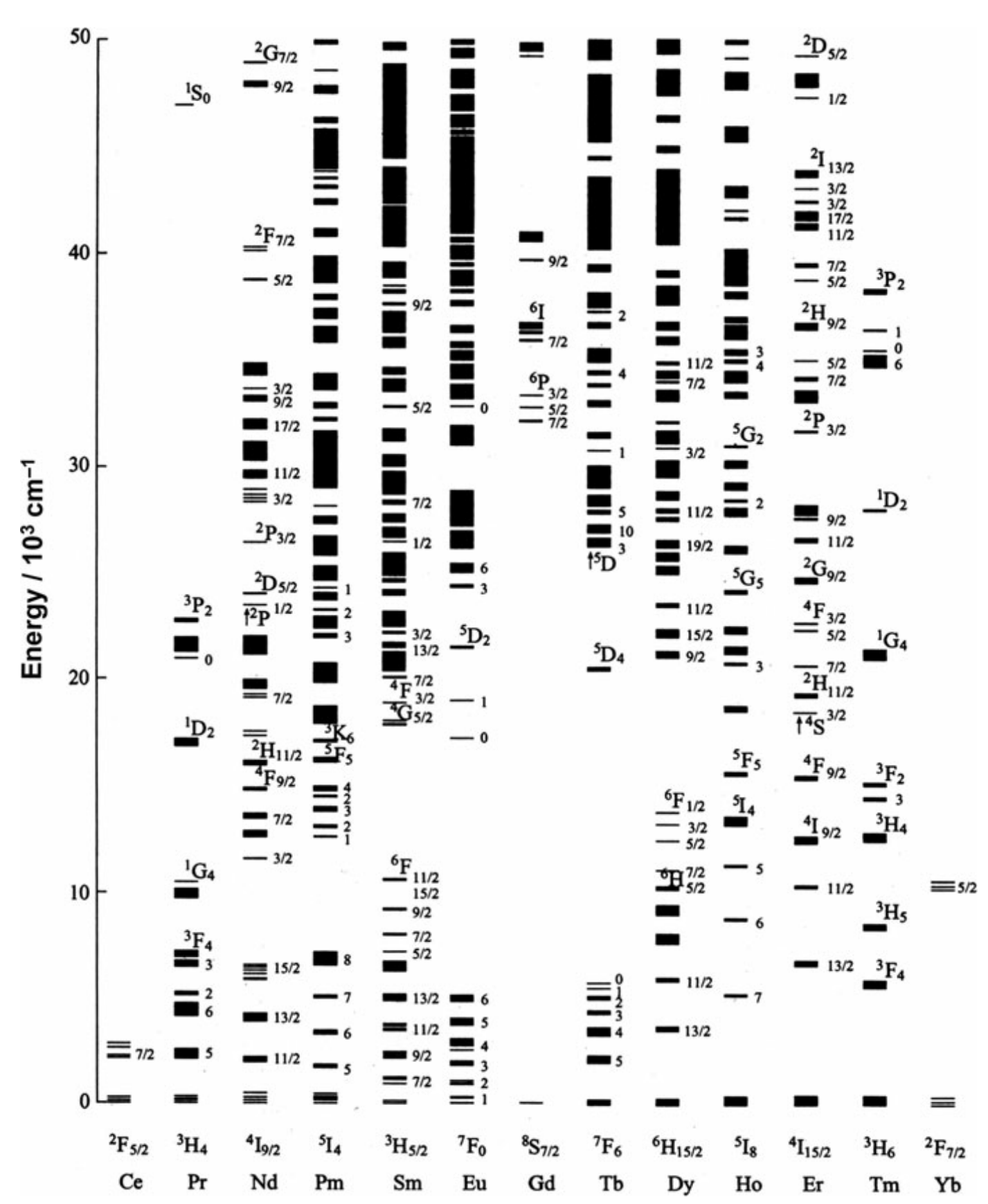

FIGURA 2.3. Diagrama dos níveis de energia da configuração $4 f^{N}$ dos íons $T R^{3+}$ dopados na matriz de $\mathrm{LaF}_{3}$ calculados a partir dos parâmetros reportados por Carnall ${ }^{16} \mathrm{e}$ reeditados. 


\section{$2.2 \quad$ Materiais luminescentes}

A luminescência é a emissão de luz de qualquer substância e ocorre a partir de estados eletronicamente excitados. A luminescência é formalmente divididas em duas classes: a fluorescência e a fosforescência, ambos são processos relacionados ao tempo de decaimento ${ }^{17}$ e a natureza do estado excitado. ${ }^{18}$ Nos estados excitados singletos, o elétron no orbital excitado está emparelhado (por paridade de spin) ao segundo elétron no orbital do estado fundamental. Consequentemente, o retorno ao estado fundamental é permitido por spin e ocorre rapidamente pela emissão de um fóton. As taxas de emissão de fluorescência são tipicamente da ordem de $10^{-8} \mathrm{~s}$.

A fluorescência possui tempos de vida extremamente curtos, ou seja, logo que a irradiação é interrompida, a emissão cessa e são da ordem de $10^{-9}$ a $10^{-6} \mathrm{~s}$ (ns a $\mu \mathrm{s}$ ). Isso ocorre devido à energia eletrônica responsável pela transição fluorescente, não envolvendo mudança no número quântico do spin do elétron e passando do nível $S_{0} \rightarrow S_{1}$ (FIG.2.4), isso faz com que emita radiação desde o nível excitado $S_{1}$ para algum dos níveis vibracionais do estado eletrônico $S_{0}$. A fluorescência é emitida em comprimentos de onda maiores àqueles de excitação, deslocando-se entre 50 e $150 \mathrm{~nm}$, quando comparado ao comprimento de onda da luz usado para a excitação da molécula. . $^{3,18,19}$ 


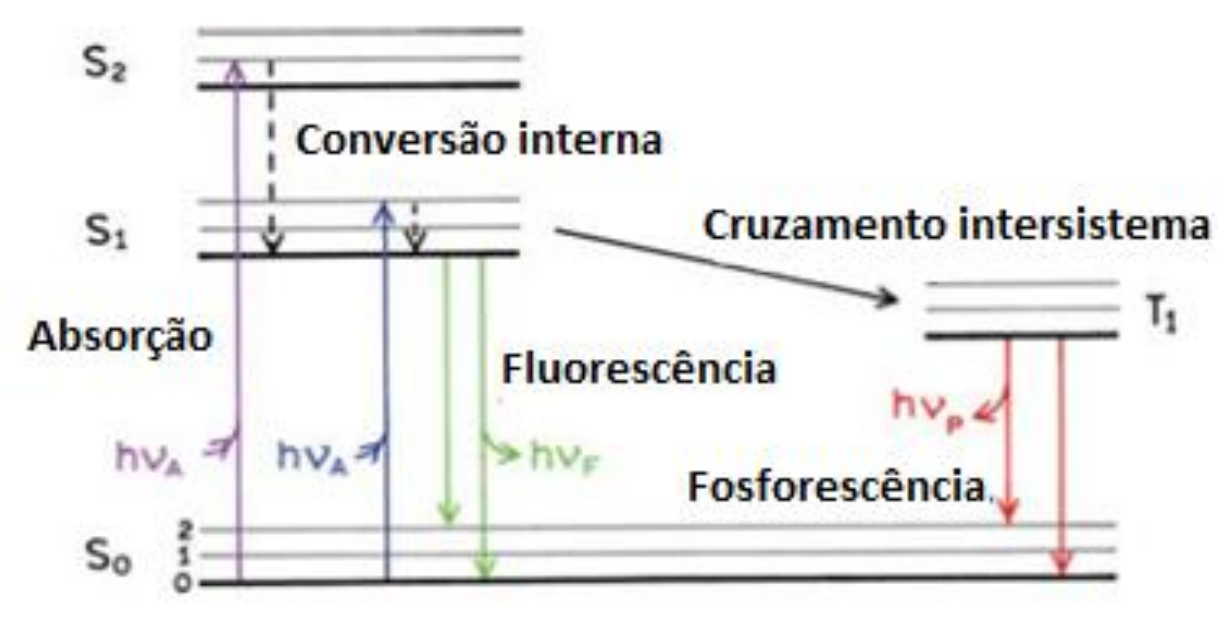

FIGURA 2.4. Processo de absorção e emissão da luz no diagrama de Jablonski.

No processo de fosforescência o fenômeno de emissão persiste por um tempo maior após o termino da irradiação e isso ocorre devido à mudança no número quântico de spin do elétron, que envolve transições proibidas por spin provenientes de um estado excitado tripleto e retornando para o estado fundamental singleto $\left(T_{1} \rightarrow S_{0}\right)$ conforme FIG.2.4. Este tipo de transição é menos provável que a transição envolvendo dois estados singletos (fluorescência). .,18,19 $^{3}$

Materiais que exibem o fenômeno de luminescência (também denominados fósforos) têm como função converter a radiação recebida em luz. A luminescência pode ocorrer como resultado de vários tipos de fonte de excitação e pode ser classificada como fotoluminescência, eletroluminescência, quimiluminescência, entre outros. ${ }^{16}$ 


\subsection{Luminescência dos íons $\mathbf{T R}^{3+}$}

As transições intraconfiguracionais $4 \mathrm{f}-4 \mathrm{f}$ dos íons $\mathrm{TR}^{3+}$ são proibidas por mecanismo de dipolo elétrico (regra de Laporte), pois apresentam $\Delta l=0$. Apesar disso, se a simetria ao redor do íon $\mathrm{TR}^{3+}$ não apresenta centro de inversão, estas transições são observadas graças a relaxações da regra de seleção de paridade devido a outros mecanismos, como misturas de paridades opostas, acoplamento vibrônico, entre outros ${ }^{20}$. Por outro lado, se o íon $\mathrm{TR}^{3+}$ está inserido em um sítio que apresenta centro de inversão, a regra de Laporte não é relaxada, e as transições $4 \mathrm{f}^{\mathrm{N}}-4 \mathrm{f}^{\mathrm{N}}$ permanecem estritamente proibidas pelo mecanismo de dipolo elétrico.

Em função de suas propriedades luminescentes, os íons $T^{3+}$ vem sendo classificados classicamente em quatro grupos. ${ }^{21,22}$

1) $\mathbf{S c}^{3+}\left(3 d^{0}\right), \mathbf{Y}^{3+}\left(4 d^{0}\right), \mathbf{L a}^{3+}\left(4 f^{0}\right)$ e $\mathbf{L u}^{3+}\left(4 f^{14}\right)$ : não exibem luminescência por não apresentarem elétrons opticamente ativos; são íons que apresentam configuração com subcamada $4 f$ vazia ou cheia.

2) $\mathbf{G d}^{3+}\left(4 f^{7}\right)$ : por apresentar a subcamada $4 f^{7}$ semipreenchida e por isso mais estável, seu primeiro nível excitado, ${ }^{6} \mathrm{P}_{7 / 2}$, apresenta energia cerca de $32000 \mathrm{~cm}^{-1}$ ( $312 \mathrm{~nm})$ acima de seu nível fundamental, ${ }^{8} \mathrm{~S}_{7 / 2}$. Esta característica torna este ín um "padrão" para estudar as propriedades luminescentes de sistemas semelhantes com o intuito de obter informações espectroscópicas de estados de transferência de carga, estados tripletos, entre outros.

3) $\mathrm{Sm}^{3+}\left(4 f^{5}\right), \mathrm{Eu}^{3+}\left(4 \mathrm{f}^{6}\right), \mathbf{T b}^{3+}\left(4 \mathrm{f}^{8}\right)$ e $\mathrm{Dy}^{3+}\left(4 \mathrm{f}^{9}\right)$ : a diferença de energia considerável entre os níveis eletrônicos excitados e fundamentais destes íons corresponde à energia da radiação visível, podendo assim apresentar alta intensidade de luminescência na região do visível.

4) $\mathrm{Ce}^{3+}\left(4 f^{1}\right), \operatorname{Pr}^{3+}\left(4 f^{2}\right), \mathbf{N d}^{3+}\left(4 f^{3}\right), \mathbf{H o}^{3+}\left(4 f^{10}\right), \operatorname{Er}^{3+}\left(4 f^{11}\right), \operatorname{Tm}^{3+}\left(4 f^{12}\right)$ e $\mathbf{Y b}^{3+}\left(4 f^{13}\right)$ : seus compostos de forma geral apresentam baixa intensidade de luminescência, 
pois as pequenas diferenças de energia entre seus níveis eletrônicos favorecem processos de decaimentos não-radiativos através de acoplamentos com os modos vibracionais dos ligantes. ${ }^{23}$

Dentre os íons $\mathrm{TR}^{3+}$ que apresentam maiores intensidades de luminescência na região do visível como observado da classificação acima estão os íons $\mathrm{Eu}^{3+}$ e $\mathrm{Tb}^{3+}$. Devido ao fato de o principal nível emissor do íon $\mathrm{Eu}^{3+}$ (nível ${ }^{5} D_{0}$ ) ser não-degenerado, as interpretações dos desdobramentos de suas bandas de emissão em função do ambiente químico são mais encontradas na literatura do que para os fósforos com térbio e ou outro lantanídeo..$^{24,25}$

Em alguns íons $\mathrm{TR}^{3+}$, a diferença de energia entre o nível emissor e alguns níveis do termo fundamental corresponde à frequência da radiação visível. Dentre estas, algumas transições são extensivamente exploradas, podendo-se citar: a transição ${ }^{5} \mathrm{D}_{0} \rightarrow{ }^{7} \mathrm{~F}_{2}$ do íon $\mathrm{Eu}^{3+}$ e a transição ${ }^{5} \mathrm{D}_{4} \rightarrow{ }^{7} \mathrm{~F}_{5}$ do íon $\mathrm{Tb}^{3+}$, que frequentemente são as mais intensas observadas para estes íons, fazendo com que seus compostos apresentem emissões de cores vermelha $\left(\mathrm{Eu}^{3+}\right)$ e verde $\left(\mathrm{Tb}^{3+}\right)$.

O íon $\mathrm{Gd}^{3+}$ é especial no estudo de materiais por não apresentar emissões de energia menores que $32000 \mathrm{~cm}^{-1}$. É utilizado como "branco" no estudo das propriedades luminescentes de complexos com outros íons $\mathrm{TR}^{3+}$. Complexos com o íon $\mathrm{Gd}^{3+}$ dificilmente apresentam transferência de energia ligante-íon $\mathrm{Gd}^{3+}$, pois as energias dos estados excitados dos ligantes orgânicos normalmente se encontram abaixo do seu nível emissor de menor energia ${ }^{6} \mathrm{P}_{7 / 2}$. Desta forma, os complexos de $\mathrm{Gd}^{3+}$ são utilizados para estudar as propriedades luminescentes dos ligantes através de suas bandas de excitação e emissão. A proximidade entre os raios iônicos dos íons $\mathrm{Eu}^{3+}$ e $\mathrm{Tb}^{3+}$ em relação ao íon $\mathrm{Gd}^{3+} \mathrm{o}$ torna um bom mimetizador desses íons. Portanto, matrizes inorgânicas contendo o íon gadolínio trivalente são utilizadas para obter informações sobre as transições de transferência de carga ligante-metal oriundas de bandas de absorção e de emissão. ${ }^{14}$ 
As principais interações que governam as estruturas dos níveis de energia dos íons $\operatorname{TR}^{3+}$ são as que estão relacionadas ao íon livre $\left(H_{L}\right)$ e a perturbação do campo ligante $\left(H_{C L}\right)$, que apresenta contribuição menor. $O$ hamiltoniano total de um íon $\mathrm{TR}^{3+}$ é dado por:

$$
H_{t o t}=H_{I L}+H_{C L}
$$

Onde $H_{l L}=H_{\text {Conf }}+H_{r e}+H_{\text {soe }} H_{\text {Conf }}$ corresponde à energia da configuração, $H_{r e}$ à energia relativa à repulsão intereletrônica e $H_{S O}$ provém da interação spin-órbita. A interação dos elétrons 4 f com o ambiente químico, apesar de fraca, é responsável pelo desdobramento dos subníveis ${ }^{2 S^{+1}} L_{J(M j)}$ em função da simetria ao redor do íon. ${ }^{20} \mathrm{O}$ termo $H_{C L}$ é descrito na forma de operadores tensoriais de Racah. ${ }^{26,27,28,29}$

A influência do mecanismo de dipolo elétrico forçado sobre a luminescência dos íons $\mathrm{TR}^{3+}$ foi descrito simultaneamente por Judd ${ }^{30} \mathrm{e}$ Ofelt ${ }^{31} \mathrm{em}$ 1962. Dois anos mais tarde Jörgensen e Judd estudaram o efeito do mecanismo de acoplamento dinâmico ${ }^{32}$ sobre a intensidade das transições hipersensíveis. Perturbações de natureza elétrica e magnética provocadas pelo ambiente químico sobre o íon terra rara, tal como o mecanismo de acoplamento dinâmico, favorecem a relaxação das regras de seleção, intensificando as emissões das transições $4 \mathrm{f}^{\mathrm{N}}-4 \mathrm{f}^{\mathrm{N}}$. Em 1942, Weissman ${ }^{33}$ observou que o íon $\mathrm{Eu}^{3+}$, em alguns ligantes, apresenta emissão bem mais intensa quando o sistema é excitado na transição do ligante.

Nestes sistemas a energia absorvida pela rede cristalina é transferida ao íon $\mathrm{Eu}^{3+}$, e a emissão apresentada é característica das transições $4 \mathrm{f}-4 \mathrm{f}$ do íon terra rara. A intensificação da emissão do íon $\mathrm{Eu}^{3+}$ se deve principalmente aos os níveis emissores ${ }^{5} D_{\jmath}$ do íon $E^{3+}$ que são mais populados por transferência de energia do que por irradiação direta, pois o ligante ou a matriz são mais eficientemente excitados do que o íon $\mathrm{TR}^{3+}$. $^{21,23}$ 


\section{$2.4 \quad$ Espectroscopia dos íons $\mathrm{TR}^{3+}$}

\subsection{1 $\mathrm{Eu}^{3+} \mathrm{e} \mathrm{Tb}$}

Em diferentes fósforos, a emissão dos íons terras raras se dá através das transições intraconfiguracionais $4 f$, por exemplo: $\mathrm{Eu}^{3+}\left(4 f^{6}\right)$ e $\mathrm{Tb}^{3+}\left(4 f^{8}\right)$. Os elétrons $f$ são blindados do ambiente químico e por este fato conservam seu caráter atômico. A consequência desta característica espectroscópica é que as bandas de absorção e emissão são bastante finas. Além disso, as transições f-f proibidas pela regra de Laporte e por isso, estas transições eletrônicas apresentam tempos de vida longos, na faixa de milissegundos. ${ }^{34}$

Uma das principais aplicações de materiais luminescentes a base de terras raras está em tubos de televisores coloridos, nos quais são usadas para produzir as três cores primárias: vermelho, azul e verde. As transições responsáveis por essas cores são ${ }^{5} \mathrm{D}_{0} \rightarrow{ }^{7} \mathrm{~F}_{2}$ do íon $\mathrm{Eu}^{3+}$ (FIG.2.5), emissão em $615 \mathrm{~nm}$ (vermelha), ${ }^{5} \mathrm{D}_{4} \rightarrow{ }^{7} \mathrm{~F}_{5}$ do íon $\mathrm{Tb}^{3+}$, emissão em $550 \mathrm{~nm}$ (verde) e a transição $5 \mathrm{~d} \rightarrow 4 \mathrm{f}$ do íon $\mathrm{Eu}^{2+}$, emissão em $450 \mathrm{~nm}$ (azul). Esses fósforos além de serem usados em televisores, são aplicados também em fibras ópticas, lâmpadas fluorescentes, LEDs, tintas, vernizes, marcadores ópticos luminescentes, telas de computadores, bem como detecção de radiação (raios gama e elétrons) ${ }^{35}$ 


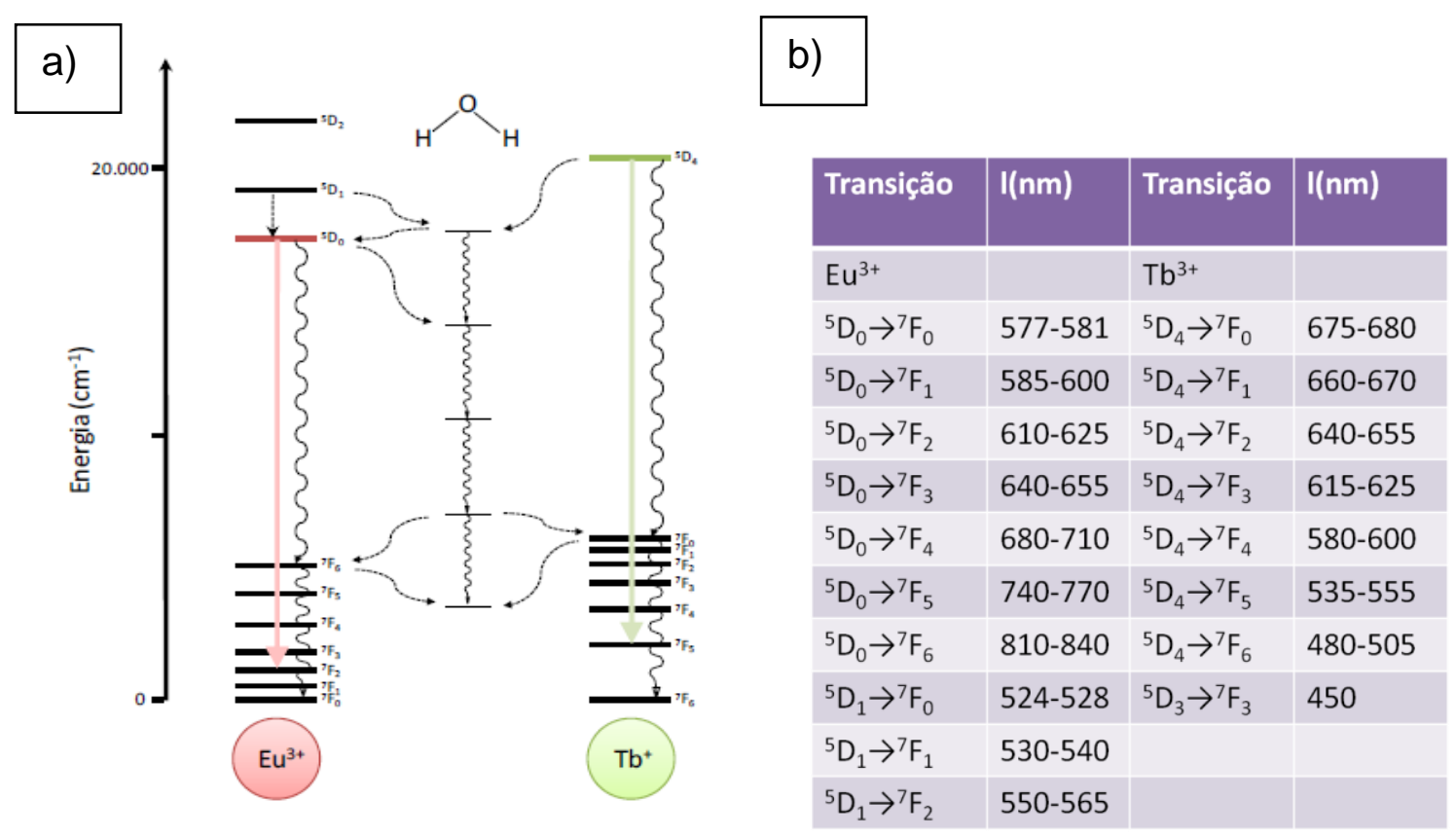

FIGURA 2.5. Diagrama esquemático dosníveis de energia envolvidos no processo de luminescência dos íons terras raras a) $\mathrm{Eu}^{3+}$ e b) $\mathrm{Tb}^{3+}$ e energias das principais transições no processo de luminescência.

Dentre os íons TR, O $\mathrm{Eu}^{3+}$ tem sido o mais estudado. Quando comparado às demais TR, os espectros de absorção e emissão do íon $\mathrm{Eu}^{3+}$ apresentam maiores facilidades de interpretação dos dados ópticos. ${ }^{38} \mathrm{O}$ campo ligante pode ser tratado como uma perturbação dos níveis eletrônicos do íon $\mathrm{Eu}^{3+}$ (FIG.2.6). ${ }^{36,37}$ 


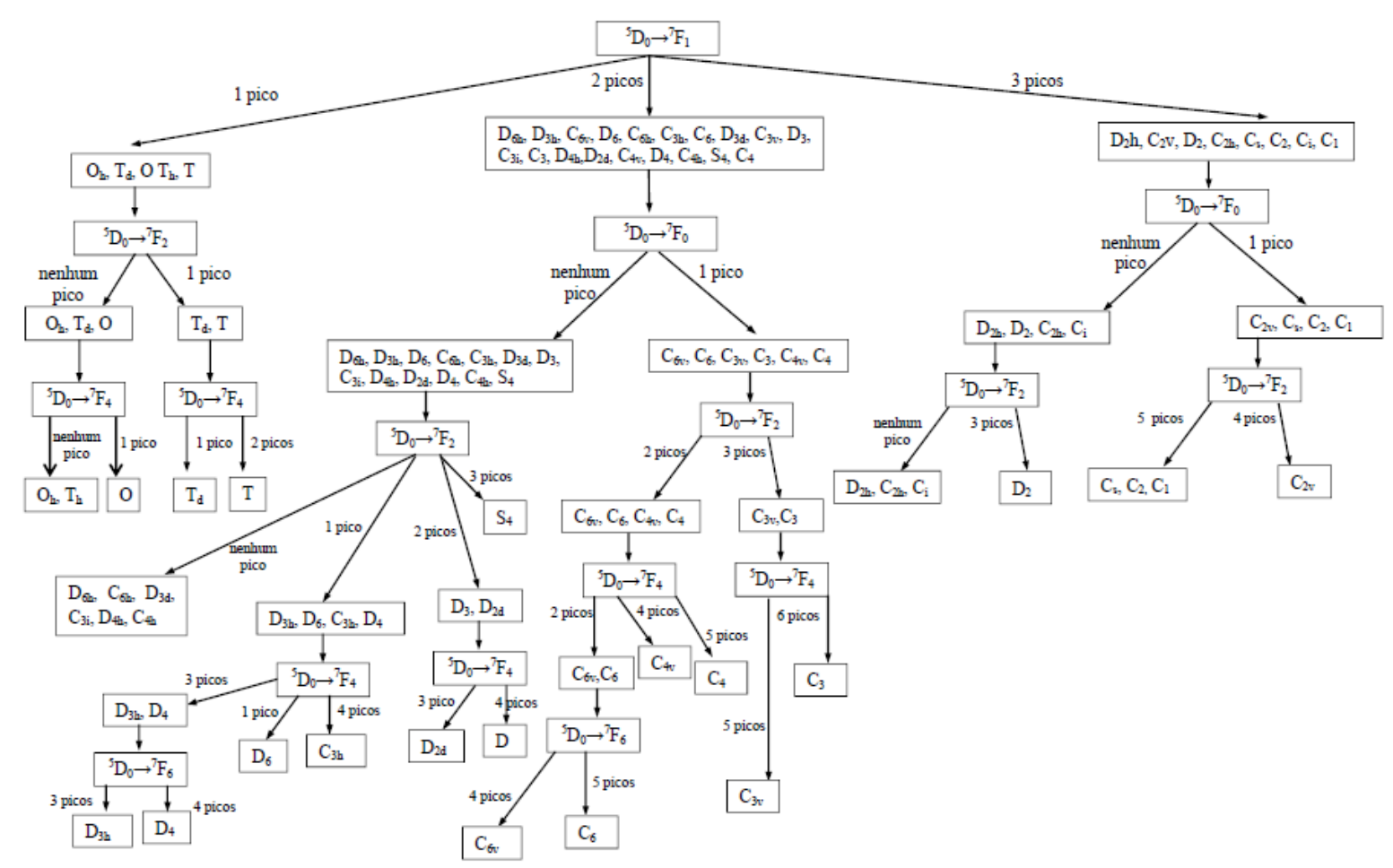

FIGURA 2.6. Uso das transições ${ }^{5} \mathrm{D}_{0} \rightarrow{ }^{7} \mathrm{~F}_{\mathrm{J}}$ do íon $\mathrm{Eu}^{3+}$ como sonda de sítios de simetria em cristais. As transições ${ }^{5} \mathrm{D}_{0} \rightarrow{ }^{7} \mathrm{~F}_{3},{ }^{7} \mathrm{~F}_{5}$ são proibidas sob as regras de seleção de $J u_{d d}{ }^{30}$ e são usualmente muito fracas, portanto, não estão incluídas. $O$ esquema refere-se às transições permitidas por dipolo elétrico, exceto o caso da transição ${ }^{5} \mathrm{D}_{0} \rightarrow{ }^{7} \mathrm{~F}_{1}$, que é permitida pelo mecanismo de dipolo magnético. ${ }^{42}$

Por isto, os baricentros dos níveis de energia do íon $\mathrm{TR}^{3+}$ coordenados se assemelham aos respectivos níveis de energia do íon livre. Por outro lado, o íon $\mathrm{Tb}^{3+}$ apresenta transições eletrônicas oriundas do nível emissor ${ }^{5} \mathrm{D}_{4}$. Devido ao fato de o nível emissor do $\mathrm{Tb}^{3+}$ ser degenerado, determinar a simetria deste íon utilizando os espectros de luminescência torna-se um estudo complexo. A degenerescência do nível emissor ${ }^{5} \mathrm{D}_{4}$ do íon $\mathrm{Tb}^{3+}$ explica porque suas bandas de emissão apresentam mais desdobramentos que as do $\mathrm{Eu}^{3+}$, à temperatura ambiente. ${ }^{38,36}$ 
Isto ocorre porque tanto o nível fundamental ${ }^{7} \mathrm{~F}_{6}$ do íon $\mathrm{Tb}^{3+}$ (que pode desdobrar-se em até 13 subníveis $M_{J}=2 \times 6+1=13$ ), quanto o nível excitado ${ }^{5} D_{4}$ $\left(M_{J}=2 \times 4+1=9\right)$ são degenerados. Ao contrário do que é observado para o íon $\mathrm{Eu}^{3+}$, os picos de absorção do íon $\mathrm{Tb}^{3+}$ são oriundos do nível ${ }^{7} \mathrm{~F}_{6}$ já que o nível ${ }^{7} \mathrm{~F}_{5}$ não é populado termicamente $\left(\Delta E\left[{ }^{7} F_{6}-{ }^{7} F_{5}\right] \sim 1000 \mathrm{~cm}^{-1}\right)$.

No caso do íon $\mathrm{Eu}^{3+}$, a transição ${ }^{5} \mathrm{D}_{0} \rightarrow{ }^{7} \mathrm{~F}_{0}$ envolve dois níveis não degenerados, apresentando um único pico não desdobrado; vale ressaltar que se esta transição for observada é possível inferir que o íon $\mathrm{Eu}^{3+}$ está localizado em um sítio cuja simetria pertence aos grupos pontuais $S_{n}, C_{n}, C_{n h}$ ou $C_{n v}$. A transição ${ }^{5} \mathrm{D}_{0} \rightarrow{ }^{7} \mathrm{~F}_{1}$, por ser permitida por mecanismo de dipolo magnético, é utilizada como referência na análise de dados espectrais de compostos com $\mathrm{Eu}^{3+}$, visto que sua intensidade é praticamente insensível ao ambiente químico.

Por outro lado, a transição ${ }^{5} D_{0} \rightarrow{ }^{7} F_{2}$ apresenta caráter hipersensível, podendo variar sua intensidade em até 200 vezes em função da simetria ao redor do íon $\mathrm{Eu}^{3+}$. A transição ${ }^{5} \mathrm{D}_{0} \rightarrow{ }^{7} \mathrm{~F}_{4}$ normalmente é observada e apresenta uma considerável sensibilidade ao ambiente químico, embora menor que a apresentada pela transição ${ }^{5} \mathrm{D}_{0} \rightarrow{ }^{7} \mathrm{~F}_{2}$. Quando registrada, a transição proibida ${ }^{5} \mathrm{D}_{0} \rightarrow{ }^{7} \mathrm{~F}_{3}$ apresenta baixa intensidade.

Comparado ao íon európio trivalente, o íon $\mathrm{Tb}^{3+}$ apresenta uma maior diferença de energia entre o nível emissor de mais baixa energia ${ }^{5} D_{4}$ e os níveis fundamentais ${ }^{7} \mathrm{FJ}_{\mathrm{J}}(\mathrm{J}=0-6) \cdot{ }^{14}$ Isto diminui a probabilidade de transição nãoradiativa através de acoplamento com modos vibracionais intermediários. Como o nível emissor ${ }^{5} D_{4}$ apresenta degenerescência (pode desdobrar-se em até 9 subníveis), as bandas de emissão ${ }^{5} \mathrm{D}_{4} \rightarrow{ }^{7} \mathrm{~F}_{\mathrm{J}}(\mathrm{J}=0-6)$ apresentam um maior número de picos em comparação às bandas observadas nos espectros do $\mathrm{Eu}^{3+}$. Isto dificulta a interpretação da estrutura de seus níveis de energia a partir dos desdobramentos de suas bandas de emissão. A transição ${ }^{5} D_{4} \rightarrow{ }^{7} F_{5}$, na faixa espectral de 545 a $555 \mathrm{~nm}$, é frequentemente a mais intensa, sendo a responsável pela emissão de cor verde característica deste íon. As bandas 
${ }^{5} D_{4} \rightarrow{ }^{7} F_{J}(J=0-2)$ são normalmente observadas, mas apresentam baixa intensidade. ${ }^{20}$

Os íons terras raras também podem apresentar as transições interconfiguracionais $4 f^{n-1}-5 d$. Por exemplo, os íons terras raras divalentes $\left(\mathrm{Sm}^{2+}\right.$, $\mathrm{Eu}^{2+}, \mathrm{Tm}^{2+}$ e $\mathrm{Yb}^{2+}$ ) e os íons $\mathrm{TR}^{3+}$ que tem tendência a oxidar, como $\mathrm{Ce}^{3+}, \mathrm{Pr}^{3+} \mathrm{e}$ $\mathrm{Tb}^{3+}$, apresentam essas transições na região do UV-Vis. ${ }^{36}$ Ao contrário das transições $4 f-4 f$, as transições $4 f-5 d$ são permitidas pela regra de Laporte e, portanto, possuem alta intensidade de absorção e emissão, além de tempos de vida muito curtos, variando de nanosegundos ( $\mathrm{Ce}^{3+}$, permitida por spin, $\Delta \mathrm{S}=0$ ) a microssegundos $\left(\mathrm{Eu}^{2+} \mathrm{e} \mathrm{Tb}^{3+}\right)$. Como os orbitais $5 \mathrm{~d}$ são mais externos, sofrem maior desdobramento por influência do campo ligante, seus espectros apresentam bandas largas devido ao acoplamento vibrônico e sofrem forte efeito nefelauxético.

Deve-se salientar que a diferença de energia entre o níveis fundamentais e os primeiros níveis $4 \mathrm{f}^{\mathrm{n}-1}-5 \mathrm{~d}$ dos íons terras raras dentro de uma determinada matriz tem comportamento semelhante, independente da matriz hospedeira. $37,39,40$

Os níveis $4 f^{n-1}-5 d$ de maior energia são para $n=7\left(E u^{2+}\right.$ e $\left.G d^{3+}\right)$ e $n=14$ $\left(\mathrm{Yb}^{2+}\right.$ e $\left.\mathrm{Lu}^{3+}\right)$. Por outro lado, os níveis $4 \mathrm{f}^{\mathrm{n}-1}-5 \mathrm{~d}$ de menor energia são encontrados para $\mathrm{n}=1$ e $8\left(\mathrm{La}^{2+}, \mathrm{Ce}^{3+}, \mathrm{Gd}^{2+}\right.$ e $\left.\mathrm{Tb}^{3+}\right)$, de acordo com a maior estabilidade das configurações de camada semipreenchida e completa. ${ }^{39}$

Assim como as transições $4 \mathrm{f}^{\mathrm{n}-1}-5 \mathrm{~d}$, as transições de transferência de carga ligante-metal (LMCT: Ligand to Metal Charge Transfer) também são permitidas pela regra de Laporte, possuindo altas intensidades de absorção. A energia para essas transições encontra-se na região do UV-Vis para os íons terras raras tetravalentes $\left(\mathrm{Ce}^{\mathrm{IV}}, \mathrm{Pr}^{\mathrm{IV}}\right.$ e $\left.\mathrm{Tb}^{\mathrm{IV}}\right)$ e para os íons trivalentes que possuem tendência a reduzir, como $\mathrm{Sm}^{3+}, \mathrm{Eu}^{3+}, \mathrm{Tm}^{3+}$ e $\mathrm{Yb}^{3+}$. Por exemplo, os óxidos $\mathrm{Pr}_{6} \mathrm{O}_{11}$ e $\mathrm{Tb}_{4} \mathrm{O}_{7}$ possuem coloração intensa devido à presença de centros 
de cor e porque as transições LMCT dos íons $\operatorname{Pr}^{\mathrm{IV}}$ e $\mathrm{Tb}^{\mathrm{IV}}$ encontram-se na região do visível. ${ }^{35,36}$

Existem na literatura métodos de utilização do íon $\mathrm{Eu}^{3+}$, como uma sonda de simetria local. Por exemplo, o grupo pontual foi estudado usando espectroscopia de absorção eletrônica polarizada por Görller-Walrand e Binnemans. ${ }^{9,41}$ Algumas deduções sobre o sítio de simetria podem ser feitas pela contagem do número de bandas de cada transição. $\mathrm{Na}$ atribuição do número de transições eletrônicas $4 f$ deve-se considerar que: $I$ ) algumas bandas podem estar sobrepostas ou ser de baixa intensidade para serem atribuídas, ii) as bandas podem corresponder à contribuições vibrônicas e não a uma transição eletrônica, devendo-se preferir espectros registrados à baixas temperaturas e iii) o método aplica-se a transições de dipolo elétrico e transições de dipolo não magnéticos.

Um esquema semelhante foi estudado por $\mathrm{Jia}^{42}$ para as transições intraconfiguracionais ${ }^{5} D_{0} \rightarrow{ }^{7} F_{J}$ do íon Eu ${ }^{3+}$ ilustrado na FIG. 2.6.

\subsection{2 $\mathrm{Nd}^{3+} \mathrm{e} \mathrm{Sm}{ }^{3+}$}

O íon $\mathrm{Sm}^{3+}\left([\mathrm{Xe}] 4 f^{5}\right)$ tem configuração com número de elétrons ímpar, e de acordocom a regra de Kramer, os seus estados são no mínimo duplamente degenerados em qualquer perturbação do campo ligante. ${ }^{43,44}$ Consequentemente, um estado oriundo donúmero quântico $\mathrm{J}$-semi-inteiro se desdobrará em no máximo ( $\mathrm{J}+1 / 2)$-componentes Stark. A degenerescência de Kramer é somente removida por meio de uma interação adicional que quebre a invariância temporeverso do Hamiltoniano do íon com configuração ímpar, tal como, as interações magnéticas entre os átomos nos compostos. ${ }^{45}$

Os compostos de $\mathrm{Sm}^{3+}$ são conhecidos por exibirem emissão alaranjada sob radiação ultravioleta. Seus espectros de emissão apresentam, principalmente, bandas finas oriundas das transições intraconfiguracionais 
${ }^{4} \mathrm{G}_{5 / 2} \rightarrow{ }^{6} \mathrm{H}_{\mathrm{J}}$ (onde $\mathrm{J}=5 / 2,7 / 2,9 / 2$ e 11/2) localizadas na região do visível. A transição ${ }^{4} \mathrm{G}_{5 / 2} \rightarrow{ }^{6} \mathrm{H}_{5 / 2}(\sim 560 \mathrm{~nm})$ e ${ }^{4} \mathrm{G}_{5 / 2} \rightarrow{ }^{6} \mathrm{H}_{7 / 2}(\sim 600 \mathrm{~nm})$ apresentam alto caráter de dipolo magnético e são, geralmente, dominadas por este mecanismo. Por outro lado, a transição hipersensível ${ }^{4} \mathrm{G}_{5 / 2} \rightarrow{ }^{6} \mathrm{H}_{9 / 2}(\sim 645 \mathrm{~nm})(\Delta \mathrm{J}=2)$ é dominada pelo mecanismo de dipolo-elétrico e é, geralmente, a transição mais intensa nos espectros de emissão dos compostos de $\mathrm{Sm}^{3+}$. Com base nesses resultados, a transição ${ }^{4} \mathrm{G}_{5 / 2} \rightarrow{ }^{6} \mathrm{H}_{5 / 2}$ tem sido tomada como referência na determinação do parâmetro $\eta S m$ que é definido como a razão entre as intensidades integradas das transições ${ }^{4} \mathrm{G}_{5 / 2} \rightarrow{ }^{6} \mathrm{H}_{9 / 2}$ e ${ }^{4} \mathrm{G}_{5 / 2} \rightarrow{ }^{6} \mathrm{H}_{5 / 2}$ nos complexos de $\mathrm{Sm}^{3+}$. ${ }^{46}$

O íon $\mathrm{Nd}^{3+}$ é muito empregado como meio ativo de lasers na região do infravermelho e como fonte de sinal para fibras de sílicas. Sua distribuição simplificada de níveis (quatro níveis atômicos) facilita em muito a inversão de população. ${ }^{47,48}$ Possui absorção na região de $800 \mathrm{~nm}\left({ }^{4} \mathrm{I}_{9 / 2} \rightarrow{ }^{4} \mathrm{~F}_{5 / 2}\right)$ e as emissões de maior interesse tecnológico são em torno de $1060 \mathrm{~nm}\left({ }^{4} \mathrm{~F}_{3 / 2} \rightarrow{ }^{4} \mathrm{I}_{11 / 2}\right)$ e $1340 \mathrm{~nm}$ $\left({ }^{4} \mathrm{~F}_{3 / 2} \rightarrow{ }^{4} \mathrm{I}_{13 / 2}\right)$. A primeira emissão citada encontra várias aplicações médicas e odontológicas (lasers de baixa potência), em espectroscopia óptica e processamento de materiais (lasers de média e alta potência), e a segunda foi originalmente estudada com o intuito de se expandir a janela de amplificação óptica de telecomunicações, em associação com amplificadores de érbio. Porém, estas emissões podem ser comprometidas por absorções de estado excitado (AEEs), que constituem canais de perda para o nível metaestável ${ }^{4} \mathrm{~F}_{3 / 2 \text {. }}{ }^{48}$

Pelo fato dos níveis finais encontrarem-se energeticamente muito próximos uns dos outros, os íons podem retornar ao nível metaestável através de decaimento multifônon, para matrizes com alta energia de fônons (tipo de vibração quântica em um retículo cristalino rígido), sendo este retorno acompanhado pela geração de calor no material (característica desfavorável para uma aplicação em laser), já para matrizes de baixa energia de fônons, observa-se também emissão radiativa na região do verde e amarelo, através do processo de upconversion. ${ }^{48}$ 


\section{$2.5 \quad$ Aplicações}

O número crescente de publicações sobre diferentes aplicações no uso de íons lantanídeos tem demonstrado sua importância em setores como: laser, agricultura, diagnósticos médicos, fósforos para lâmpadas e telas, lasers, telecomunicações ópticas, dispositivos de visão noturna, sistemas de segurança, tintas luminescentes, etiquetas antifalsificação, revestimentos luminescentes, sondas para imunoensaios luminescentes e bioconjugados para imagens médicas e tratamento de câncer por fotodinâmica. A aplicação da fotônica utilizando terras raras é demonstrada pelo número crescente de publicações sobre o assunto. ${ }^{49}$

Em 1896 foi o início do uso do fósforo $\mathrm{CaWO}_{4}$ para absorver raios $\mathrm{Xe}$ convertê-los em luz e essa tecnologia foi utilizada pelos 75 anos subsequentes ${ }^{50} \mathrm{~A}$ utilização de fósforos em tintas fosforescentes e telas de raios X ocorreu em pequena escala até meados de 1940, quando a situação começou a mudar devido à eficiência das lâmpadas e à fabricação de aparelhos de televisão, havendo um grande avanço nessa área. $O$ avanço dessa tecnologia também exigiu o uso de materiais de partida de alto grau de pureza, com dopantes adicionados em concentrações controladas, pois para alguns fósforos, quantidades de 0,1 ou $0,2 \mathrm{ppb}$ de dopante pode tornar a matriz inorgânica em material luminescente com alta eficiência..$^{51,38}$

As propriedades luminescentes características dos fósforos são obtidas pela dopagem do material hospedeiro com um íon ativador e/ou um íon sensibilizador. ${ }^{51} \mathrm{O}$ íon ativador é um centro que absorve a energia de excitação e converte em emissão de luz na região espectral do visível (FIG.2.7a). Enquanto que o sensibilizador é um íon incorporado em uma rede hospedeira capaz de transferir sua energia de absorção para o ativador em sua vizinhança, intensificando a luminescência. Quando um ativador, com emissão desejada, não apresenta absorção significante para uma determinada energia de excitação, usase um sensibilizador que absorva a energia de excitação e então, transfira sua 
energia para o íon ativador que emitirá sua luminescência característica (FIG.2.7b).

A vantagem do uso de íons $\operatorname{TR}^{3+}$ como ativadores é que seus compostos geralmente possuem luminescência intensa na região do visível e infravermelho próximo, portanto seus espectros de emissão são caracterizados por apresentarem bandas extremamente finas, quando comparados com os elementos de transição $d$ ou de compostos orgânicos.

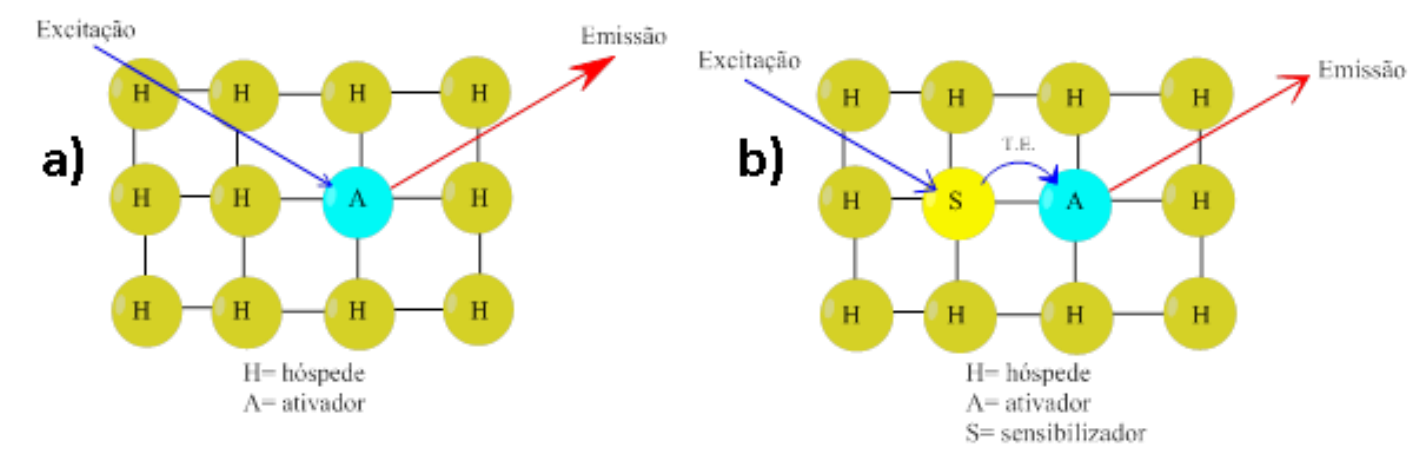

FIGURA 2.7.a) Processo da luminescência de um ativador (A) dopado em uma matriz $(H)$ e b) Transferência de energia de um sensibilizador S para um ativador A. ${ }^{38}$

\subsection{Molibdatos de terras raras}

Em 1778, C. W. Scheele isolou um novo óxido extraído de um mineral conhecido como molybdenite $\left(\mathrm{MoS}_{2}\right)$, distinguindo-o da grafite. Quatro anos após P. J. Hjelm descobriu um novo elemento a partir deste oxido cujo nome vem do grego e o denominaram molibdenio (molubdo \&, molybdos). A rocha mais importante contendo molibdênio é o sulfeto de molibdenita $\mathrm{MoS}_{2}$ onde o maior deposito se situa no Colorado, USA mas também é encontrada no Chile e 
Canadá. Rochas menos importantes do que o sulfeto de molibdenita e que são fontes de Mo são a wulfenita $\left(\mathrm{PbMoO}_{4}\right)$ e a powerlita $\left(\mathrm{Ca}(\mathrm{Mo}, \mathrm{W}) \mathrm{O}_{4}\right)$.

Os trióxidos de molibdênio diferem do crômio, pois eles são ácidos e dissolvem em solução alcalina para formar sais de íons $\mathrm{MoO}_{4}{ }^{2-}$ que são insolúveis em água e não tem propriedades de oxidação apreciáveis. O produto final da combustão do metal $\mathrm{MoO}_{3}$ com ponto de fusão de $\sim 795^{\circ} \mathrm{C}$ e suas propriedades estruturais são bem diferentes. $\mathrm{O} \mathrm{MoO}_{3}$ tem estrutura não usual composta de octaedros distorcidos $\mathrm{MoO}_{6}$. Quando o trióxido é dissolvido em solução alcalina, a solução resultante contém tetraedros de íons $\mathrm{MO}_{4}{ }^{2-}$ e molibdatos simples como $\mathrm{Na}_{2} \mathrm{MO}_{4}$. Se a solução for extremamente ácida precipitados de ácido molíbidico, $\mathrm{MoO}_{3} \cdot 2 \mathrm{H}_{2} \mathrm{O}$, é que são formados. ${ }^{52}$

Compostos de tungstatos e molibdatos de terras raras têm uma longa história de aplicações práticas devido às suas propriedades de luminescência únicas, provenientes das transições de elétrons dentro da sub camada 4f. Os compostos clássicos de molibdatos de terras raras e de molibdatos duplos de terras raras são mais frequentemente preparados empregando-se reações de estado sólido convencional ${ }^{53,54,55}$ ou reações em fluxo para crescimento de cristal $^{56,57}$ vale salientar que a reação em estado sólido tem muitas vantagens, incluindo: baixo custo, disponibilidade de precursores e são candidatas em potencial para a produção em escala industrial. Fatores como o tamanho das partículas dos reagentes (quanto menor o tamanho melhor), do grau de homogeneização e a área de contato entre os grãos têm um papel importante em reações do estado sólido. Estes materiais têm sido usados como fósforos, matrizes para lasers, contadores de cintilação, etc.

Os tungstatos/molibdatos com cátions duplo tem sido muito estudados por possuírem propriedades interessantes. Nos tungstatos e molibdatos de terras raras, estes íon ocupam os sítios de rede sem centro de inversão, e, portanto estes compostos sempre exibem comportamento luminescente não usual. ${ }^{58}$ Atualmente existe um interesse renovado nestes materiais, só que dessa vez na escala nano e micro. Como vem sendo observado nos tungstatos e molibdatos de 
terras raras quando se tem variação do tamanho, forma e dimensão do material na escala micro e nano, novas propriedades de luminescência muito desejadas são encontradas. Este novo enfoque tem resultado em uma grande quantidade de publicações nos últimos anos. Rotas de síntese diferentes das tradicionais tais como a rota hidrotermal, sais fundidos, sol-gel dentre outras são destaque na preparação destes materiais.

As condições de reação podem ser ajustadas de modo a obter várias formas e tamanhos das partículas. Muitos materiais com arquiteturas fascinantes de OD para 3D tem sido publicados. Por exemplo, as microestruturas (microcorreias, estrelas e flores) de $\mathrm{Gd}_{2}(\mathrm{WO})_{3}$ foram sintetizados via processo hidrotérmico na presença de etil trimetil brometo de amonio (CTAB), nanocristais bipirâmidais de $\mathrm{NaLa}\left(\mathrm{MoO}_{4}\right)_{2}$ foram sintetizados usando um processo hidrotérmico na presença deácido oléico e oleilamina, e nanofios de $\mathrm{Tb}_{2}\left(\mathrm{WO}_{4}\right)_{3}$ foram obtidos por uma combinação de rota de síntese sol-gel e electrospinning. ${ }^{59,60,61}$

No presente trabalho foi utilizado o molibdato como matriz nos complexos de terras raras.

\subsubsection{As terras raras como sondas biológicas}

Para estudos que envolvam interação nanopartícula/meio biológico, o processo de funcionalização da superfície da partícula é uma etapa crucial, a qual viabiliza a conjugação desejada (FIG.2.8). O objetivo da funcionalização é garantir biocompatibilidade dos materiais luminescentes; boa dispersão das partículas em meio biológico; manter grupos orgânicos específicos visando interagir com o alvo receptor; e garantir a proteção do meio biológico em casos de experimentos in vivo. $^{62,63}$

As propriedades óticas das nanopartículas recobertas com sílica são conhecidas pela excelente amplificação do sinal de luminescência, baixa 
toxicidade e biocompatibilidade. Além disso, apresentam simples processo de síntese, fácil modificação da superfície e encapsulamento para conectar diferentes moléculas, como proteínas e peptídeos. ${ }^{64}$
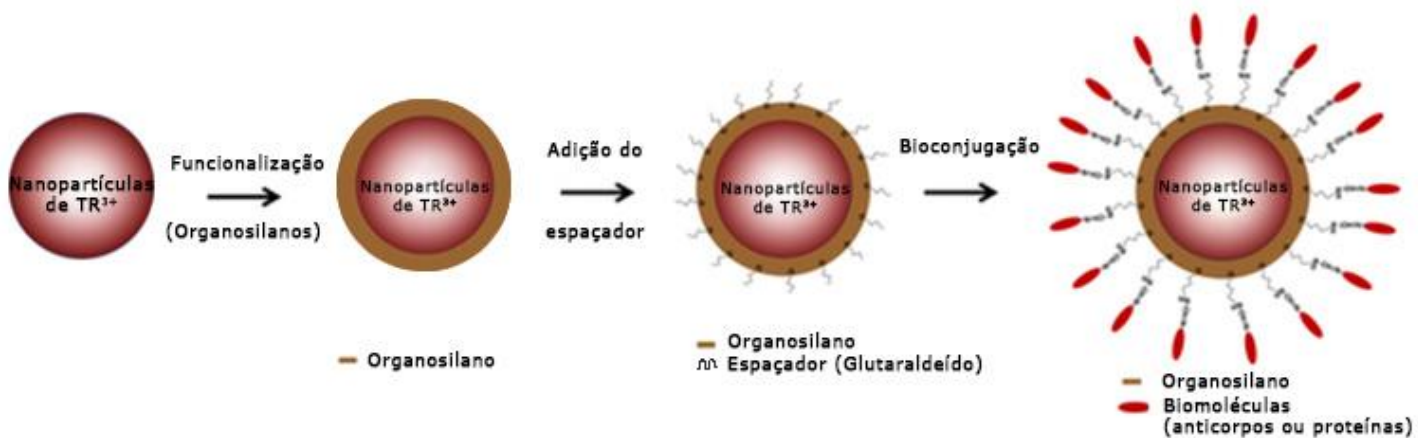

FIGURA 2.8. Processo de funcionalização das nanopartículas para bioconjugação.

Dentre os diferentes métodos de funcionalização descritos na literatura os mais utilizados são: o método de Stöber e o método de micro-ondas, ambos utilizados nessa dissertação.

O método de Stöber foi primeiramente descrito por Stöber et al. em $1968^{65}$ e consiste basicamente na hidrólise e condensação de um precursor alcóxido em etanol e amônia em meio aquoso. Nessa síntese, há adição tanto do tetraetilortosilicato (TEOS) quanto do 3-aminopropiltrietoxisilano (APTES) que forma uma dupla camada de revestimento na partícula, esse método permite incorporar fósforos em sílica utilizando a sua interação direta com o reagente silano. ${ }^{66}$

Já o método de micro-ondas utiliza o aquecimento por irradição ao invés do aquecimento convencional, com uma única adição de APTES. A transferência de energia do micro-ondas para as nanopartículas é realizada pela 
interação da radiação com a água ou outros solventes presentes. Estudos mostram uma redução de tempo de reação significativa em funcionalizações realizadas por micro-ondas, além de aumentar o rendimento de produção e a diminuição no custo. ${ }^{67}$

\subsection{O Câncer de próstata}

A próstata é uma pequena glândula localizada na pelve masculina (FIG.2.9), com peso normal de aproximadamente 20 gramas. Essa glândula é responsável por produzir de $40 \%$ a $50 \%$ dos fluídos que constituem o sêmen ou esperma, o que a caracteriza por desempenhar uma função biológica importante na fase reprodutora do homem, além de oferecer nutrientes fundamentais à sobrevivência dos espermatozóides. ${ }^{68,69}$

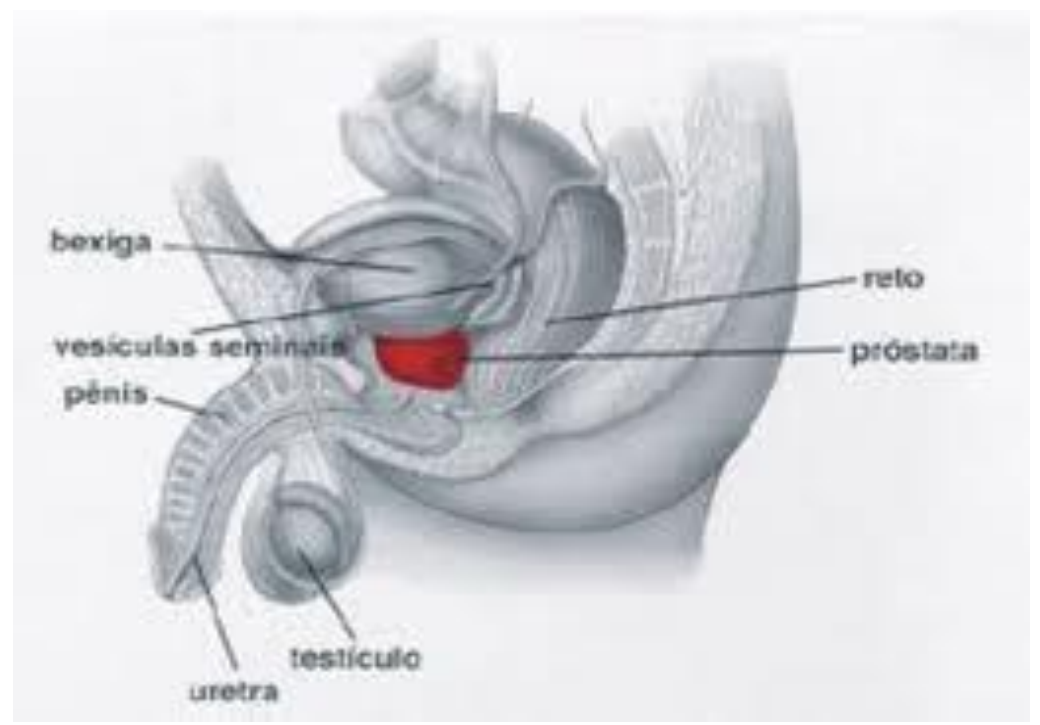

FIGURA 2.9. Localização da próstata. 
À medida que o homem envelhece, naturalmente sua próstata vai aumentando de tamanho ${ }^{69}$, ou seja, as células sofrem um tipo de disfunção que altera o processo de divisão e reprodução celular, que produz excesso de tecido (FIG.2.10), o que pode se transformar em uma verdadeira ameaça para o bemestar do homem, pois além de comprimir a uretra e a dificultar a passagem da urina ${ }^{69,70}$ possibilita o desenvolvimento de tumores que podem ser classificados como benigno ou maligno. O crescimento benigno chamado de hiperplasia prostática benigna (HPB) e o maligno denominado câncer de próstata (CP). ${ }^{69}$

a)

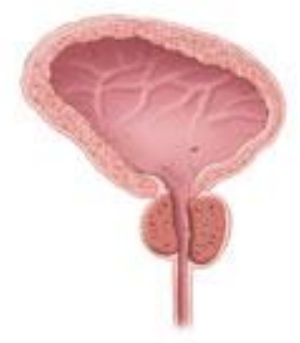

Próstata normal b)

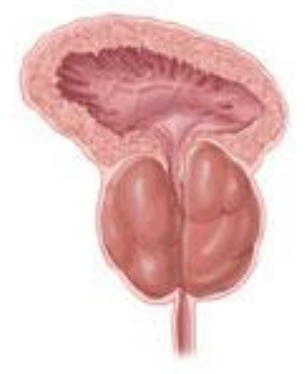

Próstata aumentada

FIGURA 2.10. Ilustração da próstata normal e próstata aumentada, respectivamente.

O câncer de próstata é terceiro maior causador de mortes no mundo (em número de novos casos ${ }^{71}$, e entre todos os tipos de câncer é o mais comum em malignância. Nos EUA é o segundo tipo de câncer causador de mortes (ocorre de 6 em cada 10 homens) e na Europa é a doença maligna mais comum. ${ }^{69,72,73}$ Segundo a Sociedade Americana de Câncer (SAC), 93\% dos homens diagnosticados com câncer de próstata sobreviverão no mínimo 5 anos e desses $72,1 \%$ sobreviverá por pelo menos 10 anos. Segundo o Instituto Nacional de Câncer (INCA), no Brasil foi estimado 60.180 novos casos de câncer da próstata em 2012 e esses valores correspondem a um risco estimado de 62 casos novos a cada 100 mil homens. ${ }^{74}$ 


\subsubsection{Problemática}

O único fator de risco bem determinado para o desenvolvimento do câncer da próstata até os dias atuais é a idade. Ainda segundo o INCA, 32\% dos casos de câncer de próstata diagnosticados no mundo acometem nos homens com 65 anos ou mais. Desta forma, diversos fatores têm influenciado nos aumentos das taxas de incidência da doença, entre eles estão: o crescimento da expectativa de vida, o aprimoramento dos testes do antígeno específico da próstata (PSA) ${ }^{74}$, além de influências ambientais (como tabaco) e alimentares (tais como o alto consumo energético, ingestão de carne vermelha, gorduras e leite). ${ }^{75}$ Outros fatores como raça (o câncer de próstata é aproximadamente 1,6 vezes mais comum em homens negros do que em homens brancos), etnia (americanos, jamaicanos e caribenhos com descendência africana apresentam as mais altas taxas de incidência desse tipo de câncer) e histórico familiar são determinantes para o diagnóstico. ${ }^{74}$

Apesar do aumento na incidência de casos de câncer de próstata nos últimos anos, existe uma significativa ausência de diagnóstico precoce na população associado à falta de informação/acesso à tecnologia, visitas não regulares ao médico e até mesmo a falta de consciência da necessidade da realização de métodos diagnósticos além de questões culturais. ${ }^{76}$

Dentre os principais instrumentos diagnósticos utilizados para diagnosticar o câncer de próstata estão o exame transretal da próstata e o antígeno prostático específico (PSA) que se apresentam como métodos de similar importância e que não podem confirmar um diagnóstico de câncer de próstata por si só, sendo complementares entre si. ${ }^{68}$ 


\subsubsection{Situação no Brasil}

O câncer de próstata no Brasil assim como no mundo inteiro, é considerado um problema de saúde pública. De acordo com registros de câncer na literatura, os tumores mais frequentes na população masculina brasileira são: o de próstata, pulmão, estômago, cólon/reto e esôfago. ${ }^{77,78}$ Estudos do Ministério da Saúde revelam ainda a distribuição regional do câncer de próstata no Brasil e pode-se observar que as maiores taxas anuais de incidência ajustadas por idade para cada 100 mil homens encontram-se no Distrito Federal $(112,1)$, Goiânia $(99,3)$ e São Paulo $(86,4) .{ }^{79}$

O Brasil atualmente investe em pesquisas que tentam relacionar o desenvolvimento do câncer de próstata (e outros tipos de câncer) a diversos fatores como: ambientais, alimentares e ocupacionais com intenção preventiva. Apesar disso, países desenvolvidos apresentam maior número de casos de câncer de próstata (FIG.2.11) devido ao maior acesso à informação, conscientização e realização dos métodos diagnósticos, como o PSA. ${ }^{78,79}$

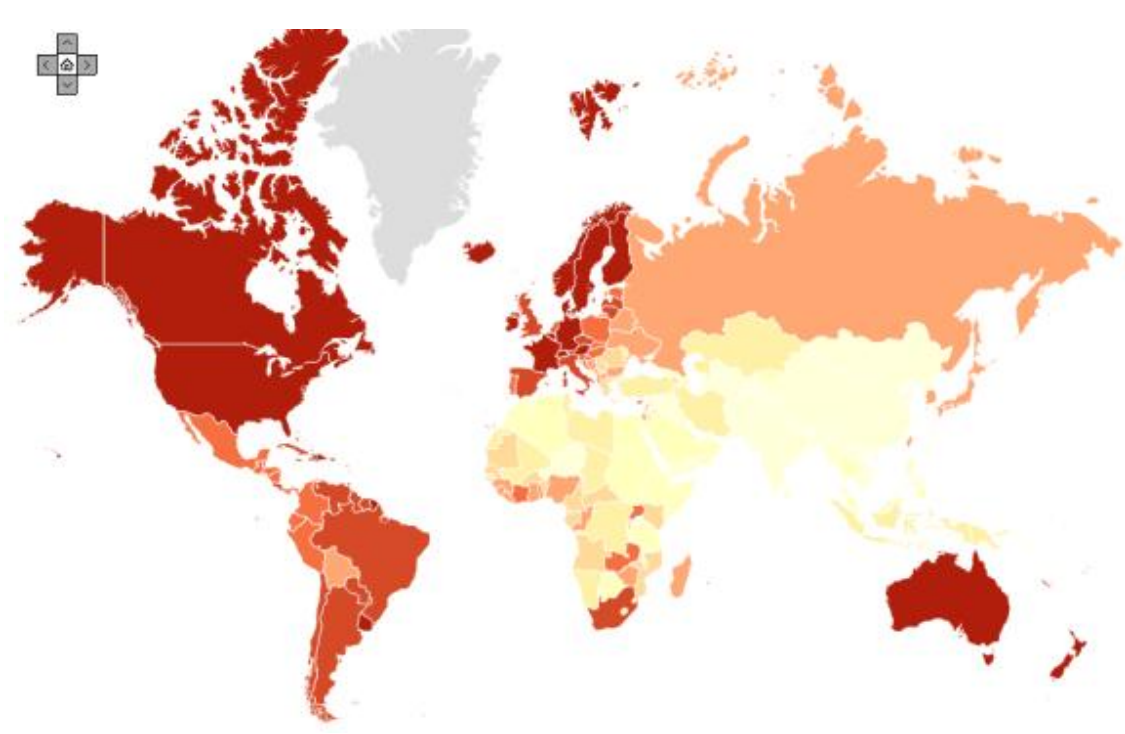

FIGURA 2.11. Ilustração das taxas de incidências de câncer de próstata no mundo. ${ }^{78}$ 


\subsubsection{Antígeno Específico da Próstata (PSA)}

O antígeno específico da próstata, também conhecido como PSA, é uma glicoproteína de cadeia simples (peso molecular de 30.000 Daltons) que pertence à família das calicreínas tecidulares. As calicreínas são serina proteases, ou seja, clivam ligações peptídicas entre os aminoácidos das proteínas nas quais um dos aminoácidos no centro ativo é uma serina. A transcrição do gene do PSA está regulada positivamente ao elo receptor de andrógenos. A testosterona sérica, principal andrógeno circulante, ao complexar-se com o receptor de androgênios, modula a expressão do gene do PSA. ${ }^{80}$

O PSA foi inicialmente descrito em 1971 por Hara e colaboradores ${ }^{81}$, purificado, isolado e caracterizado por Wang em $1977^{82}$. Esse antígeno é encontrado normalmente em baixos níveis no sangue e 4,0 $\mathrm{ngmL}^{-1}$ foi o valor limite superior ao normal determinado pelo FDA (Food and Drug Adminstration) em 1994 quando aprovou o doseamento do PSA para detecção do carcinoma da próstata. $^{83}$

Esse antígeno é produzido quase exclusivamente pelas células epiteliais dos ductos da glândula prostática, secretado para o seu lúmen e concentrado no plasma seminal, tendo fisiologicamente a função de liquefação do ejaculado. ${ }^{84}$ Quando a arquitetura normal da glândula prostática é rompida, temse elevação dos níveis sanguíneos do PSA e dentre as principais patologias prostáticas que resultam em elevação do PSA, cita-se: a hiperplasia prostática benigna (HPB), a prostatite e o CP..$^{85}$

O uso do PSA como marcador tumoral tem sido utilizado extensivamente e demonstrado utilidade clínica significativa, pois em geral, o valor preditivo positivo do PSA para diagnóstico de câncer de próstata é de $20 \%$ para pacientes com valores elevados entre $4 \mathrm{ng} \mathrm{mL}^{-1}$ e $10 \mathrm{ng} \mathrm{mL}^{-1}$ e de $60 \%$ para

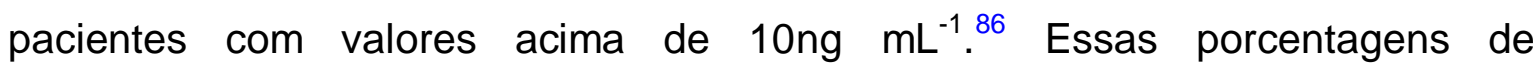


diagnósticos podem ser otimizadas a $96 \%$ quando o PSA é associado ao exame de toque retal. ${ }^{82}$

\subsubsection{O uso da nanotecnologia para o diagnóstico de doenças}

A nanotecnologia tem sido uma área de grande interesse de estudo, atribuído principalmente à escala em que seus materiais se encontram. No geral, materiais apresentam propriedades diferentes quando estão em escala nanométrica, pois quanto menor for o material maior será seu ângulo de contato com o que o rodeia, ou seja, maiores serão as superfícies de contato das partículas como, por exemplo, nas reações químicas. Além disso, o quanto menor for a partícula, maiores as mudanças em suas propriedades elétricas, óticas e magnéticas. ${ }^{87}$

Devido às diferentes propriedades que os nanomateriais apresentam, a medicina tem avançado consideravelmente quando se trata de biomarcadores, isso ocorre porque há a necessidade crescente do desenvolvimento de dispositivos específicos com a função de detectar biomoléculas alvos com sensibilidade e precocidade. Porém, o grande desafio dessa tecnologia é o de desenvolver matérias que possam oferecer segurança, reprodutibilidade, rapidez, baixo custo e identificações múltiplas de biomarcados como, por exemplo, genes e proteínas. $^{88}$

Nanopartículas podem ser usadas em detecções de tumores in vitro tanto em análises qualitativas quanto quantitativas. ${ }^{89}$ Väisänenet al. estudou nanopartículas de quelatos lantanídeos cobertas com streptavidina que foram usadas em análises imunoistoquímicas e como resultado, a quantidade de partículas detectadas e o sinal especifico da medida da imagem de TRF foram correlacionados linearmente com a quantidade do antígeno (PSA) utilizado. Outro estudo propôs o diagnóstico do câncer de próstata através de um imunossensor eletroquímico onde o PSA foi imobilizado com nanopartículas de ouro e foi 
possível obter o doseamento de PSA comprovando a viabilidade do imunossensor para deteç̧ão direta do PSA. ${ }^{84}$ Outro exemplo de método de diagnóstico foi desenvolvido e validado por Azevedo et al., e que demonstrou alta sensibilidade analítica com linearidade utilizando a alta afinidade de captura por ELISA (Ensaio Imunoensimático), para quantificar o soro de PSA, sugerindo que o método pode oferecer resultados clinicamente utilizáveis para detecção do câncer. ${ }^{90}$

A detecção de biomoléculas através de imunoensaios fluorescentes ou radioativos é importante não apenas para o avanço de experimentos biológicos, mas para diagnóstico de diversas doenças. Atualmente, quelatos lantanídeos são comercialmente utilizados como uma versão melhorada do exame convencional de Enzime Linked Immunosorbent Assay (ELISA), o qual é realizado por reações antígeno-anticorpo detectáveis através de reações enzimáticas. Esse tipo de ELISA ocorre sob excitação de luz UV para a detecção da fluorescência do íon európio visando à melhora da sensibilidade do teste. ${ }^{63}$

\subsubsection{Ensaios biológicos por fluorimetria}

O primeiro anticorpo marcado com uma sonda luminescente foi em 1941 por COONS et al. com o objetivo de visualizar antígenos. Na década de 1970, foi registrado o primeiro ensaio imunológico quantitativo por fluorescência (FIA) com o intuito de desenvolver imunoensaios homogênios além de padronizar e quantificar a técnica. ${ }^{91,92}$

A partir da década de 1980, essa técnica foi inicialmente considerada à substituir marcadores radioisótopos por apresentar um sistema de detecção com grande potencial de sensibilidade. Desde então, a técnica de fluorimetria tem sido extensamente aplicada para monitorar processos terapêuticos diversos e in situ, utilizando sondas fluorescentes como ferramenta na histoquímica, citoquímica e patologia. ${ }^{91,92}$ 


\section{REFERÊNCIAS BIBLIOGRÁFICAS}

1. International Union of Pure and Applied Chemistry (IUPAC): banco de dados. Disponível em http://www.iupac.org/. Acesso em: 08 set. 2013.

2. MARTINS, T. S. ISOLANI, C.; Terras Raras Aplicações Industriais e Biológicas. Química nova, v. 28, p.111-117, 2005.

3. COTTON, S. Lanthanide and Actinide Chemistry. Chichester: John Wiley \& Sons, p. 263, 2006.

4. WYBOURNE, B.G. Spectroscopic properties on rare earths. New York: John Wiley \& Sons, p. 236, 1965.

5. BARBOSA, H. P. Síntese e estudo da luminescência de matrizes de tungstatos dopadas com íons terras raras. 2013. Dissertação (Mestrado) Instituto de Química da Universidade de São Paulo, São Paulo.

6. PEARSON, R.G. Hard and soft acids and bases. Journal of the American Chemical Society, v. 85,n.22,p.3533, 1963.

7. AHRLAND, S.; CHATT, J., DAVIES, R.N. The relative affinities of ligand atoms for acceptor molecules and ions. Quarterly Reviews Chemical Society, v. 12,n.3, p. 265-276, 1958.

8. TEOTÔNIO, E.E.S. Síntese e investigação das propriedades fotoluminescentes de dispositivos moleculares conversores de luz (DMCL) de complexos dicetonatos de terras raras com ligantes amidas. 2004. Tese (Doutorado) - Instituto de Química da Universidade de São Paulo, São Paulo.

9. BUNZLI, J. C. G.; CHOPPIN, G. R. Lanthanide probes in life, chemical and earth sciences. New York Elsevier Science Publishers, p.432, 1989.

10. BATISTA, H. J. Novos desenvolvimentos e aplicações de métodos de química quântica para compostos de coordenação com íons lantanídeos.Tese (Doutorado). 2003. Departamento de Química da Universidade Federal de Pernambuco, p. 169. Recife.

11. NASCIMENTO, A. B. Algumas considerações sobre orbitais atômicos e teoria do campo cristalino, João Pessoa, p.133, 1985. 
12. GÉRARD, I.; KRUPA, J.C.; SIMONI, E.; MARTIN, P. Investigation of charge transfer $\mathrm{O}^{2-\rightarrow} \mathrm{Ln}^{3+}$ and $\mathrm{F}^{-} \rightarrow \mathrm{Ln}^{3+}$ in $\mathrm{LaF}_{3}:\left(\mathrm{Ln}^{3+}, \mathrm{O}^{2-}\right)$ and $\mathrm{YF}_{3}:\left(\mathrm{Ln}^{3+}, \mathrm{O}^{2-}\right)$ systems. Journal of Alloys and Compounds, v.207/208, p.120-127, 1994.

13. KRUPA, J.C. Optical excitations in lanthanide and actinide compounds. Journal of Alloys and Compounds, v. 225, n.1/2, p.1-10,1995.

14. BLASSE, G.; KEMMLER-SACK, S. Low-temperature luminescence in $\mathrm{Eu}^{3+}$ doped tungstates of the perovskite stacking-variant type. Berichte der BunsenGesellschaft fur Physikalische Chemie, v.87, n.4, p.352-355, 1983.

15. LATVA, M.; TAKALO, H.; MUKKALA, V. M., MATA CheSCU, C.; RODRIGUEZ-UBIS, J. C.; KANKARE, J. Correlation between the lowest triplet state energy level of the ligand and lanthanide (III) luminescence quantum yield. Journal of Luminescence, v.75, n.2, p.149-169, 1997.

16. CARNALL, W.T.; GOODMAN, G.L.; RAJNAK, R.S.; RANA, A. Systematic analysis of the spectra of the lanthanides doped into single crystal LaF ${ }_{3}$ Argonne National Loboratory, Argonne, IL, 1988.

17. FELdMANN, C.. JÜSTEL, T., RONDA, C. R. SCHIMIDT, P. J. Inorganic Luminescent Materials: 100 Years of Research and Application.Advanced Functional Materials, v.13, p.511-516, 2003.

18. LAKOWICZ, J.R. Principles of Fluorescence Spectroscopy. MarylandMD, $3^{\text {rd }}$ edition:Springer, 2006.

19. SOTOMAYOR, M.P.T.; DIAS, I.L.T.;LANZA, M.R.V.; MOREIRA, A. B. KUBOTA, L.T. Revisão Analítica, Aplicação e Avanços da Espectroscopia de Luminescência em Análises Farmacêuticas. Química Nova, v.31, p. 1755-1774 (2008).

20. MALTA, O.L.; CARLOS, L.D. Intensities of $4 \mathrm{f}-4 \mathrm{f}$ transitions in glass materials. Química Nova, v.26, n.6, p.889-895, 2003.

21. BRITO, H.; MALTA, O.L.; FELINTO, MCFC.; TEOTONIO, E.E.S. Luminescence phenomena involving metal enolates. In: ZABICKY, J. The chemistry of metal enolates. England: John Wiley \& Sons, cap. 5, p.131-184, 2009. 
22. BUONO-CORE, G.E.; LI, H. Quenching of excited states by lanthanide íons and chelates in solution. Coordination Chemistry Reviews, v.99, p.55-87, 1990.

23. LOURENÇO, A.V.S. Partículas de silica funcionalizadas contend complexos de TR3+ para aplicação como marcadores em ensaios biológicos. Tese (Doutorado). Instituto de Química da Universidade de São Paulo, p.210, 2010.

24. TEOTONIO, E.E.S.; BRITO, H.F., VIERTLER, H.; FAUSTINO, W.M. MALTA, O.L.; SÁ, G.F.; FELINTO, M.C.F.C.; SANTOS, R.H.A.; CREMONA, M. Synthesis and luminescent properties of $\mathrm{Eu}^{3+}-48$ complexes with 2-acyl-1,3indandionates (ACIND) and TPPO ligands: The first X-ray structure of Eu-ACIND complex. Polyhedron, v.25, n.0, p.3488-3494, 2006.

25. FAUSTINO, W.M.; MALTA, O.L.; TEOTÔNIO, E.E.S.; BRITO, H.F.; SIMAS, A.M.; SÁ, G.F. Photoluminescence of europium (III) dithiocarbamate complexes: electronic structure, charge transfer and energy transfer. Journal of Physical Chemistry, v.110, n.7, p.2510-2516, 2006.

26. RACAH, G. Theory of complex spectra I. Physical Review, v. 61, n.3/4, p.186-197, 1942.

27. RACAH, G. Theory of complex spectra II. Physical Review, v. 62, n.9/10, p.438-462, 1942

28. RACAH, G. Theory of complex spectra III. Physical Review, v. 63, n.9/10, p.367-382, 1943.

29. RACAH, G. Theory of complex spectra IV. Physical Review, v. 76, n.9, p.1352-1365, 1949.

30. JUDD, B.R. Optical absorption intensities of rare-earth ions. Physical Review, v. 127,n.3,p.750-761,1962.

31. OFELT, G.S. Intensities of of crystal spectra of rare-earth ions. The Journal of Chemical Physics, v.37, n.3, p.511-520, 1962.

32. JÖRGENSEN, C. K.; JUDD, B.R. Hypersensitive pseudoquadrupole transitions in lanthanides. Molecular Physics, v.8, n.3, p.281-290,1964. 
33. WEISSMAN, S.I. Intramolecular energy transfer : the fluorescence of complexes of europium. Journal of Chemical Physics, v.10, n.4, p.214-217, 1942.

34. RONDA, C.; JUSTEL, T.; NIKOL, H. Rare earth phosphors: fundamentals and applications. Journal of Alloys and Compounds, v. 275/277, p. 669-676, 1998.

35. GRABMAIER, B.C. Luminescent materials for medical application. Journal of luminescence, v. 60/61, p.967-970, 1994.

36. BLASSE, G.; GRABMAIER, B.C. Luminescent materials, Heidelberg Springer, p.232, 1994.

37. HÄNNINEN, P.; HÄRMA, H. Lanthanide luminescence: photophysical, analytical and biological aspects. Heidelberg Springer, p.385, 2011.

38. KODAIRA, C.A. Síntese e espectroscopia de sistemas envolvendo tungstatos e íons terras raras. Tese (Doutorado). Instituto de Química da Universidade de São Paulo, p.156, 2004.

39. DORENBOS, P. f-d transition energies of divalent lanthanides in inorganic compounds. Journal of Physics: Condensed Matter, v.15, n.3, p.575-594,2003.

40. DORENBOS, P. The $5 \mathrm{~d}$ level positions of the trivalent lanthanides in inorganic compounds. Journal of Luminescence, v. 91, n. 3, p.155-176,2000.

41. GÖLLER-WALRAND, C.; BINNERMANS, K.; GSCHNEIDER, K.A.JR.; EYRING, L. Handbook on the physics and chemistry of rare earths, Amsterdam Elsevier BV, p. 121-283, cap. 155, 1996.

42. JIA, G. Spectroscopy and energy thansfer in metal ion doped complexes. phD tesis. Hong Kong University, p. 231,2009.

43. MAY, P.S.; METCALF, D.H.; RICHARDSON, F.S.; CARTER, R.C.; MILLER, C.E.; PALMER, R.A.; J. Lumin., v.51, p.249, 1992.

44. MARTEL, J.F.; Jandl, S.; Viana, B.; Vivien, D.; J. Phys. Chem. Solids, v.61, p.1455, 2000. 
45. GRIFFITH, J.S.; The theory of transition-metal ions, Cambridge at the University Press, Londres, 1961.

46. BRITO, H.F.; MALTA, O.L.; FELINTO, M.C.F.C.; TEOTONIO, E.E.S.; MENEZES, J.F.S.; SILVA, C.F.B.; TOMYIAMA,C.S.; CARVALHO, C.A.A.; J. Alloys Compd., v.344, p. 293, 2002.

47. CRISTOVAN, F.H.; EIRAS, S.P.; CRUZ, W.O.; MARLETTA, A.; BALOGH, D.; LAURETO, E.; DUARTE, J.L.; DIAS, I.F.L. Preparação e caracterização óptica de filmes de poli(estireno sulfonados) dopados com neodímio. Quim. Nova, v. 28, n.6, p. 964-967, 2005.

48. CAMARGO, A.S.S.; NUNES, L.A.O. Técnica de bombeio e prova para medidas de absorção de estado excitado e de emissão estimulada, em materiais sólidos dopados com íons terras raras. Quim. Nova, v. 31, n. 8, p. 2083-2090, 2008.

49. BÜNZLI, J.C.G.; ELISEEVA, S.V. Intriguing aspects of lanthanide luminescence. Chemical Science, v.4, n.5, p.1939-1949, 2013.

50. HILL, C.G.A. Inorganic Luminescent Materials, Chemistry in Britain, v.19, n.9, p.723-724,1983.

51. DELUCA, J.A. An introduction to luminescence in inorganic solids. Journal of Chemical Education, v.57, n.8, p. 541-545, 1980.

52. EARNSHAW, A.; GREENWOOD, N. Chemistry of the elements, 2nd edition, 1997.

53. NEERAJ, S.; KIJIMA, N.; CHEETHAM, A.K., Novel red phosphors for solidstate lighting: the system $\mathrm{NaM}(\mathrm{WO} 4) 2-x(\mathrm{MoO} 4) x: \mathrm{Eu} 3+(\mathrm{M} ; \mathrm{Gd}, \mathrm{Y}, \mathrm{Bi})$ Chem. Phys. Lett., v.2, p.387, 2004.

54. TOMASZEWICS, E.; KACZMAREK, S.M.; FUKS, H. New cadmium and rare earth metal tungstates with the scheelite type structure. J. Rare Earths, v.27, p.569, 2009. 
55. WANG, H.; LIANG, J.; WANG, M.G.; SU, Q. Preparation of phosphors $\mathrm{AEu}(\mathrm{MoO}$ 4)2(A=Li, Na, K and Ag)by sol-gel method.Appl. Phys. Lett., v. 89,2006 .

56. STEDMAN, N.J.; CHEETHAM, A.K.; BATTLE, P.D. The crystal structures of two sodium yttrium molybdates, $\mathrm{NaY}(\mathrm{MoO} 4) 2$ and Na5Y(MoO4)4.J. Mater. Chem, v.4, p.707-711,1994.

57. VOLKOV, V.; CASCALES, C.; KLING, A.; ZALDO, C. Growth, Structure, and Evaluation of Laser Properties of $\mathrm{LiYb}\left(\mathrm{MoO}_{4}\right) 2$ Single Crystal, Chem. Mater., v.17, p. 291-300,2005.

58. GUO, C.; WANG, S.; CHEN, T.; LUAN, L.; XU, Y. Preparation of phosphors $\mathrm{Eu}\left(\mathrm{MoO}_{4}\right)_{2}(\mathrm{~A}=\mathrm{Li}, \mathrm{Na}, \mathrm{K}$ and $\mathrm{Ag})$ by sol-gel method. Appl. Phys. A: Mater. Sci. Process., v. 94, p.365,2009.

59. ZENG, Y.; LI, Z.; WANG, L.; XIONG, Y. Tunable photoluminescence and energy transfer of $\mathrm{YBO}_{3}: \mathrm{Tb}^{3+}$, $\mathrm{Eu}^{3+}$ for white light emitting diodes. Cryst Eng Comm, v.14, p.7043,2012.

60. BU, Z.; CHEN, Z.; CHEN, F.; SHI, J. Oleic Acid/Oleylamine CooperativeControlled Crystallization Mechanism for Monodisperse Tetragonal Bipyramid $\mathrm{NaLa}\left(\mathrm{MoO}_{4}\right)_{2}$ Nanocrystals.J. Phys. Chem, v. 113, p.12176,2009.

61. HOU, Z.; CHENG, Z.; LI, G.; WANG, W.; PENG, C.; LI, C.; MA, P.; YANG, D.; KANG, X.; LIN, J. Electrospinning-derived Tb2(WO4)3:Eu(3+) nanowires: energy transfer and tunable luminescence properties.Nanoscale,v.3, p.1568,2011.

62. WOLFBEIS, O.S. Lanthanide Luminescence: Photophysical, Analytical and Biological Aspects, v.7, Springer Series on Fluorescence, 2011.

63. BOUZIGUES, C.; GACOIN, T.; ALEXANDROU, A. Biological Applications of Rare-Earth, p.8488-8505, 2011.

64. DE, M.; GHOSH, P. S; ROTELLO, V.M. Applications of nanoparticles in biology. Advanced Materials,v.20, p.4225-4241, 2008. 
65. STÖBER, W.; FINK, A. Controlled growth of monodisperse silica spheres in the micron size range. Journal of colloid and interface science, v.26, p. 62-69, 1968.

66. LOURENÇO, A. V.S. Partículas de sílica funcionalizadas contendo complexos de $\mathrm{TR}^{3+}$ para aplicação como marcadores para ensaios biológicos. 2010. Tese (Doutorado) - Instituto de Química da Universidade de São Paulo, São Paulo.

67. BAHADUR, N. M.;FURUSAWA, T.; SATO, M.; KURAYAMA, F.; SIDDIQUEY, I. A.; SUZUKI, N. Fast and facile synthesis of silica coated silver nanoparticles by microwave irradiation. Journal of colloid and interface science, v.355, p.312-20, 2011.

68. RHODEN, E. L; AVERBECK, M.A. Câncer de próstata localizado. Revista da AMRIGS, v. 54, p.92-99, 2010.

69. TONON, T; SCHOFFEN, J. P. A prevenção do câncer de próstata: uma revisão da. literatura , Revista Pesquisa e Saúde, v. 2, p. 403-410, 2009.

70. CALVETE, A. C.; SROGI, M.;NESRALLHA, L. J.; DALL'OGLIO, M.F.; ORTIZ, V.Avaliação da extensão da neoplasia em câncer da próstata: valor do psa, da percentagem de fragmentos positivos e da escala de gleason. Rev. Assoc. Bras,v. 49, p. 250-254, 2003.

71. GRONBERG, H. Prostate cancer I: Prostate cancer epidemiology. The Lancet, v.361, p. 859-864, 2003.

72. GONÇALVES, I. R., PADOVANI, C.; POPIM, R. C. Caracterização epidemiológica e demográfica de homens com câncer de próstata, Ciência e Saúde Coletiva, v. 13, p.1337-1342, 2008.

73. ETON, D. T.;LEPORE, S. J. Prostate cancer and health-related quality of life: a review of the literature. Psycho-oncology, v. 11, p. 307-26, 2002.

74. INSTITUTO NACIONAL DE CÂNCER. Banco de dados. Disponível em http://www2.inca.gov.br/wps/wcm/connect/inca/portal/home, Acesso em 20 fev 2013. 
75. PAIVA, E. P. De, MOTTA, M. C. S. DA GRIEP, R. H.Conhecimentos, atitudes e práticas acerca da detecção do câncer de próstata. Acta Paul. Enfermagem, v. 23, p. 88-93, 2010.

76. JURBERG, C.; GOUVEIA, M. E. Na mira do câncer: o papel da mídia brasileira. Revista Brasileira de Cancerologia, v. 52, p. 139-146, 2005.

77. QUINN, M.; BABB, P. Patterns and trends in prostate cancer incidence, survival, prevalence and mortality. Part $\mathrm{I}$ : international comparisons. Bju International, v.90, p. 162-173, 2002.

78. INTERNATIONAL AGENCY FOR RESEARCH ON CANCER (GLOBOCAN 2008): International Review of the Red Cross 12. Disponível em http://globocan.iarc.fr/. Acesso em jan 2012.

79. GUerRA, M. R., VitóRIA, C., GALlO, D. M. AZEVEDO, G. Risco de câncer no Brasil: tendências e estudos epidemiológicos mais recentes. Revista Brasileira de Cancerologia,v. 51, 227-234, 2005.

80. BALK, S. P. Biology of ProstateSpecific Antigen. Journal of Clinical Oncology, v. 21, p.383-391, 2003.

81. HARA, M.; KOYANAGI, Y.; INOUE, T. Some physico-chemical characteristics of semiprotein, na antigenic component specific for human seminal plasma. Forensic immunological study of body fluids and secretion. Nibon Hoigaku Zassbi, v.25, p.322.324, 1971.

82. OliveiRA, G. G.; FONSECA, C. A. Uso de marcadores tumorais no diagnóstico e acompanhamento do tratamento de câncer. Revista Eletrônica de Farmácia, v.3, p. 60-74, 2011.

83. MAKAROV, D. V; LOEB, S.; GETZENBERG, R. H.; PARTIN, A. W. Biomarkers for prostate cancer. Annual review of medicine,v. 60, p.13951,2009 .

84. OLIVEIRA, N. M. P. Biossensor para deteção do antigénio específico da próstata. 2001. Dissertação (Mestrado). Universidade de Aveiro, Portugal. 
85. Ortiz, V. Impacto social do câncer da próstata. Sinopse de Urologia, v.1, p. 4-9, 2003.

86. RICARDO, J, ALMEIDA, C. DE, PEDROSA, N. D. L., LEITE, J. B., RIBEIRO, T. Marcadores Tumorais : Revisão de Literatura. Revista Brasileira de Cancerologia, v.53, 305-316, 2007.

87. WILLIAMS, L. W. A. Nanotechnology Demystified: a self-guided teaching. McGraw Hill, United Stades, 2007.

88. CHENG, M. M. C., CUDA, G., BUNIMOVICH, Y.L., GASPARI, M., HEATH, J.R., HILL, H. D., MIRKIN, C.A., NIJDAM, A.J., TERRACCIANO, R., THUNDAT, T., FERRARI, M. Nanotechnologies for biomolecular detection and medical diagnostics. Current Opinion in Chemical Biology, v. 10, p.11-19, 2006.

89. BRIGGER, I., DUBERNET, C., COUVREUR, P. Nanoparticles in cancer therapy and diagnosis. Advanced Drug Delivery Reviews, v.64, p. 24-36, 2012.

90. ACEVEDO, B., PERERA,Y., RUIZ, M., ROJAS, G., BENITEZ, J., AYALA, M., GAVILONDO,J. Development and validation of a quantitative ELISA for the measurement of PSA concentration. Clinica chimica acta; v. 317, p. 55-63, 2002.

91. COONS, A.H.; CREECH, H.J.; JONES, R.N. The demonstration of pneumococcal antigen in tissues by the use of fluorescent antibody. Journal of Immunology, v.45, p.159-170, 1941.

92. COONS, A.H.; CREECH, H.J.; JONES, R.N. Immunological properties of an antibody containing a fluorescent group. Proceeding of the Society for Experimental Biology and Medicine, v.47, p.200-202, 1941. 


\section{OBJETIVO}

O presente trabalho teve por objetivo geral desenvolver uma metodologia para quantificação de PSA em amostras sorológicas utilizando-se nanopartículas de molibdato de terras raras $\left(\mathrm{TR}^{3+}\right)$. Para alcançar o objetivo principal dividimos este trabalho em três etapas, que são aqui designadas por objetivos específicos e estão listadas a seguir:

1) A síntese e caracterização das nanopartículas de molibdato de terras raras.Onde estão incluídos neste objetivo a realização de diferentes estudos que pudessem interferir na morfologia e consequentemente nas propriedades espectroscópicas destes compostos, como: velocidade de dispersão no momento da precipitação, variação da temperatura de annealing e da porcentagem das dopagens em diferentes matrizes.

Para a caracterização das nanopartículas de molibdato de terras raras utilizou-se as seguintes técnicas: espectroscopia de absorção na região do infravermelho, análise térmica; raios $X$ - método do pó, análise termogravimétrica, microscopia de varredura e de transmissão, e teste de hemocompatibilidade.

Os estudos de fotoluminescência que compreendem: espectros de excitação, emissão e tempo de vida dos estados emissores, parâmetros de intensidade e eficiência quântica foram determinados de uma forma criteriosa.

2) Além desses estudos, as nanopartículas foram funcionalizadas com um organosilano, o 3-aminotrietiletoxisilano, APTES, valendo-se de dois diferentes métodos (método de Stöber modificado e a técnica de Micro-ondas) etapa necessária para fazer- se a posterior conjugação das nanopartículas funcionalizadas com o meio biológico (PSA). As partículas funcionalizadas também foram caracterizadas após a funcionalização, e os resultados nos permitiu - avaliar e comparar os dois diferentes métodos utilizados. 
Objetivo

3) Como terceiro e último objetivo específico deste trabalho, métodos de conjugação foram testados, para obtenção dos parâmetros de conjugação (interação nanopartícula/antígeno/anticorpo). O estabelecimento dos limites de detecção no fluoroimunoensaio também foram determinados. 


\section{PARTE EXPERIMENTAL}

A parte experimental dessa dissertação encontra-se dividida em três partes: A) a síntese e caracterização dos núcleos luminescentes de molibdatos de terras raras via método de coprecipitação com estudo de parâmetros inerentes a síntese destes materiais; b) a funcionalização desses núcleos luminescentes, com tetraetilortosilicato e com 3-aminopropiltrietoxisilano utilizando-se de duas rotas reacionais de síntese (a técnica de micro-ondas e o método de Stöber modificado) assim como e caracterizações desses materiais; e C) a conjugação destas nanopartículas à parte biológica usando o glutaraldeído como espaçador e propiciador da interação nanopartícula-anticorpo ou proteína.

\subsection{Reagentes e solventes}

Para a síntese das partículas de $\mathrm{TR}_{2}\left(\mathrm{MoO}_{4}\right)_{3}$, funcionalização e bioconjugação destes fósforos, as substâncias utilizadas foram empregadas sem tratamento prévio. Os reagentes e solventes usados nos experimentos encontram-se na TAB. 4.1. 
TABELA 4.1. Lista de reagentes e solventes utilizados nos experimentos.

\begin{tabular}{|c|c|}
\hline REAGENTES E SOLVENTES & PROCEDÊNCIA \\
\hline 3-aminopropiltrietoxisilano 98\% (APTES) & Sigma-Aldrich \\
\hline Ácido acético glacial $100 \%$ & Merck \\
\hline Ácido clorídrico 37\% & Synth \\
\hline Albumina sérica bovina (BSA) & Sigma-Aldrich \\
\hline Boro Hidreto de Sódio & Merck \\
\hline Cloreto de Potássio P.A. & Synth \\
\hline Cloreto de Sódio P.A. & Synth \\
\hline Ácido Etilenodianotetracético (EDTA) & Nuclear \\
\hline Eriochrom-schwarz T & Merck \\
\hline Etanol P.A. & Merck \\
\hline Fosfato de Potássio & Synth \\
\hline Fosfato de Sódio dibásico (P.A.) & Synth \\
\hline Glicina (P.A.) & Merck \\
\hline Glutaraldeído (P.A.) & Sigma-Aldrich \\
\hline Hidróxido de amônio (P.A.) & Labsynth \\
\hline Anti-imunoglobulina humana (anti-lgG) & Sigma-Aldrich \\
\hline Molibdato de sódio (99,5\%) & Synth \\
\hline Ninidrina (P.A.) & Merck \\
\hline Tetraetilortosilicato 98\% (TEOS) & Sigma-Aldrich \\
\hline Óxido de európio (III) 99,99\% & Ruenying Im. Exp. Co. Ltda. \\
\hline Óxido de gadolínio (III) 99,9\% & Ruenying Im. Exp. Co. Ltda. \\
\hline Óxido de ítrio (III) 99,9\% & Ruenying Im. Exp. Co. Ltda. \\
\hline Óxido de neodímio (III) 99,9\% & Ruenying Im. Exp. Co. Ltda. \\
\hline Óxido de samário (III) 99,99\% & Ruenying Im. Exp. Co. Ltda. \\
\hline Piridina & Vetec \\
\hline Quitosana - baixo peso molecular & Sigma-Aldrich \\
\hline Sulfato de amônio & Vetec \\
\hline Sulfato de zinco & Merck \\
\hline Alaranjado de Xilenol & Merck \\
\hline Coomassieblue brilliant r250 & Sigma-Aldrich \\
\hline
\end{tabular}




\subsection{Sínteses}

Neste trabalho a parte de síntese dos materiais encontra-se dividida na síntese dos núcleos luminescentes, funcionalização dos núcleos luminescentes com compostos derivados da sílica e ou organosilano e a síntese dos marcadores biológicos, que compreende a formação de uma espécie composta por um sinalizador ligado por um espaçador (glutaraldeído). A espécie biológica pode ser um anticorpo, um antígeno ou uma proteína. Nos subitens que se seguem serão relatadas todas as etapas desenvolvidas para essa dissertação.

\subsubsection{Síntese dos cloretos de terras raras}

Os cloretos de terras raras foram obtidos a partir da reação dos óxidos de terras rara sem suspensão aquosa com ácido clorídrico $37 \%$. À emulsão adicionou-se ácido clorídrico e esta solução foi mantida sob aquecimento ( 60 $\left.{ }^{\circ} \mathrm{C}\right)$ e agitação constante até que restasse apenas uma pequena quantidade do óxido de TR em suspensão. Após filtração, a solução obtida apresentou aspecto translúcido. As soluções de cloreto de TR foram cristalizadas em banho maria a $100 \stackrel{\circ}{\circ}$ e estocadas em dessecador sob vácuo. ${ }^{1}$ 


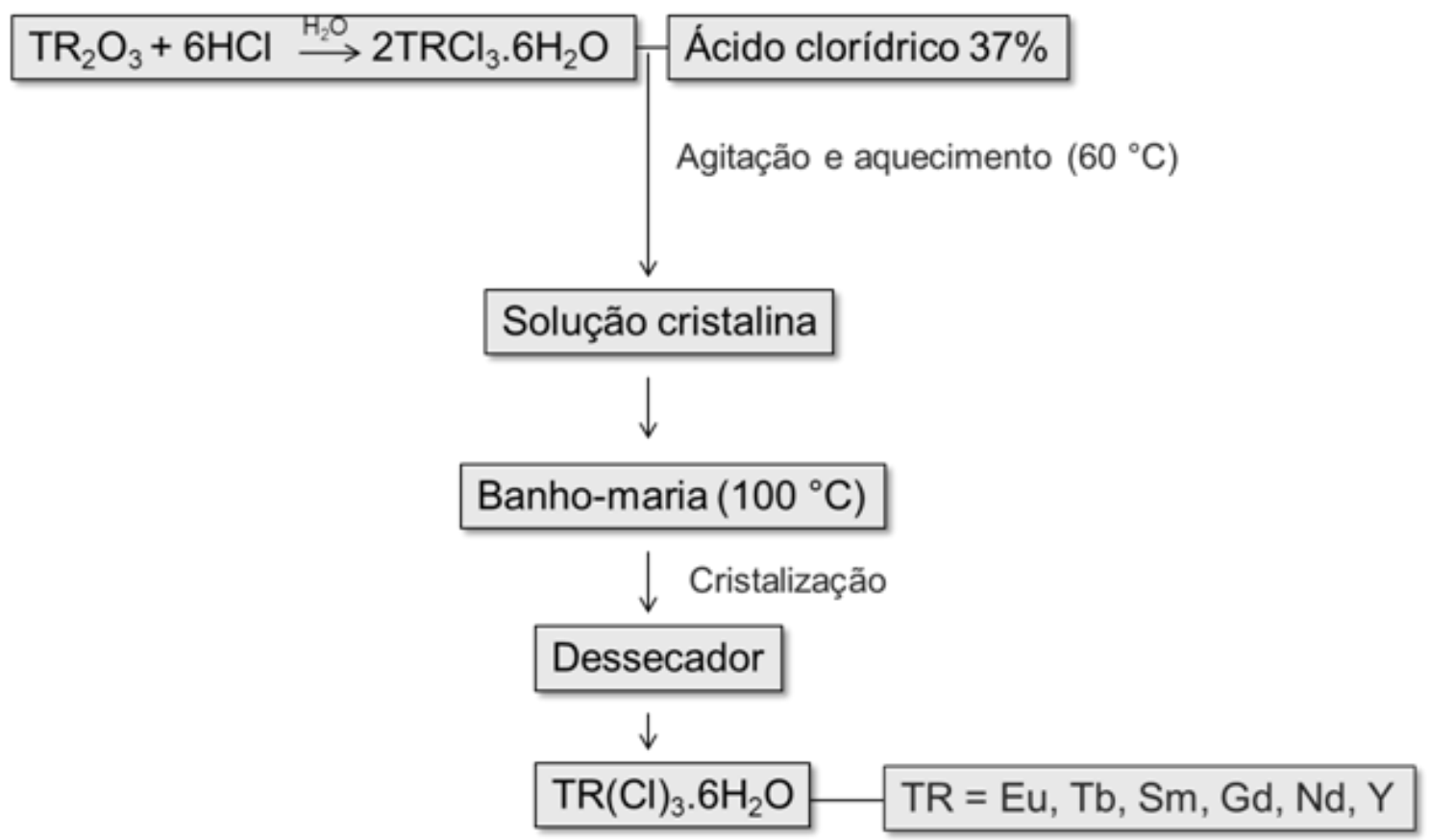

FIGURA 4.1. Fluxograma da rota de síntese dos cloretos de terras raras

$$
\left(\mathrm{TR}(\mathrm{Cl})_{3} .6 \mathrm{H}_{2} \mathrm{O}\right) \text {. }
$$

\subsubsection{Obtenção das nanopartículas de molibdato de terras raras - Via método coprecipitação}

O método de coprecipitação consiste basicamente na precipitação simultânea de dois (ou mais) íons metálicos, geralmente em solução. Os precipitados quando cristalizados como molibdatos, tungstatos, fosfatos, cromatos, etc apresentam geralmente estequiometria rigidamente definida. Porém, podem divergir em se tratando da morfologia, textura e características estruturais, que podem depender de vários parâmetros. Dentre estes parâmetros, o mais importante é a supersaturação, que é crucial em duas das etapas na formação do precipitado: a nucleação e o crescimento da partícula. ${ }^{2}$ Dessa forma, a supersaturação é um parâmetro crítico no que diz respeito ao tamanho da partícula, assim como para a textura. Se a supersaturação for alta, a taxa de consumo de reagentes pela nucleação será muito maior que o crescimento da partícula, resultando em muitas partículas, mas de tamanhos pequenos. Se for ao 
contrário, a solução apresentando baixa supersaturação e estiver livre de impurezas, obtêm-se poucas partículas com tamanho maior. A literatura também descreve a influência da supersaturação na estrutura da partícula, ou seja, quanto mais alta a supersaturação, menos organizada e estável se apresentará a estrutura.

Outros fatores que contribuem para a qualidade do precipitado: $\mathrm{opH}, \mathrm{a}$ temperatura, a natureza dos reagentes, a presença de impurezas, o método de precipitação, etc. ${ }^{2,3}$

No presente trabalho, o método de coprecipitação em pH constante foi adicionado ao mesmo tempo a solução dos sais dos cátions e a solução alcalina. Para a preparação dos fósforos foram adicionados 3 mols de solução aquosa molibdato de sódio (sem tratamento prévio) para 2 mols de solução aquosa de cloreto de terras raras. Em seguida, a solução foi mantida sob constante agitação de $2.500 \mathrm{rpm}$ (rotações por minuto) e a temperatura ambiente ( $\left.27^{\circ} \mathrm{C}\right)$. O material resultante foi filtrado e o precipitado que ficou retido nos filtros foi seco a temperatura ambiente, resultando nos molibdatos de terras raras (FIG. 4.2). 


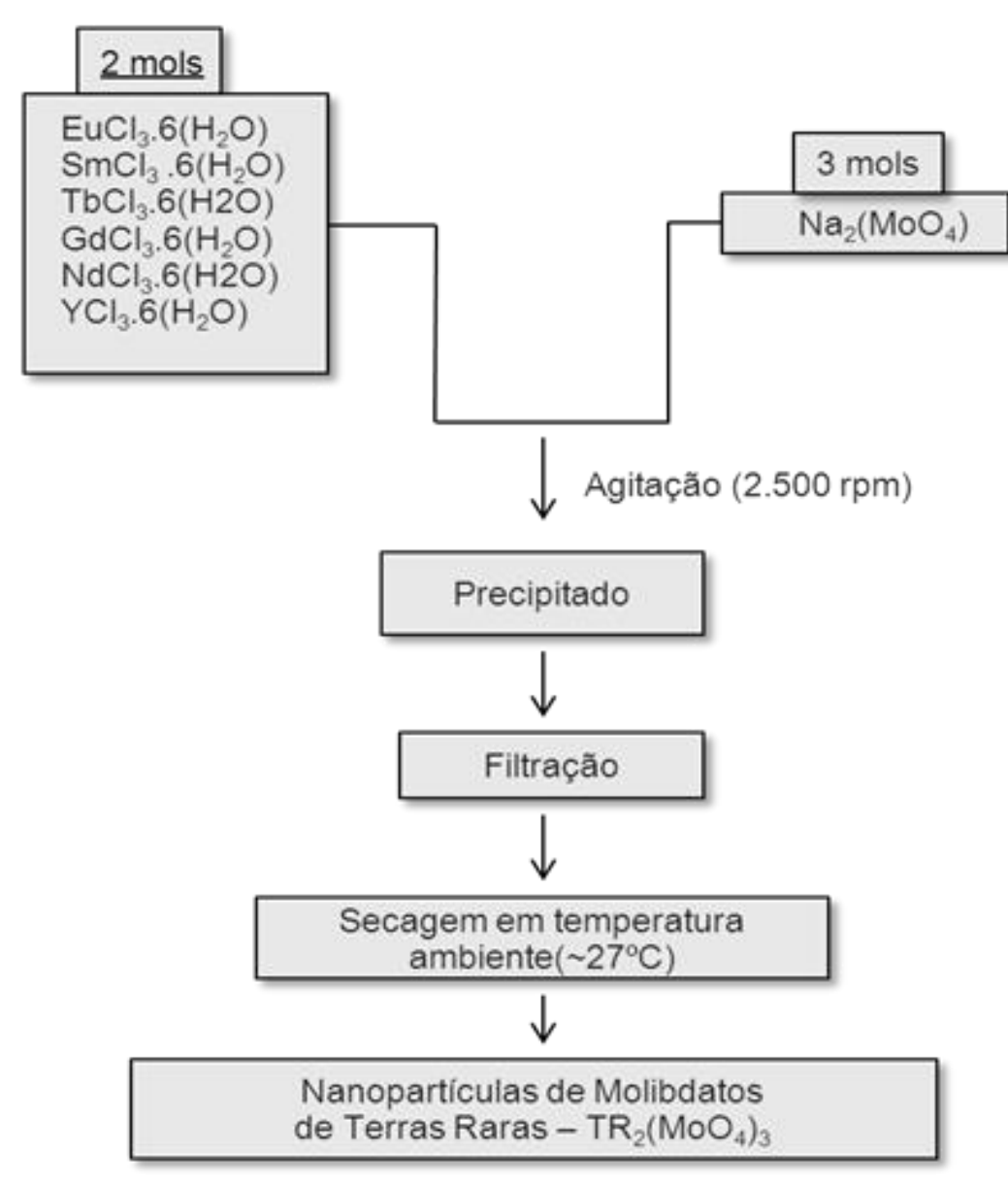

FIGURA 4.2. Fluxograma da síntese de nanopartículas de molibdatos dopadas com terras raras pelo método de coprecipitação.

\subsubsection{Estudo da influência da velocidade de dispersão na precipitação no tamanho da partícula e nas propriedades espectroscópicas de $\mathrm{Eu}_{2}\left(\mathrm{MoO}_{4}\right)_{3}$}

O estudo sobre a influência da velocidade de dispersão da precipitação no tamanho da partícula teve como objetivo avaliar a influência da velocidade de dispersão nas características físicas e espectroscópicas dos precipitados obtidos. $\mathrm{O}$ estudo foi realizado com amostras de $\mathrm{Eu}_{2}\left(\mathrm{MoO}_{4}\right)_{3}$ sintelizadas pelo método de coprecipitação em 4 diferentes velocidades de dispersão: 2.500 rpm, 8.000 rpm, 16.000 rpm e 24.000 rpm conforme esquematizado na FIG.4.3. 


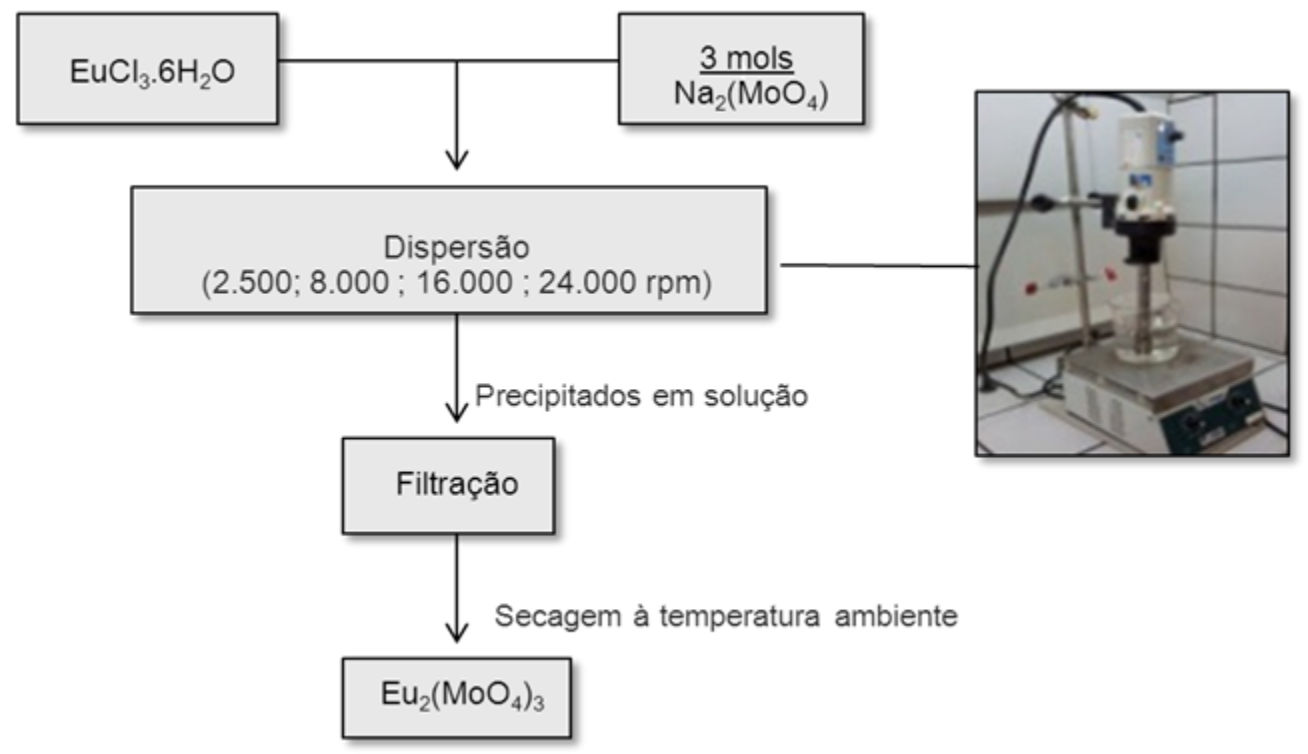

FIGURA 4.3. Fluxograma sobre o estudo da influência da velocidade de dispersão da precipitação no tamanho da partícula.

\subsubsection{Estudo da influência do tratamento térmico (Annealing) a 120 드, $300^{\circ} \mathrm{C}, 500^{\circ} \mathrm{C}, 700^{\circ} \mathrm{C}$ e $1.000^{\circ} \mathrm{C}$ nas propriedades espectroscópicas e estruturais}

O estudo de tratamento térmico (annealing) foi realizado com as amostras de $\mathrm{Eu}_{2}\left(\mathrm{MoO}_{4}\right)_{3}, \mathrm{Sm}_{2}\left(\mathrm{MoO}_{4}\right)_{3}, \mathrm{~Tb}_{2}\left(\mathrm{MoO}_{4}\right)_{3}$ e $\mathrm{Nd}_{2}\left(\mathrm{MoO}_{4}\right)_{3}$ sintetizadas pelo método de coprecipitação. O tratamento térmico foi realizado em um forno mufla com controle de temperatura e programação de 5 diferentes temperaturas $\left(120{ }^{\circ} \mathrm{C}, 300^{\circ} \mathrm{C}, 500 \stackrel{\circ}{\mathrm{C}}, 700^{\circ} \mathrm{C}\right.$ e $\left.1000 \stackrel{\circ}{\circ}\right)$ com patamares de subida de 1 hora para cada amostra em cada temperatura com gradiente de subida de $20 \stackrel{\circ}{ } \mathrm{C}$ por minuto, conforme FIG.4.4. 


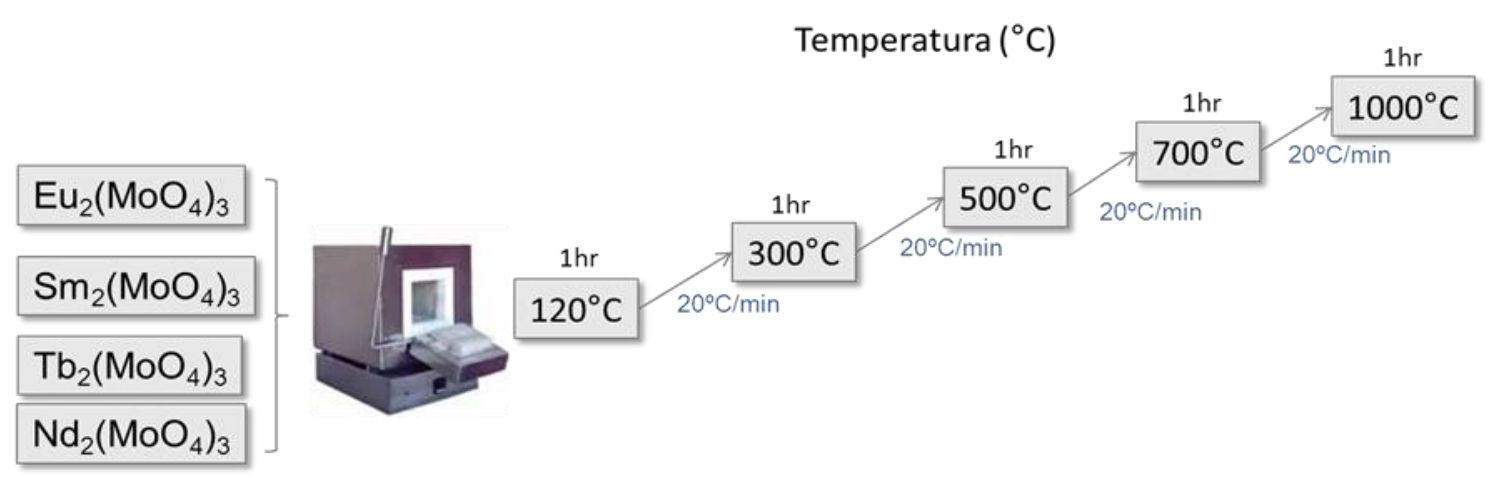

FIGURA 4.4. Fluxograma demonstrando a metodologia utilizada para proceder ao tratamento térmico (annealing) com as amostras de molibdato de terras raras.

\subsubsection{Síntese das nanopartículas de ítrio dopadas com terras raras}

Nesse trabalho foram realizadas dopagens da matriz molibdato de ítrio através do método de coprecipitação (item 4.2.2) utilizando-se o cloreto de ítrio como precursor da matriz e os cloretos de térbio e de európio como precursores dopante, utilizado em diferentes concentrações de dopagem 1\%, 3\%, 5\% e 10\% molar para obtenção dos molibdatos de ítrio dopados com európio $\left(\mathrm{Y}_{2-\mathrm{x}} \mathrm{Eu}_{\mathrm{x}}\left(\mathrm{MoO}_{4}\right)_{3}\right)$ e térbio $\left(\mathrm{Y}_{2-\mathrm{x}} \mathrm{Tb}_{\mathrm{x}}\left(\mathrm{MoO}_{4}\right)_{3}\right)$, conforme FIG.4.5. 


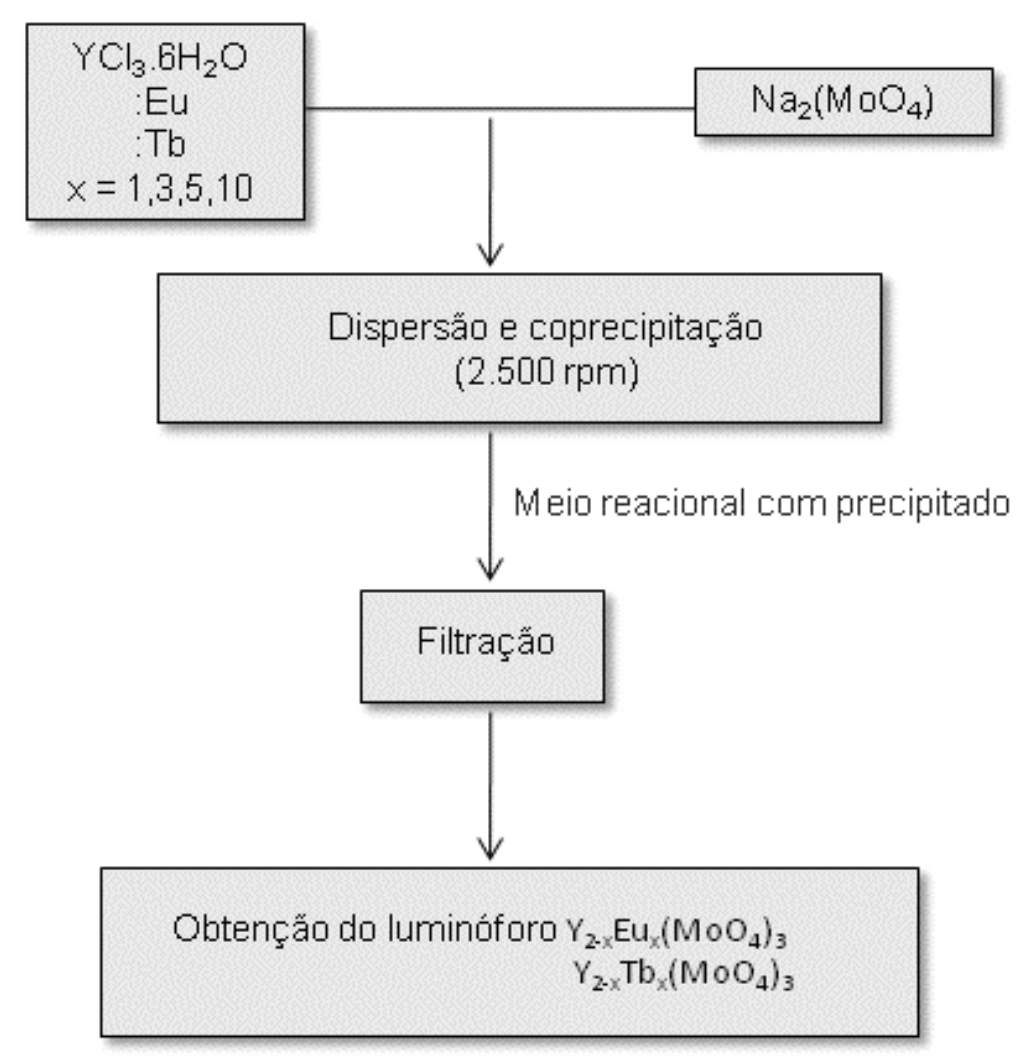

FIGURA 4.5. Fluxograma da síntese do molibdato de ítrio dopado com európio e térbio.

\subsection{Caracterização dos molibdatos de terras raras e das nanopartículas funcionalizadas de molibdatos de terras raras}

\subsubsection{Espectroscopia de Absorção no Infravermelho por Transformada de Fourier (FTIR)}

Os espectros de absorção na região do infravermelho (de 4000 a 400 $\mathrm{cm}^{-1}$ ) dos molibdatos de terras foram obtidos em um espectrômetro Thermo Scientific Nicolet 6700 FT-IR, Smart Orbit, Diamond 30,000 - $400 \mathrm{~cm}^{-1}$; Class 1 laser product por Refletância Total Atenuada (ATR). As análises foram obtidas à temperatura ambiente ( 298K) e em pastilha $\mathrm{KBr}$. O equipamento utilizado pertence ao Laboratório de Polímeros do Centro de Química e Meio Ambiente no IPEN. 


\subsubsection{Termogravimetria (TG/DTG)}

As curvas de decomposição termogavimétricas (TG) e de termogavimetria diferencial (DTG) foram obtidas em uma Termobalança SDTA822 (Mettler Toledo) usando amostras de aproximadamente $10 \mathrm{mg} \mathrm{em} \mathrm{cadinho} \mathrm{de}$ alumina, sob atmosfera dinâmica de nitrogênio, com vazão de $50 \mathrm{~mL} \mathrm{~min}^{-1} \mathrm{e}$ razão de aquecimento de $10 \stackrel{\circ}{\circ} \mathrm{Cmin}^{-1}$. As curvas DTG foram obtidas a partir da diferenciação eletrônica do sinal TG. O equipamento utilizado pertence ao Laboratório de Polímeros do Centro de Química e Meio Ambiente no IPEN.

\subsubsection{Difração de raio $X(D R X)$}

Os difratogramas de raios $X$ foram obtidos em um Difratômetro de Raios X Rigaku, modelo MiniFlex II método do pó. Foi utilizado com fonte de radiação $\operatorname{CuK}_{\alpha}(\lambda=1,54 \AA$ A $)$ e filtro de Ni. As amostras foram dispersas em lâminas de quartzo. O equipamento utilizado pertence ao Laboratório de Química Supramolecular e Nanotecnologia do Centro de Química e Meio Ambiente no IPEN.

\subsubsection{Microscopia Eletrônica de Varredura (MEV)}

Para obtenção das MEVs foi utilizado um microscópio eletrônico de varredura marca Philips modelo XR-30. As amostras foram pulverizadas sobre um suporte metálico adequado e recobertas com ouro pela técnica de spputering. $\mathrm{O}$ microscópio utilizado pertence ao Laboratório de MEV do Centro de Ciência e Tecnologia dos Materiais no IPEN. 


\subsubsection{Microscopia Eletrônica de Transmissão (TEM)}

A morfologia das amostras de molibdato de terras raras foram caracterizadas por microscopia eletrônica de transmissão modelo JEM2100, marca Jeol operando a $200 \mathrm{keV}$. A amostra foi dispersa em isopropanol na lavadora ultrassônica durante 5 min. Após a dispersão foi depositada em grades de cobre de 400 mesh (G400-Cu), previamente preparadas com recobrimento de Collodion (Parlodion) 2\% em etanoato de pentila e por evaporação de carbono para a obtenção das imagens.

\subsubsection{Estudos de Fotoluminescência}

Os espectros de luminescência, correspondentes à excitação e emissão, foram obtidos à temperatura ambiente em um espectrofluorímetro SPEX-FLUOROLOG 2, programa computacional DM3000F, com monocromadores duplos SPEX 1680 utilizando lâmpada de Xenônio de 450 W como fonte de excitação ou em um FluoroMax®-4 utilizando CCD. Os dados espectrais foram coletados em um ângulo de 22,5 (face frontal). As fendas de emissão e de excitação foram utilizadas com aberturas entre 0,1 e 2,0 mm.

Todas as medidas de espectrofluorimetria foram obtidas nos equipamentos pertencentes ao Laboratório dos Elementos do Bloco f (LEBf), no Instituto de Química da USP. E para amostras de neodímio, as análises foram realizadas em São Carlos.

\subsubsection{Leitura da placa de imunoensaios}

A leitura de fluorescência da placa de 96 poços foi realizada em fluorímetro Victor ${ }^{2} \mathrm{D}$ modelo Wallac 1420D (Perkin Elmer) usando lâmpada de 
tungstênio-halogênio continua (75W). Filtros utilizados: $340 \mathrm{~nm}$ (excitação) e $615 \mathrm{~nm}$ (emissão). O fluorímetro pertence ao CQMA do IPEN.

\subsection{Funcionalização das nanopartículas dopadas com Terras Raras}

As nanopartículas de $\mathrm{TR}_{2}\left(\mathrm{MoO}_{4}\right)_{3}$ foram funcionalizadas com ortosilicato de tetraetila (TEOS) e/ou 3-aminopropiltrietoxisilano (APTES), utilizando-se as técnicas de micro-ondas e Stöber.

\subsubsection{A técnica de micro-ondas}

A química de micro-ondas tem sido usada particularmente para explorar novas sínteses químicas ${ }^{4}$. Em particular a absorção de micro-ondas por lantanídeos tem sido demonstrada e explorada em longo espectro de aplicações. No presente trabalho, o 3-aminopropiltrietoxisilano (APTES) é transparente as micro-ondas, considerando que o molibdato de terras raras absorve na região das micro-ondas, puramente de uma absorção intrínseca ou possivelmente como um resultado de moléculas de água ou de $\mathrm{OH}$ (hidroxilas) às superfícies da partícula. A absorção diferencial na suspensão da partícula leva ao aquecimento confinado às regiões locais sem a necessidade de aquecimento do "bulk" da solução. A reação entre o APTES e a partícula estará concentrada na superfície da partícula. Uma reação na interface sólido-líquido formará uma camada Si-O- $(\mathrm{CH})_{x}-\mathrm{NH}_{2}$ que se ligará covalentemente às partículas de $\mathrm{TR}_{2}\left(\mathrm{MoO}_{4}\right)_{3}$.

Inicialmente, 0,1 g das nanoparticulas de $\mathrm{TR}_{2}\left(\mathrm{MoO}_{4}\right)_{3}$ foram colocadas em $10 \mathrm{~mL}$ de APTES por 5 minutos em banho de ultrassom modelo Maxiclean 1400. Em seguida, a amostra foi submetida ao processo de aquecimento em forno micro-ondas marca Panasonic na potência de $1000 \mathrm{w} \mathrm{min}{ }^{-1}$ em estágio de rotação, sendo posteriormente colocado novamente em banho ultrassom por 5 
minutos. Repetiu-se o procedimento de aquecimento e agitação até a suspensão apresentar uma aparência viscosa.

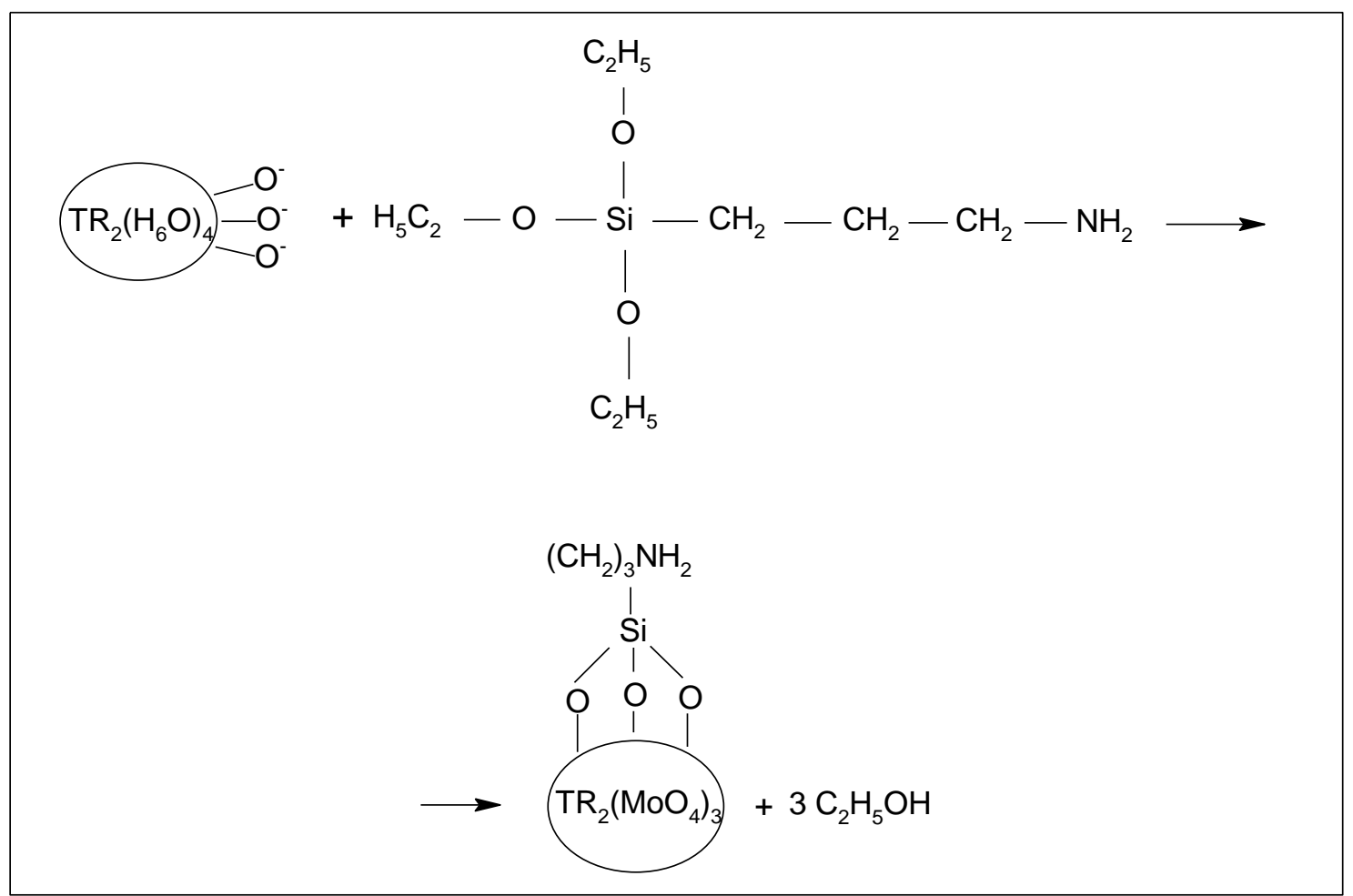

FIGURA 4.6. Esquema da silanização do $\mathrm{TR}_{2}\left(\mathrm{MoO}_{4}\right)_{3}$ utilizando o 3aminopropiltrietoxisilano.

O material foi mantido em repouso à temperatura ambiente durante uma noite e então foi submetido à aquecimento a temperatura de $150{ }^{\circ} \mathrm{C}$ em uma estufa marca Quimis, durante 30 minutos. As partículas resultantes foram suspensas em água destilada para eliminar o organosilano que não reagiu e separadas por centrifugação. As partículas silanizadas foram lavadas 5 vezes com água destilada e secas a temperatura ambiente conforme FIG.47. 5,6 


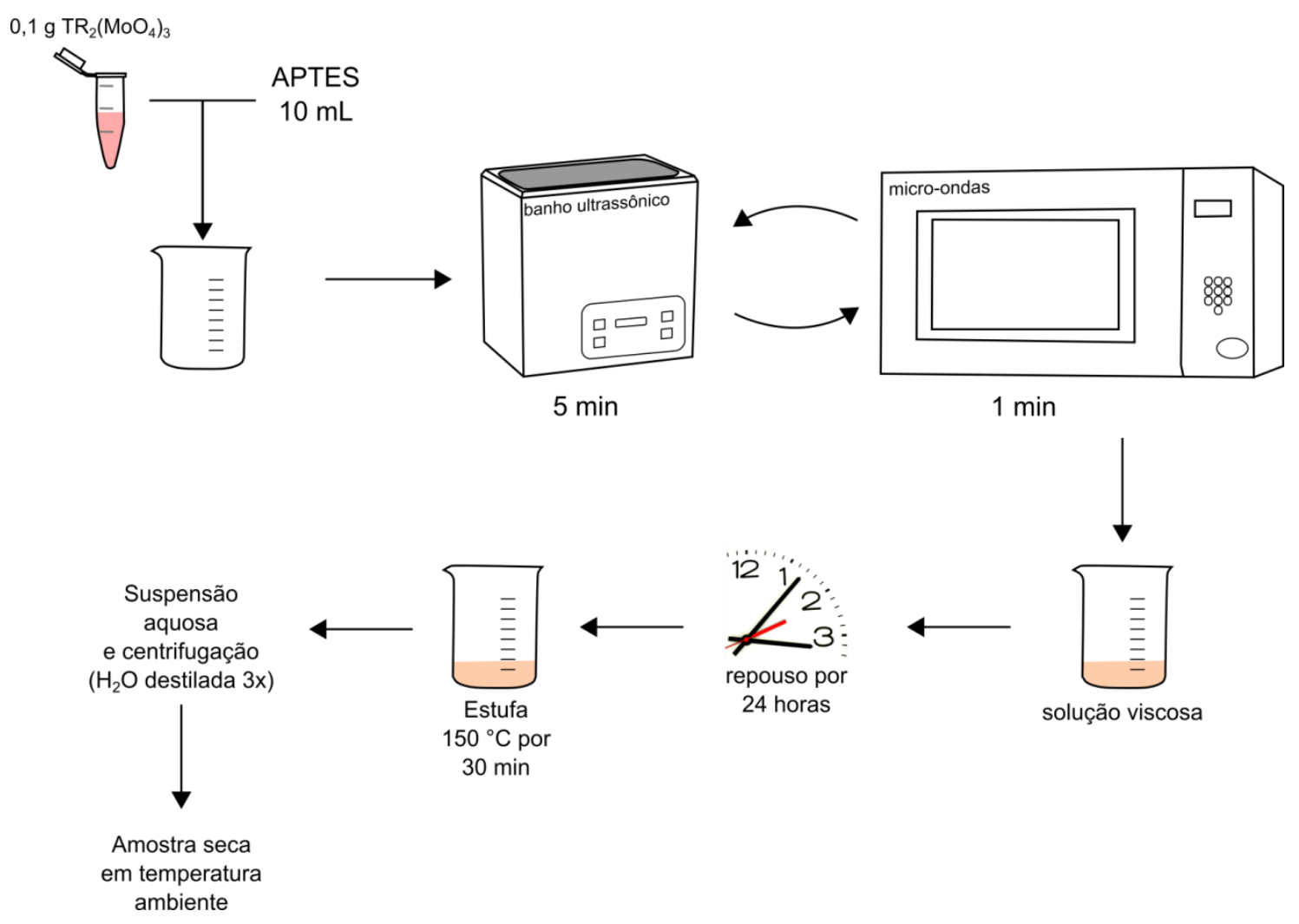

FIGURA 4.7. Ilustração do método de micro-ondas.

\subsubsection{Método de Stöber modificado}

O método de Stöber modificado (FIG 4.8) é um dos métodos mais comuns para sintetizar partículas de sílica coloidal com tamanhos menores do que $100 \mathrm{~nm}$, nanopartículas. ${ }^{7} \mathrm{O}$ processo envolve a hidrólise do precursor alcóxico de sílica (no caso, o TEOS - tetraetilortosilicato) em uma mistura de etanol e água e hidróxido de amônio. O ácido silícico é produzido durante o processo de hidrolise e quando sua concentração está acima da sua solubilidade em etanol, há nucleação homogênea de partículas de sílica em tamanho submicrométrico. A princípio esse método foi utilizado para preparação de sílica pura nanoparticulada. A incorporação de pigmentos orgânicos, complexos e partículas de materiais inorgânicos é possível por ligações covalentes a um reagente organosilano, como por exemplo, o 3-aminopropiltrietoxisilano (APTES), e então o TEOS e o APTES são condensados depois da hidrolise. ${ }^{8} \mathrm{O}$ diâmetro 
das partículas finais pode ser controlado sintonizando parâmetros variáveis como: concentração de reagentes e temperatura de reação. As partículas obtidas podem medir entre $10 \mathrm{~nm}$ até $1 \mu \mathrm{m}$ de diâmetro, sendo geralmente uma uniformidade de tamanho. Faz-se necessário então utilizar métodos de filtração para separar frações com tamanhos próximos.

As partículas de sílica contendo os molibdatos de $\mathrm{TR}^{3+}$ foram preparadas utilizando o método Stöber modificado, onde o TEOS $\left(\mathrm{Si}\left(\mathrm{OC}_{2} \mathrm{H}_{5}\right)_{4}\right)$, em solução etanólica na presença de água com amônia (como catalisador) hidrolisou e condensou. ${ }^{5}$

Em um béquer, 0,1 g do molibdato e $320 \mu \mathrm{L}$ de TEOS foram codissolvidos em $100 \mathrm{~mL}$ de etanol. Uma solução aquosa de amônia aquosa 29\% $(1,0 \mathrm{~mL})$ foi utilizada como catalisador e foi adicionada, sob agitação vigorosa. Esta solução foi agitada overnight e tornou-se turva evidenciando a formação das partículas submicrométricas, e esta mistura foi centrifugada para separar as partículas do sobrenadante e haver a remoção do TEOS que não reagiu.

A modificação da superfície das partículas para a inserção do grupo amino, foi feita através da silanização com APTES. Neste caso, o APTES tem a função de revestir as partículas de sílica fornecendo o grupo amino, biologicamente funcional, para possibilitar uma ponte de ligação com biomoléculas. Para isso, o sólido obtido foi re-disperso em etanol e nele adicionado $40 \mu \mathrm{L}$ de APTES e mantido sob agitação por 5 horas. As partículas de sílica amino-funcionalizadas incorporando o molibdato de terras raras nomeadas neste trabalho como TR $2\left(\mathrm{MoO}_{4}\right)_{3} @ S i$, foram centrifugadas, lavadas quatro vezes com etanol e duas vezes com água para remoção do material contendo sílica que não reagiu e posteriormente secas ao ar. ${ }^{5,7,9}$ 


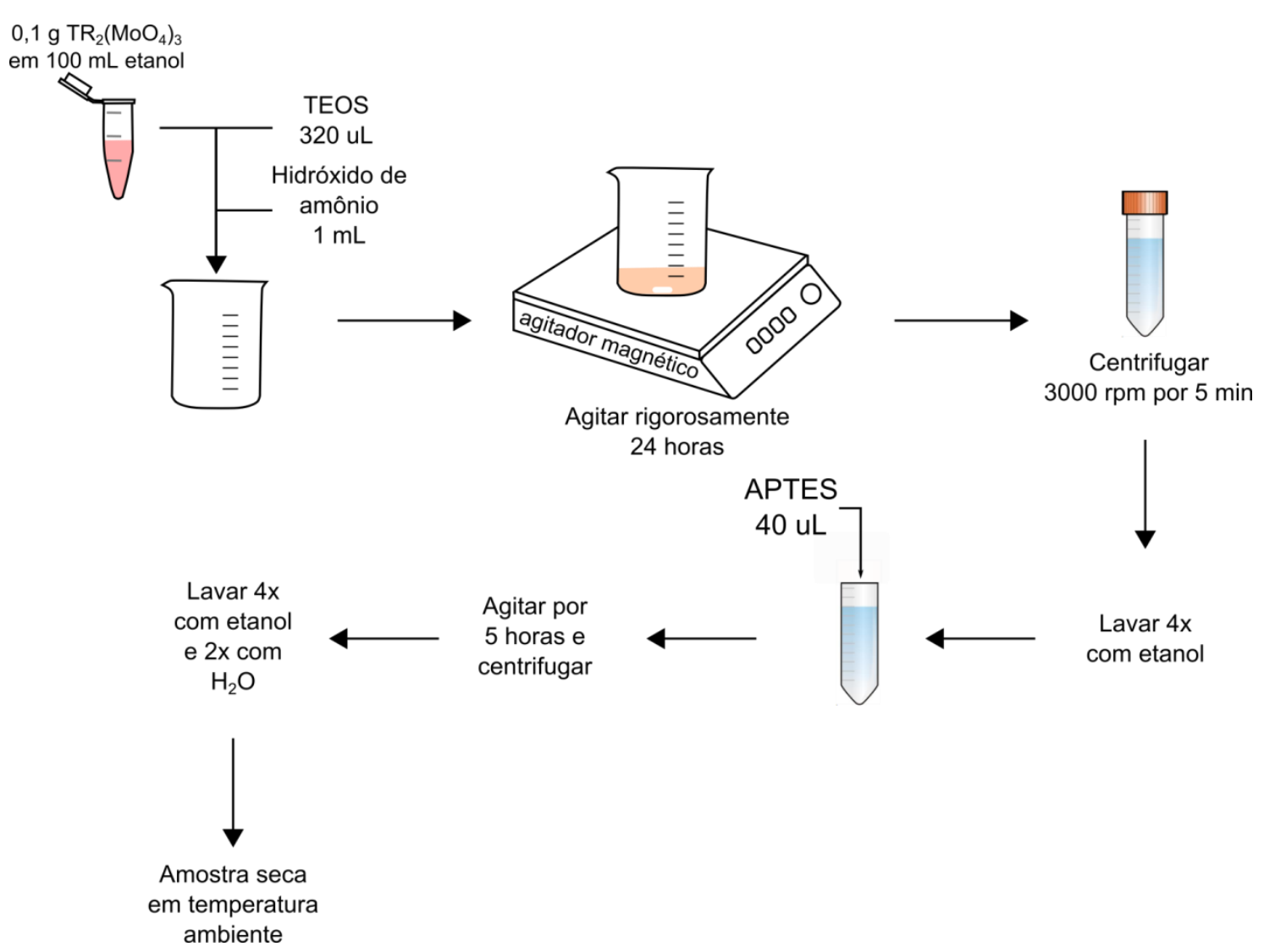

FIGURA 4.8. Ilustração do método de Stöber.

\subsubsection{Determinação de aminas primárias - método da ninidrina}

A ninidrina 2,2-di-hidróxi-1,3-indanodiano é um reagente heterocíclico (FIG.4.9) que após reagir com aminas primárias ${ }^{10}$ forma um composto conhecido como composto de Rheumann que possui coloração violeta. A concentração de aminas é diretamente proporcional a intensidade de absorção do complexo formado. 


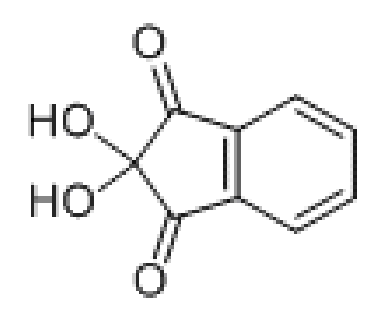

FIGURA 4.9. Estrutura da ninidrina.

A quantificação dos grupos amina $\left(\mathrm{NH}_{2}\right)$ foi feita a partir do máximo da banda de absorção na região do UV-VIS, centrada em $570 \mathrm{~nm}$, que é característica do produto da reação entre a ninidrina e os grupos $\mathrm{NH}_{2}$ (FIG.4.10). ${ }^{10}$

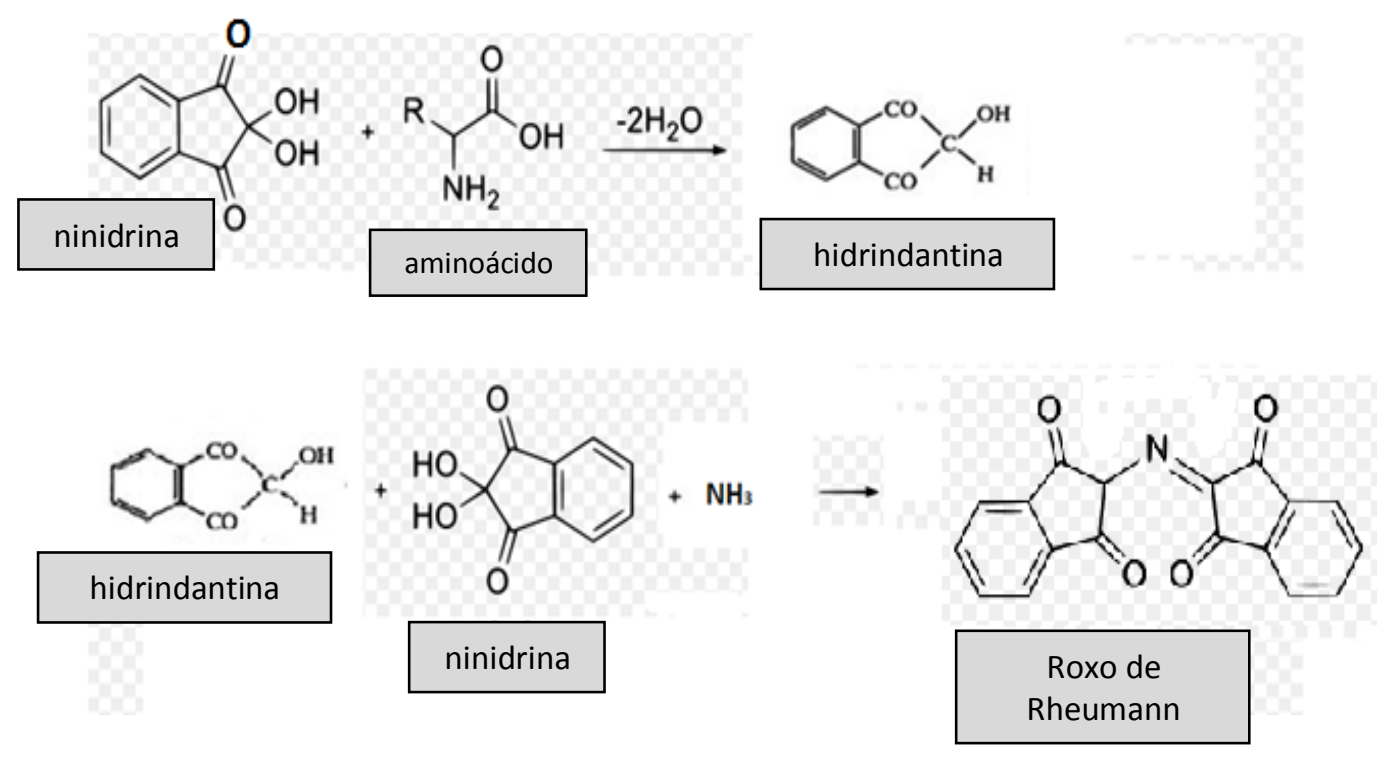

FIGURA 4.10. Representação química do teste de ninidrina.

A curva padrão de concentração foi construída usando a glicina como padrão (material de referência). 
A medida de aminas primárias pode ser feita utilizando reação colorimétrica da ninidrina. Esta reação baseia-se na formação de seu produto de cor roxa, em intervalo de $\mathrm{pH} 6,4$ a 6,5 podendo os grupos $\mathrm{NH}_{2}$ serem quantificados.

Para construir a curva padrão de concentração utilizou-se glicina como padrão e uma solução de ninidrina $(5 \% \mathrm{~m} / \mathrm{v}$ em etanol) como reagente, vale salientar que o produto formado da reação entre a ninidrina e os grupos $\mathrm{NH}_{2}$ apresentando 2 máximos de absorção no intervalo espectral de 300 a $900 \mathrm{~nm}$ com máximos em $100 \mathrm{~nm}$ e $570 \mathrm{~nm}$.

\subsubsection{Curva padrão de concentração}

Para construir a Curva Padrão de Concentração (C.P.C) preparou-se uma solução padrão de glicina com concentração de $1.0 \times 10^{-2} \mathrm{~mol} \mathrm{~L}^{-1}$.

Em um tubo de ensaio, adicionou-se $1,0 \mathrm{~mL}$ da solução de glicina $1 \times 10^{-2} \mathrm{~mol} \mathrm{~L}^{-1}, 2,5 \mathrm{~mL}$ de tampão fosfato $0,1 \mathrm{~mol} \mathrm{~L}^{-1}(\mathrm{pH} 6,4-6,5)$ e $0,5 \mathrm{~mL}$ da solução de ninidrina $(5 \% \mathrm{~m} / \mathrm{v}$ em etanol). Aqueceu-se o sistema por 1 hora à temperatura de $70 \stackrel{\circ}{\circ}$. Após aquecimento o sistema foi resfriada até temperatura ambiente $\left(\sim 25^{\circ} \mathrm{C}\right)$, e a solução foi transferida para um balão volumétrico de $50 \mathrm{~mL}$, e o volume foi aferido com água deionizada.

Constituiu-se uma curva, variando a concentração de glicina de $2 \times 10^{-4}$ a $1,0 \times 10^{-5} \mathrm{~mol} \mathrm{~L}^{-1}$ monitorando-se a absorbância em $570 \mathrm{~nm}$. O procedimento utilizado para preparação do "branco" foi análogo ao descrito acima, mas sem adição da glicina. Todos os resultados são valores médios obtidos de ensaios feitos em triplicata. 


\subsubsection{Quantificação de aminas nas partículas}

Em um tubo de ensaio contendo $5,0 \mathrm{mg}$ de partículas de $\mathrm{TR}_{2}\left(\mathrm{MoO}_{4}\right)_{3} @ \mathrm{Si}$ amino-funcionalizadas, adicionou-se $0,5 \mathrm{~mL}$ de tampão fosfato $0,1 \mathrm{~mol} \mathrm{~L}^{-1}(\mathrm{pH} 6,4-6,5)$ e $0,1 \mathrm{~mL}$ da solução etanóica de ninidrina $(5 \% \mathrm{~m} / \mathrm{v})$. A mistura foi aquecida durante 1 hora, tempo reacional pré-estabelecido. Depois de 1 hora, o sistema foi resfriado até temperatura ambiente $\left(\sim 25^{\circ} \mathrm{C}\right)$, e o sobrenadante foi transferido para um balão volumétrico de $10 \mathrm{~mL}$. Adicionou-se $1 \mathrm{~mL}$ de água deionizada $(70 \stackrel{\circ}{\circ})$ ao material sólido contido no tubo de ensaio e a mistura permaneceu no banho de aquecimento por 10 minutos. Em seguida o sobrenadante de cor roxa, foi transferido para o balão que continha 0 sobrenadante inicial. Este procedimento de lavagem foi repetido até que o sobrenadante não apresentasse mais a cor roxa. O volume da solução foi aferido no ao balão e a absorbância foi registrada em $570 \mathrm{~nm}$ contra prova em branco, preparada da mesma forma, sem a partícula funcionalizada. ${ }^{10}$ As leituras também foram expressas como valores médios obtidos de dosagens realizadas em triplicatas.

\subsection{Conjugação das nanopartículas $\mathrm{TR}_{2}\left(\mathrm{MoO}_{4}\right)_{3}$}

Depois do recobrimento das nanopartículas de $\mathrm{TR}_{2}\left(\mathrm{MoO}_{4}\right)_{3}$ com a camada de sílica, para a obtenção das entidades $\mathrm{TR}_{2}\left(\mathrm{MoO}_{4}\right)_{3} @ S i$, estas foram funcionalizadas com o glutaraldeído para se ligarem as espécies biológicas.

\subsubsection{Reação das entidades $\mathrm{TR}_{2}\left(\mathrm{MoO}_{4}\right)_{3} @ \mathrm{Si}$ com o espaçador glutaraldeído}

A partícula funcionalizada com o glutaraldeído foi preparada a partir de $2 \mathrm{mg}$ da partícula $\mathrm{TR}_{2}\left(\mathrm{MoO}_{4}\right)_{3} @$ Si com $100 \mu \mathrm{L}$ de solução de PBS $\left(0,05 \mathrm{~mol} \mathrm{~L}{ }^{-1}\right.$ $\mathrm{pH} 7,4$ ) contendo $2,5 \%$ de glutaraldeído (FIG.4.11). Esta mistura foi mantida a temperatura ambiente de $4^{\circ} \mathrm{C}$ por 12 horas. Em seguida, as partículas foram 
lavadas quatro vezes com PBS. ${ }^{11}$ Posteriormente, a quantidade de grupamentos amino foram determinados pelo método da ninidrina.

$=\mathrm{TR}_{2}\left(\mathrm{MoO}_{4}\right)_{3}$
$=\mathrm{TR}_{2}\left(\mathrm{MoO}_{4}\right)_{3}-\mathrm{Glu}$
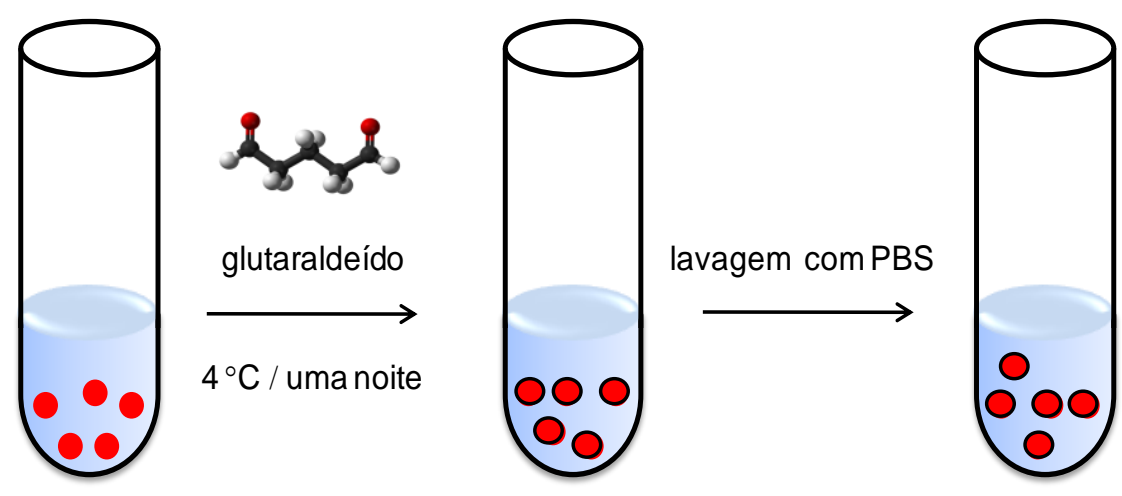

FIGURA 4.11. Esquema representativo da reação do marcador luminescente com o glutaraldeído

\subsubsection{Reação das nanopartículas $\mathrm{Nd}_{2}\left(\mathrm{MoO}_{4}\right)_{3} @$ Si-Glu com a Albumina Sérica Bovina (BSA)}

Para a conjugação das nanopartículas funcionalizadas com a parte biológica, primeiramente foi utilizado uma proteína (BSA) em concentrações diferentes $(1: 1 ; 1: 2 ; 1: 5 ; 1: 7,5 ; 1: 10)$ e esse volume foi completado com PBS $1: 10$.

Após adição do BSA, os tubos foram agitados suavemente e os mesmos foram mantidos em geladeira overnight. Após reagir por uma noite, foi adicionado borohidreto de sódio $\left(\mathrm{NaBH}_{4}\right)\left(1 \mathrm{mg} \mathrm{mL}^{-1}\right)$ em cada tubo, os tubos foram levados à geladeira por 1 hora e lavados 4x com PBS (FIG.4.12). 


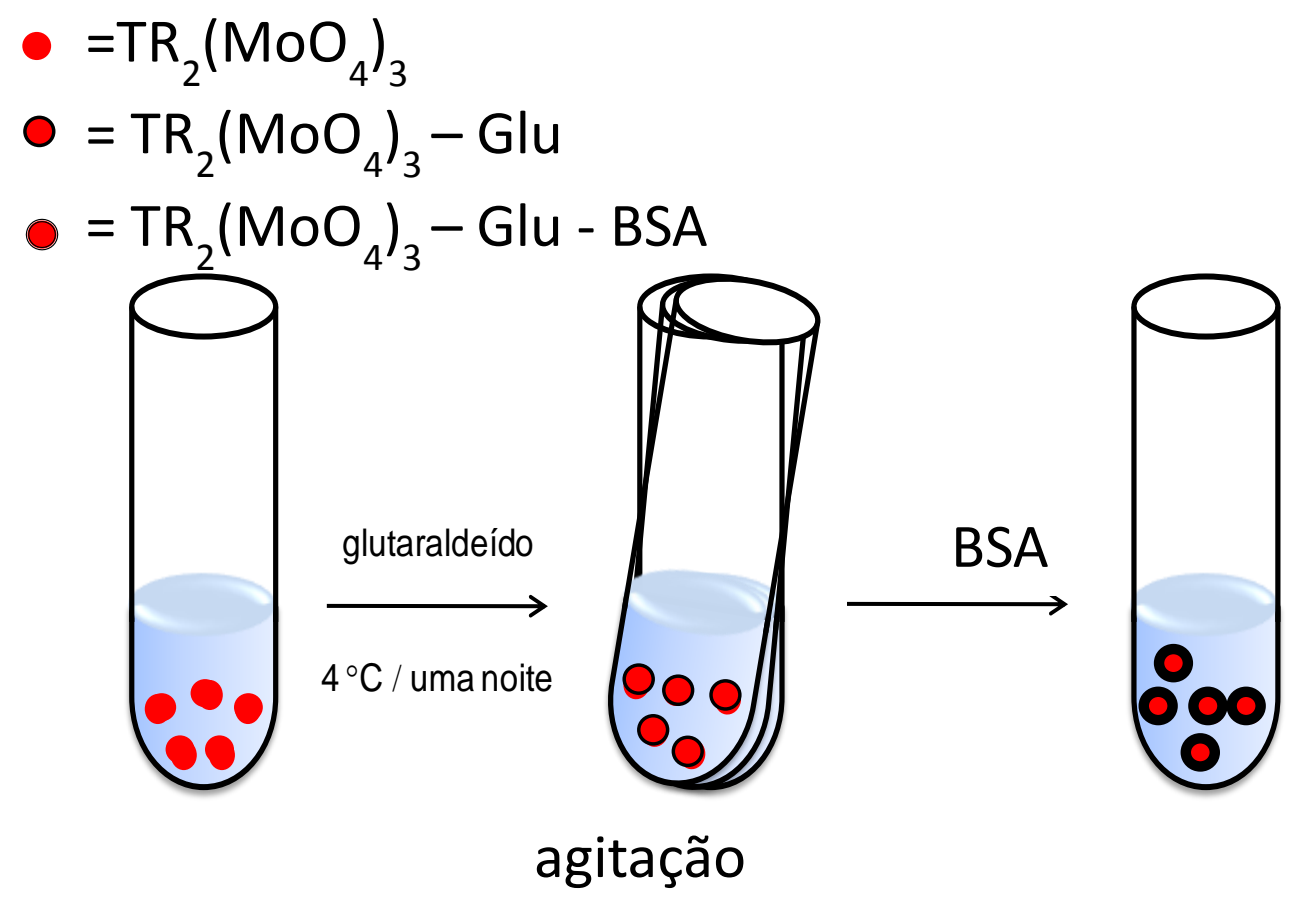

FIGURA 4.12. Esquema representativo da reação do marcador luminescente com a proteína BSA.

\subsubsection{Reação das nanopartículas $\mathrm{Eu}_{2}\left(\mathrm{MoO}_{4}\right)_{3} @$ Si-Glu com o anticorpo de marcação para o antígeno específico da próstata (PSA)}

O anticorpo monoclonal (H2P8) foi diluído em diferentes concentrações em solução de PBS $(1: 1 ; 1: 2 ; 1: 5 ; 1: 7,5 ; 1: 10)$. Em seguida, adicionou-se 200 $\mu \mathrm{L}$ de solução do anticorpo (H2P8) em microtubos contendo 2,0 mg de partícula com o espaçador glutaraldeído e mantido à temperatura de $4{ }^{\circ} \mathrm{C}$ por 12 horas. Então adicionou-se $20 \mathrm{~mL}$ da solução de $\mathrm{NaBH}_{4}\left(1,25 \mathrm{~mol} \mathrm{~L}^{-1}\right)$ e o sistema permaneceu a $4{ }^{\circ} \mathrm{C}$. Após 30 minutos, foi acrescido ao meio reacional $2 \mu \mathrm{L}$ de solução de glicina $\left(0,5 \mathrm{~mol} \mathrm{~L}^{-1}\right)$ e mantido o sistema em repouso por 30 minutos a $4{ }^{\circ} \mathrm{C}^{12}$ Finalmente $\mathrm{o}$ sistema foi lavado com PBS por 4 vezes. As águas de 
lavagem foram estocadas para posterior controle dos anticorpos que não reagiram.

\subsubsection{Método de Bradford para detecção de proteínas}

O método de Bradford (de Coomassie Brilliant Blue G-250) e o de Folin-Lowry são os métodos colorimétricos com maior índice de citação da literatura devido sua sensibilidade (Sensibilidade 0,06 a 0,3 $\mathrm{mg}$ por $\mathrm{mL}$ para Bradford e 0,1 a 0,3 mg por mL Folin-Lowry). ${ }^{13,14}$ Estes métodos são utilizado para detecção de proteínas em solução ou após precipitação com ácidos ou outros agentes, assim como precipitados antígeno-anticorpo e em insulina. $O$ teste sugere que a determinação seja feita de no mínimo 0,2y de proteína. Quando em pH ácido, o corante aniônico Coomassie Blue forma complexo com proteínas que contenham aminoácidos básicos e/ou aromáticos. A interação entre a proteína e o corante acarreta na alteração do comprimento de onda de absorção máxima do corante (465 nm - corante livre) para $595 \mathrm{~nm}$ (corante complexado a proteína).

\subsubsection{Preparo da curva padrão}

Preparou-se $10 \mathrm{~mL}$ de uma solução de BSA a $1,58 \mathrm{mg} \mathrm{mL}^{-1}$ e a partir dessa solução preparou-se $1 \mathrm{~mL}$ de solução de BSA $1,58 \mathrm{mg} \mathrm{mL}^{-1}$. Foram feitas cinco diluições seriadas a partir dessa solução, procedeu-se as diluições seriadas em $\mathrm{H}_{2} \mathrm{O}$ (Milli-Q) para a obtenção das demais concentrações $\left(0,754 \mathrm{mg} \mathrm{mL}^{-1}\right.$; $0,377 \mathrm{mg} \mathrm{mL}^{-1}, 0,1885 \mathrm{mg} \mathrm{mL}^{-1}$ e $0,09425 \mathrm{mg} \mathrm{mL}^{-1}$ ) como demonstrado no esquema abaixo. Para o branco foi utilizando o reagente de Bradford e $50 \mathrm{~mL}$ de água Milli-Q.

\subsubsection{Preparo da amostra}


Foi adicionado em um tubo de microcentrífuga $50 \mu \mathrm{L}$ de amostra e $950 \mu \mathrm{L}$ do reagente de Bradford. Para as reações dos procedimentos 1, 2 e 3, foi mantido a temperatura ambiente por 15 minutos e medido a absorbância em $595 \mathrm{~nm}$.

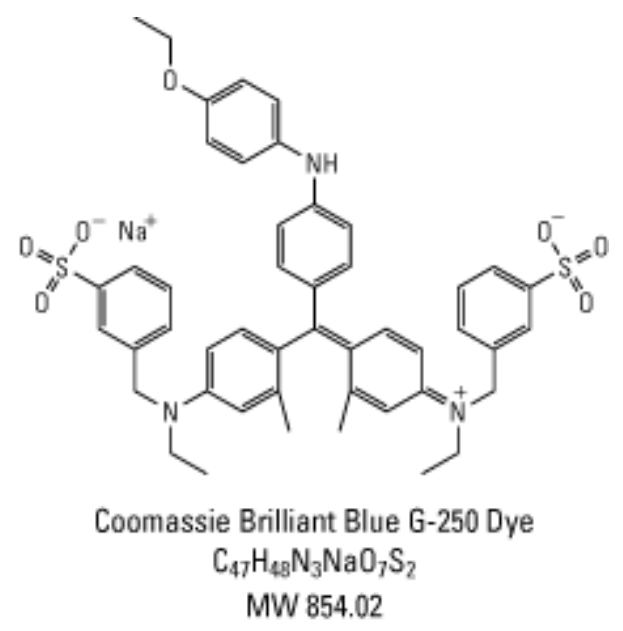

FIGURA 4.13. Representação química do corante Coomassie Brilliant Blue G250.

\subsubsection{Sensibilização da placa com o anticorpo de captura H11P8 para PSA}

Para efetuar a sensibilização das placas a serem utilizadas nos ensaios com o anticorpo monoclonal H11P8 seguiu-se o protocolo padrão:

- Dilui-se o anticorpo monoclonal em PBS nas concentrações de 0,066 $\mu \mathrm{g} \mathrm{mL}^{-1}, 0,033 \mu \mathrm{g} \mathrm{mL}^{-1} ; 0,0165 \mu \mathrm{g} \mathrm{mL}^{-1}$ e $0,008 \mu \mathrm{g} \mathrm{mL}^{-1}$ )

- Homogeneizou-se o material e pipetou-se $100 \mu \mathrm{L}$ de solução em cada poço. 
- Verteu-se a solução na pia e a placa foi vedada para estocagem com controle de temperatura e umidade.

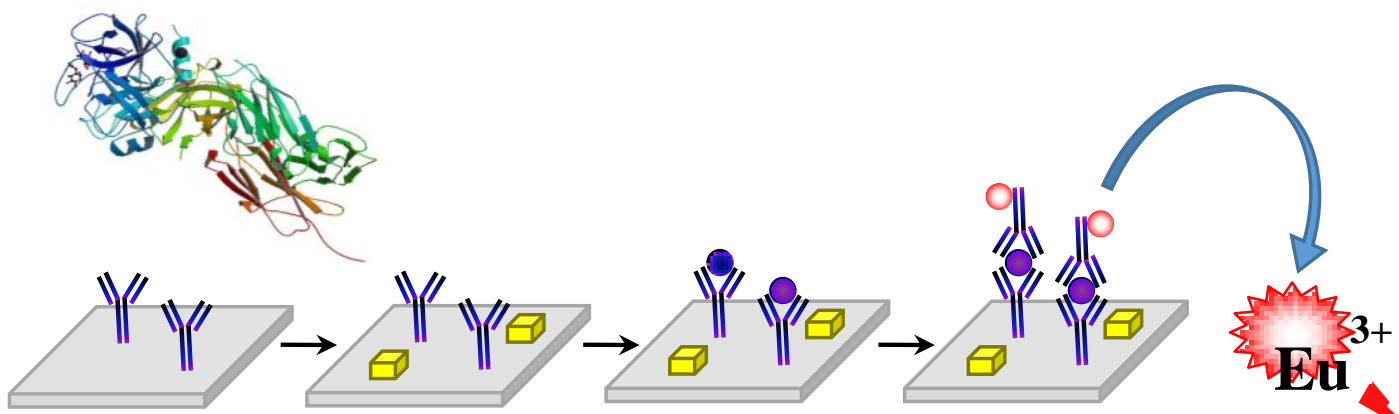

FIGURA 4.14. Estrutura cristalina do antígeno específico da próstata humano complexado a um anticorpo anti-PSA e esquema do imonoensaio para detecção do mesmo.

\section{5 . Desenvolvimento do imunoensaio para determinar 0 antígeno específico da próstata PSA}

Neste trabalho foi desenvolvido um protocolo para o ensaio biológico (imunoensaio) utilizando um marcador luminescente à base de terras raras. $O$ objetivo do fluoroimunoensaio é detectar e quantificar a reação do Ag-Ac (antígeno-anticorpo), empregando os anticorpos monoclonais anti-PSA (H2P8 e H11P8 anticorpos de marcação e captura respectivamente) e o antígeno especifico da próstata PSA. Os ensaios basearam-se na sensibilização de uma microplaca de poliestireno (suporte sólido) com o anticorpo de captura. A microplaca é lavada para retirar o excesso de anticorpo e então se adiciona um agente de bloqueio. Em seguida 0 antígeno de PSA que está presente em amostras de soro humano foi adicionado para ocorrer a imunoreação. Em seguida, a partícula contendo o espaçador glutaraldeído conjugada com o anticorpo de marcação H2P8 é adicionada a placa. Então, após a reação Ac-Ag- 
$A^{m}$, a placa é lavada seguida de leitura para quantificação. Os dados de intensidades luminescentes da placa foram obtidos no fluorímetro da Perkin Elmer cujo modelo é Victor ${ }^{2} D^{\circledR}$. Este método usado está classificado como um método direto ou imunoensaio homogêneo.

\subsection{Teste de Hemocompatibilidade}

O estudo de hemocompatibilidade foi inserido no projeto com o intuito de se investigar como as amostras que foram sintetizadas nesse trabalho se comportam em contato direto com o sangue humano, uma vez que o estudo atual tem como perspectiva futura o desenvolvimento de um kit de diagnóstico para câncer de próstata que seja realizado in vitro.

Para que a interação sangue/nanopartículas pudesse ser estudada morfologicamente, foi necessário o desenvolvimento de um filme com as partículas e para que esse filme não influenciasse na interação, fez-se necessário a escolha de um filme já conhecido como sendo biocompativel e neutro em meio biológico, ou seja, um filme a base de quitosana. ${ }^{15}$

\subsubsection{Preparação dos filmes de quitosana}

Para o preparo da solução de quitosana a 14,85 $\mathrm{g} \mathrm{L}^{-1}$, utilizou-se $2,85 \mathrm{~g}$ de pó de quitosana, $100 \mathrm{~mL}$ de solução de ácido acético $(2 \% \mathrm{~m} / \mathrm{v})$ e a solução ficou em agitação por 4 horas em temperatura ambiente. Após a agitação, adicionou-se mais $100 \mathrm{~mL}$ da solução de acético, $5 \mathrm{~mL}$ de glutaraldeído a $5 \%$ e adicionou-se as nanopartículas em um dos filmes e no outro não houve adição, que foi considerado como o branco. ${ }^{16}$ 


\subsubsection{Método de Hemocompatibilidade}

No teste de hemocompatibilidade as amostras dos filmes de quitosana contendo nanopartículas de $\mathrm{Eu}_{2}\left(\mathrm{MoO}_{4}\right)_{3}$ e sem nanopartículas, tinham tamanho aproximado de $25 \mathrm{~mm}^{2}$ foram aderidos à uma lamínula com fita dupla face. As lamínulas com os filmes foram colocadas em uma placa de Petri e essa foi inserida dentro de outra placa de Petri maior contento água, essas placas foram levadas à estufa $37^{\circ} \mathrm{C}$ por 15 minutos a fim de umidificar o meio.

O sangue foi centrifugado e recobriu-se os filmes com o plasma, as amostras foram novamente acondicionadas no conjunto de placas e levadas à estufa por $37^{\circ} \mathrm{C}$ por 1 minuto.

As amostras foram lavadas com solução salina $(0,2 \mathrm{M})$ e imersas em glutaraldeído (2,5\%) por 10 minutos a temperatura ambiente e então desidratadas com etanol nas concentrações de 50\% (por 5 minutos), $75 \%$ (por 10 minutos) e 95\% (por 15 minutos) conforme FIG.4.15. ${ }^{17}$

As amostras foram caracterizadas por microscopia eletrônica de varredura (MEV).
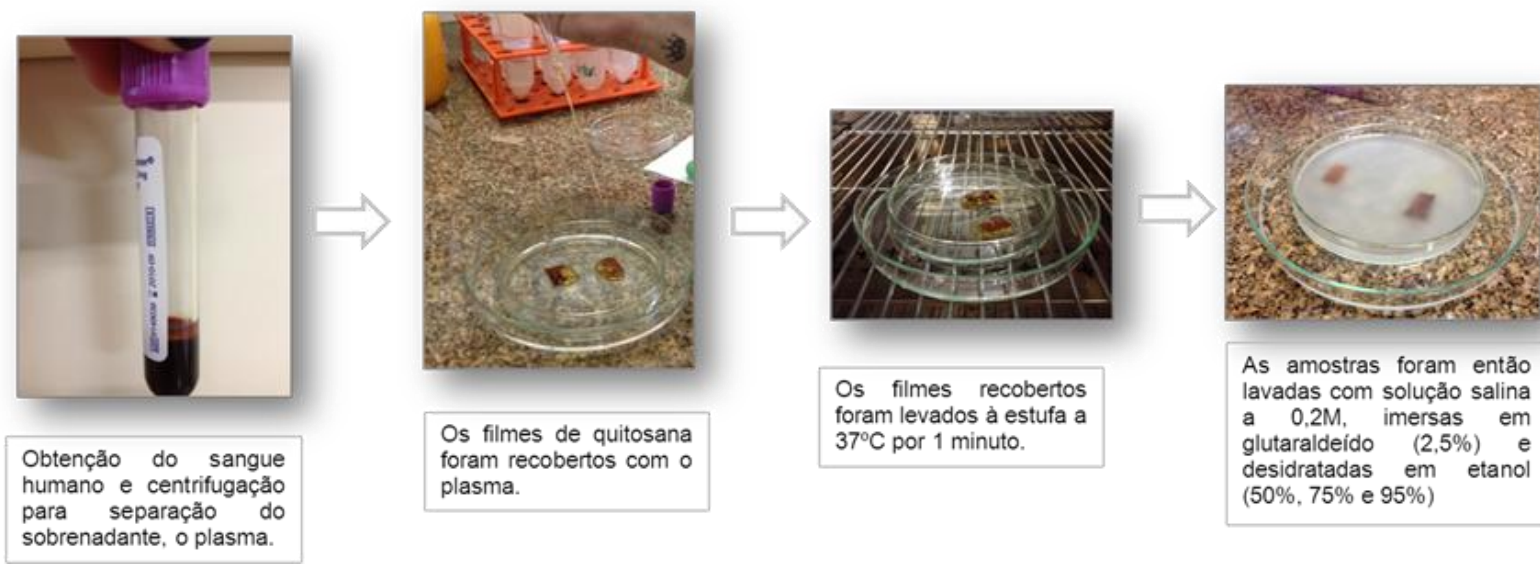

FIGURA 4.15. Esquema ilustrativo do método de preparação para o teste de hemocompatibilidade. 


\section{REFERÊNCIAS BIBLIOGRÁFICAS}

1. SPEDDING, F. H.; LEGVOLD, S.; DAANE, A. H.; JENNINGS, L.D. Some physical properties of the rare earth metals. Jornal of metals, v.6 p.504, 1954.

2. COURTY, P. \& MARCILLY, C. A scientific approach to the preparation of bulk mixed oxide catalysts. Studies in surface science and catalysis, p. 485$519,1983$.

3. PINHEIRO, E. A. Uso de métodos sol-gel e de coprecipitação na preparação de óxidos metálicos. 1992. Tese (Doutorado) - Instituto de Química - Universidade Estadual de Campinas.

4. FENG, J.; SHAN, G.; MAQUIEIRA, A.; KOIVUNEN M. E.; GUO, B; HAMMOCK, B. D.; KENNEDY, I. M.Functionalized europium oxide nanoparticles used as a fluorescent label in an immunoassay for atrazine. Anal. Chem,v. 75, p. 5282-5286, 2003,

5. LOURENÇO, A.V.S. Partículas de sílica funcionalizadas contendo complexos de $T R^{3+}$ para aplicação como marcadores em ensaios biológicos. Tese (Doutorado). Instituto de Química da Universidade de São Paulo, p.210, 2010.

6. BAHADUR, N. M.; FURUSAWA, T.; SATO, M.; KURAYAMA, F.; SIDDIQUEY, I. A.; SUZUKI, N. Fast and facile synthesis of silica coated silver nanoparticles by microwave irradiation. Journal of colloid and interface science, v.355, p.312-20, 2011.

7. STÖBER, W. controlled growth of monodisperse silica spheres in the micron size range. Journal of colloid and interface science,v.26, p. 62-69, 1968.

8. BLAADEREN, A. V.; VRIJ, A. Synhesis and characterization of monodisperse colloidal organo-silica spheres. Journal of colloid and interface science, v.156, p.1-18, 1992. 
9. WONG, Y. J.; ZHU, L. TEO, W. S.; TAN, Y. W.; YANG, Y.; WANG, C; CHEN, H. Revising the Stöber method: Inhomogenity in silica shells. Journal of the American Chemical Society, v.133, p. 11422-11425, 2011.

10. TAYLOR, I. \& HOWARD, A. G. Measurement of primary amine groups on surface-modified silica and their role in metal binding. Analytica Chimica Acta, v. 271, p. 77-82, 1993.

11. YANG, W.; ZHANG, C.G.; QU, H.Y.; YANG, H.H.; XU, J.G. Novel fluorescent silica nanoparticles probe for ultrasensitive immunoassays. Analytical Chemica Acta, v.503, p. 163-169, 2004.

12. LYLE, S.J.; WIITS, A.D. A critical examination of some methods for the preparation of tri sans tetrakis diketonates of europium (III). Inorganic Chemica Acta, v.5, p. 481-484, 1971.

13. SOUZA, J.S. Funcionalização da superfície de nanopartículas superparamagnéticas encapsuladas por quitosana para a imobilização de proteínas. 2010. Dissertação (Mestrado). Instituto de Pesquisas Energéticas e Nucleares - Universidade de São Paulo.

14. ROE, S. Protein purification techniques. Oxford University Press, 2nd ed., p. 263, 2006.

15. ZHANG, M., LI, X. H., GONG, Y. D., ZHAO, N. M. \& ZHANG, X. F. Properties and biocompatibility of chitosan films modified by blending with PEG. Biomaterials,v.23, p. 2641-8, 2002.

16. COSTA, E. S.; MANSUR, H. S. Preparação e caracterização de blendas de quitosana/poli(álcool vinílico) reticuladas quimicamente com glutaraldeído para aplicação em engenharia de tecido. Química Nova, v. 31, p.1460-1466, 2008.

17. ALMEIDA, A.T.Obtenção de superfícies hemocompatíveis por meio da modificação de materiais poliméricos pela radiação ionizante. 2000. Dissertação (Mestrado).Instituto de Pesquisas Energéticas e Nucleares Universidade de São Paulo. 


\section{RESULTADOS E DISCUSSÃO - Sínteses e Caracterizações}

5.1 Síntese dos molibdatos de terras raras $\mathrm{TR}_{2}\left(\mathrm{MoO}_{4}\right)_{3}\left(\mathrm{TR}=\mathrm{Y}^{3+}, \mathrm{Nd}^{3+}\right.$, $\mathrm{Sm}^{3+}, \mathrm{Eu}^{3+}, \mathrm{Gd}^{3+} \mathrm{e} \mathrm{Tb}^{3+}$ )

São vários os métodos de obtenção dos molibdatos de terras raras, $\mathrm{TR}_{2}\left(\mathrm{MoO}_{4}\right)_{3}$. Segundo dados da literatura, os molibdatos e tungstatos de terras raras atualmente são obtidos pelos métodos:

a) reações hidro(solvo)termal: é o metodo de síntese mais usado, para a preparação de molibdato e tungstato de terras raras na forma de nano- e micromateriais. O crescimento cristalino para obtenção das partículas é feita a partir de uma solução de água, a temperatura elevada num aparelho que consiste de um recipiente de pressão de aço (autoclave) mais frequentemente revestidas com Teflon. Para a síntese dos molibdatos e tungstatos de terras raras, geralmente, as autoclaves são mantidas a uma temperatura de $120-200^{\circ} \mathrm{C}$ durante um intervalo que vai de 1 a $72 \mathrm{~h}$. Normalmente, um sal de nitrato/cloreto de terras raras e um tungstato de sódio/ hidróxido de amônio ou sal molibdato são utilizados como reagentes de partida. Vários pesquisadores também empregaram como precursores o $\mathrm{Y}(\mathrm{OH})_{3}$ e $\mathrm{Y}(\mathrm{OH}) \mathrm{CO}_{3}$ como fonte de ions de terras raras. $\mathrm{Na}$ maioria dos casos, os produtos finais puros são obtidos após calcinação. ${ }^{1,2,3}$

b) reações assistidas termicamente por micro-ondas: no caso de reações hidrotermais convencionais o calor tem que primeiramente passar através das paredes do recipiente a fim de atingir o solvente e os reagentes. Em um processo hidrotermal assistido por micro-ondas pares de micro-ondas atuam diretamente nas moléculas da mistura de reação, sendo, apenas o conteúdo do recipiente aquecido. A síntese assistida por micro-ondas está sendo usada com mais frequência para síntese de nanomateriais inorgânicos ${ }^{4}$, que na maioria das vezes é empregado sal de nitrato terra raras, um sal de tungstato ou de molibdato 
de sódio como reagente de partida. Zhang et al. relataram a síntese de microcristais $\mathrm{NaLa}(\mathrm{MoO} 4)_{2}$ com morfologia dendrito usando um modelo de microondas convencional. ${ }^{5} \mathrm{~A}$ suspensão é irradiada durante $10 \mathrm{~min}$ a $180{ }^{\circ} \mathrm{C}$ sob agitação magnética. Da mesma forma, Tian et al sintetizou microarquiteturas de $\mathrm{NaY}\left(\mathrm{WO}_{4}\right)_{2} 3 \mathrm{D}$ em forma de flor utilizado síntese hidrotérmica assistida por microondas. ${ }^{6}$ Esta síntese foi efetuada na presença de citrato trissódico e aqueceu-a em $200{ }^{\circ} \mathrm{C}$ com uma potência de irradiação de micro-ondas de $90 \mathrm{~W}$.

c) síntese por sais fundidos: os molibdatos e tungstatos de terras raras também podem se preparados utilizando a técnica de sal fundido, que é uma síntese alternativa e atraente devido à sua simplicidade, baixo custo e tempo curto de reação. Uma grande quantidade de um sal com um ponto de fusão relativamente baixo (por exemplo, um sal de cloreto ou sulfato de sódio) é adicionado aos reagentes e se aquece acima do ponto de fusão do sal. Segue-se então o resfriamento deste sal fundido até temperatura ambiente e os produtos são lavados com um solvente apropriado para remover o sal. Numa síntese típica de sal fundido os óxidos de terras raras e óxidos de molibdato ou tungstato são utilizados como reagentes. Lei \&Yan relataram o uso da síntese por sal fundido para a preparação de $\mathrm{Gd}_{2} \mathrm{WO}_{6}$ e $\mathrm{Gd}_{2} \mathrm{MoO}_{6}{ }^{7}$ As sínteses foram realizadas a $950 \stackrel{\circ}{\mathrm{C}}$ durante $6 \mathrm{~h}$ usando $\mathrm{NaCl}$ e $\mathrm{KCl}$, como meios reacionais (as temperaturas de fusão dos sais são 801 e $770{ }^{\circ} \mathrm{C}$, respectivamente). Quando o $\mathrm{NaCl}$ foi utilizado como meio reacional, partículas com um tamanho médio de $100 \mathrm{~nm}$, foram obtidas. Vale salientar que quando se considerou a utilização de $\mathrm{KCl}$ obteve-se materiais na forma de hastes 200-400 nm em comprimento e de cerca de $150 \mathrm{~nm}$ de largura. Os materiais $\mathrm{Gd}_{2} \mathrm{WO}_{6}$ e $\mathrm{Gd}_{2} \mathrm{MoO}_{6}$ obtidos pela técnica de sal fundido eram menores e menos agregados em comparação com aqueles anteriormente sintetizado por Chen et al. usando as reações de estado sólido. ${ }^{8}$

d) método sol-gel: a síntese de molibdatos e tungstatos de terras raras pelo método sol-gel foi utilizada na preparação de vários nanomateriais com sucesso. Normalmente um sal de terra rara como o nitrato e um sal de tungstato ou de molibdato são empregados como reagentes de partida neste tipo de reação. O processo sol-gel envolve a formação de um sol, que é uma suspensão 
de partículas sólidas num líquido. Os agregados do sol terão sua viscosidade aumentada até formar um gel, que é um material com a forma de um sólido difásico encapsulando um líquido. O gel pode então ser seco por evaporação ou sob condições supercríticas. $\mathrm{Gd}_{2}\left(\mathrm{MoO}_{4}\right)_{3}$ e $\mathrm{Gd}_{2} \mathrm{MoO}_{6}$ foram preparados por Pan et al empregando este método modificado utilizando ácido cítricoe etilenoglycol. ${ }^{9} \mathrm{O}$ produto final foi obtido após a sinterização dos precursores a $900{ }^{\circ} \mathrm{C}$ durante $5 \mathrm{~h}$. Esta reação resultou em partículas esféricas com cerca de $60 \mathrm{~nm}$ de tamanho.

e) método por microemulsão: microemulsão é uma dispersão termodinamicamente estável de dois fluídos imiscíveis, onde o sistema é estabilizado pela adição de um surfactante. A adição de componentes polares ou iônicos no sistema leva as micelas a ficarem compartimentadas no centro do núcleo e devido ao movimento browniano estas micelas colidem e formam dímeros, os quais podem em seguida se separam novamente. Neste tipo de síntese são utilizados como reagentes de partida um sal de nitrato de terras raras e um sal de tungstato de sódio ou molibidato. ${ }^{10}$

f) reações de estado sólido: a técnica de reação em estado sólido convencional tem sido utilizada na síntese de tungstatos e molibdatos de terras raras. Em uma reação típica de estado sólido convencional, óxidos de terras raras de molibdato e de tungstato são utilizados como reagentes de partida. Nesta síntese, pós dos precussores são primeiramente cominuidos em pós com granulometria mais fina, para maximizar o efeito de área superficial, misturados e aquecidos a uma temperatura adequada. Por exemplo, He et al. utilizaram esta técnica para sintetizar partículas com formas de pseudo- pompom no tamanho de 6-8 $\mathrm{mm}$, obtidos a partir de vários flakes. Estas microestruturas de $\mathrm{Gd}_{2}\left(\mathrm{MoO}_{4}\right)_{3}$ foram obtidas depois de aquecer em mulfla o material de partida até $800{ }^{\circ} \mathrm{C} .{ }^{11}$

g) reações de co-precipitação: o processo de síntese por coprecipitação homogênea pode resultar em nanopartículas com um largo espectro de tamanho variando de $5-180 \mathrm{~nm} .{ }^{12}$ O processo é bem simples e consiste na mistura de sais inorgânicos em ambiente aquoso seguido de precipitação. $O$ precipitado formado é então digerido, filtrado e seco em estufa ou ao ar. 
Dentre todos os métodos citados anteriormente o método de coprecipitação destaca-se por apresentar inúmeras vantagens, tais como: homogeneidade química, temperaturas de reação e sinterização baixas, partículas finas com espectro de distribuição de tamanho numa faixa estreita, equipamentos para produção de baixo custo, pós com boa reatividade, economia de tempo, fácil ampliação da escala para produção e baixíssimo custo.

O processo de coprecipitação homogênea resulta na formação de sólidos, cristalinos ou amorfos que dependem das condições do processo no qual foram formados, isto é, de variáveis tais como: pH, tipo de ânion, ordem de adição dos reagentes, concentração dos metais, razão molar dos metais, temperatura, velocidade de agitação, e outras. Estas variáveis ${ }^{13}$ afetam de forma significativa a natureza, a homogeneidade, o tamanho, o comportamento magnético e a energia da superfície.

O método de coprecipitação consiste de dois processos: a nucleação (formação de centros de cristalização) e o crescimento subsequente das partículas. As taxas relativas desses dois processos determinam o tamanho e a polidispersão das partículas obtidas. Coloides polidispersos são obtidos como resultado simultâneo da formação de novos núcleos e do crescimento das partículas formadas recentemente. Se a nucleação predomina, o resultado é um número grande de partículas pequenas. Entretanto se o crescimento predomina, o resultado será um número pequeno de partículas maiores. Uma menor dispersão do tamanho do coloide é obtida quando a taxa de nucleação é alta e a taxa de crescimento das partículas é baixa.

O controle do tamanho de partícula é estabelecido na etapa de coprecipitação. Desta forma, para que os resultados sejam reprodutíveis, é importante que as condições experimentais iniciais citadas acima sejam fixadas. É sabido que quanto maior a velocidade de agitação da solução, menor é o diâmetro médio das partículas. Este comportamento parece indicar que o mecanismo de crescimento das partículas em função da velocidade de agitação por reação de condensação química é dominado principalmente, pela difusão das 
nanopartículas através do meio, ao invés da difusão dos cátions aquosos na superfície das nanopartículas. Esta conclusão parece óbvia, uma vez que os cátions estão em toda parte na solução enquanto que as nanopartículas representam apenas uma fração pequena do volume.

Usando este método, nanoparticulas de $\mathrm{TR}_{2}\left(\mathrm{MoO}_{4}\right)_{3}$ foram produzidas neste trabalho segundo reação abaixo:

$$
2 \mathrm{TR}^{3+}+3\left(\mathrm{MoO}_{4}{ }^{=}\right) \rightleftharpoons \mathrm{TR}_{2}\left(\mathrm{MoO}_{4}\right)_{3} \text { ת }
$$

Como produtos de síntese, foram obtidos pós cristalinos brancos, exceção feita ao molibdato de neodímio que apresentou coloração lilás, com comportamento de insolubilidade em água e outros solventes como metanol, acetona, clorofórmio, etc., embora possuam boa dispersão. As FIG.5.1 a 5.4apresentam fotografias dos molibdatos de terras raras obtidas por uma câmera digital sob luz ambiente e sob irradiação ultravioleta (366nm). As amostras apresentaram comportamento higroscópico à temperatura ambiente $\left(\sim 25^{\circ} \mathrm{C}\right)$.
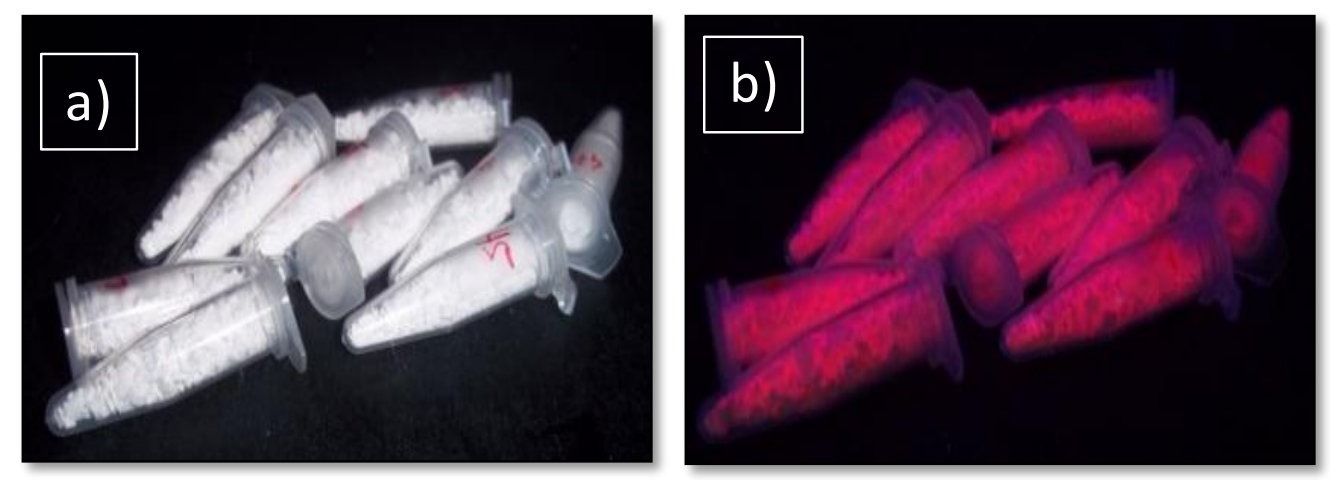

FIGURA 5.1. Fotografias do molibdato de európio: a) sob luz ambiente e b) sob irradiação ultravioleta $\left(\lambda_{\mathrm{ex}}=366 \mathrm{~nm}\right)$. 
Resultados e discussões - Sínteses e Caracterizações
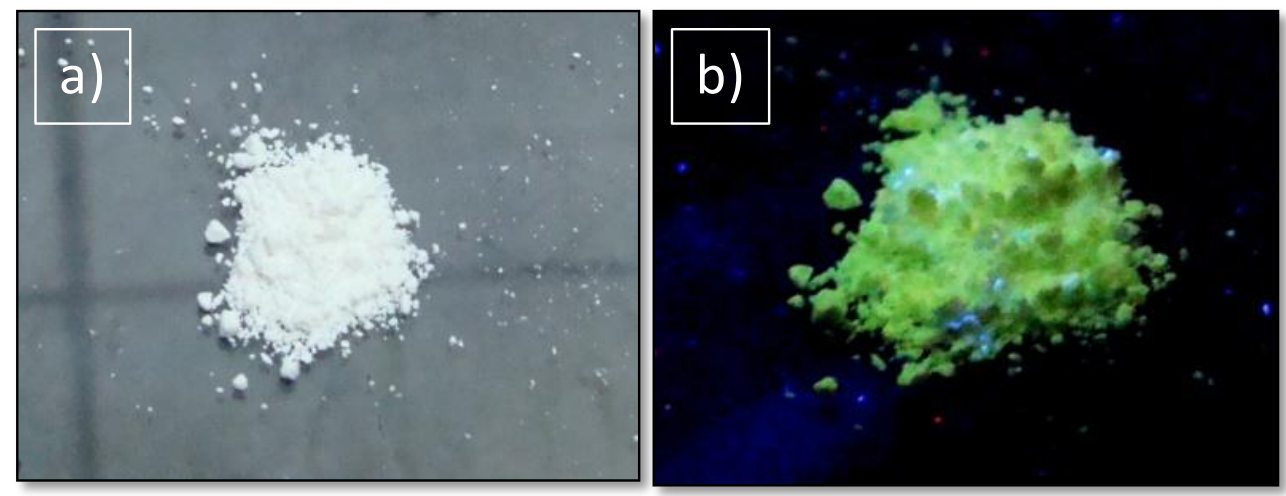

FIGURA 5.2. Fotografias do molibdato de térbio a) sob luz ambiente e b) sob irradiação ultravioleta $\left(\lambda_{\mathrm{ex}}=366 \mathrm{~nm}\right)$.

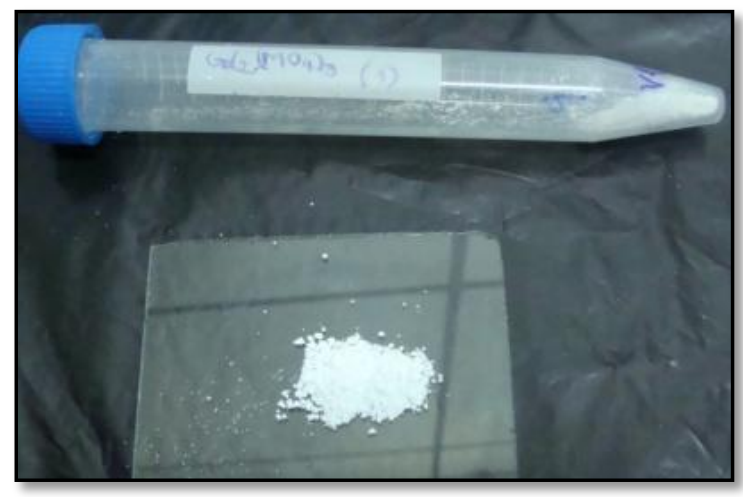

FIGURA 5.3. Fotografias do molibdato de gadolínio sob luz ambiente.

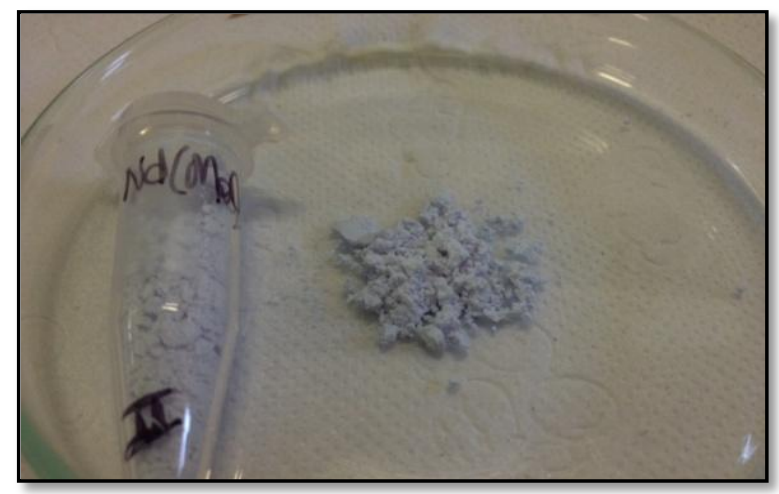

FIGURA 5.4. Fotografias do molibdato de neodímio sob luz ambiente. 


\subsection{Caracterizações dos molibdatos de terras raras $\mathrm{TR}_{2}\left(\mathrm{MoO}_{4}\right)_{3}$}

Com o intuito de obter informações sobre a estrutura, morfologia, distâncias de ligação, estabilidade térmica, dentre outras propriedades para os sistemas $\mathrm{TR}_{2}\left(\mathrm{MoO}_{4}\right)_{3}\left(\mathrm{TR}^{3+}: \mathrm{Y}, \mathrm{Nd}, \mathrm{Sm}, \mathrm{Eu}, \mathrm{Tb}, \mathrm{Gd}\right)$ estes foram caracterizados pelas técnicas: espectroscopia de absorção no infravermelho, termogravimetria (TG e DTG), difração de raios $X$, microscopia eletrônica de varredura e transmissão.

\subsubsection{Espectroscopia de absorção no infravermelho com transformada de Fourrier (FTIR) dos molibdatos de terras raras $\mathrm{TR}_{2}\left(\mathrm{MoO}_{4}\right)_{3}$}

A chamada radiação infravermelha corresponde à parte do espectro eletromagnético situada entre as regiões do visível e das micro-ondas. A porção de maior utilidade para o químico orgânico está situada entre 4000 e $400 \mathrm{~cm}^{-1}$. O interesse nas regiões do infravermelho próximo $\left(14290-4000 \mathrm{~cm}^{-1}\right)$ e do infravermelho distante $\left(700-200 \mathrm{~cm}^{-1}\right)$ vem aumentando muito nos ultimos anos. $^{14}$

A espectroscopia de infravermelho se baseia nas ligações químicas das substâncias que possuem freqüências de vibrações específicas, as quais correspondem a níveis de energiamoleculare é um tipo de espectroscopia de absorção que usa a região do infravermelho do espectro eletromagnético. ${ }^{14}$

Embora o espectro de infravermelho seja característico da molécula como um todo, certos grupos de átomos dão origem a bandas que ocorrem mais ou menos na mesma freqüência, independentemente da estrutura da molécula. É justamente a presença destas bandas características de grupos que permite ao químico a obtenção, através de simples exame do espectro e consulta a tabelas específicas, informações estruturais úteis e é neste fato que se fundamenta a identificação de estruturas. ${ }^{14}$ 
A radiação infravermelha de freqüência na faixa $10000-100 \mathrm{~cm}^{-1}$ quando absorvida converte-se em energia de vibração molecular. O processo é quantizado e o espectro vibracional aparece como uma série de bandas ao invés de linhas porque a cada mudança de energia vibracional corresponde a uma série de mudanças na energia rotacional. As linhas se sobrepõem dando lugar às bandas observadas. São estas bandas de vibração-rotação, particularmente as que ocorrem entre 4000 e $400 \mathrm{~cm}^{-1}$, que serão utilizadas neste trabalho. A frequência ou o comprimento de onda de uma absorção depende das massas relativas dos átomos, das constantes de força das ligações e da geometria dos átomos. ${ }^{14}$

A técnica de espectroscopia de absorção na região do infravermelho (IV) foi utilizada como ferramenta na caracterização dos materiais $\mathrm{TR}_{2}\left(\mathrm{MoO}_{4}\right)_{3}$ com o intuito de investigar a presença de bandas de absorção referentes aos modos vibracionais metal-oxigênio ( $\mathrm{M}-\mathrm{O}$ ) e para comprovar a ausência de bandas atribuídas aos precursores. Os espectros de absorção no IV dos materiais foram registrados em pastilhas de $\mathrm{KBr}$ na região espectral de 400 à $4000 \mathrm{~cm}^{-1}$ à temperatura ambiente.

Os molibdatos investigados por Oliveira ${ }^{15}$ apresentam à temperatura ambiente estrutura ortorrômbica pertencente ao grupo espacial $\mathrm{Pba2}\left(\mathrm{C}_{2 v}{ }^{8}\right)$ com quatro fórmulas por célula unitária. $\mathrm{O}$ grupo $\mathrm{MoO}_{4}{ }^{2-}$ tem simetria $\mathrm{Td}$ cujas representações irredutíveis são $A_{1}, E, T_{1}$ e $T_{2}$. No cristal, estes grupos ocupam sítios de simetria $C_{1}$ cuja representação irredutível é $A$. Esta representação irredutível se transforma em $A_{1}, A_{2}, B_{1}$ e $B_{2}$ para simetria $C_{2 v}$.

Os modos de estiramentos internos do íon molibdato são esperados que ocorram nas regiões de estiramento $\left(750-990 \mathrm{~cm}^{-1}\right)$ e deformação em (250$\left.400 \mathrm{~cm}^{-1}\right)^{2}$. Ions molibdatos são espécies tetraédricas e quando se ligam com um metal, muitas vezes, diminuem a simetria. As bandas em $\sim 933$ e $\sim 860 \mathrm{~cm}^{-1}$ (s), $\sim 760 \mathrm{~cm}^{-1}$ (s) e $\sim 700 \mathrm{~cm}^{-1}$ (s) que são atribuídas ao estiramento $\mathrm{M}-\mathrm{O}$ da fase tetragonal do íon molibdato desdobrada em uma simetria mais baixa como mencionados na TAB. 5.1. 
TABELA 5.1. Carta de correlação dos modos vibracionais do $\mathrm{RE}_{2}\left(\mathrm{MoO}_{4}\right)_{3}{ }^{15}$.

\begin{tabular}{lcc}
\hline \hline$T_{d}$ & $D_{2 d}$ & \multicolumn{1}{c}{$C_{2 v}$} \\
\hline$A_{1}$ & $A_{1}$ & $A_{1}$ \\
$A_{2}$ & $B_{1}$ & $A_{2}$ \\
$E$ & $A_{1}+B_{1}$ & $A_{1}+A_{2}$ \\
$F_{1}$ & $A_{2}+E$ & $A_{2}+B_{1}+B_{2}$ \\
$F_{2}$ & $B_{2}+E$ & $A_{1}+B_{1}+B_{2}$ \\
\hline \hline
\end{tabular}

Os espectros de absorção no infravermelho dos fósforos $\mathrm{TR}_{2}\left(\mathrm{MoO}_{4}\right)_{3}$ (FIG 5.5) mostram que as bandas de absorção do grupo O-H ( 1625 e $\sim 3400 \mathrm{~cm}^{-1}$ ) foram observadas devido às moléculas de água oriundas do próprio material e do $\mathrm{KBr}$ das pastilhas.

A região espectral de 1000 a $400 \mathrm{~cm}^{-1}$ compreende as frequências atribuídas à ligação Mo-O, onde as regiões de 900 a $1000 \mathrm{~cm}^{-1}$ e de 500 a 900 $\mathrm{cm}^{-1}$ são atribuídas aos estiramentos simétrico e assimétrico da ligação Mo-O, e O-Mo-O respectivamente.

Também se observou uma similaridade no perfil dos espectros de infravermelho de todos os molibdatos de terras raras estudados nesse trabalho. $\mathrm{Na}$ (TAB 5.2) estão as atribuições das bandas dos $\mathrm{TR}_{2}\left(\mathrm{MoO}_{4}\right)_{3}$. Os desdobramentos dos estiramentos v1 e v3 no espectro de acordo com Bazhenov $^{16}$,é devido a distorção da simetria tetraédrica. 


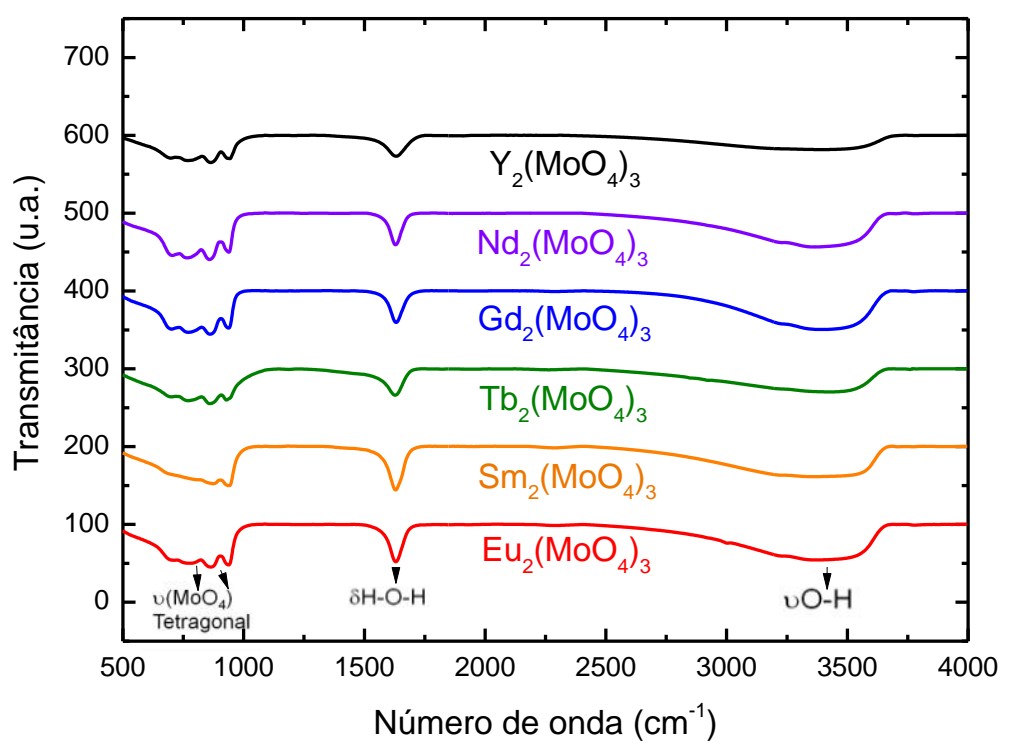

FIGURA 5.5.Espectros de infravermelho dos molibdatos de terras raras.

TABELA 5.2.Principais frequências dos modos vibracionais do molibdato de terra rara.

\begin{tabular}{l|cccc}
\hline \multirow{2}{*}{ Composto } & \multicolumn{4}{|c}{ Estiramento $\left(\mathrm{cm}^{-1}\right)$} \\
& $v 1$ & $v 1$ & $v 3$ & $v 3$ \\
\hline $\mathrm{Eu}_{2}\left(\mathrm{MoO}_{4}\right)_{3}$ & 933 & 864 & 771 & 710 \\
$\mathrm{Sm}_{2}\left(\mathrm{MoO}_{4}\right)_{3}$ & 933 & 868 & 784 & 690 \\
$\mathrm{~Tb}_{2}\left(\mathrm{MoO}_{4}\right)_{3}$ & 933 & 860 & 768 & 692 \\
$\mathrm{Gd}_{2}\left(\mathrm{MoO}_{4}\right)_{3}$ & 933 & 860 & 765 & 700 \\
$\mathrm{Nd}_{2}\left(\mathrm{MoO}_{4}\right)_{3}$ & 933 & 860 & 768 & 700 \\
$\mathrm{Y}_{2}\left(\mathrm{MoO}_{4}\right)_{3}$ & 933 & 860 & 766 & 690 \\
\hline
\end{tabular}




\subsubsection{Análise Termogravimétrica (TG/DTG)}

A termogravimetria (TG) é uma técnica na qual a perda ou o ganho de massa de uma amostra é determinado em função da temperatura e/ou do tempo. Uma análise utilizando a termogravimetria pode ser realizada de três maneiras distintas. $^{14}$

i) Termogravimetria dinâmica - A variação na massa da amostra é registrada em função da temperatura e/ou tempo, quando um programa prédeterminado é responsável pelo aumento ou diminuição da temperatura, preferencialmente a uma velocidade constante;

ii) Termogravimetria isotérmica - A massa da amostra é monitorada em função do tempo a uma temperatura constante;

iii) Termogravimetria quase-isotérmica - A amostra é aquecida a uma razão linear enquanto não ocorre variação de massa. Quando a balança detecta variação de massa, a temperatura é mantida constante até novo patamar. Este procedimento é repetido diversas vezes.

As curvas obtidas em uma análise termogravimétrica através do método dinâmico podem ser utilizadas na obtenção de dados para fins quantitativos. Em compostos de coordenação, por exemplo, pode-se estimar a quantidade de ligante que é liberado em uma determinada etapa e também o resíduo procedente dessa etapa. Esses dados podem ser determinados com o auxílio da primeira derivada da curva TG, a DTG. A curva DTG fornece a perda de massa sofrida pelas amostras proporcionais às áreas picos. Além disso, através da curva DTG, pode-se obter uma melhor visualização do início e do término de um processo de decomposição térmica, bem como ter uma informação com maior exatidão sobre o ponto de perda de águas - de hidratação e/ou coordenação - e assim determinar o número de mols de $\mathrm{H}_{2} \mathrm{O}$ que constitui o material. 
As curvas de decomposição termogravimétricas dessa dissertação foram obtidas numaTermobalança SDTA-822 (Mettler Toledo) usando amostras de aproximadamente $10 \mathrm{mg}$ em cadinho de alumina,pertencente ao Laboratório de Polímeros do Centro de Química e Meio Ambiente no IPEN, usando cadinhos de alumina com 5-10 mg de amostra, em atmosfera de nitrogênio.

As FIG.5.6 a 5.11 mostram curvas de decomposição térmica dos molibdatos de terras raras obtidos após secagem à temperatura ambiente. Na sua maioria apresentam 3 eventos que foram atribuídos a perda de águas de umidade e de água de cristalização. O primeiro evento que vai de aproximadamente 30 até $100^{\circ} \mathrm{C}$ é atribuído à perda de massa devido à evaporação da água adsorvida nos cristais, um segundo evento no intervalo de 100 a $200 \stackrel{\circ}{\circ} \mathrm{C}$ atribuiu-se à perda de água de cristalização e após essa temperatura, foi atribuída à perda de grupos de água dentro dos interstícios do cristal retidos na reação de precipitação. Analisando-se os dados de temperatura onset, o molibdato de ítrio é o mais termicamente estável $\left(359^{\circ} \mathrm{C}\right)$. Essa massa de água agregada foi da ordem de $10 \%$ o que corrobora com o fato dos materiais serem higroscópicos. Dentro deste perfil de decomposição térmica, são exceções os molibdatos de $\mathrm{Nd}$ e $\mathrm{Tb}$. O molibdato de térbio apresenta um quarto evento e o de neodímio apenas um. 


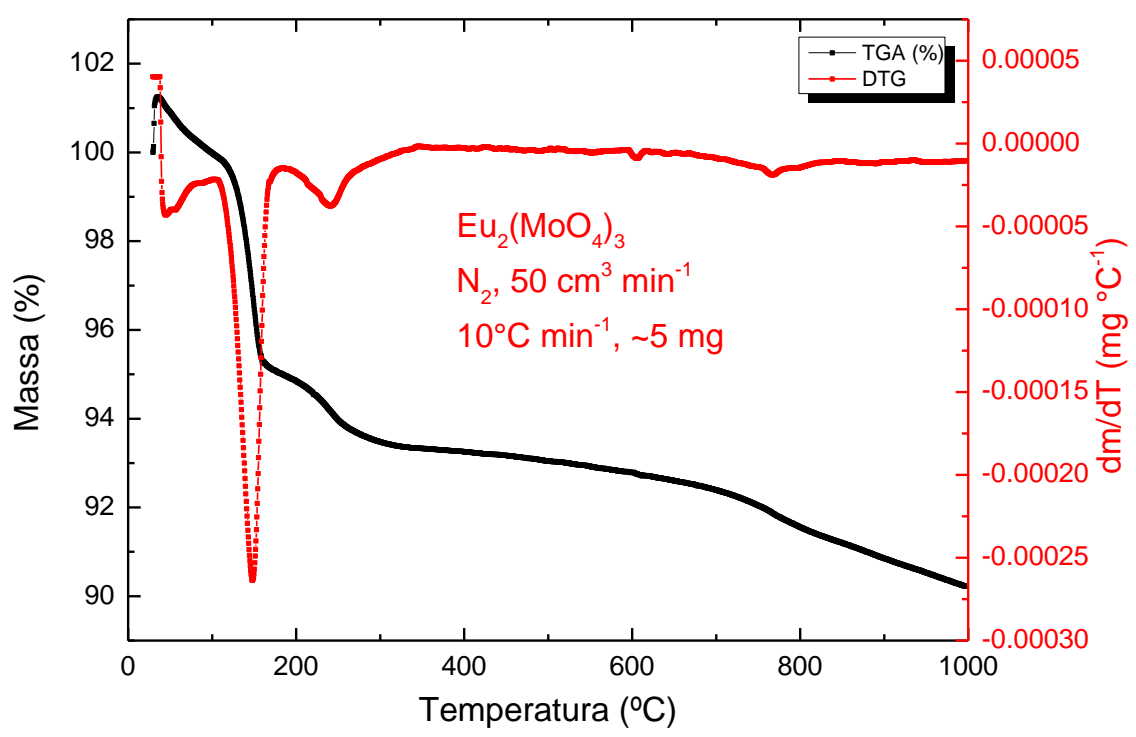

FIGURA 5.6. Curva TGA/DTG registradas no intervalo de 0 a $1000^{\circ} \mathrm{C}$, sob atmosfera dinâmica de $\mathrm{N}_{2}$ do $\mathrm{Eu}_{2}\left(\mathrm{MoO}_{4}\right)_{3}$.

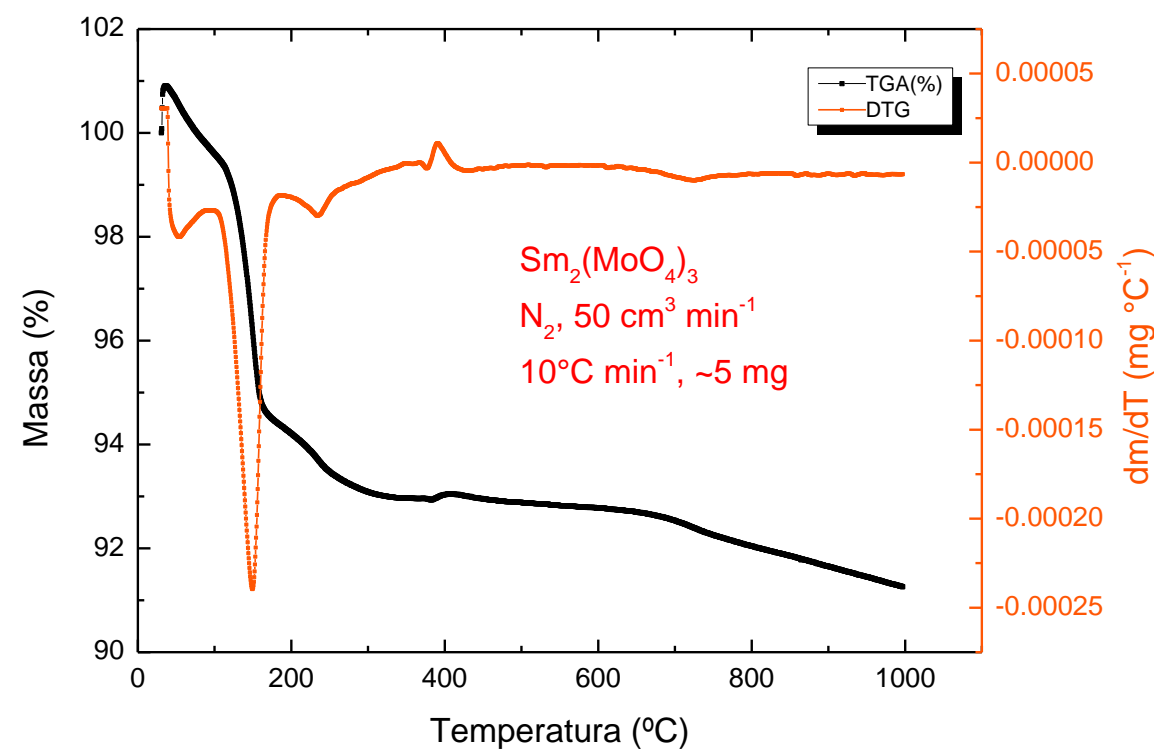

FIGURA 5.7. Curvas TGA/DTG registradas no intervalo de 0 a $1000^{\circ} \mathrm{C}$, sob atmosfera dinâmica de $\mathrm{N}_{2}$ do $\mathrm{Sm}_{2}\left(\mathrm{MoO}_{4}\right)_{3}$. 


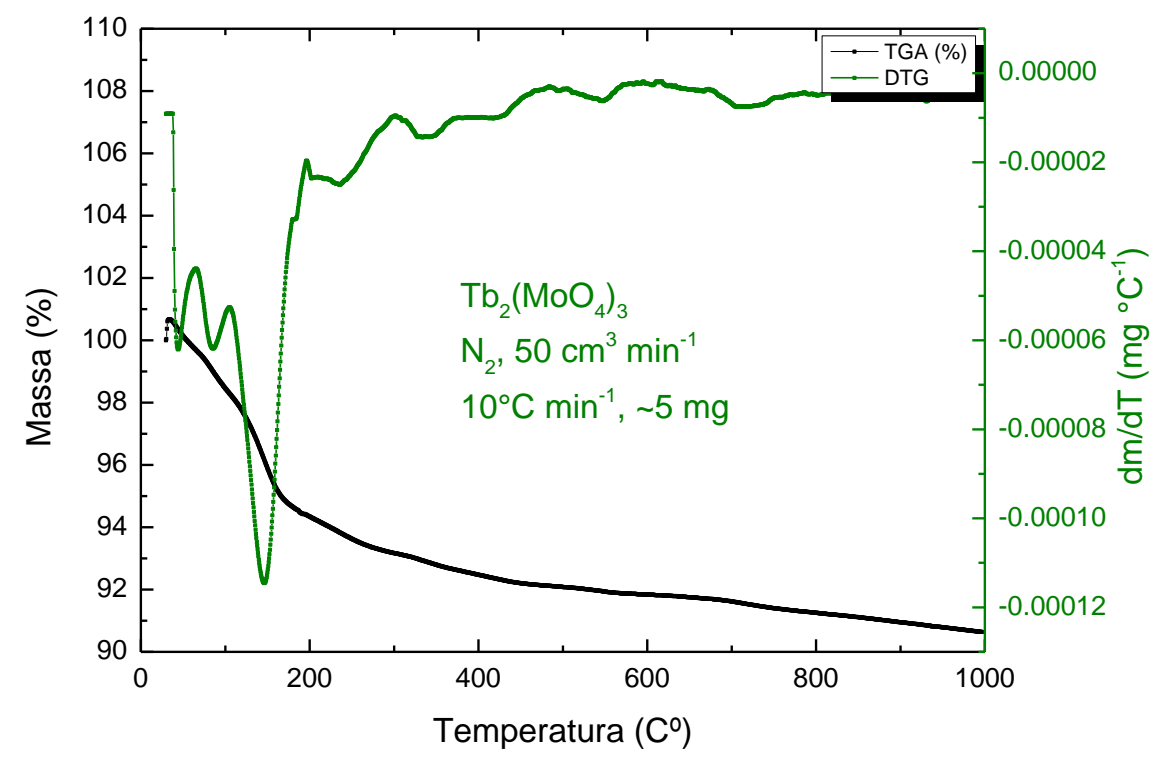

FIGURA 5.8.Curvas TGA/DTG registradas no intervalo de 0 a $1000 \stackrel{\circ}{\circ}$, sob atmosfera dinâmica de $\mathrm{N}_{2}$ do $\mathrm{Tb}_{2}\left(\mathrm{MoO}_{4}\right)_{3}$.

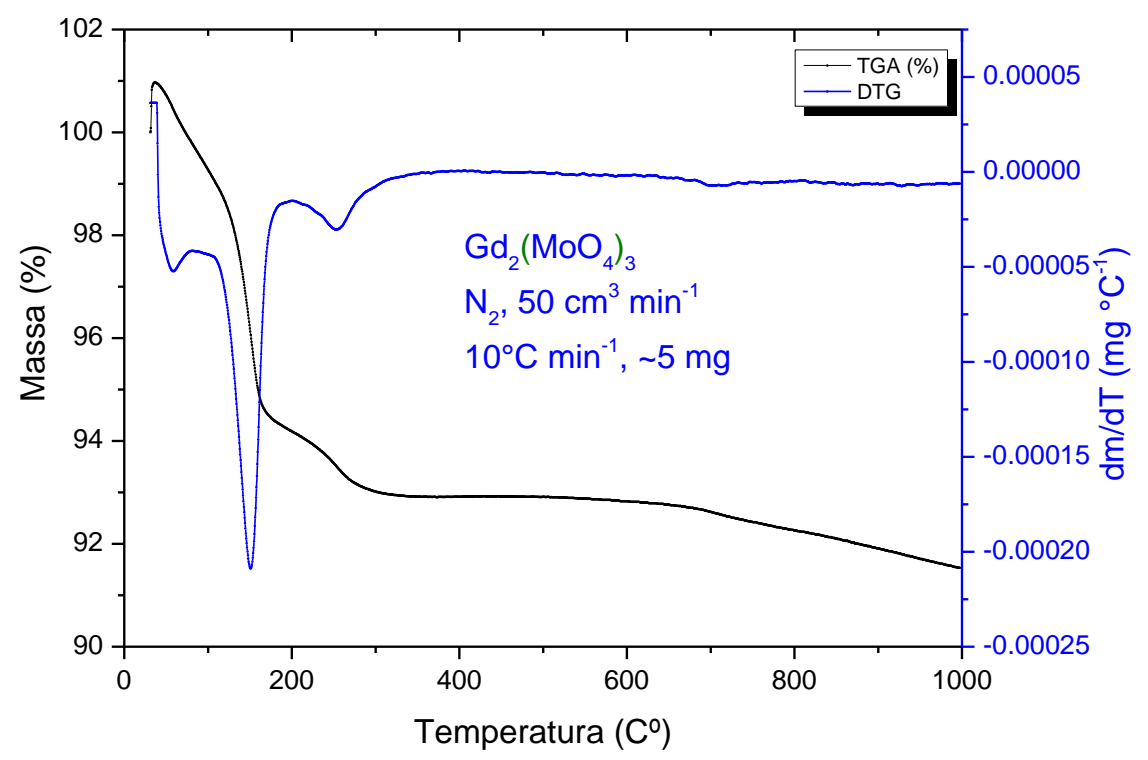

FIGURA 5.9.Curvas TGA/DTG registradas no intervalo de 0 a $1000^{\circ} \mathrm{C}$, sob atmosfera dinâmica de $\mathrm{N}_{2}$ do $\mathrm{Gd}_{2}\left(\mathrm{MoO}_{4}\right)_{3}$. 


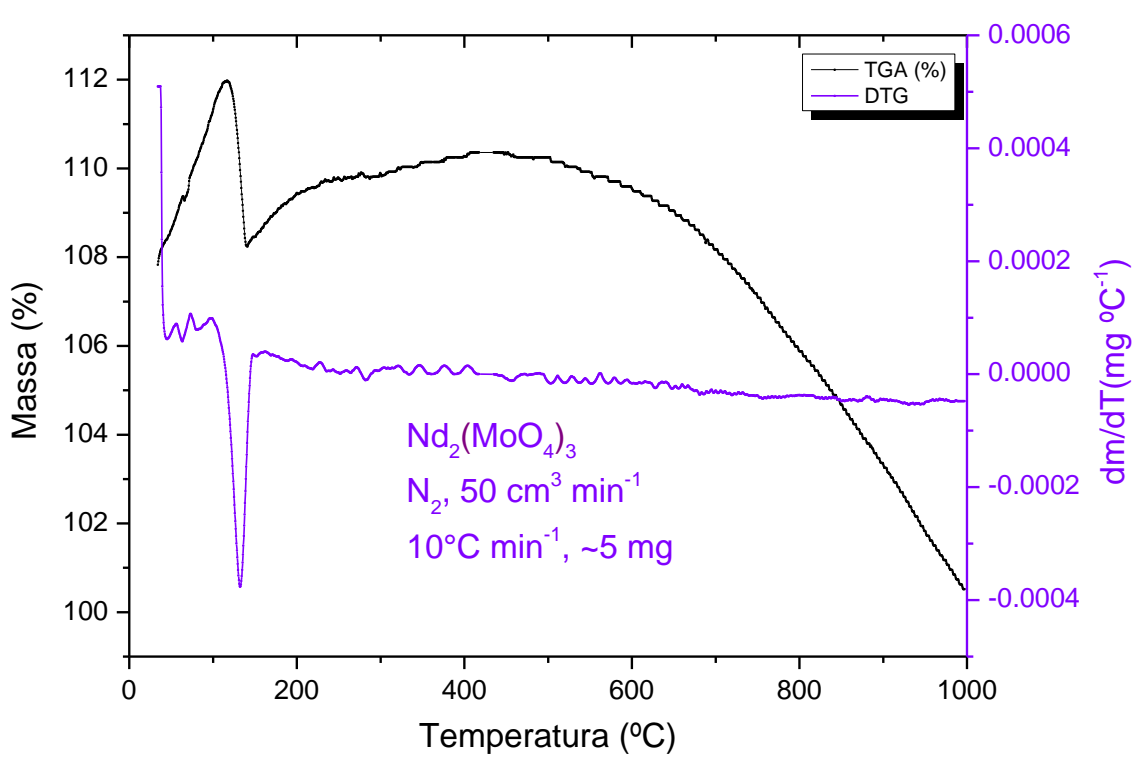

FIGURA 5.10.Curvas TGA/DTG registradas no intervalo de 0 a $1000{ }^{\circ} \mathrm{C}$, sob atmosfera dinâmica de $\mathrm{N}_{2}$ do $\mathrm{Nd}_{2}\left(\mathrm{MoO}_{4}\right)_{3}$.

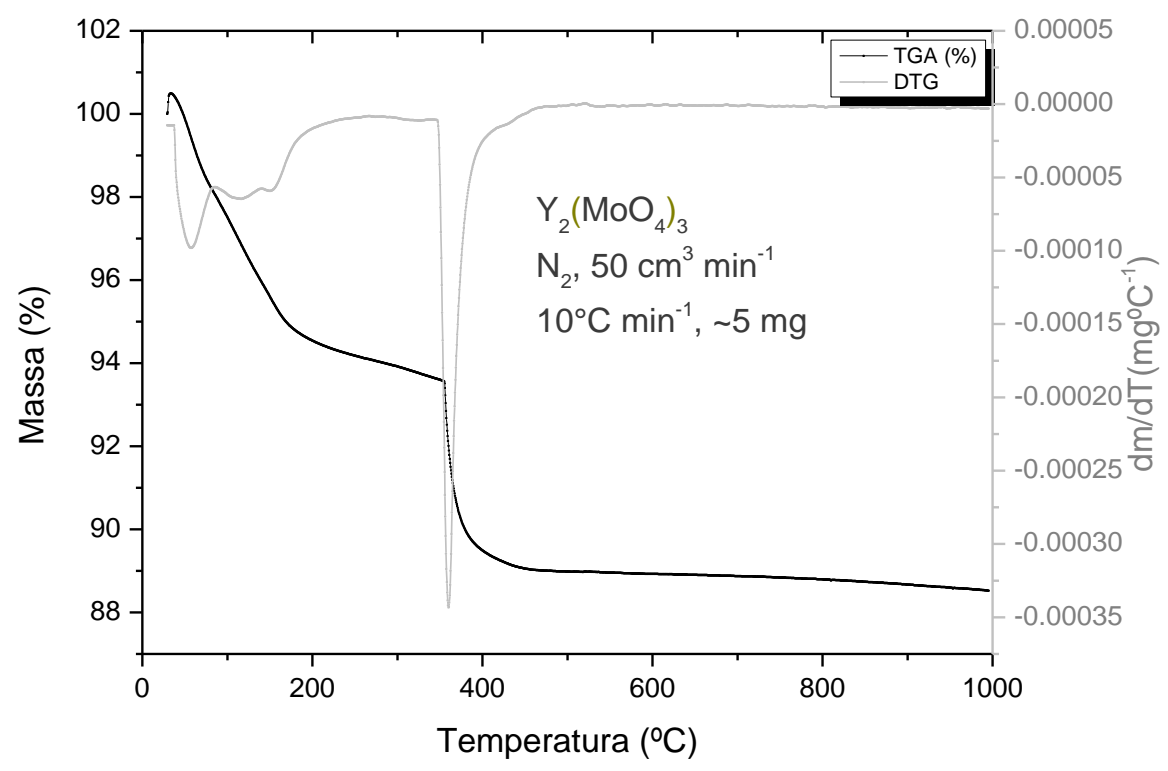

FIGURA 5.11.Curvas TGA/DTG registradas no intervalo de 0 a $1000{ }^{\circ} \mathrm{C}$, sob atmosfera dinâmica de $\mathrm{N}_{2}$ do $\mathrm{Y}_{2}\left(\mathrm{MoO}_{4}\right)_{3}$. 


\subsubsection{Difração de raios $\mathrm{X}$ - método do pó (DRX)}

A caracterização por difração de raios $\mathrm{X}$ possibilitou a análise dos fósforos quanto à cristalinidade e quanto ao cálculo do tamanho do cristalito. $O$ equipamento utilizado foi um difratômetro de raios $X$, marca Rigaku modelo MiniFlex II. Utilizou-se fonte de radiação $\operatorname{CuK}_{\alpha}(\lambda=1,54 \AA)$ e filtro de Ni. As amostras foram dispersas em lâminas de quartzo e medidas com ângulo de varredura de $5-80^{\circ}$ e velocidade de $0,05^{\circ} \mathrm{s}^{-1}$.

Através desta técnica também foi possível calcular o diâmetro do cristalito pela equação de Scherrer (equação 5.2) ${ }^{17,18}$ que está relacionado com a largura de um pico de difração de uma amostra na forma de pó com a dimensão média dos cristalitos da mesma:

$$
\Phi=\frac{K \lambda}{\beta \cos \theta}
$$

Onde: $\mathrm{K}$ é a constante que depende da forma das partículas (igual a 0,94 para partículas esféricas), $\lambda$ é o comprimento de onda da radiação em $\mathrm{nm}$, ßé a largura a meia altura da linha em radianos na escala $2 \theta$ (FWHM) e $\theta$ é o ângulo de difração. $O$ parâmetro $\beta$ foi corrigido para a largura instrumental usando a equação 5.3:

$$
\beta=\sqrt{\beta_{\exp }^{2}-\beta_{i n s t}^{2}}
$$

Onde $\beta_{\exp }$ é a largura experimental e $\beta_{\text {inst }}$ é a largura instrumental extraída de uma amostra padrão de $\mathrm{NaCl}$ ou $\mathrm{KCl}^{19}{ }^{19}$ É importante lembrar que o tamanho do cristalito não é o tamanho do agregado policristalino. Geralmente, um cristal, ou cristalito refere-se à um domínio de difração discreto que coerentemente dispersa raios $X$. 
$\mathrm{Na}$ FIG. 5.12 tem-se a estrutura ortorrômbica dos compostos $\mathrm{TR}_{2}\left(\mathrm{MoO}_{4}\right)_{3}$. Esta estrutura apresenta uma forte ligação entre os átomos que formam os tetraedros $\mathrm{MoO}_{4}$ no $\mathrm{RE}_{2}\left(\mathrm{MoO}_{4}\right)_{3}$, a estrutura desses cristais pode ser considerada como sendo composta de duas sub-redes: uma composta pelos cátions $\mathrm{RE}^{3+}$ e a outra pelos íons livres $\mathrm{MoO}_{4}{ }^{2-}$, estando ambas ocupando o sítio de simetria $C_{1}$. O Mo é coordenado por quatro íons de oxigênio $\mathrm{O}^{2-}$, formando tetraedros $\mathrm{MoO}_{4}$. Nestes cristais cada íon $\mathrm{RE}^{3+}$ é coordenado por sete átomos de oxigênio (O) formando gaiolas (cages) poliédricas, como mostrado na FIG.5.13, sendo que quatro destes átomos de oxigênio pertencem a três diferentes tetraedros $\left(\mathrm{MoO}_{4}\right)$.

Todos os poliedros compartilham seus vértices entre si e com os tetraedros formados pelos grupos $\mathrm{REO}_{7}$, para dar forma a uma rede tridimensional.

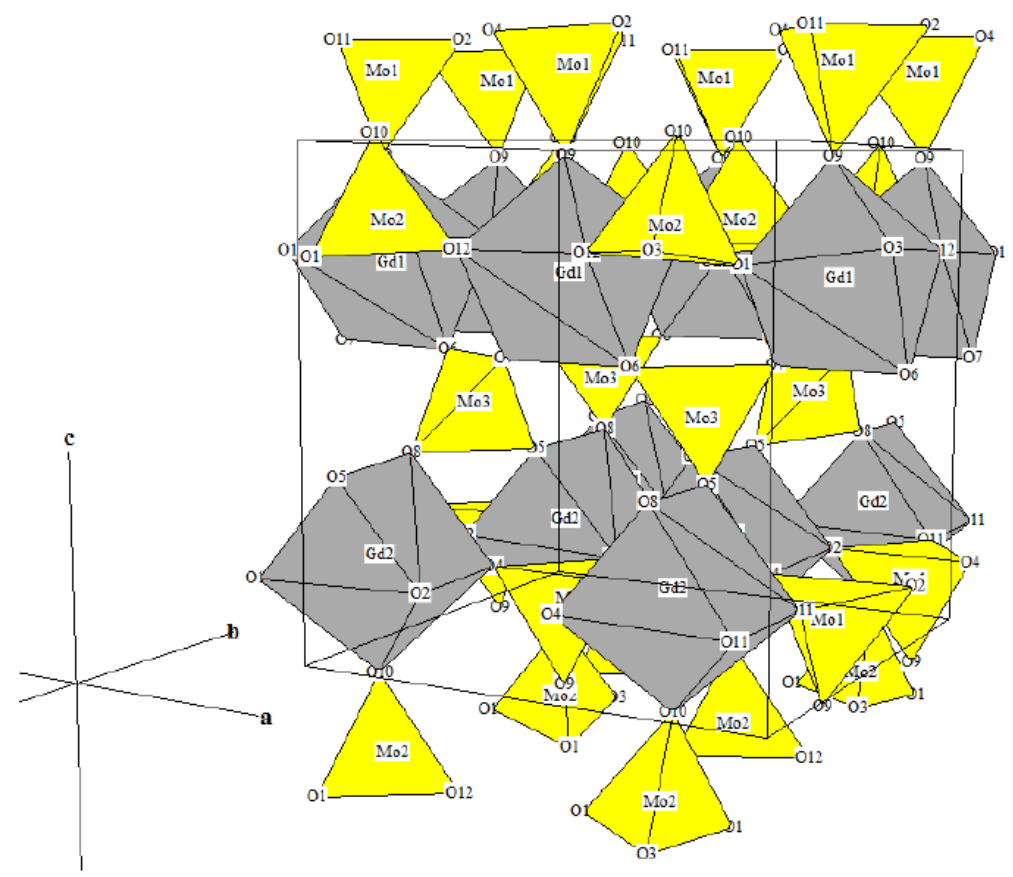

FIGURA 5.12. Estrutura ortorrômbica dos $\mathrm{TR}_{2}\left(\mathrm{MoO}_{4}\right)_{3}$. 


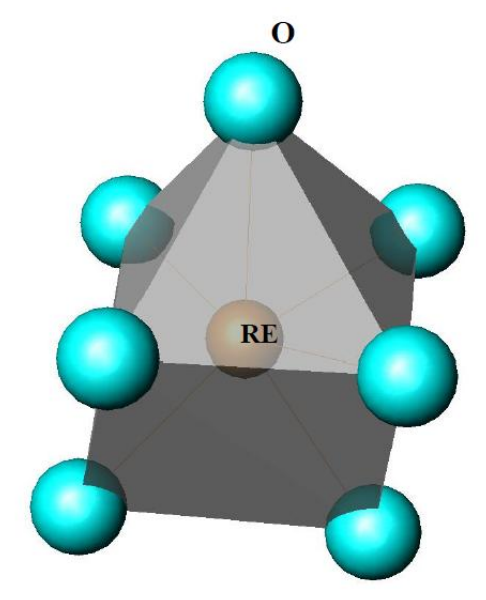

FIGURA 5.13. Poliedro formado pela estrutura cristalina $\mathrm{REO}_{7}$.

Os molibdatos trivalentes de terras raras do tipo $R E_{2}\left(M_{0} M_{4}\right)_{3}$, formam estruturas cristalinas complexas. ${ }^{20} \mathrm{Um}$ estudo estrutural compreensivo dessa série de materiais foi publicado por Nassau et al. ${ }^{21}$ Muitas dessas estruturas são derivadas da schellita, mas variam no modo como os cátions e como as vacâncias de cátions se arranjam, levando a inversões de simetria para os íons TR na matriz cristalina. A síntese hidrotermica tem sido muito usada resultando em $\mathrm{La}_{2}\left(\mathrm{MoM}_{4}\right)_{3}: \mathrm{Eu}^{3+} \mathrm{e} \mathrm{Y}_{\mathrm{x}} \mathrm{Gd}_{2-\mathrm{x}}\left(\mathrm{MoM}_{4}\right)_{3}: \mathrm{Eu}^{3+}$ com novas estruturas $\mathrm{e}$ forte luminescência, o que é atribuído a sua morfologia especial. ${ }^{22,23}$ Wanget al. ${ }^{24}$ tem preparado fósforos do tipo $\mathrm{Eu}_{x} \mathrm{Gd}_{2-x}\left(\mathrm{MoM}_{4}\right)_{3}(\mathrm{x}=0,2-2,0)$ e encontraram que a estrutura destes materiais é ortorrômbica (grupo espacial Pba2). Recentemente, Guoet al. ${ }^{25}$ reportou uma série de materiais $\operatorname{Eu}_{\mathrm{x}} \mathrm{TR}_{2-\mathrm{x}}\left(\mathrm{MoM}_{4}\right)_{3}(\mathrm{R}=\mathrm{La}, \mathrm{Y}$ e Gd) preparados pelo método sol-gel, focando especialmente na composição $x=1,2$. Wang et al. ${ }^{24}$ relatam sobre a influência da concentração de $\mathrm{Eu}^{3+}$ na estrutura e propriedades luminescentes da série $\mathrm{Eu}_{\mathrm{x}} \mathrm{Y}_{2-\mathrm{x}}\left(\mathrm{MoM}_{4}\right)_{3}(\mathrm{x}=0,4,0,8,1,2,1,4,1,6,1,8$, e 2,0) preparados por reação no estado sólido na faixa de temperatura de 700 $800{ }^{\circ} \mathrm{C}$. A estrutura cristalina destes materiais dependem da concentração do itrio e da temperatura de tratamento térmico. Eles encontraram uma mistura de estrutura monoclínica (C2/c) com ortorrômbica (Pba2, Pbna). 
Os molibdatos de TR dessa dissertação são isoestruturais com exceção feita ao neodímio. Os difratogramas da FIG.5.14 concordam com uma estrutura majoritária tetragonal com formação de fase monoclínica JCPDS. Os difratogramas mostram picos alargados para os materiais secos a temperatura ambiente. Este alargamento está relacionado com o diâmetro do cristalito. $O$ cálculo do diâmetro do cristalito foi feito usando-se a equação de Scherrer e levando-se em consideração a média dos picos mais intensos presentes no difratograma. Na TAB. 5.3 apresenta-se o valor destes diâmetros.

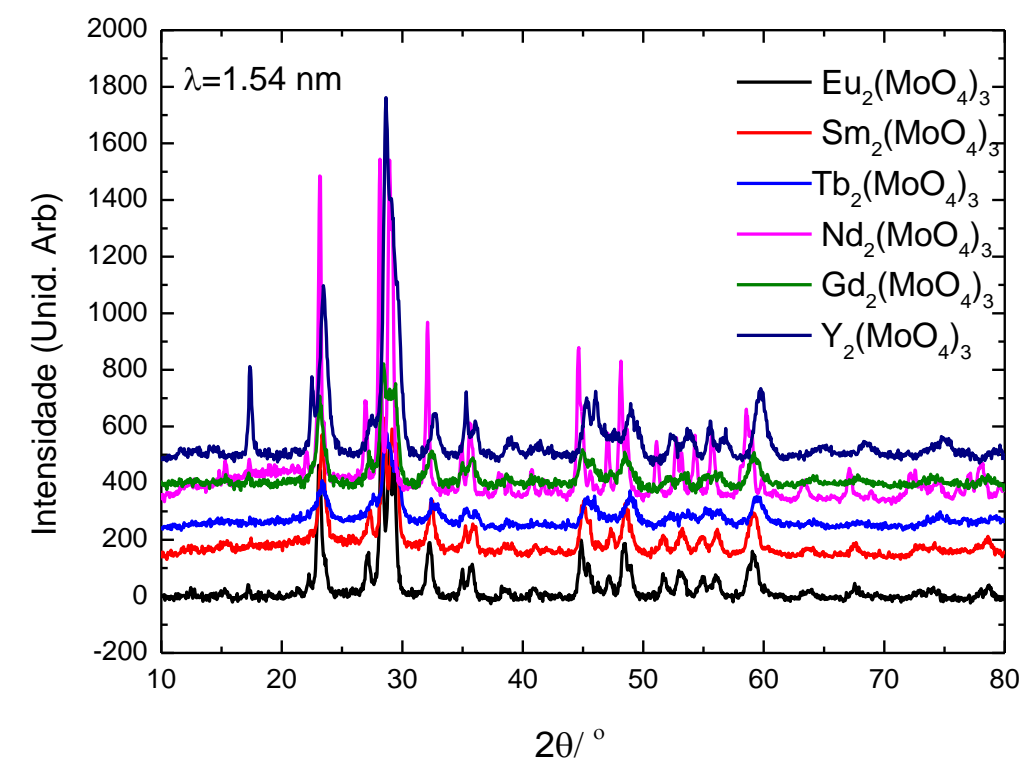

FIGURA 5.14.Difratograma de raios $X$ - método do pó dos $\mathrm{TR}_{2}\left(\mathrm{MoO}_{4}\right)_{3}$. 
TABELA 5.3. Diâmetro do cristalito calculados pela formula de Scherrer.

\begin{tabular}{l|cc}
\hline Amostras & $\begin{array}{c}\text { Diâmetro do raio do } \\
\text { íon } \mathbf{T R}^{3+} \\
(\AA)\end{array}$ & $\begin{array}{c}\text { Tamanho do } \\
\text { cristalito }(\mathrm{nm})\end{array}$ \\
\hline $\mathrm{Nd}_{2}\left(\mathrm{MoO}_{4}\right)_{3}$ & 1,109 & 21,13 \\
$\mathrm{Sm}_{\mathbf{2}}\left(\mathrm{MoO}_{4}\right)_{3}$ & 1,079 & 19,24 \\
$\mathrm{Eu}_{2}\left(\mathrm{MoO}_{4}\right)_{3}$ & 1,066 & 27,30 \\
$\mathrm{Gd}_{2}\left(\mathrm{MoO}_{4}\right)_{3}$ & 1,053 & 11,78 \\
$\mathrm{~Tb}_{2}\left(\mathrm{MoO}_{4}\right)_{3}$ & 1,040 & 6,32 \\
$\mathbf{Y}_{\mathbf{2}}\left(\mathrm{MoO}_{4}\right)_{3}$ & 0,93 & 21,10 \\
\hline
\end{tabular}

\subsubsection{Microscopia eletrônica de varredura (MEV)}

A microestrutura e tamanho de partículas dos pós sintetizados foram examinados por microscopia eletrônica de varredura. As micrografias obtidas dos molibdatos de terras raras mostram que as partículas de molibdato possuem morfologia regular para cada lantanídeo e são compostas por um grande número de camadas, diferindo no formato dos aglomerados para cada terra rara.

As micrografias de $\mathrm{Eu}_{2}\left(\mathrm{MoO}_{4}\right)_{3}$ (FIG. 5.15) apresentam pequenos aglomerados de nanopartículas, similares a flocos granulados. $\mathrm{O} \mathrm{Sm}_{2}\left(\mathrm{MoO}_{4}\right)_{3}$ difere do $\mathrm{Eu}_{2}\left(\mathrm{MoO}_{4}\right)_{3}$ tanto em tamanho dos aglomerados (sendo os últimos muito maiores), quanto em sua morfologia (característica de formato de folhas). Já para - $\mathrm{Gd}_{2}\left(\mathrm{MoO}_{4}\right)_{3}$ observa-se morfologia homogênea com tamanhos de aglomerados similares aos observados no $\mathrm{Eu}_{2}\left(\mathrm{MoO}_{4}\right)_{3}$, e com partículas na forma de flocos. $\mathrm{O}$ $\mathrm{Tb}_{2}\left(\mathrm{MoO}_{4}\right)_{3}$ apresenta granulometria homogênea com tamanho de grãos uniformes e diferenciado dos demais $\mathrm{TR}_{2}\left(\mathrm{MoO}_{4}\right)_{3}$. $\mathrm{O} \quad \mathrm{Nd}_{2}\left(\mathrm{MoO}_{4}\right)_{3}$ apresenta grandes aglomerados de nanopartículas, que levam à formação de camadas lamelares, organizados na forma de rosas. 
Resultados e discussões - Sínteses e Caracterizações
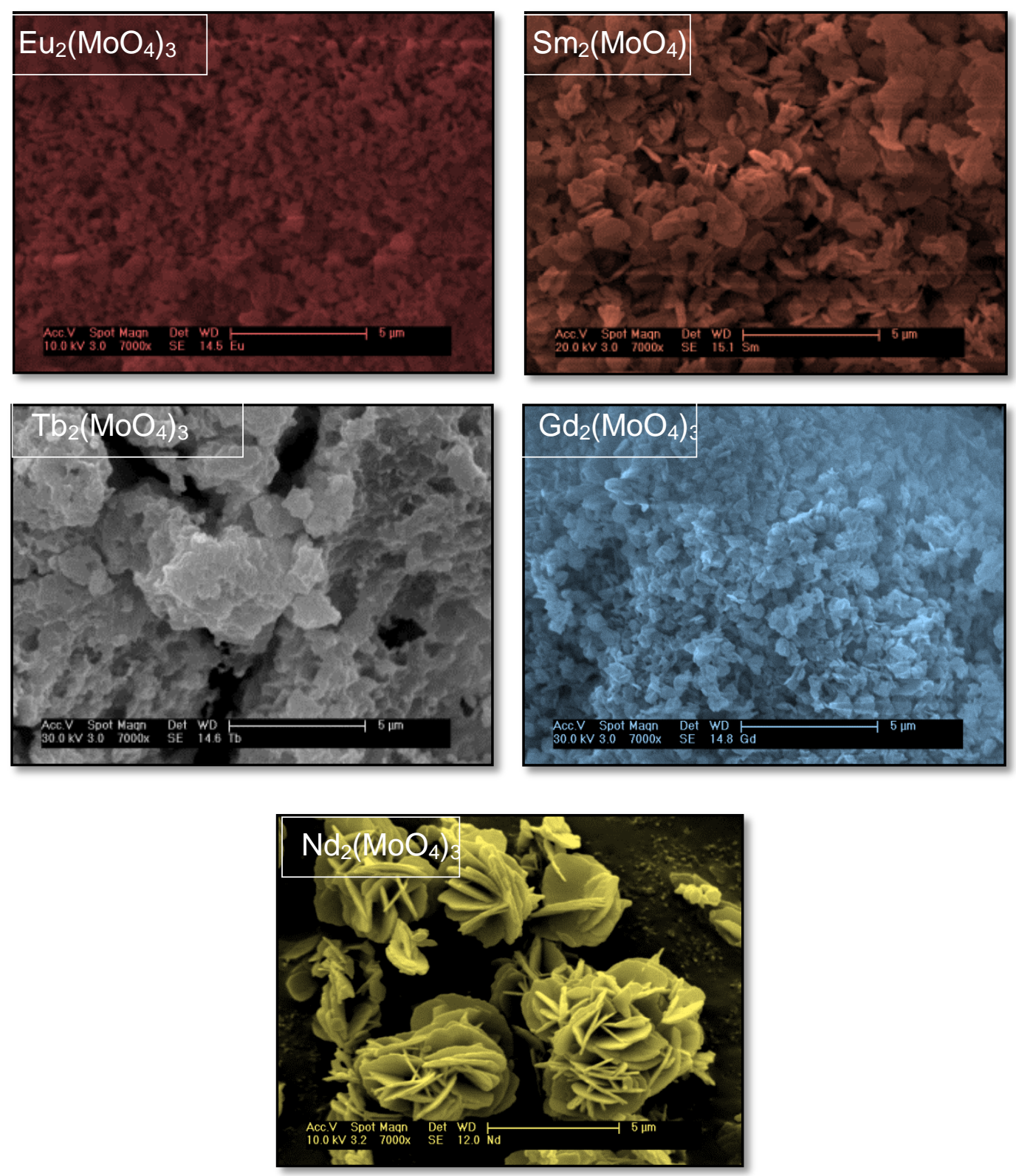

FIGURA 5.15.Micrografias dos molibdatos de terras raras.

\subsubsection{Estudo fotoluminescente dos $\operatorname{TR}_{2}\left(\mathrm{MoO}_{4}\right)_{3}$}

Os estudos de luminescência das matrizes sintetizadas pelo método de coprecipitação estão separados de acordo com o íon terra rara (európio, samário, gadolinio, ítrio, térbio e neodímio). Os íons $\mathrm{Eu}^{3+}$ e $\mathrm{Tb}^{3+}$ foram escolhidos por possuírem uma luminescência característica com emissão no vermelho e verde, 
respectivamente e são muito utilizados como marcadores biológicos, principalmente usando as técnicas de luminescência resolvida no tempo (FIA). Já o neodímio possui excitação no infravermelho próximo (NIR), região que os materiais biológicos não são excitados. Além disto, possui intensidade de emissão luminescente em torno de 1060 nm não sendo necessário o uso de técnicas de resolução no tempo para detectar a luminescência, uma vez que a intensidade pode ser registrada para concentrações muito baixas de $\mathrm{Nd}^{3+}$. A matriz também não apresenta emissão luminescente no NIR e assim não interfere na análise. O gadolínio e o ítrio foram usados para informações da matriz e o samário por apresentar luminescência pouco comum no laranja.

\subsubsection{Comportamento espectroscópico do íon $\mathrm{Gd}^{3+}$ na matriz $\mathrm{Gd}_{2}\left(\mathrm{MoO}_{4}\right)_{3}$}

O estudo de sistemas contendo o íon gadolínio trivalente vem crescendo significantemente devido a sua grande importância nas investigações espectroscópicas. No caso de complexos, estes estudos são para obter informações sobre os estados tripletos $(\mathrm{T})$ dos ligantes em compostos de európio e térbio trivalentes, por apresentarem grande semelhança nos raios iônicos das terras raras, "mimetizando" o ambiente químico em torno do íon $\mathrm{TR}^{3+}$. Neste trabalho, a função do íon $\mathrm{Gd}^{3+}$ no fósforo $\mathrm{Gd}_{2}\left(\mathrm{MoO}_{4}\right)_{3}$ é determinar as bandas das transições de transferência de carga ligante metal $\mathrm{O}^{2-}(2 \mathrm{p}) \rightarrow \mathrm{Mo}^{6+}$ e $\mathrm{O}^{2-}(2 \mathrm{p}) \rightarrow \mathrm{TR}^{3+}$ (LMCT) para as matrizes de molibdatos e dos sistemas dopados com íons terras raras, respectivamente.

Esta característica espectroscópica importante do íon $\mathrm{Gd}^{3+}$ se deve ao fato que a estrutura dos níveis de energia do íon $\mathrm{Gd}^{3+}$ apresenta uma grande diferença entre o estado fundamental $\left({ }^{8} \mathrm{~S}_{7 / 2}\right)$ e o estado excitado de menor energia ${ }^{6} \mathrm{P}_{7 / 2}$ em torno de $32000 \mathrm{~cm}^{-1} .{ }^{26}$ Considerando que qualquer banda de absorção ou emissão observada na região espectral acima de $320 \mathrm{~nm}$ em sistemas contendo o íon gadolínio, não são oriundas das transições intraconfiguracionais $4 f^{7}$ do íon $\mathrm{Gd}^{3+}$. Portanto, o uso desse íon permitirá a investigação de transições 
como por exemplo: $4 \mathrm{f}-4 \mathrm{f}$ de outro íons $\mathrm{TR}^{3+}$, interconfiguracionais $4 f^{6} 5 d^{1} \rightarrow 4 f^{7}\left({ }^{8} S_{7 / 2}\right)$ do íon $E u^{2+}$, bandas de transferência de carga ligante metal $\mathrm{O}^{2-}$ $(2 p) \rightarrow \mathrm{TR}^{3+}(\mathrm{LMCT})$ e bandas das matrizes localizadas acima $320 \mathrm{~cm}$.

Foram registrados os espectros de emissão dos fósforos $\mathrm{Gd}_{2}\left(\mathrm{MoO}_{4}\right)_{3}$ sob excitação em $360 \mathrm{~nm}$ na região espectral de 400 a $750 \mathrm{~nm}$, à temperatura ambiente (FIG.5.16). O espectro apresenta uma banda larga entre 450 e $700 \mathrm{~nm}$ com máximo em torno de $470 \mathrm{~nm}$, atribuída à emissão de defeitos semelhante ao relatado na literatura. ${ }^{27}$

O espectro mostra que a banda de emissão larga não é simétrica, e isto sugere que alguns tipos de defeitos estão participando efetivamente do processo de luminescência da matriz. $O$ formato dessa banda no espectro de luminescência é conhecido na literatura como "spread eagle"28 induzido pelo efeito Jahn-Teller no tetraedro $\left[\mathrm{MoO}_{4}\right]^{2-}$.

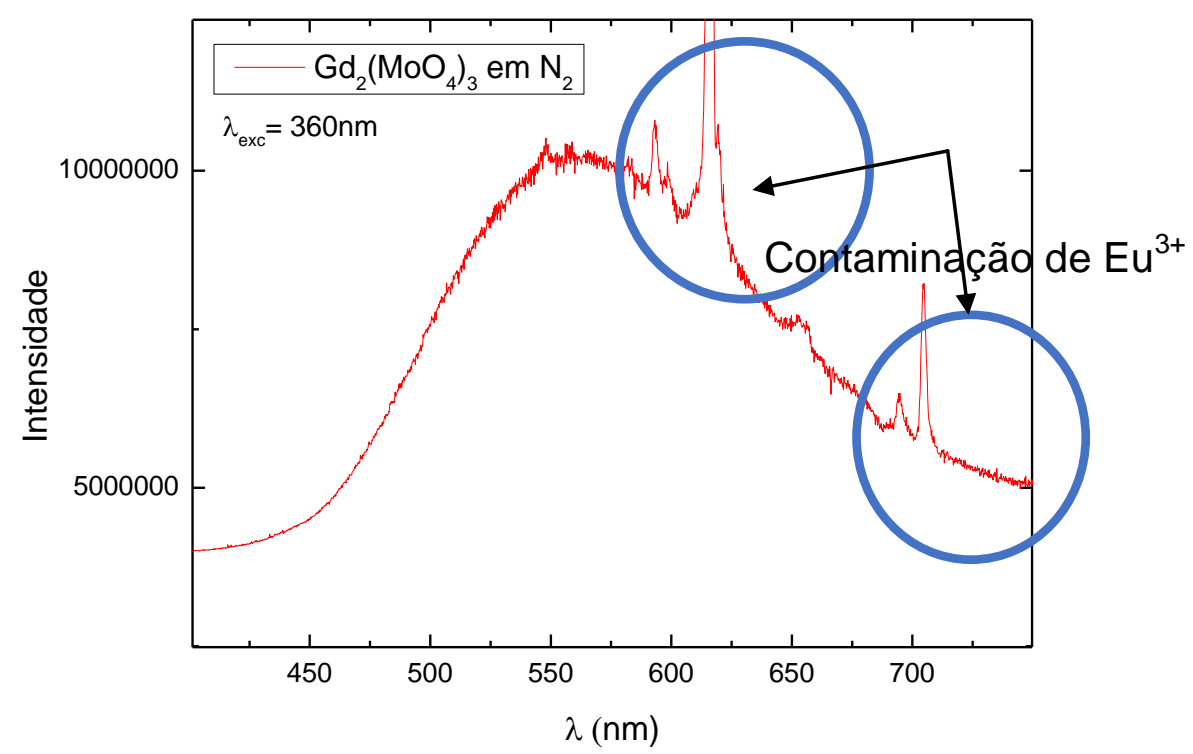

FIGURA 5.16. Espectro de emissão do $\mathrm{Gd}_{2}\left(\mathrm{MoO}_{4}\right)_{3}$. 


\subsubsection{Comportamento espectroscópico do íon $\mathrm{Y}^{3+}$ na matriz $\mathrm{Y}_{2}\left(\mathrm{MoO}_{4}\right)_{3}$}

Sistemas tetragonais ou monoclínicos $\mathrm{M}^{6+}(\mathrm{M}=\mathrm{Mo}$ ou $\mathrm{W})$ são rodeados por quatro ou seis átomos de $\mathrm{O}^{2-}$ respectivamente. Um número de coordenação alto resulta em um comprimento de ligação longo $\mathrm{M}-\mathrm{O}$ e uma banda de transferência de carga em energia baixa. Wang et al. ${ }^{24}$ e Kano et al. ${ }^{29}$ reportaram que fósforos $\mathrm{Y}_{2}\left(\mathrm{MO}_{4}\right)_{3}: \mathrm{Eu}^{3+}(\mathrm{M}=\mathrm{Mo}$ e $\mathrm{W}$ ) em sistemas tetragonais exibem a borda da banda de CT em comprimento de onda menor do que da fase monoclínica com coordenação octaédrica.

Nas FIG.5.17 e 5.18 apresentam-se os espectros de excitação e emissão da matriz $\mathrm{Y}_{2}\left(\mathrm{MoO}_{4}\right)_{3}$ registrados a temperatura ambiente. $\mathrm{O}$ espectro de excitação mostra uma banda larga com máximo de excitação em 402,7 nm que foi atribuída a transferência de energia Mo $\rightarrow$ O. Já o espectro emissão da matriz apresenta uma banda larga atribuída à fosforescência da mesma com máximo em $480 \mathrm{~nm}$.

O espectro mostra que a banda de emissão larga não é simétrica, e isto sugere que alguns tipos de defeitos estão participando efetivamente do processo de luminescência da matriz. O formato dessa banda no espectro de luminescência é conhecido na literatura como "spread eagle" ${ }^{24}$ induzido pelo efeito Jahn-Teller no tetraedro $\left[\mathrm{MoO}_{4}\right]^{2-}$. 
Resultados e discussões - Sínteses e Caracterizações

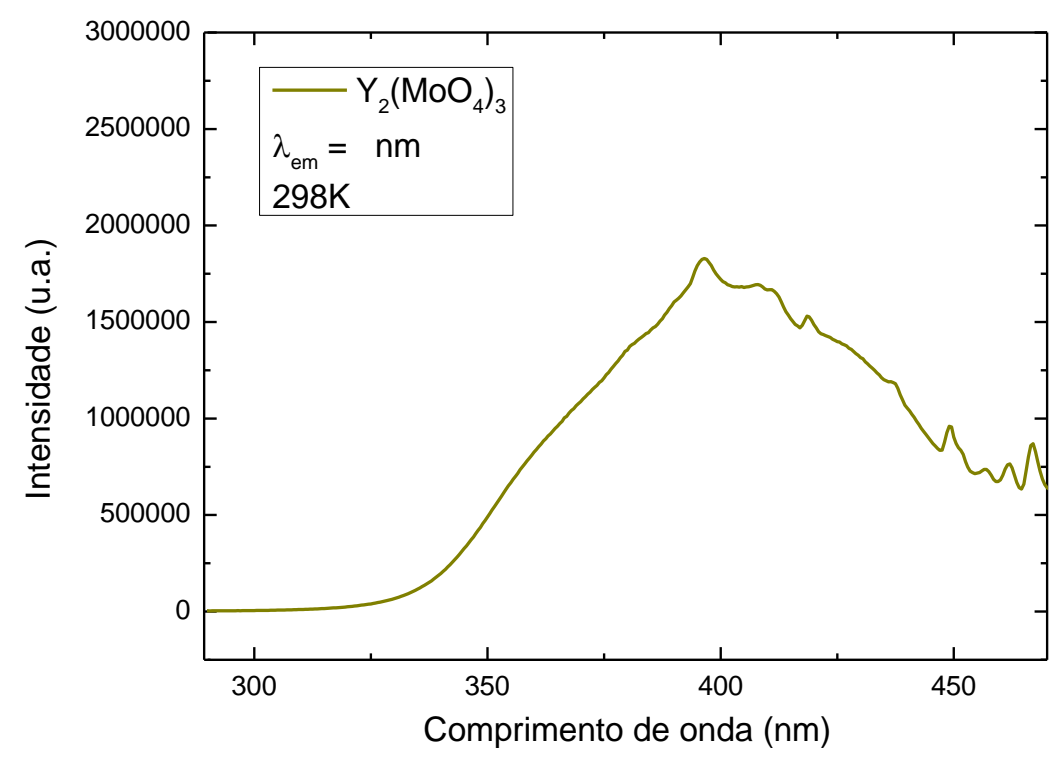

FIGURA 5.17.Espectro de excitação do $\mathrm{Y}_{2}\left(\mathrm{MoO}_{4}\right)_{3}$.

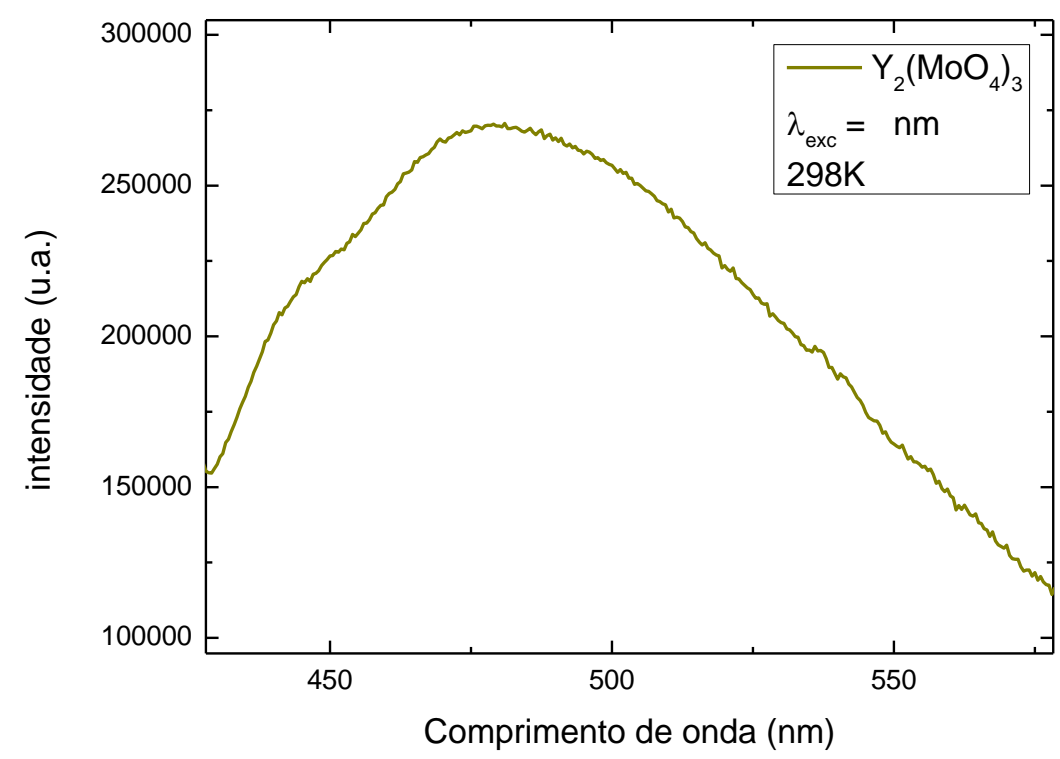

FIGURA 5.18.Espectro de emissão do $\mathrm{Y}_{2}\left(\mathrm{MoO}_{4}\right)_{3}$. 


\subsubsection{Comportamento espectroscópico do íon $\mathrm{Eu}^{3+}$ na matriz $\mathrm{Eu}_{2}\left(\mathrm{MoO}_{4}\right)_{3}$.}

Os compostos contendo o íon $\mathrm{Eu}^{3+}$ (configuração $[\mathrm{Xe}] 4 f^{6}$ ) têm sido extensivamente estudados por apresentarem alta luminescência monocromática de cor vermelha. Além disso, a partir de seus espectros de emissão podem-se obter informações sobre o desdobramento do campo ligante, processos de transferência de energia e eficiência quântica do estado emissor.

Uma das principais vantagens em usar materiais contendo íons $\mathrm{Eu}^{3+}$ é devido à facilidade de interpretação de seus espectros comparados com complexos contendo outros íons terras raras (por exemplo: $\mathrm{Tb}^{3+}$ ). $\mathrm{O}$ íon $\mathrm{Eu}^{3+}$ possui o estado emissor ${ }^{5} \mathrm{D}_{0}$ não degenerado, ao contrário do íon $\mathrm{Tb}^{3+}$ que possui nível emissor ${ }^{5} D_{4}$ e pode se desdobrar em nove componentes, tornando a análise dos espectros muito complexa. Além disso, quando a transição ${ }^{5} D_{0} \rightarrow{ }^{7} F_{0}$ do íon $\mathrm{Eu}^{3+}$ é observada, esta apresenta um único pico para um dado sítio de simetria e consequentemente propicia ao íon $\mathrm{Eu}^{3+}$ um caráter de sonda local sendo uma ferramenta útil para informações sobre a heterogeneidade de coordenação ao redor do íon $\mathrm{Eu}^{3+} .30$

A intensidade da transição ${ }^{5} \mathrm{D}_{0} \rightarrow{ }^{7} \mathrm{~F}_{1}$ não é influenciada pelo ambiente químico (mecanismo de dipolo magnético) e pode ser usado como transição de referência interna. Por outro lado, a transição ${ }^{5} D_{0} \rightarrow{ }^{7} F_{2}$ é hipersensível ao ambiente químico ao redor do íon $\mathrm{Eu}^{3+}$, e este fator pode fornecer informações sobre a primeira esfera de coordenação deste íon. Além disso, o íon $\mathrm{Eu}^{3+}$ também apresenta tempo de vida luminescente longo para 0 nível emissor ${ }^{5} \mathrm{D}_{0}$ (milisegundos) e deslocamento Stokes grande quando os espectros de emissão são obtidos por excitação direta da transição ${ }^{7} \mathrm{~F}_{0} \rightarrow{ }^{5} \mathrm{~L}_{6}$ a $394 \mathrm{~nm} \cdot{ }^{30}$

Uma vez que as bandas de emissão do íon $\mathrm{Eu}^{3+}$ na região do visível são de fácil interpretação, devido à estrutura dos seus níveis de energia, este íon tem sido utilizado como sonda espectroscópica na obtenção de valiosas informações em sistemas bioinorgânicos, tais como: i) a determinação do número de ambientes químicos ao redor do íon $\mathrm{Eu}^{3+}$ através do número de bandas 
relativo à transição ${ }^{5} \mathrm{D}_{0} \rightarrow{ }^{7} \mathrm{~F}_{0}$; ii) Constante de ligação dos íons biomolécula- $\mathrm{Eu}^{3+}$, determinada por curvas de titulação e iii) distância doador-receptor (R), normalmente assumindo o mecanismo de acoplamento dipolo-dipolo fraco.

Os espectros de excitação do $\mathrm{Eu}_{2}\left(\mathrm{MoO}_{4}\right)_{3}$ foram registrados no intervalo de 240 a 594 nm, com emissão monitorada na transição hipersensível ${ }^{5} \mathrm{D}_{0} \rightarrow{ }^{7} \mathrm{~F}_{2}(\sim 614 \mathrm{~nm})$ a temperatura ambiente e do $\mathrm{N}_{2}$ (FIG.5.19).

Para o espectro a 298 K (FIG.5.19) observou-se uma banda de baixa intensidade na região de 298 a 350 nm atribuída à Transferência de Carga do Ligante para o Metal (LMCT) do $\mathrm{O} \rightarrow \mathrm{Mo}$ e $\mathrm{O} \rightarrow \mathrm{Eu}^{3+}$, respectivamente. As bandas fixas em aproximadamente 361; 375, 393, 414, 464, 533, 525 e 578 nm correspondem às transições ${ }^{7} \mathrm{~F}_{0} \rightarrow{ }^{5} \mathrm{D}_{\mathrm{J}},{ }^{5} \mathrm{~L} \mathrm{~J}$, do íon $\mathrm{Eu}^{3+}$.

Nos espectros registrados a 77 K (FIG 5.19) observou-se a intensificação da banda larga centrada em $\sim 311 \mathrm{~nm}$ atribuída a banda de condução do $\mathrm{SnO}_{2}$. O espectro de excitação da matriz sem dopagem, obtido em 298 K, nas mesmas condições, está representado na figura FIG 5.19.

Fósforos dopados com európio foram registrados no intervalo de 240 a $594 \mathrm{~nm}$, com emissão monitorada na transição hipersensível ${ }^{5} D_{0} \rightarrow{ }^{7} F_{2}(\sim 614 \mathrm{~nm})$ (FIG. 5.19).

Para o espectro a 298 K (FIG. 5.19) observou-se uma banda de baixa intensidade na região de 250 a 350 nm atribuída à Transferência de Carga do Ligante para o Metal (LMCT) do $\mathrm{O} \rightarrow \mathrm{Mo} \mathrm{e} \mathrm{O} \rightarrow \mathrm{Eu}^{3+}$, respectivamente. As bandas fixas em aproximadamente 361; 367, 373, 376,384, 394,409, 416, 464, 473, 486, 526,534 , e $539 \mathrm{~nm}$ correspondem às transições ${ }^{7} \mathrm{~F}_{0} \rightarrow{ }^{5} \mathrm{D}_{\mathrm{J}},{ }^{5} \mathrm{~L}$, do íon $\mathrm{Eu}^{3+}$.

Nos espectros registrados a 77 K (FIG 5.19) observou-se a intensificação da banda larga centrada em $290 \mathrm{~nm}$ atribuída a Transferência de Carga do Ligante para o Metal (LMCT) do $\mathrm{O} \rightarrow \mathrm{Mo}$ e $\mathrm{O} \rightarrow \mathrm{Eu}^{3+}$. 
Na FIG.5.20 apresentam-se os espectros de emissão do luminóforo $\mathrm{Eu}_{2}\left(\mathrm{MoO}_{4}\right)_{3}$ a $298 \mathrm{~K}$ e $77 \mathrm{~K}$. Os espectros de emissão foram obtidos com excitação monitorada no íon $\mathrm{Eu}^{3+}$ ( $394 \mathrm{~nm}$ ) e foram registrados na região do visível, no intervalo de 420 a $750 \mathrm{~nm}$.

Na região do espectro em aproximadamente $578-750 \mathrm{~nm}$ observam-se picos correspondentes às transições intraconfiguracionais ${ }^{5} D_{0} \rightarrow{ }^{7} F_{0-4}$. Estes espectros apresentam também bandas provenientes dos níveis emissores ${ }^{5} D_{J}(J$ $=0$ e 1) $450-570$.

O espectro do $\mathrm{Eu}_{2}\left(\mathrm{MoO}_{4}\right)_{3}$ apresenta um único pico na região de $\sim 579$ $\mathrm{nm}$ correspondente a transição ${ }^{5} \mathrm{D}_{0} \rightarrow{ }^{7} \mathrm{~F}_{0}$ de baixíssima intensidade indicando a distorção de uma simetria tetragonal em torno de íon terra rara (FIG. 5.20) mostrando a ineficiência do processo de mistura dos $\mathrm{Js}(\mathrm{J}=0$ a 4$) .{ }^{30} \mathrm{O}$ espectro registrado a temperatura do nitrogênio líquido embora tenha um mesmo perfil apresenta uma melhor resolução e intensificação da transição ${ }^{5} \mathrm{D}_{0} \rightarrow{ }^{7} \mathrm{~F}_{0}$.

Foi observada também a presença de bandas relativas à transição ${ }^{5} \mathrm{D}_{0} \rightarrow{ }^{7} \mathrm{~F}_{1}$, permitidas por dipolo magnético, onde se observa o desdobramento em duas componentes na região entre 590 a $600 \mathrm{~nm}$. Enquanto que a transição hipersensível ${ }^{5} \mathrm{D}_{0} \rightarrow{ }^{7} \mathrm{~F}_{2}$ (permitida por dipolo elétrico forçado), na faixa de 610 a $630 \mathrm{~nm}$ apresenta apenas duas componente desobedecendo à regra de $(2 \mathrm{~J}+1)$ componentes evidenciando que o íon európio encontra-se em ambiente químico de simetria alta. É importante frisar que o valor da relação entre as intensidades das transições ${ }^{5} \mathrm{D}_{0} \rightarrow{ }^{7} \mathrm{~F}_{2}$ e ${ }^{5} \mathrm{D}_{0} \rightarrow{ }^{7} \mathrm{~F}_{1}$ é relativamente grande indicando que estes compostos não são centros simétricos. Segundo o esquema apresentado por Jia ${ }^{31}$ para as transições intraconfiguracionais ${ }^{5} \mathrm{D}_{0} \rightarrow{ }^{7} \mathrm{~F}_{\mathrm{J}}$ do íon $\mathrm{Eu}^{3+}$ ilustrado na FIG. 5.20 o sistema $\mathrm{Eu}_{2}\left(\mathrm{MoO}_{4}\right)_{3}$ pertence ao grupo $\mathrm{C}_{6 \mathrm{~V}}$ ou $\mathrm{C} 6$. 


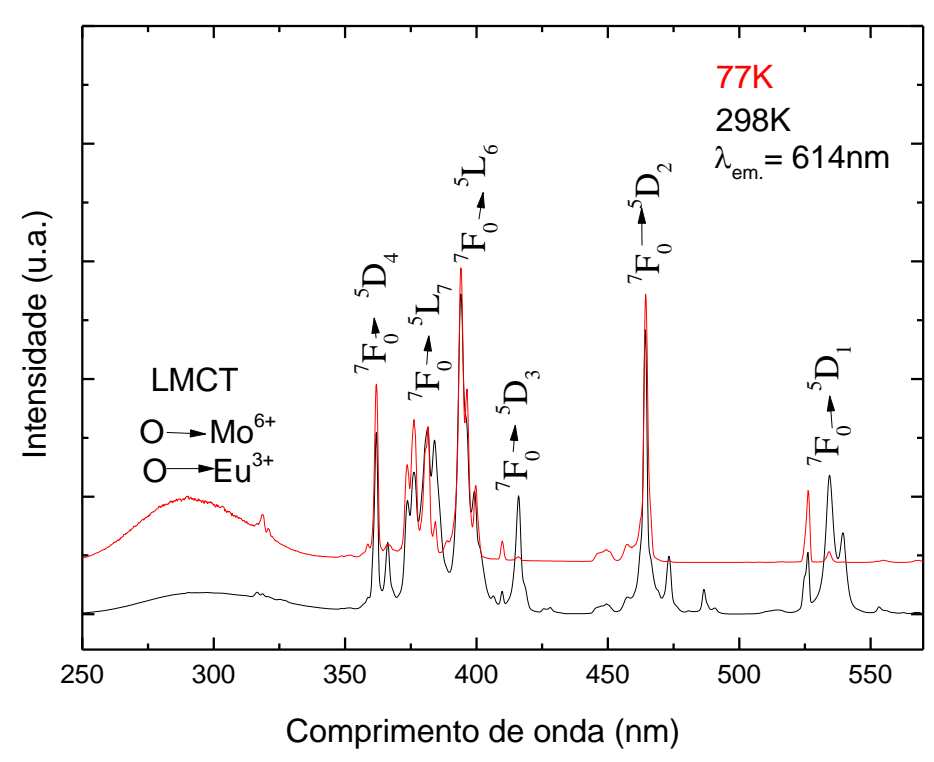

FIGURA 5.19.Espectro de excitação do $\mathrm{Eu}_{2}\left(\mathrm{MoO}_{4}\right)_{3}$.

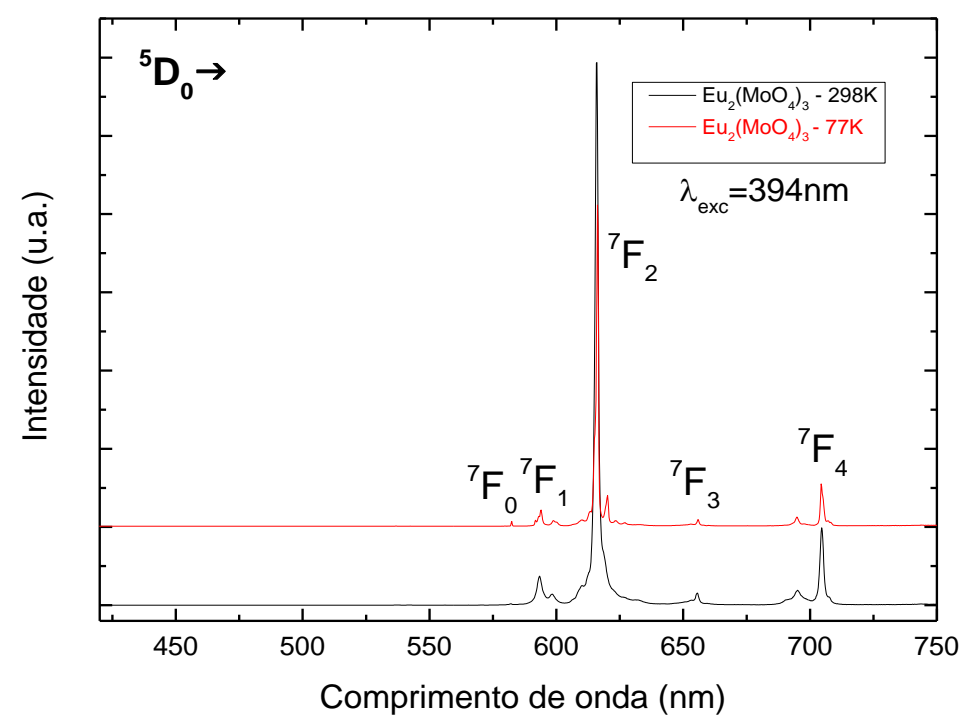

FIGURA 5.20. Espectro de emissão do $\mathrm{Eu}_{2}\left(\mathrm{MoO}_{4}\right)_{3}$. 


\subsubsection{Parâmetros de intensidade}

A intensidade de luminescência (I) das transições provenientes do nível emissor ${ }^{5} D_{0}$ para os níveis ${ }^{7} F_{J},(J=0-4)$ do íon $\mathrm{Eu}^{3+}$, pode ser expressa pela equação 5.4, onde: $\hbar \omega_{0}$ é a energia da transição $\left(\mathrm{em} \mathrm{cm}^{-1}\right), A_{0 \rightarrow J}$ é o coeficiente de emissão espontânea de Einstein e $N_{0}$ é a população do nível emissor $\left({ }^{5} D_{0}\right)$.

$$
\mathrm{I}_{0 \rightarrow \mathrm{J}}=\hbar \omega_{0 \rightarrow \mathrm{J}} \mathrm{A}_{0 \rightarrow \mathrm{J}} \mathrm{N}_{0}
$$

A determinação experimental do coeficiente de emissão espontânea $\left(A_{0 \rightarrow J}\right)$, é feita a partir dos espectros de emissão utilizando-se a transição permitida por dipolo magnético ${ }^{5} \mathrm{D}_{0} \rightarrow{ }^{7} \mathrm{~F}_{1}$, que formalmente é insensível ao ambiente do campo ligante do composto de $\mathrm{Eu}^{3+}$, podendo ser usada como uma transição de referência. ${ }^{32} \mathrm{O}$ valor de $\mathrm{A}_{0 \rightarrow \mathrm{J}}$ para transições de dipolo elétrico forçado é dado pela equação 5.5 :

$$
A_{J J^{\prime}}=\frac{4 e^{2} \omega^{3}}{3 \hbar c^{3}} \frac{1}{2 J+1} \chi \sum_{\lambda} \Omega_{\lambda}\left\langle{ }^{5} D_{0}\left\|U^{(\lambda)}\right\|^{7} F_{J}\right\rangle^{2}
$$

Onde: $\omega$ é a freqüência angular da transição $\alpha J \rightarrow \alpha$ 'J', e é a carga do elétron, c é a velocidade da luz, $\chi$ é o fator de correção de campo local de Lorentz, dado por $\left[\eta_{0}\left(\eta_{0}^{2}+2\right)^{2} / 9\right]$ em que $n_{0}$ é o índice de refração do meio (no sistema estudado utilizou-se $\eta_{0}=1,5$ que é o índice de refração do $\left.\mathrm{MoO}_{2}\right) .{ }^{33,34,35,36} \mathrm{O}$ termo $\left\langle{ }^{5} D_{0}\left\|U^{(\lambda)}\right\|{ }^{7} F_{J}\right\rangle^{2}$ representa os elementos de matriz reduzido ao quadrado e são tabelados na literatura, cujo os valores são 0,0032 para $\mathrm{J}=2 ; 0,0023$ para $\mathrm{J}=4$ e 0,0002 para $\mathrm{J}=6 .{ }^{37}$

Os parâmetros de intensidade experimentais $\Omega_{\lambda}(\lambda=2,4$ e 6$)$, também chamados de parâmteros de Judd-Ofelt, e que este ano completam 50 anos da teoria, possuem contribuições dos mecanismos de dipolo elétrico e acoplamento 
dinâmico. ${ }^{38,39}$ Estes parâmetros são determinados experimentalmente por meio das intensidades das respectivas transições ${ }^{5} \mathrm{D}_{0} \rightarrow{ }^{7} \mathrm{~F}_{\jmath}$ do íon $\mathrm{Eu}^{3+}{ }^{32}$

Os coeficientes $A_{0 \rightarrow J}$ apresentam uma relação direta com os elementos de matriz reduzidos, consequentemente, os parâmetros de intensidade $\Omega_{2}, \Omega_{4} \mathrm{e}$ $\Omega_{6}$ também podem ser determinados a partir dos respectivos valores de coeficientes de emissão espontânea (A) de acordo com a equação 5.6:

$$
\Omega_{\lambda}=\frac{4 \mathrm{e}^{2} \omega^{3} \mathrm{~A}_{0 \rightarrow \lambda}}{3 \hbar \mathrm{c}^{3} \chi\left\langle{ }^{7} \mathrm{~F}_{\lambda}\left\|\mathrm{U}^{(\lambda)}\right\|^{5} \mathrm{D}_{0}\right\rangle^{2}}
$$

Neste trabalho, não será considerado o valor de $\Omega_{6}$, uma vez que a transição ${ }^{5} \mathrm{D}_{0} \rightarrow{ }^{7} \mathrm{~F}_{6}$ não foi registrada.

O tempo de vida e as taxas de decaimento não radiativos $\left(A_{\text {nrad }}\right)$ e radiativos $\left(A_{r a d}\right)$ se relacionam através da equação 5.7 , onde $A_{\text {rad }}$ é obtido pela somatória das taxas radiativas $\mathrm{A}_{0\lrcorner}$ para cada transição $0^{5} \mathrm{D}_{0} \rightarrow^{7} \mathrm{~F}_{J}\left(A_{\text {rad }}=\sum_{J} A_{0 J}\right)$.

$$
A_{\text {total }}=\frac{1}{\tau}=A_{\text {rad }}+A_{\text {nrad }}
$$

A eficiência quântica do nível emissor ${ }^{5} \mathrm{D}_{0}$ pode ser obtida através da equação 5.8:

$$
\eta=\frac{A_{\text {rad }}}{A_{\text {rad }}+A_{\text {rad }}}
$$

Com base nos dados espectrais e nas equações foram determinados os tempos de vida $(\tau)$, os parâmetros de intensidade experimentais $\left(\Omega_{2}\right.$ e $\left.\Omega_{4}\right)$, as taxas radiativas e não-radiativas ( $A_{r a d}$ e $A_{n r a d}$ ) e a eficiência quântica $(\eta)$ do nível emissor ${ }^{5} D_{0}$, determinado para o molibdato de európio em $298 \mathrm{~K}$ e estão representados na TAB.5.4 como pode ser observado, os valores do parâmetro de 
Resultados e discussões - Sínteses e Caracterizações

intensidade $\Omega_{2}$ são equivalentes aos de outras matrizes estudadas pelo grupo ou menores do que para complexos. ${ }^{40-45}$ Esses dados indicam que o íon $\mathrm{Eu}^{3+}$ nessa matriz encontra-se em um ambiente químico menos polarizável.

TABELA 5.4.Parâmetros de intensidade experimentais $\left(\Omega_{\lambda}\right)^{46}$, taxas não radiativas $\left(A_{\text {nrad }}\right)$, radiativas $\left(A_{\text {rad }}\right)$ e totais $\left(A_{\text {total }}\right)$, tempo de vida $(T)$, eficiência quântica de emissão ( $\eta$, para os sistemas $\mathrm{MWO}_{4}: \mathrm{Eu}^{3+},\left(\mathrm{M}^{2+}: \mathrm{Ca}, \mathrm{Sr}, \mathrm{Ba}\right)$ à temperatura ambiente.

\begin{tabular}{|c|c|c|c|c|c|c|c|c|}
\hline Fósforos & $\begin{array}{l}\Omega_{2\left(10^{-}\right.} \\
\left.{ }^{20} \mathrm{~cm}^{2}\right)\end{array}$ & $\begin{array}{l}\Omega_{4\left(10^{-}\right.} \\
\left.{ }^{20} \mathrm{~cm}^{2}\right)\end{array}$ & $\begin{array}{l}\Omega_{6\left(10^{-}\right.} \\
\left.{ }^{20} \mathrm{~cm}^{2}\right)\end{array}$ & $\begin{array}{c}A_{\text {rad }} \\
\left.s^{-1}\right)\end{array}$ & $\begin{array}{l}A n_{\text {ra }} \\
d\left(s^{-1}\right)\end{array}$ & $\begin{array}{l}A_{\text {totol }} \\
\left(\mathbf{s}^{-1}\right)\end{array}$ & $t_{1 / 2}(m s)$ & (\%) \\
\hline $\begin{array}{l}\mathrm{Eu}_{2}\left(\mathrm{MoO}_{4}\right)_{3} \\
(2500 \mathrm{rpm})\end{array}$ & 14 & 10 & - & 622 & 2015 & 2637 & 0.337 & 24 \\
\hline $\begin{array}{c}\mathrm{CaWO}_{4}: \mathrm{Eu}^{3+} \\
0,1 \%\end{array}$ & 7 & 6 & 29 & 54 & 35 & 389 & 0,72 & 3 \\
\hline $\begin{array}{c}\mathrm{CaWO}_{4}: \mathrm{Eu}^{3+} \\
5,0 \%\end{array}$ & 5 & 0 & 8 & 82 & 757 & 439 & 0,41 & 8 \\
\hline $\begin{array}{c}\mathrm{CaWO}_{4}: \mathrm{Eu}^{3+} \\
10 \%\end{array}$ & 6 & 1 & 4 & 94 & 937 & 632 & 0,38 & 6 \\
\hline $\begin{array}{c}\mathrm{SrWO}_{4}: \mathrm{Eu}^{3+} \\
0,1 \%\end{array}$ & 9 & & 32 & 27 & 07 & 235 & 0,81 & 4 \\
\hline $\begin{array}{c}\mathrm{SrWO}_{4}: \mathrm{Eu}^{3+} \\
5,0 \%\end{array}$ & 4 & 1 & 9 & 36 & 189 & 825 & 0,55 & 5 \\
\hline $\begin{array}{c}\mathrm{SrWO}_{4}: \mathrm{Eu}^{3+} \\
10 \%\end{array}$ & 6 & 1 & 2 & 12 & 40 & 552 & 0,64 & 6 \\
\hline $\begin{array}{c}\mathrm{BaWO}_{4}: \mathrm{Eu}^{3+} \\
0,1 \%\end{array}$ & & & 48 & 14 & 129 & 642 & 0,61 & 1 \\
\hline $\begin{array}{c}\mathrm{BaWO}_{4}: \mathrm{Eu}^{3+} \\
5,0 \%\end{array}$ & 4 & 2 & 8 & 59 & 880 & 539 & 0,40 & 6 \\
\hline $\begin{array}{c}\mathrm{BaWO}_{4}: \mathrm{Eu}^{3+} \\
10 \%\end{array}$ & 5 & 2 & 6 & 07 & 143 & 850 & 0,35 & 5 \\
\hline
\end{tabular}




\subsubsection{Comportamento espectroscópico do íon $\mathrm{Sm}^{3+}$ na matriz $\mathrm{Sm}_{2}\left(\mathrm{MoO}_{4}\right)_{3}$}

Apesar de ser menos estudado, o samário é um lantanídeo emissor interessante, pois apresenta luminescência visível (cor vermelho/laranja) em diferentes comprimentos de ondas ${ }^{47}$ Além disso, há uma grande contribuição de resultados da luminescência do íon $\mathrm{Sm}^{3+}$ situados na região do infravermelho do espectro eletromagnético. ${ }^{48}$

O íon $\mathrm{Sm}^{3+}$ ([Xe]4f $\left.{ }^{5}\right)$ tem configuração com número de elétrons ímpar, e de acordo com a regra de Kramer, os seus estados são no mínimo duplamente degenerados em qualquer perturbação do campo ligante. ${ }^{49}$ Consequentemente, um estado oriundo do número quântico $\mathrm{J}$-semi-inteiro se desdobrará em no máximo (J+1/2)-componentes Stark. A degenerescência de Kramer é somente removida por meio de uma interação adicional que quebre a invariância temporeverso do Hamiltoniano do íon com configuração ímpar, tal como, as interações magnéticas entre os átomos nos compostos. ${ }^{14}$

Os compostos de $\mathrm{Sm}^{3+}$ são conhecidos por exibirem emissão alaranjada sob radiação ultravioleta. Seus espectros de emissão apresentam, principalmente, bandas finas oriundas das transições intraconfiguracionais ${ }^{4} \mathrm{G}_{5 / 2} \rightarrow{ }^{6} \mathrm{H}_{\mathrm{J}}$ (onde $\mathrm{J}=5 / 2,7 / 2,9 / 2$ e 11/2) localizadas na região do visível. A transição ${ }^{4} \mathrm{G}_{5 / 2} \rightarrow{ }^{6} \mathrm{H}_{5 / 2}(\sim 560 \mathrm{~nm}) \mathrm{e}^{4} \mathrm{G}_{5 / 2} \rightarrow{ }^{6} \mathrm{H}_{7 / 2}(\sim 600 \mathrm{~nm})$ apresentam alto caráter de dipolo magnético e são, geralmente, dominadas por este mecanismo. Por outro lado, a transição hipersensível ${ }^{4} G_{5 / 2} \rightarrow{ }^{6} \mathrm{H}_{9 / 2}(\sim 645 \mathrm{~nm})(\Delta \mathrm{J}=2)$ é dominada pelo mecanismo de dipolo-elétrico e é, geralmente, a transição mais intensa nos espectros de emissão dos compostos de $\mathrm{Sm}^{3+}$.

Com base nesses resultados, a transição ${ }^{4} \mathrm{G}_{5 / 2} \rightarrow{ }^{6} \mathrm{H}_{5 / 2}$ tem sido tomada como referência na determinação doparâmetro $\eta_{S m}$ que é definido como a razão entre as intensidades integradas das transições ${ }^{4} G_{5 / 2} \rightarrow{ }^{6} H_{9 / 2}$ e ${ }^{4} G_{5 / 2} \rightarrow{ }^{6} H_{5 / 2}$ nos complexos de $\mathrm{Sm}^{3+} .50$ 


$$
\eta_{\mathrm{Sm}}=\frac{\mathrm{S}\left({ }^{4} \mathrm{G}_{5 / 2} \rightarrow{ }^{6} \mathrm{H}_{9 / 2}\right)}{\mathrm{S}\left({ }^{4} \mathrm{G}_{5 / 2} \rightarrow{ }^{6} \mathrm{H}_{5 / 2}\right)}
$$

No presente trabalho investigou-se as propriedades luminescentes do $\mathrm{Sm}_{2}\left(\mathrm{MoO}_{4}\right)_{3}$.Os espectros de excitação da matriz $\mathrm{Sm}_{2}\left(\mathrm{MoO}_{4) 3}\right.$ com emissão monitorada na transição hipersensível ${ }^{4} \mathrm{G}_{5 / 2} \rightarrow{ }^{6} \mathrm{H}_{9 / 2}(\sim 645 \mathrm{~nm})$ foram registrados no intervalo de 250 a $600 \mathrm{~nm}$, a $298 \mathrm{~K}$ e $77 \mathrm{~K}$ (Figura 5.21). Estes espectros apresentam bandas finas oriundas das transições intraconfiguracionais $4 f^{5}$ envolvendo o estado fundamental ${ }^{6} \mathrm{H}_{5 / 2}$ e os estados excitados excitados (em nm): ${ }^{4} \mathrm{D}_{7 / 2}+{ }^{4} \mathrm{D}_{9 / 2} \quad(\sim 345),{ }^{4} \mathrm{~F}_{9 / 2} \quad(\sim 362),{ }^{4} \mathrm{~L}_{17 / 2},{ }^{5} \mathrm{D}_{1 / 2}{ }^{6} \mathrm{P}_{7 / 2} \quad(\sim 376),{ }^{4} \mathrm{H}_{11 / 2} \mathrm{M}_{15 / 2} \quad$ ( 391), ${ }^{4} \mathrm{~F}_{7 / 2}{ }^{4} \mathrm{~L}_{13 / 2}{ }^{6} \mathrm{P}_{3 / 2}$ ( 403), ${ }^{4} \mathrm{M}_{19 / 2}{ }^{6} \mathrm{P}_{5 / 2}(\sim 417),{ }^{4} \mathrm{I}_{15 / 2}{ }^{6} \mathrm{M}_{17 / 2}{ }^{4} \mathrm{G}_{9 / 2}(\sim 440),{ }^{4} \mathrm{~F}_{3 / 2}(1) \quad(\sim 450)$, ${ }^{4} \mathrm{I}_{13 / 2}(\sim 463),{ }^{4} \mathrm{I}_{13 / 2}(\sim 463),{ }^{4} \mathrm{I}_{13 / 2}(\sim 467),{ }^{4} \mathrm{I}_{9 / 2}(\sim 471),{ }^{4} \mathrm{G}_{7 / 2}(\sim 499),{ }^{4} \mathrm{~F}_{3 / 2}(2)(\sim 528) \mathrm{e}$ ${ }^{4} G_{5 / 2}(\sim 559)$, conforme FIG 5.21 .

Os espectros de emissão (FIG. 5.22) do $\mathrm{Sm}_{2}\left(\mathrm{MoO}_{4}\right)_{3}$ foi registrado no intervalo espectral de 550 a $750 \mathrm{~nm}$, a $77 \mathrm{~K}$ e $298 \mathrm{~K}$. Como pode ser observado, esses espectros consistem de bandas finas atribuídas às transições ${ }^{4} G_{5 / 2} \rightarrow{ }^{6} \mathrm{H}_{\lrcorner}$ (onde $\mathrm{J}=5 / 2,7 / 2,9 / 2$ e 11/2) centradas no íon $\mathrm{Sm}^{3+}$, sendo a transição hipersensível ${ }^{4} \mathrm{G}_{5 / 2} \rightarrow{ }^{6} \mathrm{H}_{9 / 2}(\sim 650 \mathrm{~nm})$ apresentando maior intensidade. A presença de bandas largas oriundas da fosforescência da matriz foram observadas e evidenciam a ineficiente transferência de energia matriz- $\mathrm{Sm}^{3+}$. Os espectros de emissão mostram ainda que as bandas atribuídas às transições ${ }^{4} \mathrm{G}_{5 / 2} \rightarrow{ }^{6} \mathrm{H}_{\lrcorner}$não estão desdobradas no número máximo de $(\mathrm{J}+1 / 2)$-componentes indicando que o íon $\mathrm{Sm}^{3+}$ ocupa um ambiente químico de simetria não totalmente degenerada. $\mathrm{O}$ calculo do valor do parâmetro experimental $\eta_{\mathrm{Sm}}$ resultou em 5,0. 


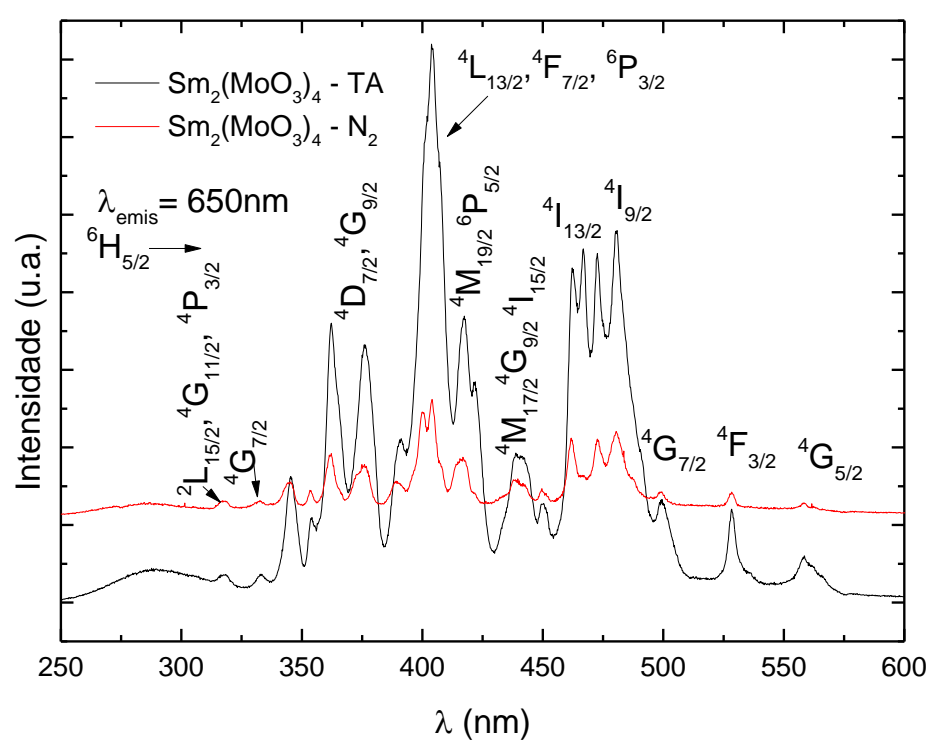

FIGURA 5.21.Espectro de excitação do $\mathrm{Sm}_{2}\left(\mathrm{MoO}_{4}\right)_{3}$.

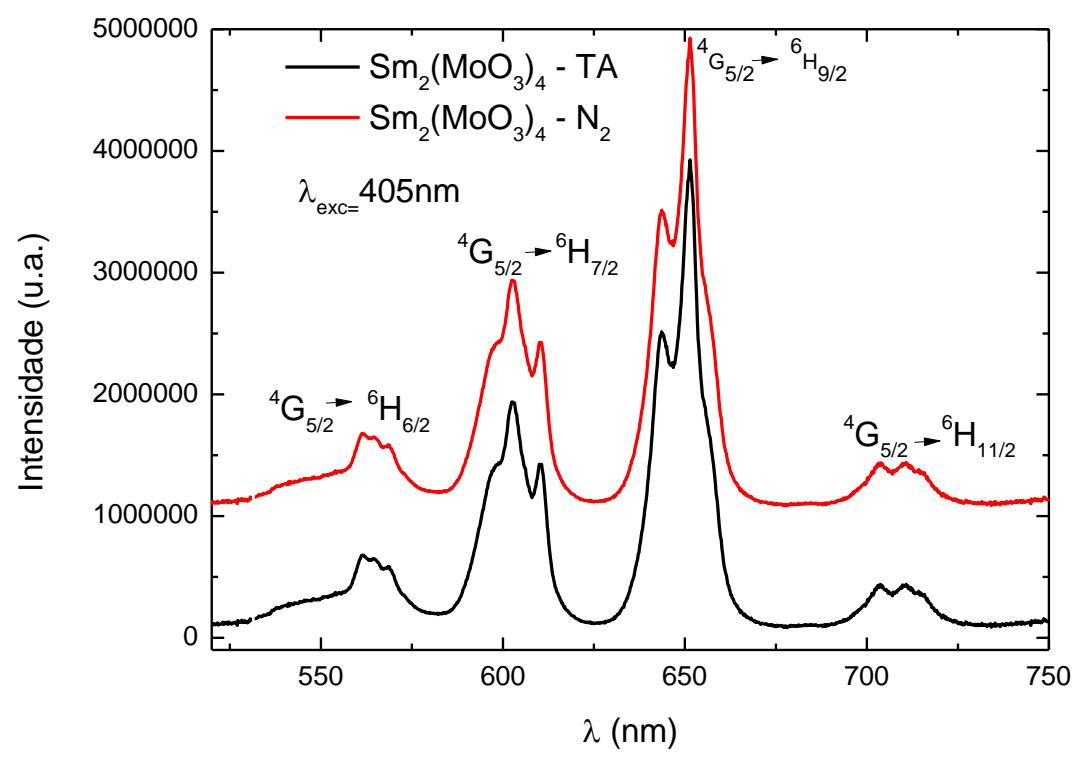

FIGURA 5.22. Espectro de emissão do $\mathrm{Sm}_{2}\left(\mathrm{MoO}_{4}\right)_{3}$. 
5.2.11 Comportamento espectroscópico do íon $\mathrm{Tb}^{3+}$ na matriz $\mathrm{Tb}_{2}\left(\mathrm{MoO}_{4) 3}\right.$

O íon térbio trivalente tem a configuração eletrônica $4 f^{8}$ e contém os níveis Stark do íon $\mathrm{Eu}^{3+}\left(4 \mathrm{f}^{6}\right)$, porém invertidos. Por exemplo, o nível fundamental é ${ }^{7} F_{6}$ e seu primeiro estado emissor é o nível ${ }^{5} D_{4}$ (FIG. 5.23).

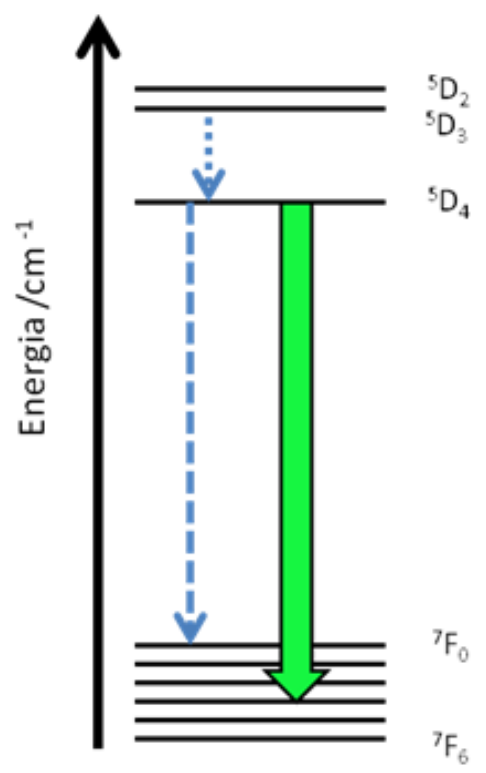

$\mathrm{Tb}^{3+}\left(4 \mathrm{f}^{\mathrm{9}}\right)$

FIGURA 5.23.Estado fundamental e os primeiros estados emissores do térbio

Todas as transições são relativamente fortes, em contraste com as transições ${ }^{5} \mathrm{D}_{\jmath} \rightarrow{ }^{7} \mathrm{~F}_{5-6}$ do íon $\mathrm{Eu}^{3+}$ que geralmente são muito fracas e situadas na região do infravermelho.

Devido à alta degenerescência desses níveis, ambas as atribuições das transições ${ }^{7} \mathrm{~F}_{6} \rightarrow{ }^{5} \mathrm{D}_{\jmath}$ e ${ }^{5} \mathrm{D}_{4} \rightarrow{ }^{7} \mathrm{~F}_{\jmath}$ ' a partir dos espectros de excitação e emissão do íon $\mathrm{Tb}^{3+}$ tendem a ser mais complicados quando comparados àquelas do íon $\mathrm{Eu}^{3+}$. Portanto, o estudo das propriedades espectroscópicas dos compostos derivados do íon $\mathrm{Tb}^{3+}$, do ponto de vista teórico tem atraído uma atenção modesta quando comparado com o íon $\mathrm{Eu}^{3+}{ }^{31,51,52}$ 
O intervalo de energia entre os níveis ${ }^{7} \mathrm{~F}_{0}$ e o ${ }^{5} \mathrm{D}_{4}$ e ${ }^{5} \mathrm{D}_{3}$ (14000 e 20000 $\mathrm{cm}^{-1}$, respectivamente) coloca quase todas as transições ${ }^{5} \mathrm{D}_{3,4} \rightarrow{ }^{7} \mathrm{~F}_{0-6}$ na região visível do espectro (com exceção da transição ${ }^{5} D_{3} \rightarrow{ }^{7} F_{6}$ situada na região do UV próximo). Todas as transições são relativamente fortes, em contraste com as transições ${ }^{5} D_{\jmath} \rightarrow{ }^{7} F_{5-6}$ do íon $E^{3+}$ que geralmente são muito fracas e situadas na região do infravermelho. Em geral, os processos de sensibilização para os complexos de $\mathrm{Tb}^{3+}$ pela irradiação ultravioleta são semelhantes àqueles dos complexos de $\mathrm{Eu}^{3+}$. Entretanto, é necessário que o estado tripleto do ligante se localize em região de maior energia ou em ressonância com o primeiro nível de emissão ${ }^{5} \mathrm{D}_{4}\left(\sim 20400 \mathrm{~cm}^{-1}\right)$ do íon térbio. ${ }^{53,54}$

Os espectros de excitação foram registrados no intervalo de 250 a $550 \mathrm{~nm}$, com emissão monitorada na transição ${ }^{5} \mathrm{D}_{4} \rightarrow{ }^{7} \mathrm{~F}_{5}(\sim 547 \mathrm{~nm})$. Diferenças significativas foram observadas entre os espectros de excitação registrados a 298 e 77 K (FIG.5.24). Os espectros de excitação do material $\mathrm{Tb}_{2}\left(\mathrm{MoO}_{4}\right)_{3}$ a temperatura ambiente e do nitrogênio líquido,mostram os picos referentes às transições 4f-4f característicos do íon $\mathrm{Tb}^{3+}$, na faixa espectral entre 250-550 nm.

Nos espectros, verificou-se uma banda larga na região de 250 a 344 $\mathrm{nm}$ com máximo em $\sim 281 \mathrm{~nm}$, atribuída à banda $\mathrm{O} \rightarrow$ Mo do $\mathrm{Tb}_{2}\left(\mathrm{MoO}_{4}\right)_{3}$. As bandas fixas em 350,4; 357,8; 368,2; 376,4; 467,2 e 484,6, aproximadamente, correspondem às transições ${ }^{7} F_{6} \rightarrow{ }^{5} G_{J},{ }^{5} L_{\jmath}$ e ${ }^{5} D_{\jmath}$ do íon $\mathrm{Tb}^{3+}$.

Todas as transições são relativamente fortes, em contraste com as transições ${ }^{5} \mathrm{D}_{\jmath} \rightarrow{ }^{7} \mathrm{~F}_{5-6}$ do íon $\mathrm{Eu}^{3+}$ que geralmente são muito fracas e situadas na região do infravermelho..$^{55,56,57}$

A FIG. 5.25 apresenta os espectros de emissão do fósforo $\mathrm{Tb}_{2}\left(\mathrm{MoO}_{4}\right)_{3}$ com excitação monitorada em $300 \mathrm{~nm}$, apresentando as transições ${ }^{5} \mathrm{D}_{4} \rightarrow{ }^{7} \mathrm{~F}_{\mathrm{J}}(\mathrm{J}=$ 0-6) no intervalo entre 450 e $700 \mathrm{~nm}$.

A relaxação não-radiativa entre estados eletrônicos dos íon $\mathrm{TR}^{3+} \mathrm{em}$ sólidos ocorre geralmente por emissão multi-fóton ou por processo de relaxação 
cruzada. ${ }^{58,59}$ Este último envolve a interação entre um íon ativador excitado e um (ou mais) íons do estado fundamental vizinhos que tenha transições aproximadamente ressonantes com o intervalo através do qual a relaxação poderia ocorrer.

A transição ${ }^{5} \mathrm{D}_{4} \rightarrow{ }^{7} \mathrm{~F}_{5}$ é a principal emissão, que pode ser explicada pelos valores grandes dos elementos de matriz reduzida em $\mathrm{J}=5$ e pela teoria de Judd-Ofelt. ${ }^{1,2}$

Pelo espectro de emissão torna-se claro que a matriz transfere energia eficientemente para 0 íon $\mathrm{Tb}^{3+}$ pois 0 espectro não mostra fosforescência da matriz.

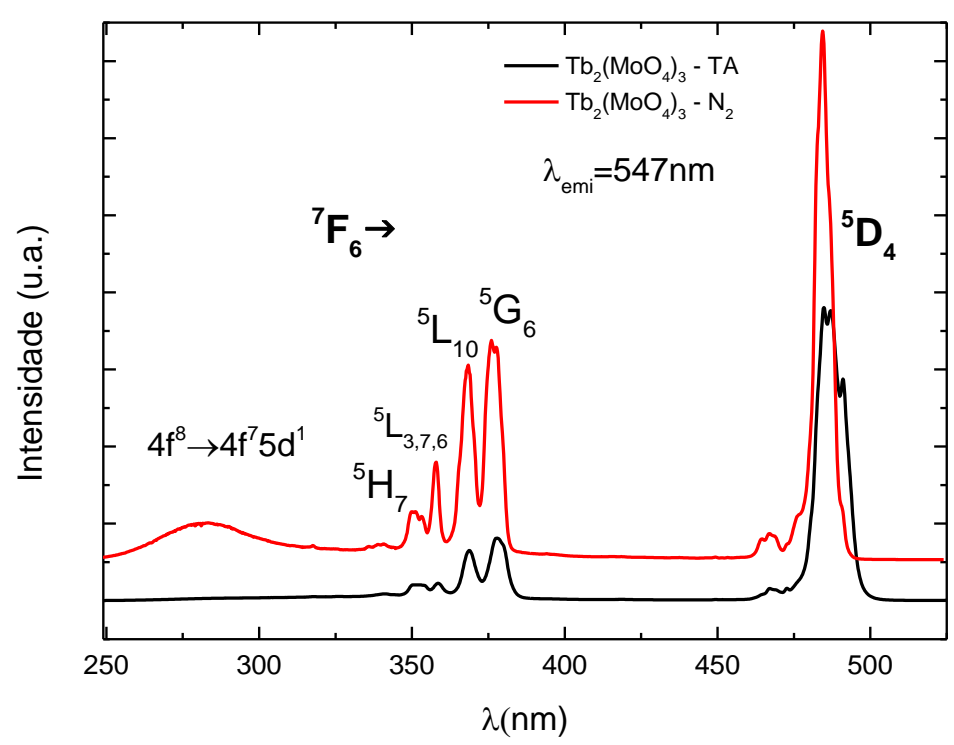

FIGURA 5.24. Espectro de excitação do $\mathrm{Tb}_{2}\left(\mathrm{MoO}_{4}\right)_{3}$. 


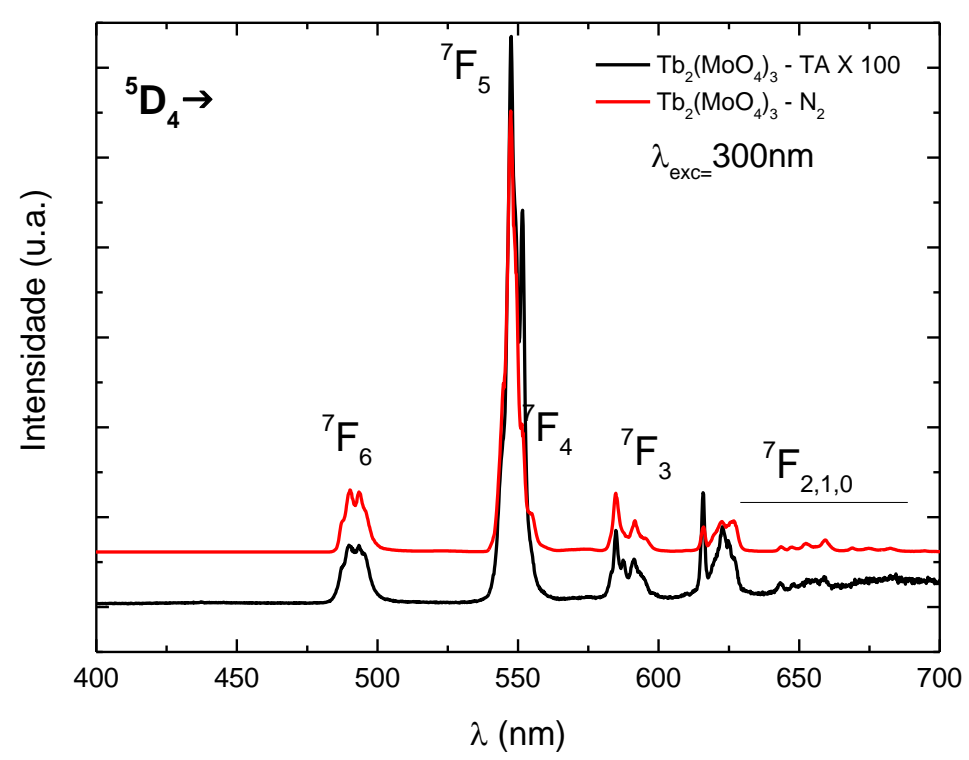

FIGURA 5.25.Espectro de emissão do $\mathrm{Tb}_{2}\left(\mathrm{MoO}_{4}\right)_{3}$.

\subsubsection{Comportamento espectroscópico do íon $\mathrm{Nd}^{3+}$ na matriz $\mathrm{Nd}_{2}\left(\mathrm{MoO}_{4}\right)_{3}$}

O grande interesse em se estudar o íon $\mathrm{Nd}^{3+}$ é devido esse elemento possuir uma configuração eletrônica envolvendo o nível $4 f^{3}$ com transições de alta eficiência quântica e emissão de luz aproximadamente em 1060 nm (atribuída à transição $\left.{ }^{4} \mathrm{~F}_{3 / 2} \rightarrow{ }^{4} \mathrm{I}_{11 / 2}\right)(\mathrm{FIG}$. 5.26)

O neodímio é considerado um dos elementos de maior interesse na produção de materiais aplicados à fabricação de dispositivos para emissão laser. Outra característica importante deste material é sua distribuição simplificada de níveis (quatro níveis atômicos), o que facilita em muito a inversão de população. ${ }^{60}$

O $\mathrm{Nd}^{3+}:[\mathrm{Xe}] 4 f^{3}$ foi utilizado nesse trabalho devido seu ótimo desempenho como emissor de luz em matrizes sólidas em especial no conhecido YAG (Yttrium Aluminum Garnet), tendo sua emissão no infravermelho próximo (NIR). 
O espectro do íon neodímio é rico em bandas nas regiões do visíveis e do infravermelho, elas ocorrem devido às transições do estado fundamental ${ }^{4} l_{9 / 2}$ aos níveis excitados $J$ ' da configuração $4 f^{3}$. Os níveis excitados das bandas na região do visível e do infravermelho são fundamentalmente determinados pelos parâmetros de repulsão intereletrônica (integrais $F_{k}$ ) e, em menor intensidade, pelo acoplamento de spin-órbita. ${ }^{61}$

O íon neodímio trivalente $\mathrm{Nd}^{3+}\left([\mathrm{Xe}] 4 \mathrm{f}^{3}\right)$ tem configuração com número de elétrons ímpar, e de acordo com a regra de Kramer, os seus estados são no mínimo duplamente degenerados em qualquer perturbação do campo ligante. ${ }^{62,63}$ Consequentemente, um estado oriundo do número quântico $\mathrm{J}$-semi-inteiro se desdobrará em no máximo $(\mathrm{J}+1 / 2)$-componentes Stark.

A degenerescência de Kramer é somente removida por meio de uma interação adicional que quebre a invariância tempo-reverso do Hamiltoniano do íon com configuração ímpar, tal como, as interações magnéticas entre os átomos nos compostos. ${ }^{64}$

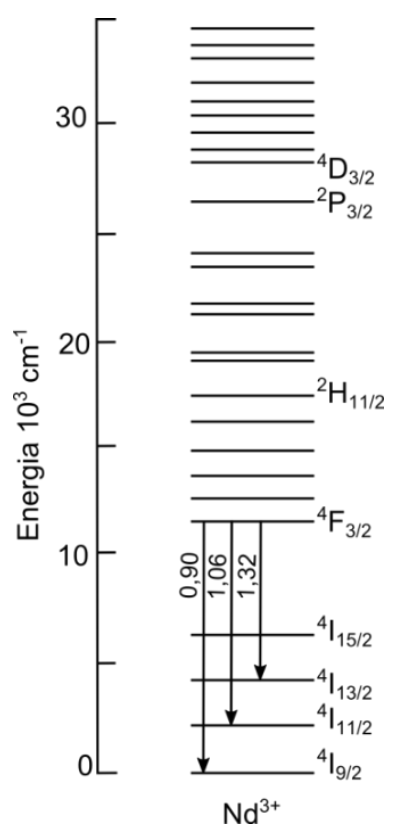

FIGURA 5.26. Diagrama parcial de nível de energia para o íon $\mathrm{Nd}^{3+}$. 
Os espectros de emissão no infravermelho próximo foram obtidos a $298 \mathrm{~K}$ no intervalo de 790 - $1150 \mathrm{~nm}$ com excitação em $250 \mathrm{~nm}$ e $810 \mathrm{~nm}$ com uma lâmpada de xenônio de 450W (FIG. 5.27). Observa-se emissão do nível ${ }^{4} \mathrm{~F}_{3 / 2}$ para os níveis ${ }^{4} \mathrm{I}_{9 / 2} \mathrm{e}^{4} \mathrm{I}_{11 / 2}, 900$ e $1048 \mathrm{~nm}$ respectivamente, sendo que a transição ${ }^{4} \mathrm{~F}_{3 / 2} \rightarrow{ }^{4} \mathrm{I}_{11 / 2}(1048 \mathrm{~nm})$ é a mais intensa e aparece na "janela de transparência" das moléculas de água, onde água e tecido biológico não emite.

Quando a matriz é excitada em $250 \mathrm{~nm}$ um conjunto de bandas na região de 800 a $850 \mathrm{~nm}$ aparece no espectro, estas bandas foram atribuídas a transição ${ }^{4} \mathrm{~F}_{5 / 2} \rightarrow{ }^{4} \mathrm{I}_{/ 2}$.

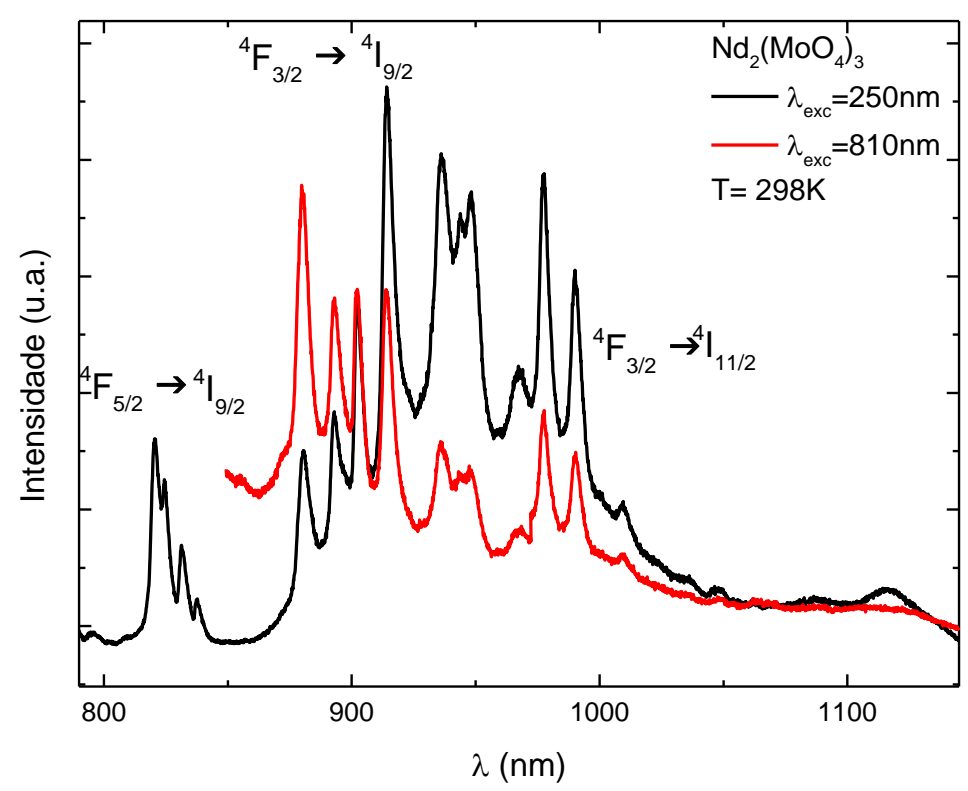

FIGURA 5.27. Espectro de emissão do $\mathrm{Nd}_{2}\left(\mathrm{MoO}_{4}\right)_{3}$. 
5.3 Estudo da influência da velocidade de dispersão usada para precipitação dos molibdatos no tamanho da partícula e nas propriedades espectroscópicas de $\mathrm{Eu}_{2}\left(\mathrm{MoO}_{4}\right)_{3}$

\subsubsection{Características qualitativas}

O estudo sobre a da influência da velocidade de dispersão da precipitação no tamanho da partícula e das propriedades espectroscópicas para o $\mathrm{Eu}_{2}\left(\mathrm{MoO}_{4}\right)_{3}$ foi realizado.Para se avaliar a influência da velocidade da dispersão na morfologia do precipitado e nas propriedades luminescentes dos materiais gerados utilizou-se quatro velocidades de dispersão 2500 rpm, 8000 rpm, 16000 rpm e 24000 rpm.

As amostras $\mathrm{Eu}_{2}\left(\mathrm{MoO}_{4}\right)_{3}-8.000 \mathrm{rpm}, \mathrm{Eu}_{2}\left(\mathrm{MoO}_{4}\right)_{3}-16.000 \mathrm{rpm}$ e $\mathrm{Eu}_{2}\left(\mathrm{MoO}_{4}\right)_{3}-24.000 \mathrm{rpm}$ foram sintetizadas com sucesso. Na figura 5.28, os compostos sobre excitação de uma fonte de UV 366nm mostraram forte luminescência com emissão no vermelho, com diminuição da intensidade da cor com o aumento do número de rotações.
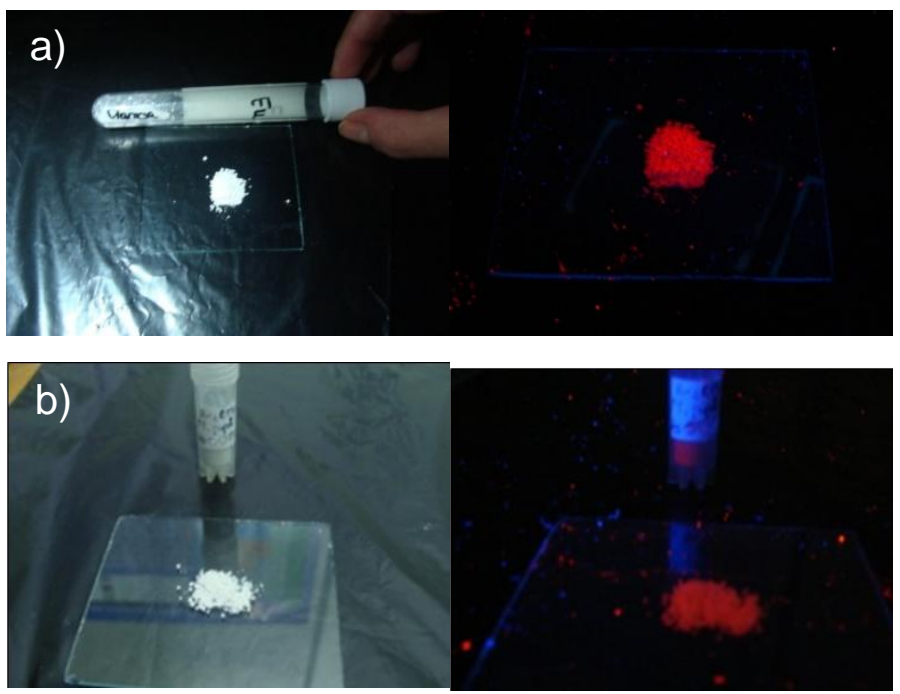
Resultados e discussões - Sínteses e Caracterizações
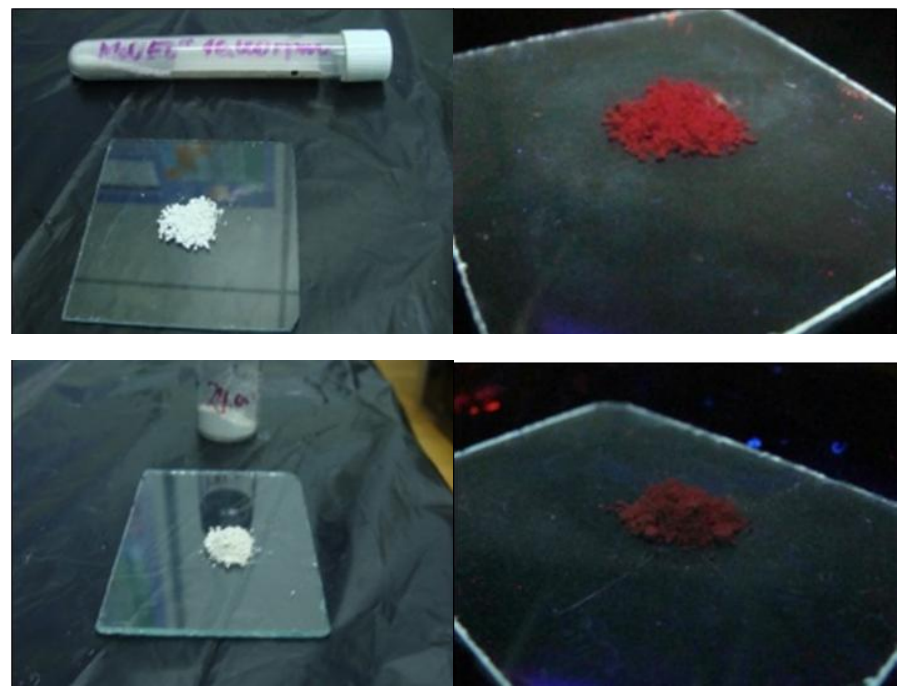

FIGURA 5.28. Fotografias do molibdato de európio com velocidade de dispersão a) 2500 , b) 8000 , c) 16000 e d) 24000 rpm sob irradiação ultravioleta $\left(\lambda_{\text {ex }}=366 \mathrm{~nm}\right.$ ).

\subsubsection{Espectroscopia de infravermelho com transformada de Fourrier (FTIR)}

A caracterização por espectroscopia de IR mostrou bandas atribuídas as frequências fundamentais de estiramentos $v \mathrm{O}-\mathrm{H}$ em $\sim 3370 \mathrm{~cm}^{-1}, \delta \mathrm{H}-\mathrm{O}-\mathrm{H}$ em $1629 \mathrm{~cm}^{-1}$ e bandas em 935 simetrico e $875 \mathrm{~cm}^{-1}$ (s) assimétrico e 756 e 696 $\mathrm{cm}^{-1}$ (s), que são características da fase tetragonal do íon $\left(\mathrm{MoO}_{4}\right)^{-2}$ (FIG. 5.29) e que segundo Ullman et al ${ }^{55}$ são atribuidas aos estiramentos $v 1$ e $v 3$ respectivamente concordando com dados de outros pesquisadores. ${ }^{66,67,68}$ 




FIGURA 5.29. Espectro de infravermelho do $\mathrm{Eu}_{2}\left(\mathrm{MoO}_{4}\right)_{3}$ : com a velocidades de dispersão em 2.500, 8.000, 16.000 e 24.000 rpm.

\subsubsection{Análise Termogravimétrica (TG/DTG)}

As figuras 5.30 a 5.33 apresentam as curvas de TG/DTG (termogravimetrias/termogravimetricas diferencial) da amostra de molibdato de európio obtidas em diferentes velocidades de dispersão (2.500, 8.000, $16.000 \mathrm{e}$ 24.000 rpm). As curvas mostram três eventos de decomposição sendo atribuídos o primeiro a perda de água adsorvida na superfície dos cristais pois apresentam higroscopicidade em até $100{ }^{\circ} \mathrm{C}, 0$ segundo evento perda de água do interior dos retículos dos cristais entre 120 e $200{ }^{\circ} \mathrm{C}$ e um terceiro evento referente a perda das hidroxilas livres a partir de $230^{\circ} \mathrm{C}$. Observou-se também que o material obtido a 8000rpm apresentou maior higroscopicidade tendo uma massa residual de $83.44 \%$ do valor inicial. 


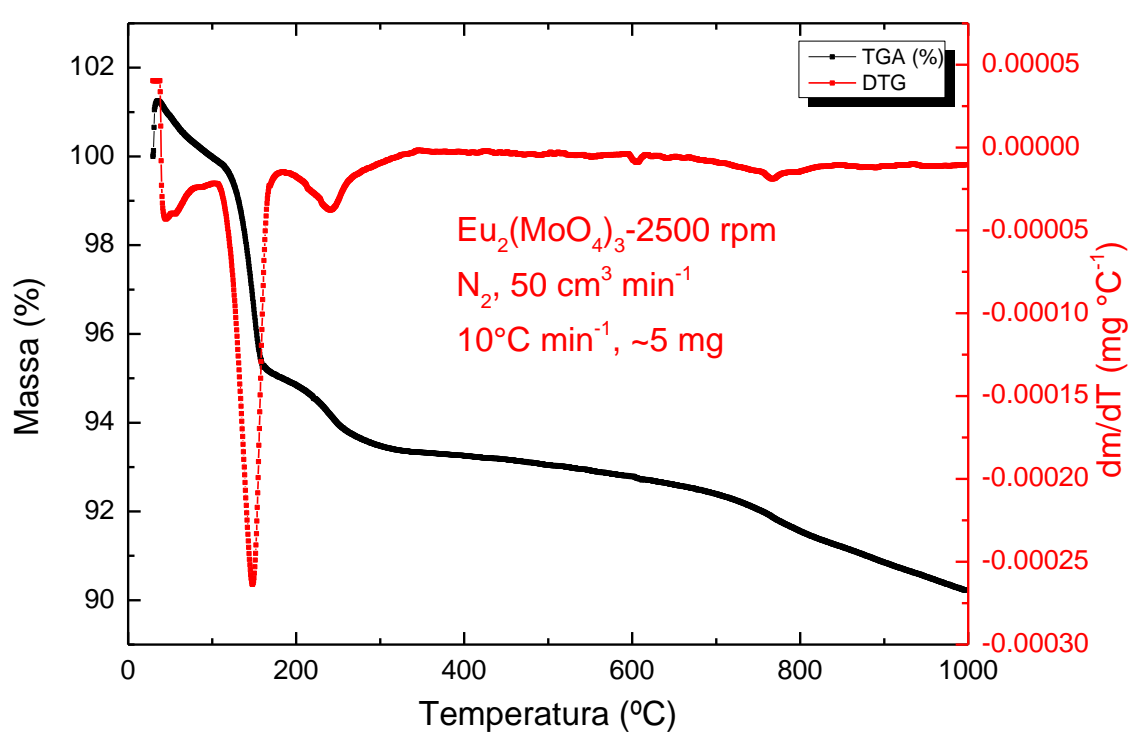

FIGURA 5.30. Curvas TGA/DTG registradas no intervalo de 0 a $1000^{\circ} \mathrm{C}$, sob atmosfera dinâmica de $\mathrm{N}_{2}$, do $\mathrm{Eu}_{2}\left(\mathrm{MoO}_{4}\right)_{3}-2.500$ rpm.

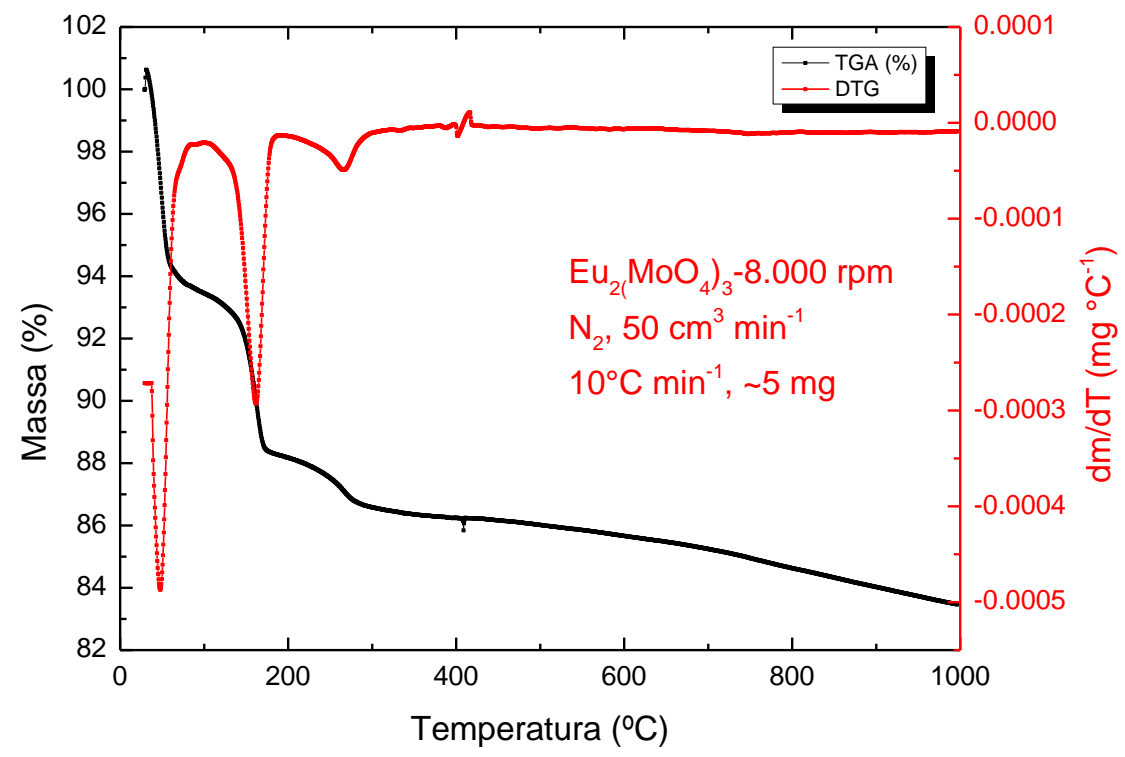

FIGURA 5.31. Curvas TGA/DTG registradas no intervalo de 0 a $1000{ }^{\circ} \mathrm{C}$, sob atmosfera dinâmica de $\mathrm{N}_{2}$, do $\mathrm{Eu}_{2}\left(\mathrm{MoO}_{4}\right)_{3}-8.000$ rpm. 


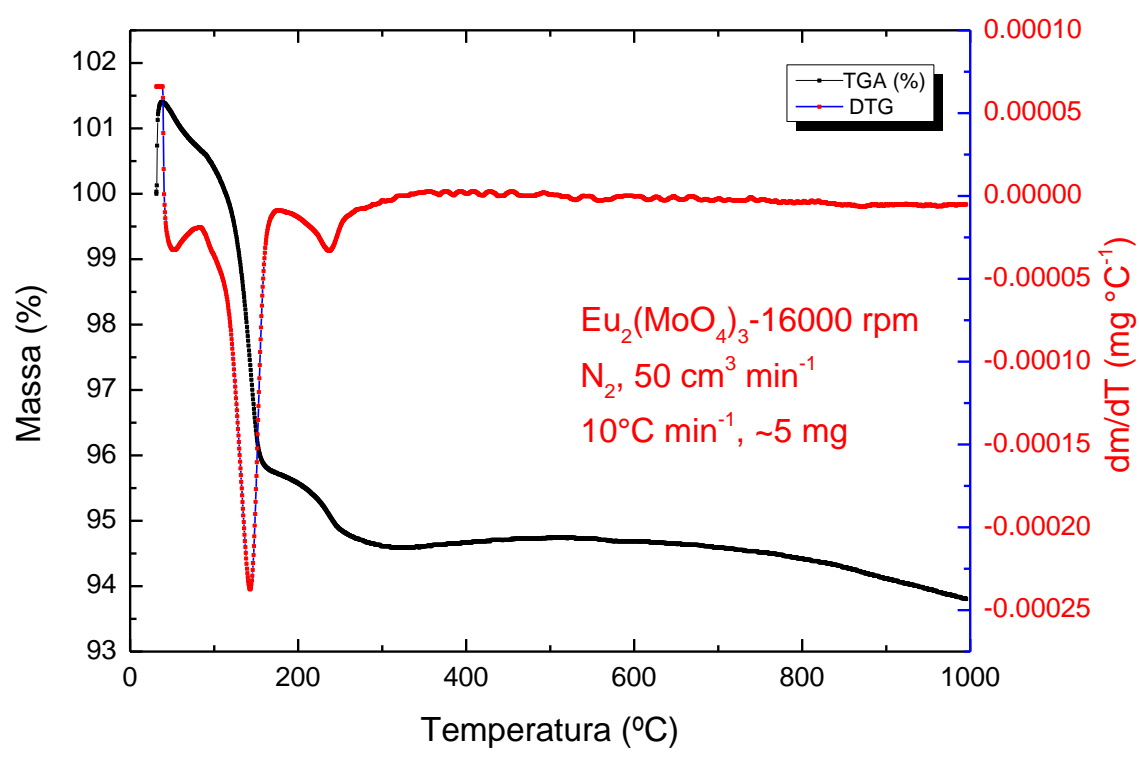

FIGURA 5.32. Curvas TGA/DTG registradas no intervalo de 0 a $1000{ }^{\circ} \mathrm{C}$, sob atmosfera dinâmica de $\mathrm{N}_{2}$, do $\mathrm{Eu}_{2}\left(\mathrm{MoO}_{4}\right)_{3}-16.000 \mathrm{rpm}$.

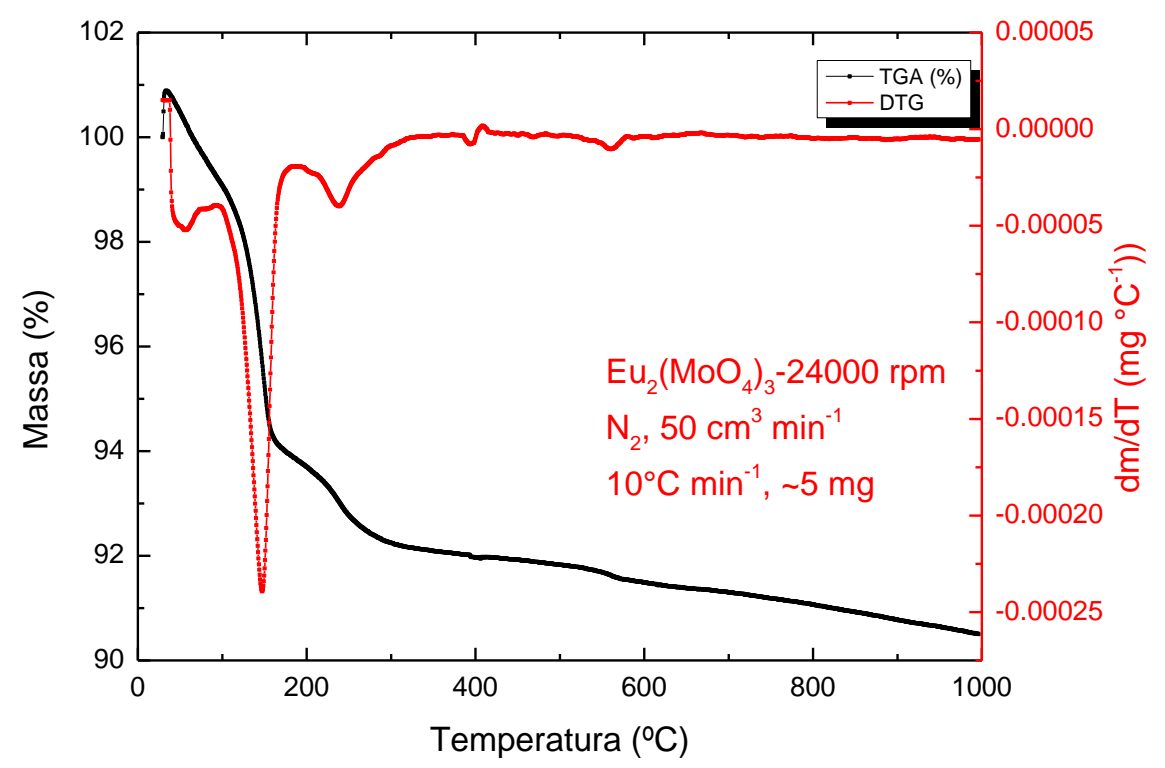

FIGURA 5.33.Curvas TGA/DTG registradas no intervalo de 0 a $1000 \stackrel{\circ}{\circ}$, sob atmosfera dinâmica de $\mathrm{N}_{2}$, do $\mathrm{Eu}_{2}\left(\mathrm{MoO}_{4}\right)_{3}-24.000$ rpm. 


\subsubsection{Difração de raios X (DRX)}

A difração de raios $X$ pelo método do pó (FIG 5.34) mostrou que as nanopartículas de $\mathrm{Eu}_{2}\left(\mathrm{MoO}_{4}\right)_{3}$ são cristalinas. Há a formação das fases tetragonal e monoclínica onde não apresenta diferenças significativas na cristalinidade, conforme houve o aumento da velocidade da dispersão das partículas no momento da precipitação. $O$ tamanho médio do cristalito dos molibdatos foram calculados utilizando a fórmula de Scherrer e os dados estão na TAB 5.5 onde pode-se observar uma diminuição do tamanho do cristalito com o aumento da velocidade de dispersão. Observou-se também que em 24000 rpm um halo de amorficidade muito discreto aparece no difratograma.

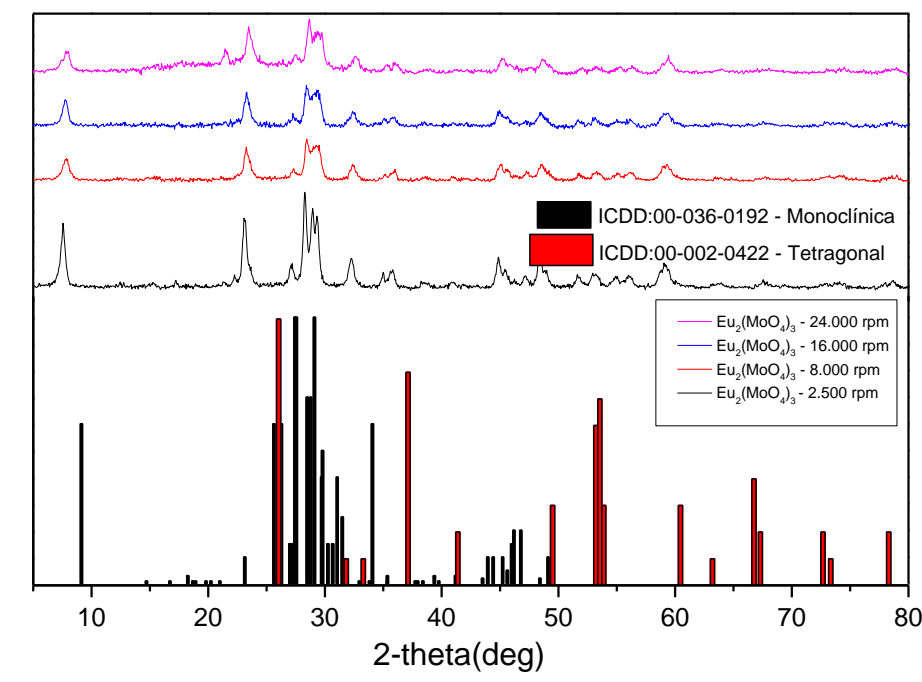

FIGURA 5.34. Difratograma de $\mathrm{Eu}_{2}\left(\mathrm{MoO}_{4}\right)_{3}$ nas diferentes velocidades de dispersão da nanopartícula de $\mathrm{Eu}_{2}\left(\mathrm{MoO}_{4}\right)_{3}$ 
Resultados e discussões - Sínteses e Caracterizações

TABELA 5.5. Diâmetro do cristalito calculado pelo método de Sherrer,

\begin{tabular}{l|l}
\hline Composto & $\varnothing$ \\
\hline $\mathrm{Eu}_{2}\left(\mathrm{MoO}_{4}\right)_{3}(2500 \mathrm{rpm})$ & 27,30 \\
$\mathrm{Eu}_{2}\left(\mathrm{MoO}_{4}\right)_{3}(8000 \mathrm{rpm})$ & 23,94 \\
$\mathrm{Eu}_{2}\left(\mathrm{MoO}_{4}\right)_{3}(16000 \mathrm{rpm})$ & 23,57 \\
$\mathrm{Eu}_{2}\left(\mathrm{MoO}_{4}\right)_{3}(24000 \mathrm{rpm})$ & 20.92 \\
\hline
\end{tabular}

\subsubsection{Microscopia eletrônica de varredura (MEV)}

Na FIG.5.35 as micrografias das nanopartículas de $\mathrm{Eu}_{2}\left(\mathrm{MoO}_{4}\right)_{3}$ estão dispostas conforme o aumento de velocidade de dispersão da partícula (a) 8000; b) 16000 e c) 24000 rpm). Os aglomerados apresentam visível diferença na forma de distribuição e aglomeração das nanopartículas assim como há a aparente diminuição da formação lamelar dos aglomerados conforme a velocidade de dispersão aumenta, conforme FIG.5.35 (a) - (c)). 

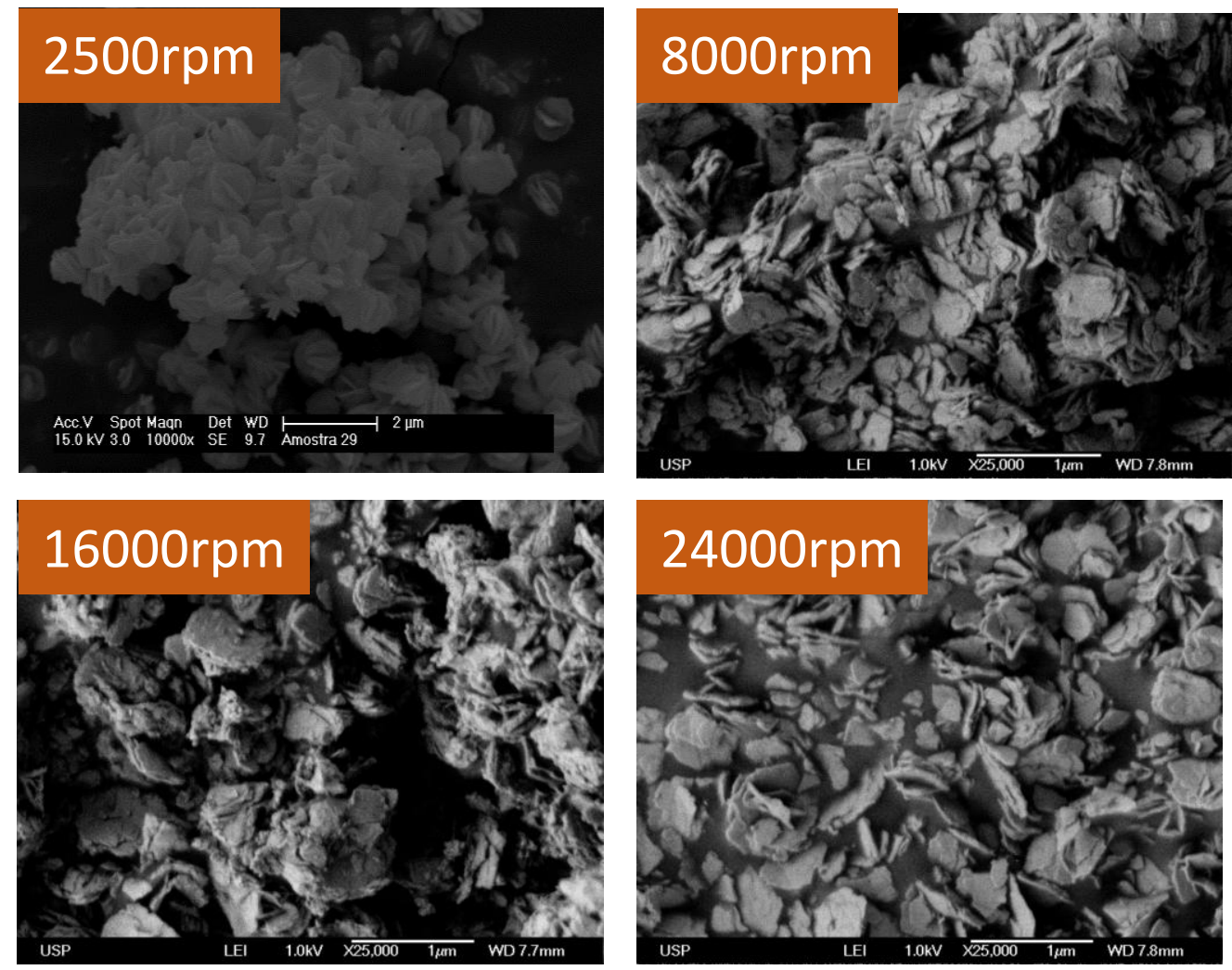

FIGURA 5.35.Micrografias de $\mathrm{Eu}_{2}\left(\mathrm{MoO}_{4}\right)_{3}$ com velocidades de dispersão de: a)2500; b)8000; c) 16000 e d) 24000 rpm.

\subsubsection{Propriedades espectroscópicas luminescentes}

No estudo fotoluminescente do $\mathrm{Eu}_{2}\left(\mathrm{MoO}_{4}\right)_{3}$, os espectros de luminescência foram registrados à temperatura ambiente e na temperatura do nitrogênio líquido(FIG. 5.36 e 5.37). Os espectros de excitação foram obtidos monitorando a emissão em $\sim 615 \mathrm{~nm}$ no intervalo de 250 a $590 \mathrm{~nm}$. Eles apresentam uma banda larga centrada em 290nm atribuída a transições LMCT O $\rightarrow \mathrm{Eu}^{3+}$ e $\mathrm{O} \rightarrow \mathrm{Mo}^{6+}$ e bandas finas oriundas dos níveis da configuração $4 f^{6}$ do $E^{3+}$ na região de 350 a $590 \mathrm{~nm}$. Entre estas transições pode-se citar: ${ }^{7} \mathrm{~F}_{0^{-}}$ ${ }^{5} \mathrm{~L}_{6}(393 \mathrm{~nm}),{ }^{7} \mathrm{~F}_{0^{-}}{ }^{5} \mathrm{D}_{2}(465 \mathrm{~nm})$ e ${ }^{7} \mathrm{~F}_{0^{-}}{ }^{5} \mathrm{D}_{1}$ (533 nm) linhas são as mais intensas.

Comparando-se os dois espectros a $298 \mathrm{~K}$ e $77 \mathrm{~K}$ pode-se dizer que 0 que os diferencia são as bandas dos estados LMCT que na temperatura do 
nitrogênio líquido são mais proeminentes que a temperatura ambiente devido ao enrijecimento da matriz.

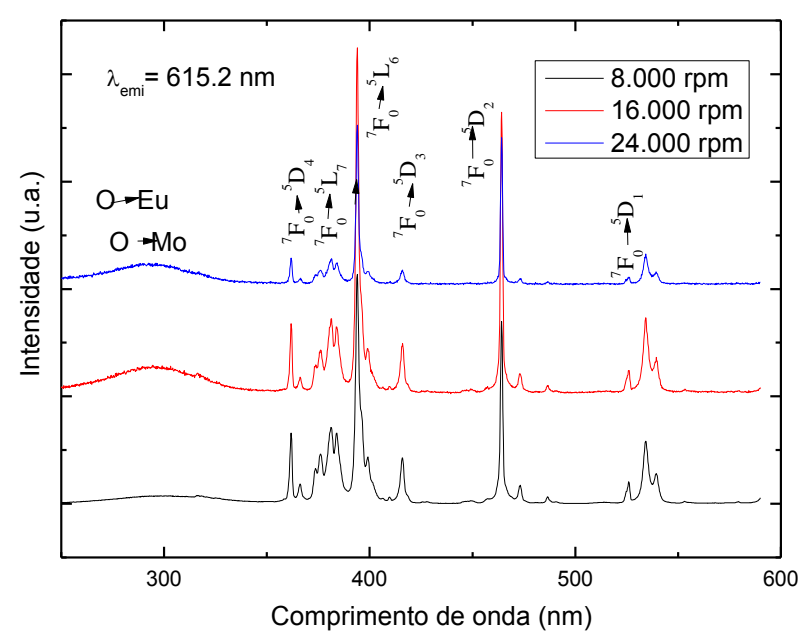

FIGURA 5.36. Espectros de excitação do luminóforo $\mathrm{Eu}_{2}\left(\mathrm{MoO}_{4}\right)_{3}$ obtidos em diferentes velocidades de dispersão (8000 rpm, 16000 rpm e 24000 rpm) em temperatura ambiente.

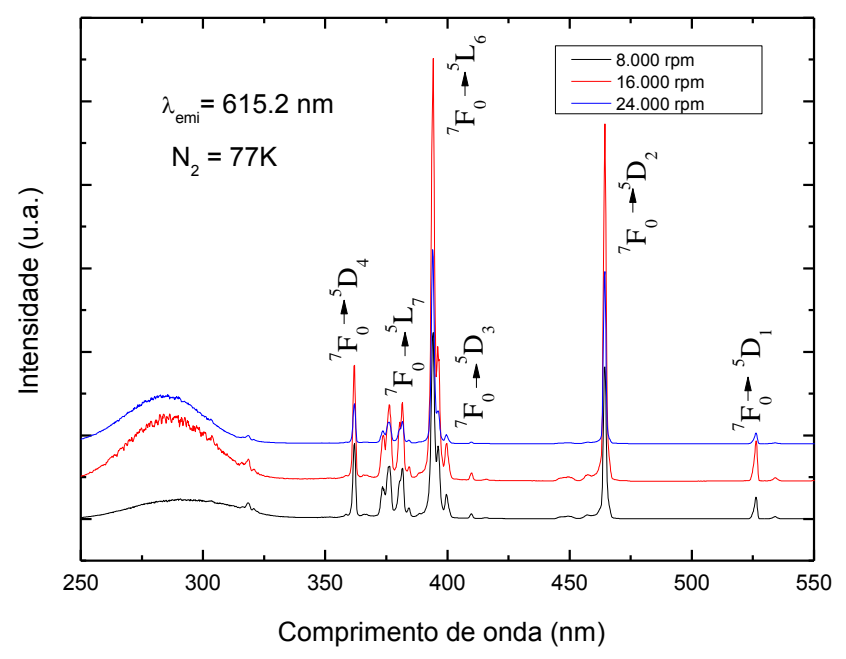

FIGURA 5.37. Espectros de excitação do luminóforo $\mathrm{Eu}_{2}\left(\mathrm{MoO}_{4}\right)_{3}$ obtidos em diferentes velocidades de dispersão (8000 rpm, 16000 rpm e 24000 rpm) em N $N_{2}$ líquido. 
Quanto aos espectros de emissão (FIG 5.38 E 5.39) estes foram obtidos com excitação monitorada no estado ${ }^{7} \mathrm{~F}_{0} \rightarrow{ }^{5} \mathrm{~L}_{6}(394 \mathrm{~nm})$ a temperatura ambiente e do $\mathrm{N}_{2}$ liquido, no intervalo espectral de 430 a $750 \mathrm{~nm}$. Nos espectros de emissão somente as bandas características da emissão do $\mathrm{Eu}^{3+}$, que corresponde a ${ }^{5} D_{0}{ }^{7} F_{J}(J=0-4)$ são observadas. Dentre estas bandas no espectro de emissão, a centrada em $\sim 615.2,{ }^{5} \mathrm{D}_{0}-{ }^{7} \mathrm{~F}_{2}$, é a mais proeminente e está relacionada com $\mathrm{O}$ ambiente local do íon $\mathrm{Eu}^{3+}$. As bandas oriundas da fosforescência da matriz que deveriam aparecer na região de 400 a 550 nm não foram registradas demonstrando a eficiência nos processos de transferência de energia da matriz para o ion $\mathrm{Eu}^{3+}$ (FIG. 5.39).

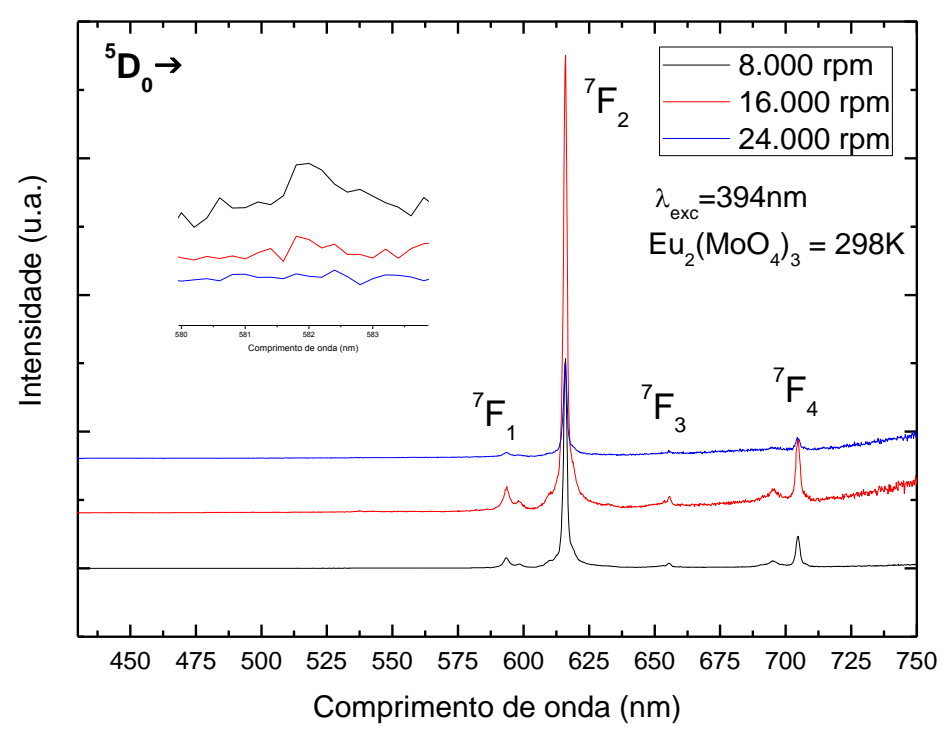

FIGURA 5.38. Espectros de emissão do luminóforo $\mathrm{Eu}_{2}\left(\mathrm{MoO}_{4}\right)_{3}$ obtidos em diferentes velocidades de dispersão (8000 rpm, 16000 rpm e 24000 rpm) em temperatura ambiente em temperatura ambiente $(a)$.

À baixa temperatura (77K) são observadas transições oriundas do nível emissor ${ }^{5} D_{1}$. Além disso, a transição ${ }^{5} D_{0} \rightarrow{ }^{7} F_{0}$ aparece mais definida e intensificada com máximo em $583 \mathrm{~nm}$. No caso do espectro de emissão (FIG 5.39) obtido a 77K, sob excitação no estado de LMCT O $\rightarrow \mathrm{Eu}^{3+}$, não é observada 
nenhuma banda relativa às transições ${ }^{5} D_{\lrcorner} \rightarrow{ }^{7} F_{\jmath}$ nessa região espectral de 420 a $570 \mathrm{~nm}$, sugerindo que esse processo de supressão ocorra mesmo à baixa temperatura (77K). Deve-se salientar que as intensidades de emissão das transições ${ }^{5} D_{1} \rightarrow{ }^{7} F_{J}$ são extremamente fracas e de baixa resolução mesmo quando obtidas à $77 \mathrm{~K}$.

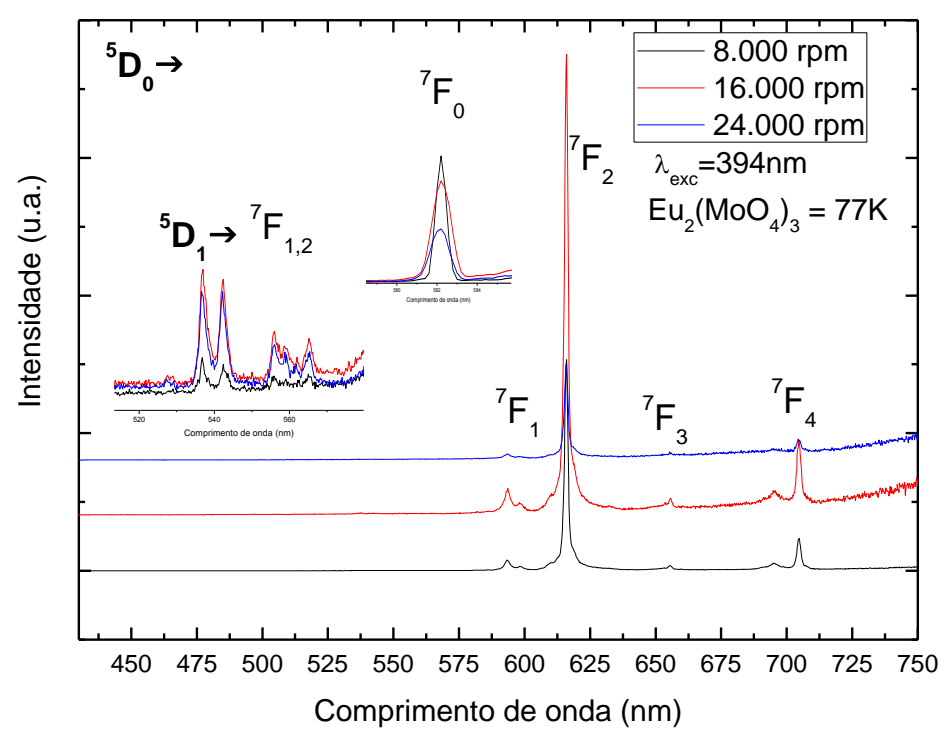

FIGURA 5.39. Espectros de emissão do luminóforo $\mathrm{Eu}_{2}\left(\mathrm{MoO}_{4}\right)_{3}$ obtidos em diferentes velocidades de dispersão (8000, 16000 e 24000 rpm) em temperatura ambiente em $\mathrm{N}_{2}$ líquido.

Os parâmetros de intensidade experimentais $\Omega_{\lambda}(\lambda=2$ e 4$)$ foram determinados para os compostos $\mathrm{Eu}_{2}\left(\mathrm{MoO}_{4}\right)_{3}$ a partir dos dados espectrais de emissão.

Os $\Omega_{\lambda}$ também chamados de parâmetros de Judd-Ofelt ${ }^{1,2}$ são determinados por meio das intensidades das respectivas transições ${ }^{5} D_{0} \rightarrow{ }^{7} F_{J}(J=$ 
2 e 4) do íon $\mathrm{Eu}^{3+}$ onde os mecanismos de dipolo elétrico forçado (DEF) e acoplamento dinâmico (AD) são considerados simultaneamente.

Com base nos dados espectrais,nos tempos de vida $(\tau)$,e nas equações foram determinados os parâmetros de intensidade experimentais $\left(\Omega_{2} \mathrm{e}\right.$ $\left.\Omega_{4}\right)$, as taxas radiativas e não-radiativas $\left(\mathrm{A}_{\mathrm{rad}} \mathrm{e} \mathrm{A}_{\text {nrad }}\right)$ e a eficiência quântica $(\eta)$ do nível emissor ${ }^{5} D_{0}$, para o luminóforo $\mathrm{Eu}_{2}\left(\mathrm{MoO}_{4}\right)_{3} \mathrm{em} 298 \mathrm{~K}$ e são apresentados na TAB. 5.6. Pode-se observar que o tempo de vida do estado emissor ${ }^{5} \mathrm{D}_{0}$ diminuiu com o aumento da velocidade de dispersão da ordem de $72 \%$ e a eficiência quântica, $79 \%$. Os parâmetros de intensidade são da mesma ordem de magnitude mostrando que a polarizabilidade e a simetria tem contribuições equivalentes nesse caso.

TABELA 5.6. Tempos de vida $(\tau)$, parâmetros de intensidade $\left(\Omega_{\lambda}\right)$, taxa radiativa $\left(A_{\text {rad }}\right)$, taxa não-radiativa $\left(A_{\text {nrad }}\right)$ e eficiência quântica $(\eta)$ de emissão do nível emissor ${ }^{5} D_{0}$ determinado para o luminóforo dopado com európio em $298 \mathrm{~K}$.

\begin{tabular}{c|ccccccc}
\hline Compostos & $\boldsymbol{\Omega}_{2}$ & $\boldsymbol{\Omega}_{4}$ & $\mathbf{A}_{\text {rad }}$ & $\mathbf{A}_{\text {nrad }}$ & $\boldsymbol{A}_{\text {tot }}$ & $\tau^{5} \mathbf{D}_{\text {o(ms })}$ & $\eta$ \\
\hline $\mathrm{Eu}_{2}\left(\mathrm{MoO}_{4}\right)_{3}(2500 \mathrm{rpm})$ & 14 & 10 & 622 & 2015 & 2637 & 0,337 & 24 \\
$\mathrm{Eu}_{2}\left(\mathrm{MoO}_{4}\right)_{3}(8000 \mathrm{rpm})$ & 17 & 11 & 712 & 3659 & 4371 & 0,229 & 16 \\
$\mathrm{Eu}_{2}\left(\mathrm{MoO}_{4}\right)_{3}(16000 \mathrm{rpm})$ & 13 & 13 & 642 & 8973 & 9615 & 0,104 & 8 \\
$\mathrm{Eu}_{2}\left(\mathrm{MoO}_{4}\right)_{3}(24000 \mathrm{rpm})$ & 8 & 9 & 564 & 9914 & 10470 & 0,096 & 5 \\
\hline
\end{tabular}

\subsection{Dopagens das nanopartículas de molibdato de ítrio com elementos de terras raras}

Para se obter dados sobre a solubilização do dopante na matriz de $\mathrm{MoO}_{4}$ sintetizou-se o molibdato de ítrio dopado com Eu e $\mathrm{Tb}$ nas concentrações de 1, 3, 5 e 10\% molar do dopante. O método de síntese foi o mesmo utilizado no restante do trabalho, por coprecipitação. Quando o íon $\mathrm{Eu}^{3+}$ é adicionado à matriz 
$\mathrm{Y}_{2}\left(\mathrm{MoO}_{4}\right)_{3} \circ$ íon európio substitui o $\mathrm{Y}^{3+}$ visto que o raio do $\mathrm{Y}$ é mais semelhante ao raio do Eu. Esta diferença de raios iônicos entre o íon $\mathrm{Y}^{3+}(1,12 \AA$; Número de Coordenação: 8) e o do $\mathrm{Eu}^{3+}$ (1,066 Aं; NC: 8) obedece estritamente à Lei de Vegard 69 a qual estabelece uma diferença de $15 \%$ para obter uma completa solubilização entre o íon dopante e o cátion da matriz.

Como resultado da síntese, foram obtidos pós cristalinos, branco e insolúvel em água e alguns solventes. A FIG. 5.40 apresenta fotografias obtidas por uma câmera digital do $\mathrm{Y}_{2-x}\left(\mathrm{MoO}_{4}\right)_{3} \% \mathrm{Eu}(\mathrm{x}=0,01,0,03,0,05$ e 0,1$)$ sob luz ambiente e sob irradiação ultravioleta $(366 \mathrm{~nm})$ emitindo cor avermelhada intensa. Para o $\mathrm{Y}_{2-x}\left(\mathrm{MoO}_{4}\right)_{3} \% \mathrm{~Tb}(\mathrm{x}=0,01,0,03,0,05$ e 0,1$)$ não houve emissão de cor verde em sob excitação em $250 \mathrm{nmn}$.

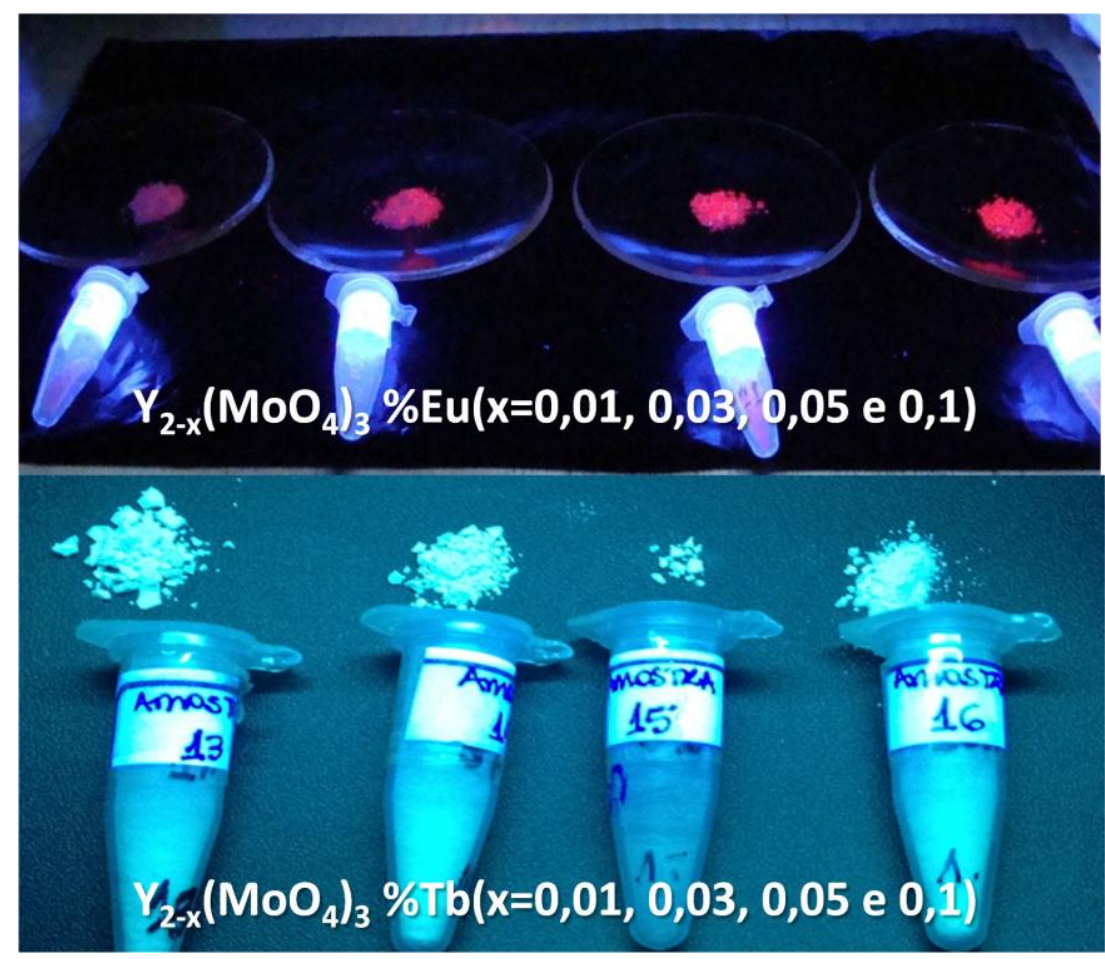

FIGURA 5.40. Imagem da emissão do sistema $Y_{2-x}\left(M_{0 O}\right)_{3} \% E u(x=0,01,0,03$, $0,05$ e 0,1$)$ e excitadoscom luz ambiente e com irradiação ultravioleta $(366 \mathrm{~nm})$ emitindo cor avermelhada intensa e do sistema $\mathrm{Y}_{2-\mathrm{x}}\left(\mathrm{MoO}_{4}\right)_{3} \% \mathrm{~Tb}(\mathrm{x}=0,01,0,03$, $0,05$ e 0,1$)$ excitadoscom luz ambiente e com irradiação ultravioleta (366nm) não emitindo cor. 


\subsubsection{Espectroscopia de infravermelho com transformada de Fourrier (FTIR)}

Os materiais obtidos pela dopagem da matriz molibdato de ítrio com térbio e európio foram analisados por espectroscopia de absorção na região do infravermelho. Os espectros mostraram bandas atribuídas aos estiramentos $\mathrm{vO}-\mathrm{H}$ em $\sim 3370 \mathrm{~cm}^{-1}, \delta \mathrm{H}-\mathrm{O}-\mathrm{H}$ em $1629 \mathrm{~cm}^{-1}$ e bandas em 943, $862 \mathrm{~cm}^{-1}$ (s), 760 e706 $\mathrm{cm}^{-1}$ (s), que são características da fase tetragonal do íon $\left(\mathrm{MoO}_{4}\right)^{-2}$ e foram atribuídas aos estiramentos $v 1$ e $v 3$ respectivamente (FIG. 5.41$) \cdot{ }^{65-68}$ O perfil dos espectros é o mesmo tanto para a matriz dopada com térbio quanto a dopada com európio.

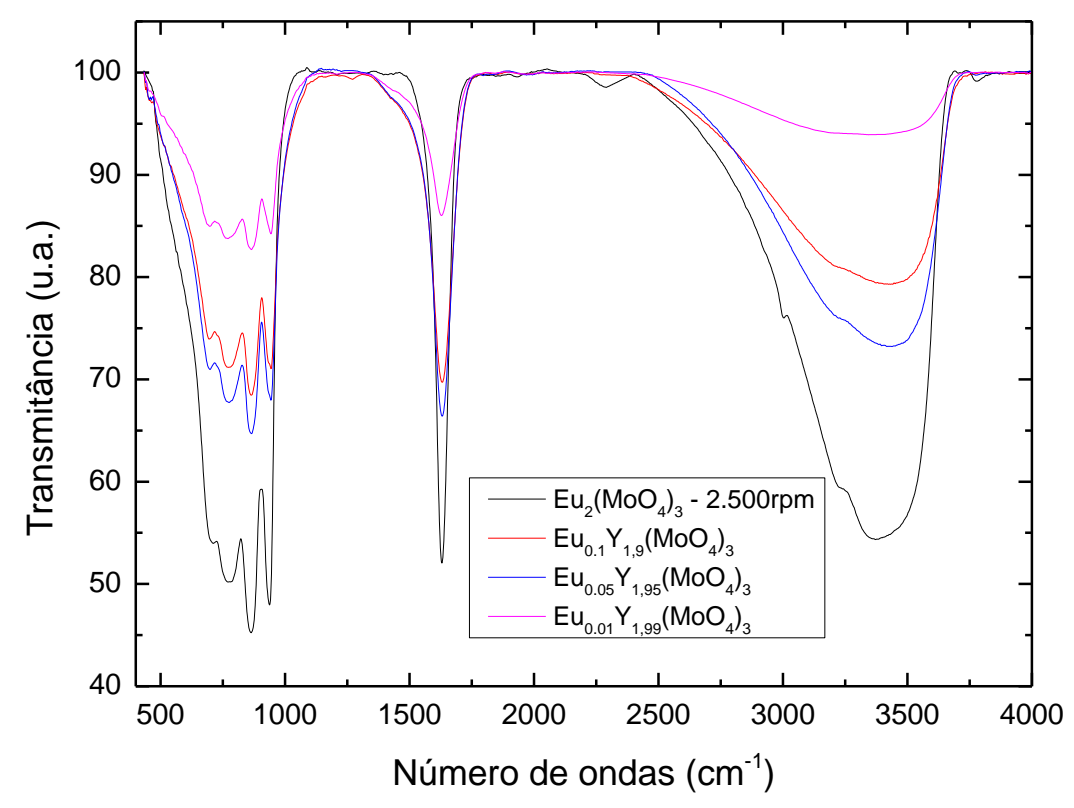

FIGURA 5.41. Espectros de Infravermelho dos do sistema $\mathrm{Y}_{2-x}\left(\mathrm{MoO}_{4}\right)_{3}$ $\% \operatorname{Eu}(x=0,01 ; 0,03 ; 0,05,0,1$ e 2.0$)$. 


\subsubsection{Difração de raio X (DRX)}

A FIG. 5.42 apresentam os difratogramas das amostras de $\mathrm{Y}_{2}\left(\mathrm{MoO}_{4}\right)_{3}$ $\left(1 \%, 3 \%, 5 \%\right.$ e $\left.10 \% \mathrm{Eu}^{3+}\right)$ e pode-se observar o mesmo padrão de difração para as quatro dopagens, estrutura isomorfa. A partir do cálculo do tamanho do cristalito pela fórmula de Scherrer observa-se que o tamanho do cristalito apresentou valores próximos com o aumento da dopagem do material.

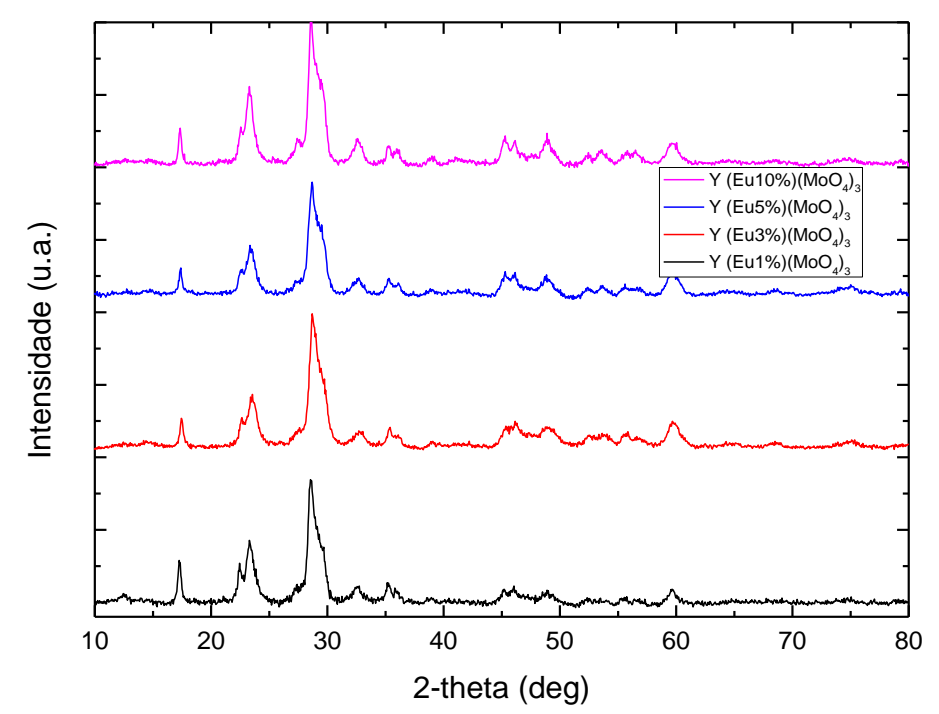

FIGURA 5.42. Difratograma das amostras de $\mathrm{Y}_{2-\mathrm{x}}\left(\mathrm{MoO}_{4}\right)_{3} \% \mathrm{Eu}(\mathrm{x}=0,01,0,03,0,05$ e 0,1$)$ 
Resultados e discussões - Sínteses e Caracterizações

TABELA 5.7. Diâmetro do cristalito calculado pelo método de Sherrer,para $Y_{2^{-}}$ $x\left(\mathrm{MoO}_{4}\right)_{3} \% \mathrm{Eu}(\mathrm{x}=0,01,0,03,0,05$ e 0,1$)$ e $\mathrm{Y}_{2}-\mathrm{x}\left(\mathrm{MoO}_{4}\right)_{3} \% \mathrm{~Tb}(\mathrm{x}=0,01,0,03,0,05 \mathrm{e}$ $0,1)$

\begin{tabular}{l|l}
\hline Amostra & $\varnothing$ \\
\hline $\mathrm{Eu}_{0,01} \mathrm{Y}_{1,99}\left(\mathrm{MoO}_{4}\right)_{3}(2500 \mathrm{rpm})$ & 13,5 \\
$\mathrm{Eu}_{0,03} \mathrm{Y}_{1,97}\left(\mathrm{MoO}_{4}\right)_{3}(2500 \mathrm{rpm})$ & 6,7 \\
$\mathrm{Eu}_{0,05} \mathrm{Y}_{1,95}\left(\mathrm{MoO}_{4}\right)_{3}(2500 \mathrm{rpm})$ & 12.7 \\
$\mathrm{Eu}_{0,10} \mathrm{Y}_{1,90}\left(\mathrm{MoO}_{4}\right)_{3}(2500 \mathrm{rpm})$ & 16,0 \\
$\mathrm{~Tb}_{0,01} \mathrm{Y}_{1,99}\left(\mathrm{MoO}_{4}\right)_{3}(2500 \mathrm{rpm})$ & 16,10 \\
$\mathrm{~Tb}_{0,03} \mathrm{Y}_{1,97}\left(\mathrm{MoO}_{4}\right)_{3}(2500 \mathrm{rpm})$ & 14,1 \\
$\mathrm{~Tb}_{0,05} \mathrm{Y}_{1,95}\left(\mathrm{MoO}_{4}\right)_{3}(2500 \mathrm{rpm})$ & 14,4 \\
$\mathrm{~Tb}_{0,10} \mathrm{Y}_{1,90}\left(\mathrm{MoO}_{4}\right)_{3}(2500 \mathrm{rpm})$ & 14,7 \\
\hline
\end{tabular}

A FIG. 5.43 demonstra o mesmo comportamento observado para $\circ \mathrm{Y}_{2^{-}}$ $x\left(\mathrm{MoO}_{4}\right)_{3} \% \mathrm{Eu}(\mathrm{x}=0,01,0,03,0,05$ e 0,1$)$. Os dados de raio $\mathrm{X}$ concordam com uma simetria tetragonal distorcida para monoclínica como é demonstrado por Wang et al. e colaboradores. ${ }^{24}$ 


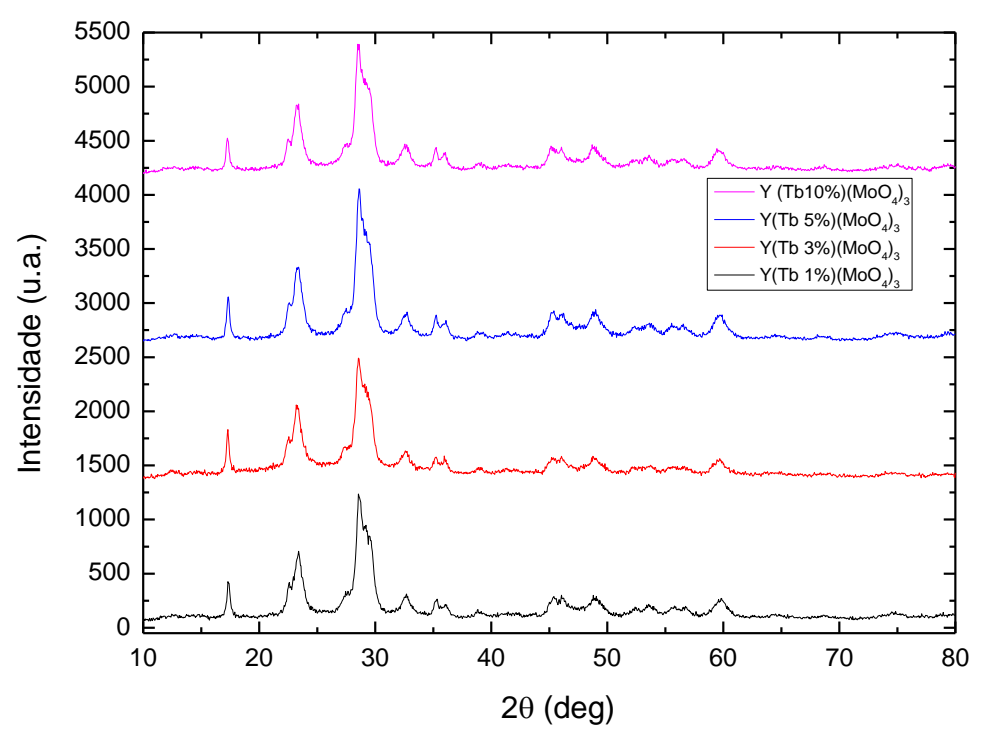

FIGURA 5.43. Difratograma das amostras de $\mathrm{Y}_{2-\mathrm{x}}\left(\mathrm{MoO}_{4}\right)_{3} \% \mathrm{~Tb}(\mathrm{x}=0,01,0,03,0,05$ e 0,1$)$.

\subsubsection{Microscopia eletrônica de varredura (MEV)}

Na FIG. 5.44 são apresentadas as imagens de MEV dos fósforos $Y_{2^{-}}$ $\mathrm{x}\left(\mathrm{MoO}_{4}\right)_{3} \% \mathrm{Eu}^{3+}$ dopados com diferentes concentrações de $\mathrm{Eu}^{3+}\left(\% \mathrm{Eu}^{3+}=0,01\right.$, $0,03,0,05$ e 0,1$)$ com magnificação de 10000 vezes. Observam-se aglomerados de superfície homogênea, com distribuição de tamanho de grão heterogêneo em sua maioria e com tamanhos menores que $20 \mu \mathrm{m}$, para todas as dopagens.

As imagens de MEV apresentadas nas FIG.5.45 são do luminóforo $Y_{2^{-}}$ $x\left(\mathrm{MoO}_{4}\right)_{3} \% \mathrm{~Tb}$, nas dopagens de $(\mathrm{x}=0,01,0,03,0,05$ e 0,1$)$. Respectivamentee aumento de 10000 vezes. Assim como no luminóforo dopado com európio, estes fósforos também se apresentam na forma de aglomerados de superfície homogênea e distribuição granulométrica heterogênea. É possível observar que a variação da dopagem não influência no aspecto dos aglomerados.. Também não foi observado segregação de fases. O aspecto dos materiais com Eu são de caráter esponjoso enquanto os de térbio tem aspecto de flor construída por flocos 
Resultados e discussões - Sínteses e Caracterizações

interligados entre si. As amostras dopadas com diferentes concentrações de európio (1\%, 3\% 5\%, 10\%) apresentam superfície porosa. Estas imagens são similares as imagens reportadas por Ko et at. ${ }^{70}$
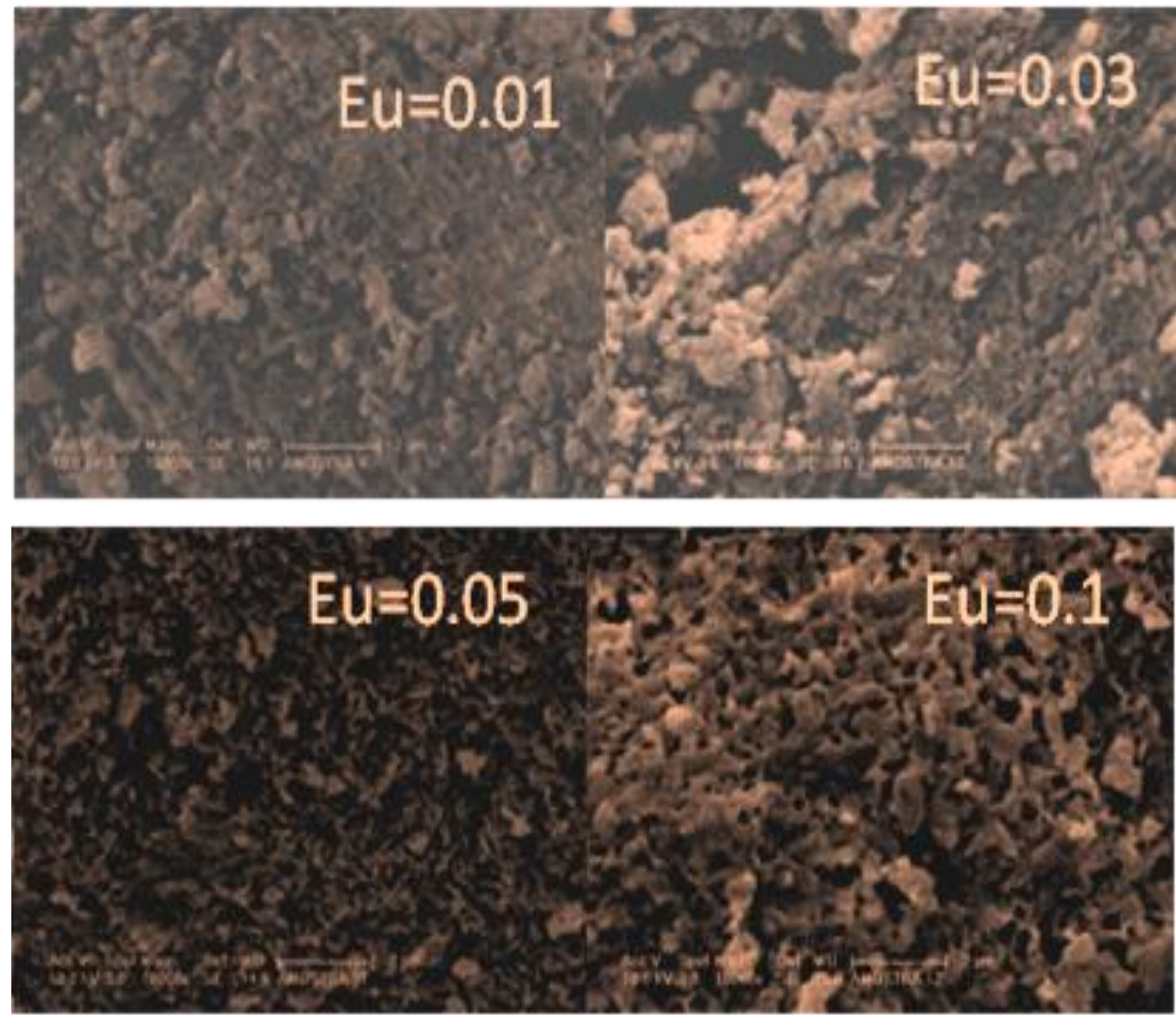

FIGURA 5.44. Micrografias de nanopartículas de $\mathrm{Y}_{2}-\mathrm{x}\left(\mathrm{MoO}_{4}\right)_{3} \% \mathrm{Eu}(\mathrm{x}=0,01,0,03$, $0,05$ e 0,1$)$. 
Resultados e discussões - Sínteses e Caracterizações

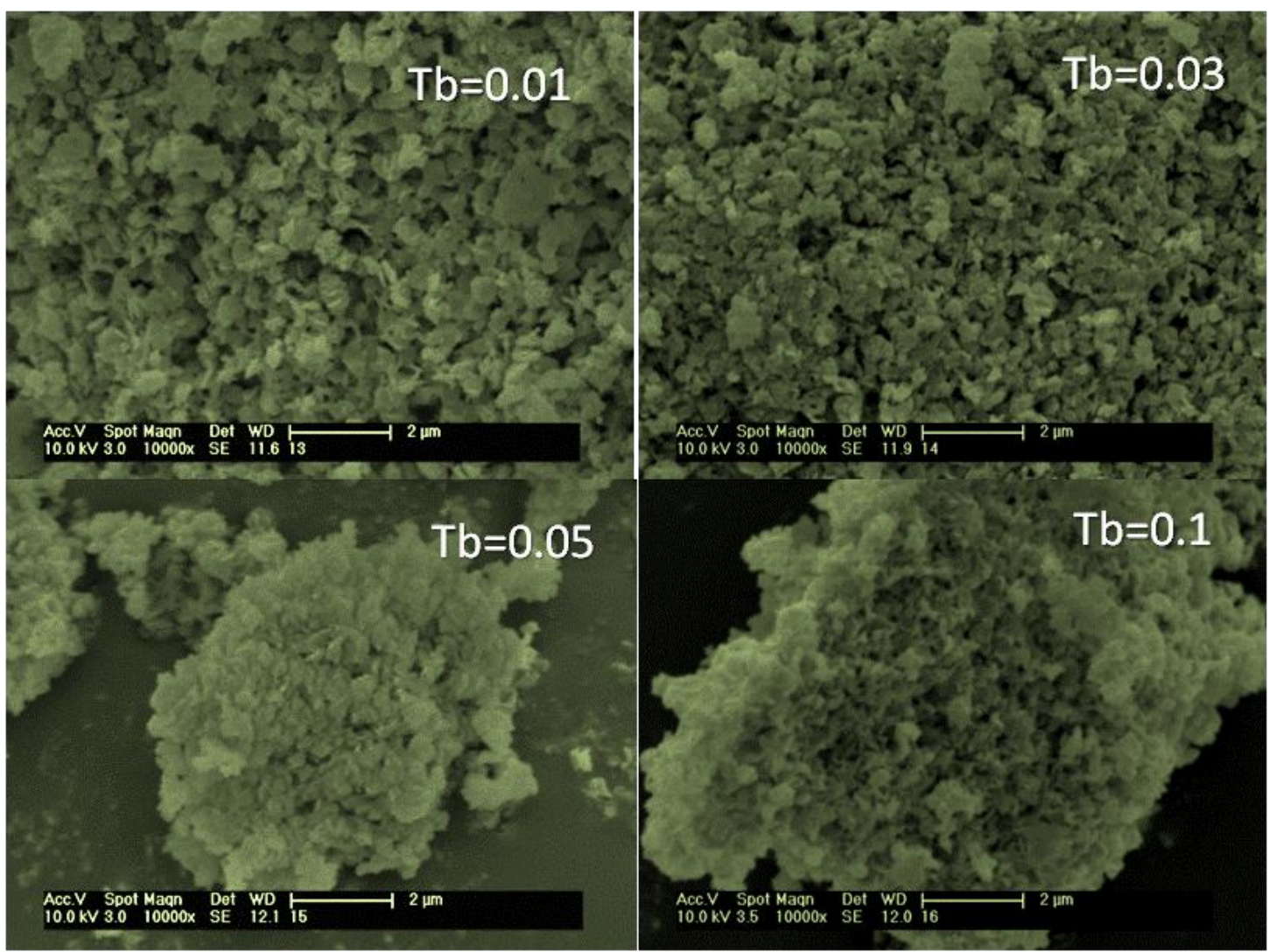

FIGURA 5.45. Micrografias de nanopartículas de $\mathrm{Y}_{2}-\mathrm{x}\left(\mathrm{MoO}_{4}\right)_{3} \% \mathrm{~Tb}(\mathrm{x}=0,01,0,03$, $0,05$ e 0,1$)$.

\subsubsection{Estudo das propriedades luminescentes}

As propriedades espectroscópicas luminescentes deste molibdatos de itrio dopados com Eu e Tb foram obtidas através dos dados dos espectros de emissão e excitação. Os espectros de excitação das nanopartículas de $\mathrm{Eu}_{2}\left(\mathrm{MoO}_{4}\right)_{3}$ e $\mathrm{x} \% \mathrm{Eu}^{3+}: \mathrm{Y}_{2-\mathrm{x}}\left(\mathrm{MoO}_{4}\right)_{3}$ (FIG. 5.46) foram obtidos a temperatura ambiente com emissão monitorada em $614 \mathrm{~nm}$. Eles mostram bandas finas características das transições $4 \mathrm{f}-4 \mathrm{f}$ e uma banda larga depois de $250 \mathrm{~nm}$ atribuídas as transições O-Metal que para matriz. Já na matriz de ítrio as transições LMCT $\rightarrow$ O-M se desloca para região do ultravioleta (omitido da figura). 


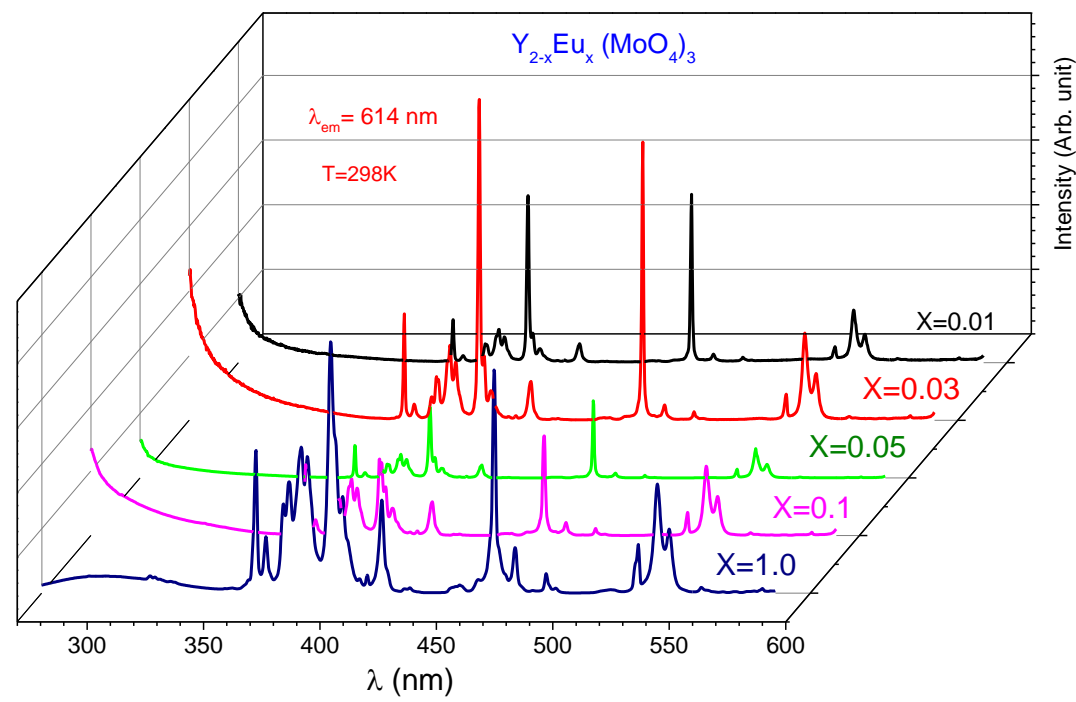

FIGURA 5.46. Espectros de excitação das amostras de $\mathrm{Y}_{2-x}\left(\mathrm{MoO}_{4}\right)_{3} \% \mathrm{Eu}(\mathrm{x}=0,01$, $0,03,0,05$ e 0,1$)$.

Os espectros de emissão das nanopartículas $\mathrm{Y}_{2-\mathrm{x}}\left(\mathrm{MoO}_{4}\right)_{3} \% \mathrm{Eu}(\mathrm{x}=0,01$, $0,03,0,05$ e 0,1 ) com excitação monitorada em 394 nm são apresentados na FIG. 5.47. Os espectros de emissão consistem essencialmente de linhas intensas e finas no intervalo de 420 a $750 \mathrm{~nm}$, que são atribuídas as transições ${ }^{5} \mathrm{D}_{0} \rightarrow{ }^{7} \mathrm{~F}_{\mathrm{J}}$.

Quatro grupos de linhas centradas em 580, 590, $\sim 612$ e $\sim 700 \mathrm{~nm}$ correspondendo às transições dentro da configuração $4 f$ entre 0 estado ${ }^{5} D_{0}$ para os níveis de energia mais baixos ${ }^{7} F_{J}(J=0,1,2,4)$. O pico em $~ 580 \mathrm{~nm}$ é proibido por dipolo elétrico e magnético e está presente em simetrias do tipo $C_{n v}, C_{n}$ e $C_{s}$ devido à mistura dos estados eletrônicos $\mathrm{J}(\mathrm{J}-$ mixing). Nos espectros também são observadas transições provenientes do primeiro nível excitado de emissão ${ }^{5} D_{1}$ para os níveis ${ }^{7} F_{1,2}$, com intensidade da ordem de $10^{5}$ nas regiões de $537 \mathrm{~nm}$ e $556 \mathrm{~nm}$, respectivamente. Estas bandas são suprimidas devido, provavelmente, aos processos de relaxação cruzada $\left({ }^{5} D_{\jmath} \rightarrow{ }^{5} D_{0}\right) \rightarrow\left({ }^{7} F_{0} \rightarrow{ }^{7} F_{\jmath}\right)$.A presença da transição ${ }^{5} \mathrm{D}_{0} \rightarrow{ }^{7} \mathrm{~F}_{0}$ é atribuída ao efeito de mistura dos J's através da componente de paridade par do campo cristalino. 
As bandas em $\sim 590 \mathrm{~nm}$ são atribuídas à transição ${ }^{5} \mathrm{D}_{0} \rightarrow{ }^{7} \mathrm{~F}_{1}$, que é permitida por dipolo magnético e o coeficiente de transição para esta transição não se altera com a modificação no sítio de simetria (a probabilidade de ocorrer transição ${ }^{5} \mathrm{D}_{0} \rightarrow{ }^{7} \mathrm{~F}_{1}$ não é afetada pela simetria porque é permitida por regra de seleção de paridade). Sendo assim, a simetria do sítio cristalino em que os íons $\mathrm{Eu}^{3+}$ estão localizados, pode ser determinada pela razão entre as transições ${ }^{5} \mathrm{D}_{0} \rightarrow{ }^{7} \mathrm{~F}_{1}$ e ${ }^{5} \mathrm{D}_{0} \rightarrow{ }^{7} \mathrm{~F}_{2}$. Em um sítio com centro de inversão a transição ${ }^{5} \mathrm{D}_{0} \rightarrow{ }^{7} \mathrm{~F}_{1}$ de dipolo magnético é a transição dominante no espectro. ${ }^{43}$

A banda mais proeminente no espectro de emissão centrada em $\sim 614 \mathrm{~nm}$ e responsável pela emissão no vermelho é atribuída a transição permitida por dipolo elétrico ${ }^{5} \mathrm{D}_{0} \rightarrow{ }^{7} \mathrm{~F}_{2}$.

A transição ${ }^{5} D_{0} \rightarrow{ }^{7} F_{2}$ é muito sensível a pequenas alterações no ambiente químico dos íons $\mathrm{Eu}^{3+}$. A intensidade desta transição de dipolo elétrico é significativamente afetada pelo grau de simetria do ambiente ao redor dos íons $\mathrm{Eu}^{3}{ }^{44}$

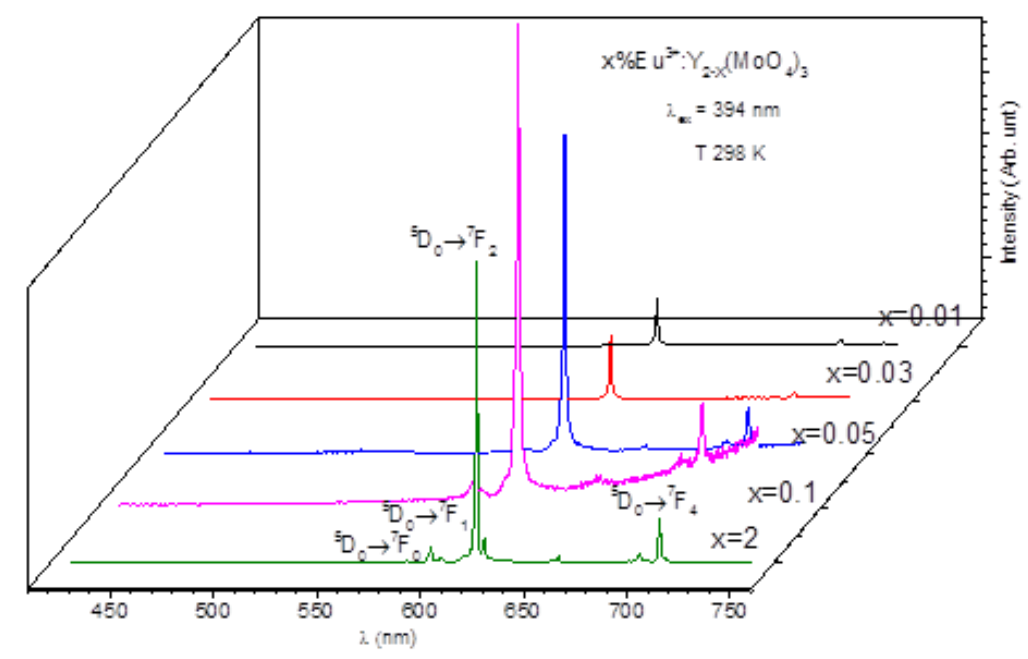

FIGURA 5.47. Espectros de emissão das nanopartículas de $\mathrm{Y}_{2}\left(\mathrm{MoO}_{4}\right)_{3}$

$$
\left(1 \%, 3 \%, 5 \% \text { e } 10 \% \mathrm{Eu}^{3+}\right) \text {. }
$$


Com base nos dados espectrais e nas equações foram determinados os tempos de vida $(\tau)$, os parâmetros de intensidade experimentais $\left(\Omega_{2}\right.$ e $\left.\Omega_{4}\right)$, as taxas radiativas e não-radiativas $\left(\mathrm{A}_{\text {rad }}\right.$ e $\left.\mathrm{A}_{\text {nrad }}\right)$ e a eficiência quântica $(\eta)$ do nível emissor ${ }^{5} \mathrm{D}_{0}$, determinado para o luminóforo $\mathrm{Y}_{2}\left(\mathrm{MoO}_{4}\right)_{3} \quad(1 \%, 3 \%, 5 \%$ e $10 \%$ $\mathrm{Eu}^{3+}$ ).em $298 \mathrm{~K}$ e estão representados na TAB.5.7. Como pode ser observado, os valores do parâmetro de intensidade $\Omega_{2}$ são da ordem das outras matrizes estudadas pelo grupo e menores do que para os complexos. ${ }^{40}$ Esses dados indicam que o íon $\mathrm{Eu}^{3+}$ nessa matriz encontra-se em um ambiente químico menos polarizável.

De um modo geral os valores de eficiência quântica $(\eta)$ do nível emissor ${ }^{5} \mathrm{D}_{0}$ se diminui com o aumento das concentrações de dopagem.

TABELA 5.8. Tempos de vida $(\tau)$, parâmetros de intensidade $\left(\Omega_{\lambda}\right)$, taxa radiativa $\left(A_{\text {rad }}\right)$, taxa não-radiativa $\left(A_{n r a d}\right)$ e eficiência quântica $(\eta)$ de emissão do nível emissor ${ }^{5} D_{0}$ determinado para os fósforos dopados com európio em $298 \mathrm{~K}$.

\begin{tabular}{c|ccccccc}
\hline $\begin{array}{c}\text { Dopagem } \\
(\%)\end{array}$ & $\begin{array}{c}\tau_{\text {médio }} \\
(\mathrm{ms})\end{array}$ & $\begin{array}{c}\Omega_{2} \\
\left(10^{20} \mathrm{~cm}^{2}\right)\end{array}$ & $\begin{array}{c}\Omega_{4} \\
\left(10^{-20} \mathrm{~cm}^{2}\right)\end{array}$ & $\begin{array}{c}A_{R A D} \\
\left(\mathrm{~s}^{-1}\right)\end{array}$ & $\begin{array}{c}A_{\text {NRAD }} \\
\left(\mathrm{s}^{-1}\right)\end{array}$ & $\begin{array}{c}A_{\text {tot }} \\
\left(\mathrm{s}^{-1}\right)\end{array}$ & $\begin{array}{c}\eta \\
(\%)\end{array}$ \\
\hline 1 & 0.764 & 18 & 14 & 779 & 531 & 1310 & 60 \\
3 & 0.765 & 16 & 15 & 745 & 563 & 1308 & 57 \\
5 & 0,712 & 16 & 15 & 745 & 661 & 1406 & 57 \\
10 & 0,627 & 10 & 8 & 477 & 1118 & 1595 & 30 \\
100 & 0,337 & 14 & 10 & 622 & 2015 & 2637 & 24 \\
\hline
\end{tabular}

Os espectros de excitação do material $\mathrm{Y}_{2}\left(\mathrm{MoO}_{4}\right)_{3}(1 \%, 3 \%, 5 \%$ e $10 \%$ $\mathrm{Tb}^{3+}$ ). foram registrados no intervalo de 250 a520 nm, com emissão monitorada na transição ${ }^{5} \mathrm{D}_{4} \rightarrow{ }^{7} \mathrm{~F}_{5}(\sim 547 \mathrm{~nm})$ e a temperatura ambiente. Eles apresentam bandas características do íon $\mathrm{Tb}^{3+}$ atribuídas às transições ${ }^{7} \mathrm{~F}_{6} \rightarrow{ }^{5} \mathrm{~L}$. Não foram 
observadas bandas atribuídas às transições de transferência de carga do metal ou do dopante para o ligante.

Os espectros de emissão das nanopartículas de $\mathrm{Y}_{2}-\mathrm{x}\left(\mathrm{MoO}_{4}\right)_{3}$ $\% \operatorname{Tb}(x=0,01,0,03,0,05$ e 0,1$)$ com excitação monitorada em 300 nm são apresentados na FIG 5.48 e apresentam as bandas características do íon térbio ${ }^{5} D_{4} \rightarrow{ }^{7} F_{J=0-5}$. Nota-se que o comportamento de emissão para os íons dopados são com Tb e Eu são similares, uma vez que apresentam emissões mais intensas quando dopadas a $10 \%$, esse comportamento confirma a hipótese de quanto maior a porcentagem de dopagem com o íon terra rara, maior a intensidade de emissão de luminescência e que em altas concentrações do dopante ocorre supressão da luminescência. Os espectros de emissão mostram as transições intraconfiguracionais relativas ao íon $\mathrm{Tb}^{3+}$ onde a mais proeminente é a ${ }^{5} \mathrm{D}_{4} \rightarrow{ }^{7} \mathrm{~F}_{5}$. $\mathrm{Da}$ análise da área desta transição foi possível mostrar que a intensidade de luminescência é diretamente proporcional a concentração de íons dopantes na matriz e quando o dopante é $100 \%$. Observa-se um quenching de luminescência devido o cruzamento intersistemas.

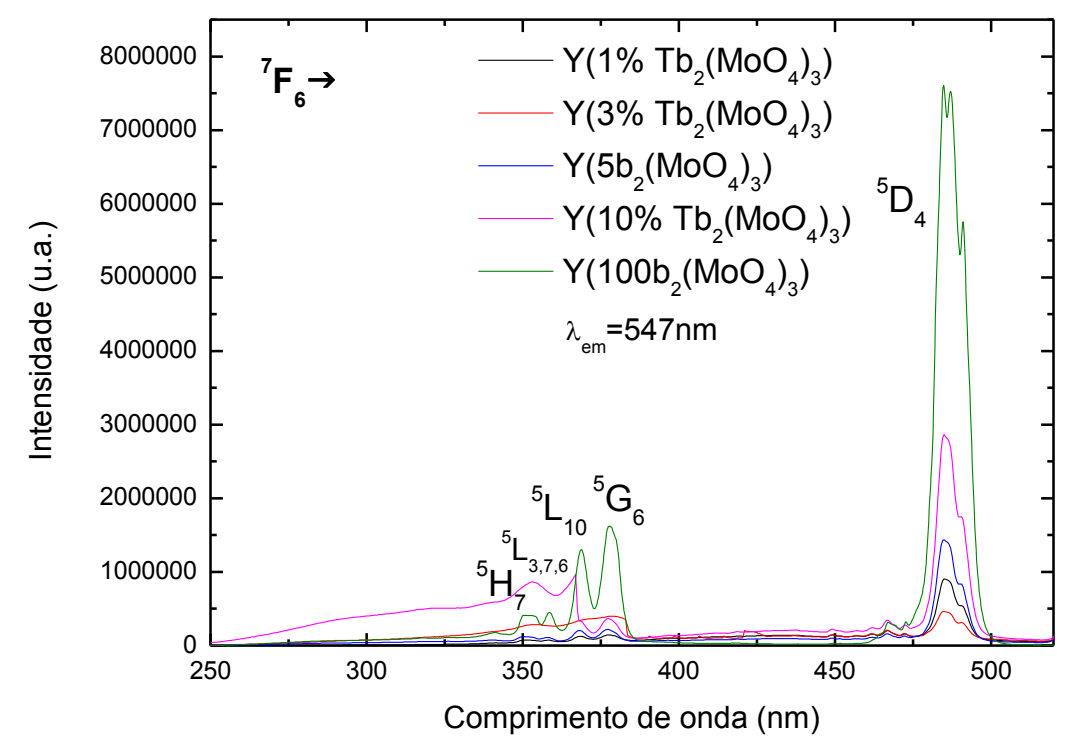

FIGURA 5.48. Espectros de excitação das nanopartículas de $\mathrm{Y}_{2-x}\left(\mathrm{MoO}_{4}\right)_{3} \% \mathrm{~Tb}$ $(x=0,01,0,03,0,05$ e 0,1$)$. 


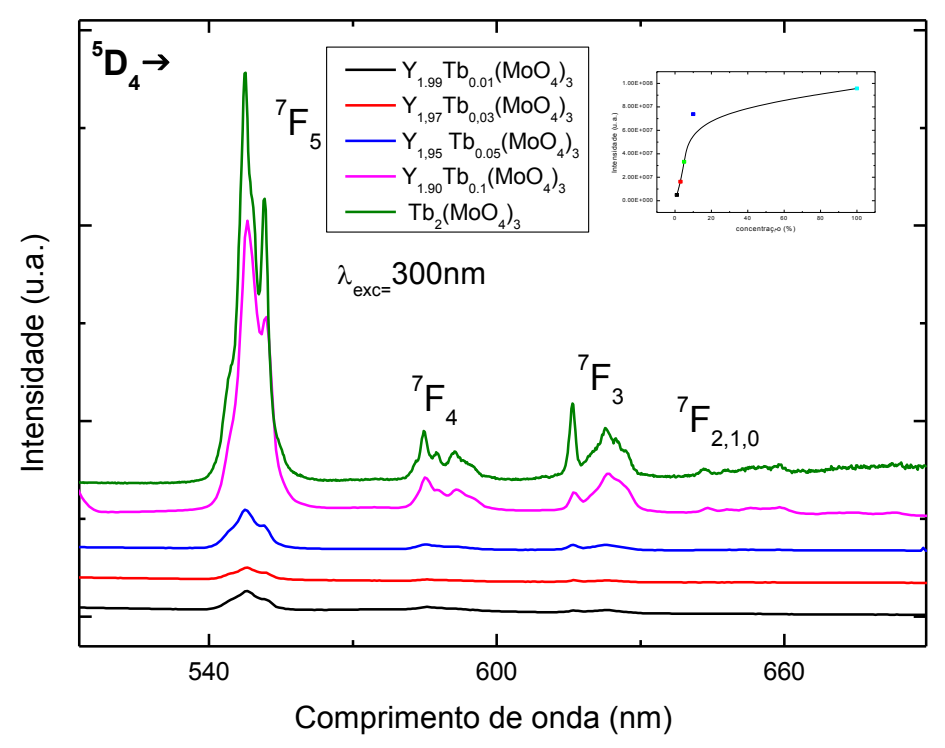

FIGURA 5.49. Espectros de emissão das nanopartículas de $\mathrm{Y}_{2-x}\left(\mathrm{MoO}_{4}\right)_{3} \% \mathrm{~Tb}$ $(x=0,01,0,03,0,05$ e 0,1$)$.

5.5 Estudo de Influência do tratamento térmico (Annealing) nas propriedades estruturais e luminescentes do luminóforo $\mathrm{Eu}_{2}\left(\mathrm{MoO}_{4}\right)_{3}$, $\mathrm{Sm}_{2}\left(\mathrm{MoO}_{4}\right)_{3}, \mathrm{~Tb}_{2}\left(\mathrm{MoO}_{4}\right)_{3} \mathrm{Ndd}_{2}\left(\mathrm{MoO}_{4}\right)_{3}$.

Com o intuito de melhorar as propriedades luminescentes dos fósforos através do aumento de cristalinidade do material fez-se um estudo sobre a influência do tratamento térmico nas propriedades luminescentes dos mesmos. Para este estudo escolheu-se as matrizes $\mathrm{Eu}_{2}\left(\mathrm{MoO}_{4}\right)_{3}, \mathrm{Sm}_{2}\left(\mathrm{MoO}_{4}\right)_{3}, \mathrm{~Tb}_{2}\left(\mathrm{MoO}_{4}\right)_{3} \mathrm{e}$ $\mathrm{Nd}_{2}\left(\mathrm{MoO}_{4}\right)_{3}$ para a execução dos experimentos. Após o processo de calcinação das partículas em quatro temperaturas distintas: $300,500,700$ e $1000{ }^{\circ} \mathrm{C}$, os materiais foram caracterizados por espectroscopia de infravermelho, difração de raios $\mathrm{X}$, microscopia eletrônica de varredura e espectroscopia de luminescência, para avaliação das modificações nas suas propriedades. 
Todas as amostras foram termicamente tratadas em uma mufla nas temperaturas citadas acima com permanência de 1 hora em cada temperatura e a velocidade de aquecimento realizada para cada aumento de $20 \stackrel{\circ}{\circ}$ por minuto para que fosse estudado o efeito do aumento da temperatura nas propriedades das amostras.

\subsubsection{Características qualitativas dos materiais tratados termicamente}

As amostras de $\mathrm{Sm}_{2}\left(\mathrm{MoO}_{4}\right)_{3} / \mathrm{Tb}_{2}\left(\mathrm{MoO}_{4}\right)_{3} / \mathrm{Eu}_{2}\left(\mathrm{MoO}_{4}\right)_{3} / \mathrm{Nd}_{2}\left(\mathrm{MoO}_{4}\right)_{3}$ após serem submetidas ao tratamento térmico, foram expostas e fotografadas à luz ambiente, obtendo-se pó branco. Devido ao aumento da temperatura, o pó apresentou cor amarelada relacionada muito provavelmente com as bandas de transferência de carga (para as amostras de Tb e Sm). Quando expostas a irradiação UV estes materiais calcinados emitem no vermelho, laranja e verde. O neodímio intensifica sua coloração lilás embora só apresente luminescência na região do infravermelho. 
Resultados e discussões - Sínteses e Caracterizações

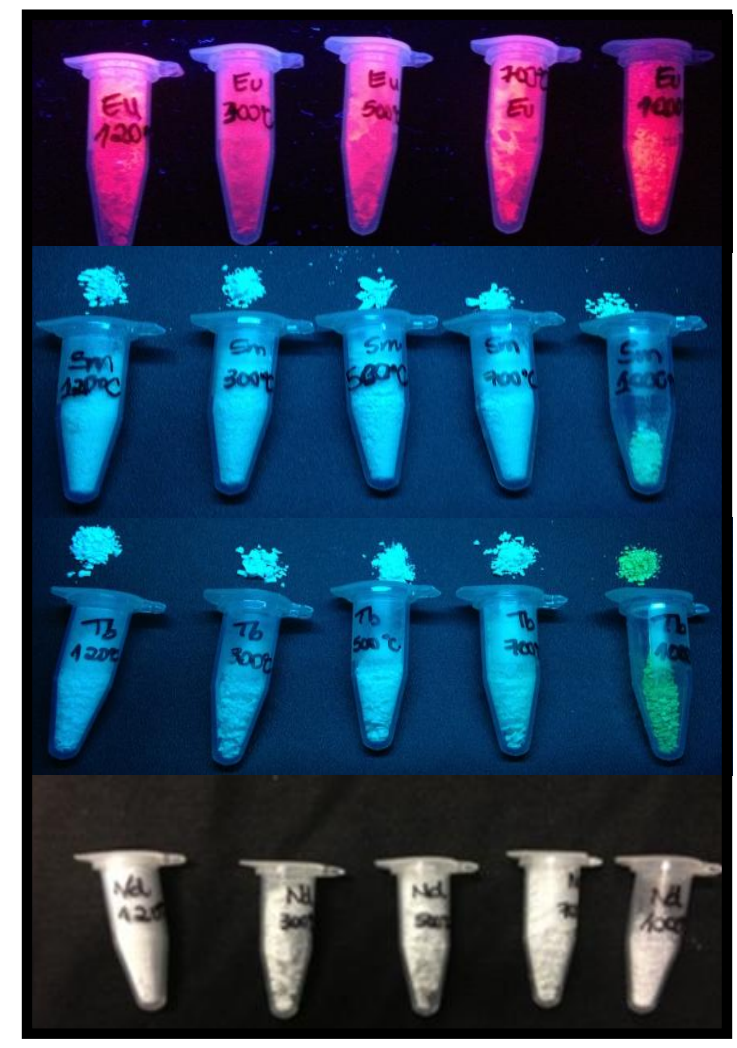

FIGURA 5.50. Amostras submetidas ao tratamento térmico sob luz ambiente e irradiação ultravioleta (366nm).

A literatura reporta diversas situações de tratamento térmico com molibdatos de terras raras. ${ }^{21,71,72,73}$, Kassau et al. ${ }^{21}$ reportaram diversos estudos utilizando molibdatos e tungstatos de terras raras e a partir desses estudos, eles apresentaram as temperaturas de derretimento para cada molibdato de terra rara utilizado juntamente com suas temperaturas de transição e estruturas. $\mathrm{Na}$ TAB 5.9 observam-se os íons terras raras utilizados nesse estudo com suas principais características térmicas. ${ }^{21}$ 
Resultados e discussões - Sínteses e Caracterizações

TABELA 5.9. Dados de temperaturas de derretimento, transição e estruturas dos molibdatos de terras raras.

\begin{tabular}{l|lll}
\hline \multicolumn{3}{c|}{ Molibdatos de Terras Raras } & Estrutura \\
$\mathrm{L}_{2}\left(\mathrm{MoO}_{4}\right)_{3}$ & $\begin{array}{l}\text { Derretimento } \\
\left({ }^{\circ} \mathrm{C}\right)\end{array}$ & $\begin{array}{l}\text { Transição } \\
(\text { oC) }\end{array}$ & $\begin{array}{l}\text { Temperaturas } \\
\text { altas }\end{array}$ \\
\hline $\mathrm{Nd}$ & 1080 & 960 & Tetragonal \\
$\mathrm{Sm}$ & 1085 & 940 & Tetragonal \\
$\mathrm{Eu}$ & 1150 & 880 & Tetragonal \\
$\mathrm{Tb}$ & 1170 & $\begin{array}{l}\text { não } \\
\text { observada }\end{array}$ & Tetragonal \\
\hline
\end{tabular}

5.5.2 Caracterização das matrizes termicamente tratadas por Espectroscopia de infravermelho com transformada de Fourrier (FTIR)

Na figura 5.51 apresenta-se o espectro de infravermelho das amostras de $\mathrm{Nd}_{2}\left(\mathrm{MoO}_{4}\right)_{3}$ representando os molibdatos de terras raras submetidos ao annealing. Os outros molibdatos estudados apresentaram espectros de infravermelho similares.

As bandas características do molibdato de terra rara são deslocadas para região de maior energia quando comparados aos espectros de infravermelho dos mesmos materiais sem tratamento térmico. As bandas referentes aos estiramento $v 1$ apresentam-se desdobradas e aparecem em 940—914 e 859-829 $\mathrm{cm}^{-1}$, já o estiramento $v 3$ que também estão desdobradas, aparecem na região de $764-760 \mathrm{~cm}-1$ ou desaparece uma das bandas (para 700 e $1000^{\circ} \mathrm{C}$ ). Em todas as temperaturas neste caso foi possível observar o estiramento $v 2$ na região de $430 \mathrm{~cm}-1$. Já as bandas na região do $\mathrm{H}-\mathrm{O}-\mathrm{H}\left(\sim 1630 \mathrm{~cm}^{-1}\right)$ e O-H $(\sim 3385)$ apresentaram uma mudança significativadas amostras de $700 \stackrel{\circ}{\circ} \mathrm{C}$ e $1000 \stackrel{\circ}{\circ} \mathrm{C}$ conforme figura 5.51 . 


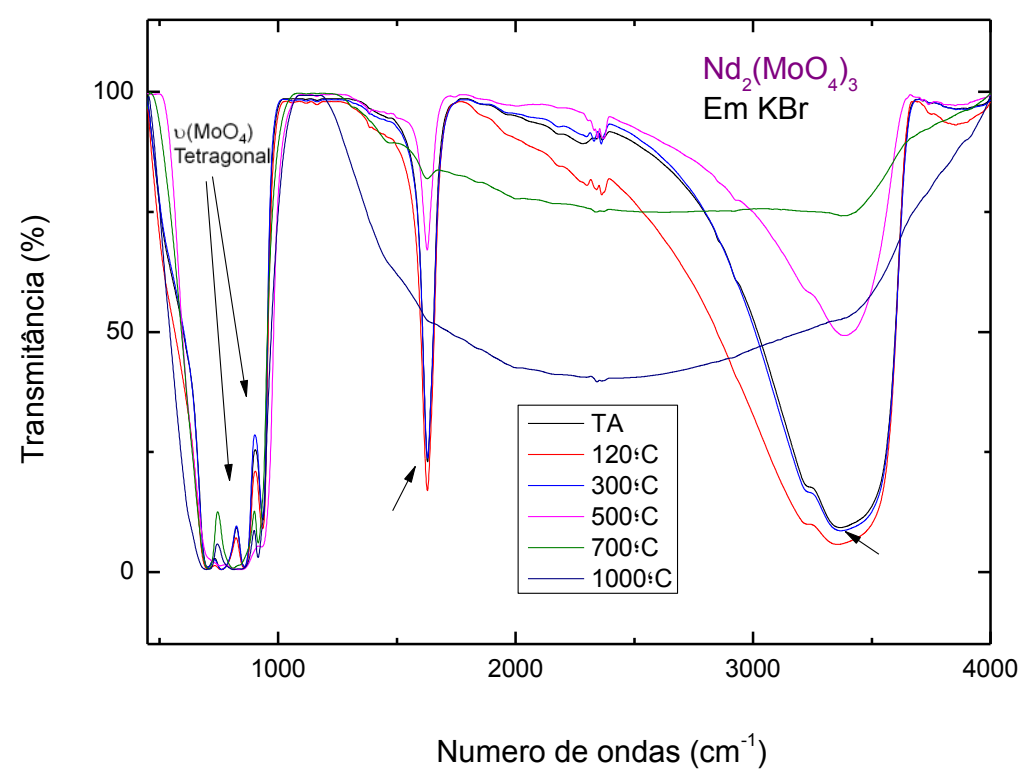

FIGURA 5.51.Espectros de infravermelho das amostras de $\mathrm{Nd}_{2}\left(\mathrm{MoO}_{4}\right)_{3}$.

\subsubsection{Difração de raio $X(D R X)$}

As análises dos difratogramas de raio $\mathrm{X}$ obtidos das amostras de $\mathrm{Eu}_{2}\left(\mathrm{MoO}_{4}\right)_{3}, \quad \mathrm{~Tb}_{2}\left(\mathrm{MoO}_{4}\right)_{3}, \quad \mathrm{Sm}_{2}\left(\mathrm{MoO}_{4}\right)_{3}$ e $\mathrm{Nd}_{2}\left(\mathrm{MoO}_{4}\right)_{3}$ termicamente tratadas demonstram que até $300^{\circ} \mathrm{C}$ os materiais aqui obtidos, apresentam-se como os preparados sem tratamento térmico. Na temperatura de $500^{\circ} \mathrm{C}$ estes materiais tem sua estruturas cristalinas completamente modificadas e apenas o pico em 28,2 graus é presente no difratograma, exceção feita ao samário. A partir de $700^{\circ} \mathrm{C}$, há uma aparente mudança e aumento da intensidade dos picos em todo o difratograma e visível modificação da estrutura pelo aumento na intensidade dos picos devido aos seus estreitamentos, que foi comprovado pela medida de largura a meia altura do pico e o desaparecimento de uns e aparecimento de outros planos de difração. Estes dados concordam com os dados de caracterização por infravermelho destas matrizes termicamente tratadas. Tang et $a^{74}$ que estudou 0 tratamento térmico de nanotubos de molibdato de európio e relatou aumento na intensidade dos picos do difratograma de raios $X$ e que os mesmos 
apresentaram-se mais finos com o aumento da temperatura do tratamento térmico, o mesmo comportamento foi observado para as amostras de $\mathrm{Eu}_{2}\left(\mathrm{WO}_{4}\right)_{3}$. Nassau et al. ${ }^{21}$ estudaram as várias fases de molibdatos de terras raras em função da temperatura de tratamento térmico. Em trabalhos iniciais, Nassau et al. ${ }^{75,76}$ eles descreveram a ocorrência de ao menos seis fases estruturais distintas dentre os compostos do tipo $L_{2}\left(M_{4}\right)_{3}$ onde $L$ são os elementos terras raras trivalentes ou qualquer elemento trivalente que tenha características parecidas com esses e M são os metais de transição ${ }^{75}$ Mo e W. Nesse trabalho, Nassau et al ${ }^{75}$, identificou mais 5 fases inclusive uma transição de fase a alta temperatura que anteriormente não tinha sido reconhecida em compostos de $\mathrm{TR}_{2}\left(\mathrm{Mo}_{4}\right)_{3}$. As várias fases são então distribuídas em três grupos principais com variações atribuídas às desordens e pequenas distorções na estrutura baseada sub-celula da schellita

A existência de regiões de vários tipos de estruturas é mostrada na figura 5.52 para os molibdatos e tungstatos respectivamente. 

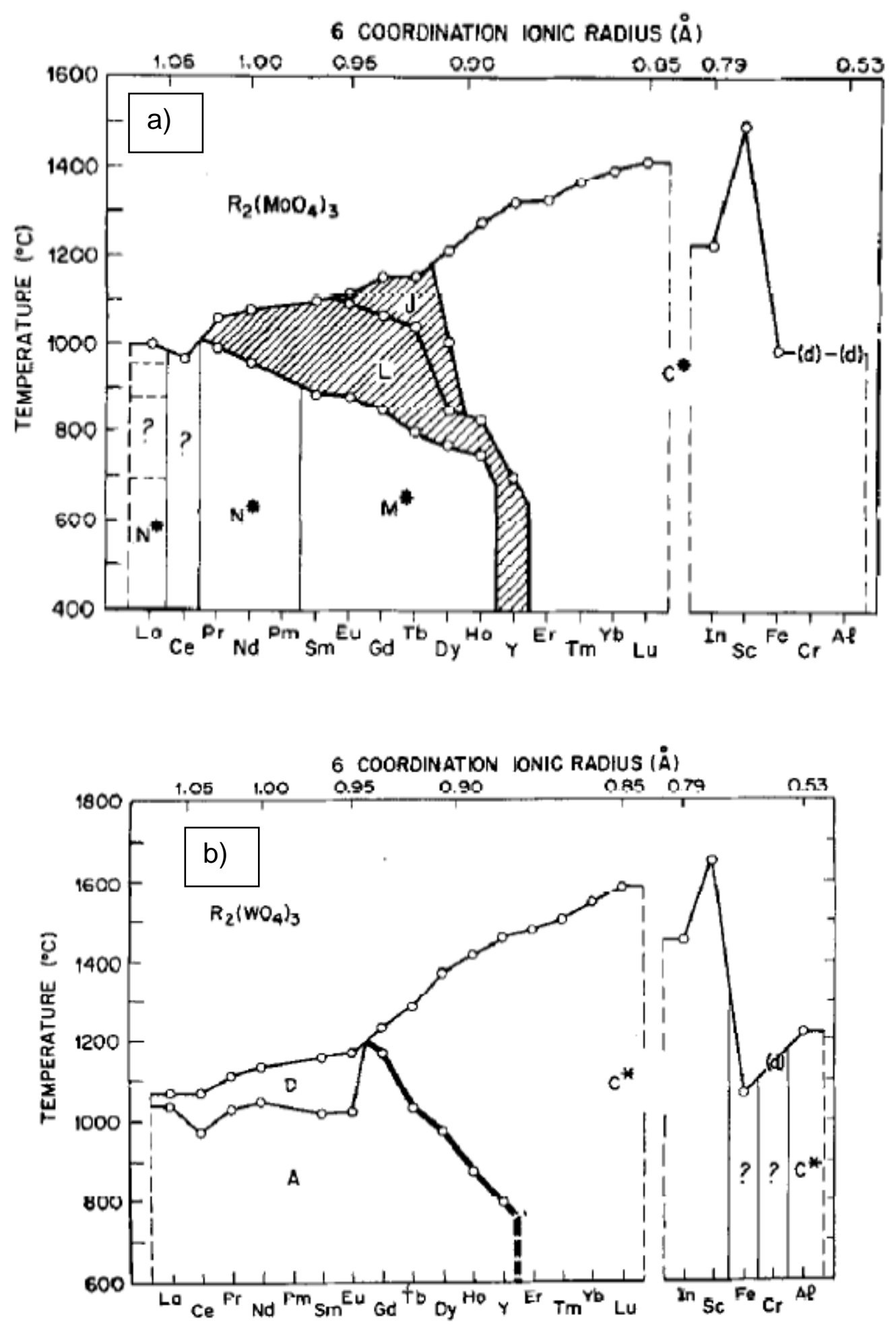

FIGURA 5.52. Temperaturas de fusão e de transição e tipos de estruturas ocorrendo na família de compostos a) $\mathrm{TR}_{2}\left(\mathrm{MoO}_{4}\right)_{3}$ e b) $\mathrm{TR}_{2}\left(\mathrm{WO}_{4}\right)_{3}{ }^{75}$ 
As FIG. 5.53-56 mostram os difratogramas das amostras de $\mathrm{Eu}_{2}\left(\mathrm{MoO}_{4}\right)_{3}, \mathrm{~Tb}_{2}\left(\mathrm{MoO}_{4}\right)_{3}, \mathrm{Sm}_{2}\left(\mathrm{MoO}_{4}\right)_{3}$ e $\mathrm{Nd}_{2}\left(\mathrm{MoO}_{4}\right)_{3}$ submetidas ao tratamento térmico (annealing) e todas as amostras obedeceram ao mesmo perfil de decomposição térmica. Para os quatro íons terras raras estudados, um evento pouco comum a materiais cristalinos, que sofrem processo de annealing, foi observado. A formação de uma fase pseudo vítrea que segundo o diagrama do trabalho de $\mathrm{Nassau}^{75}$ ocorre em temperaturas mais altas que tenha se deslocado para temperaturas mais baixa, ou seja, uma nova fase até então não identificada para materiais bulk, mas identificada neste trabalho em nanomateriais. O tamanho do cristalito aumenta com o aumento da temperatura do tratamento térmico devido a agregação no processo de annealing, dessa forma observam-se picos mais finos.

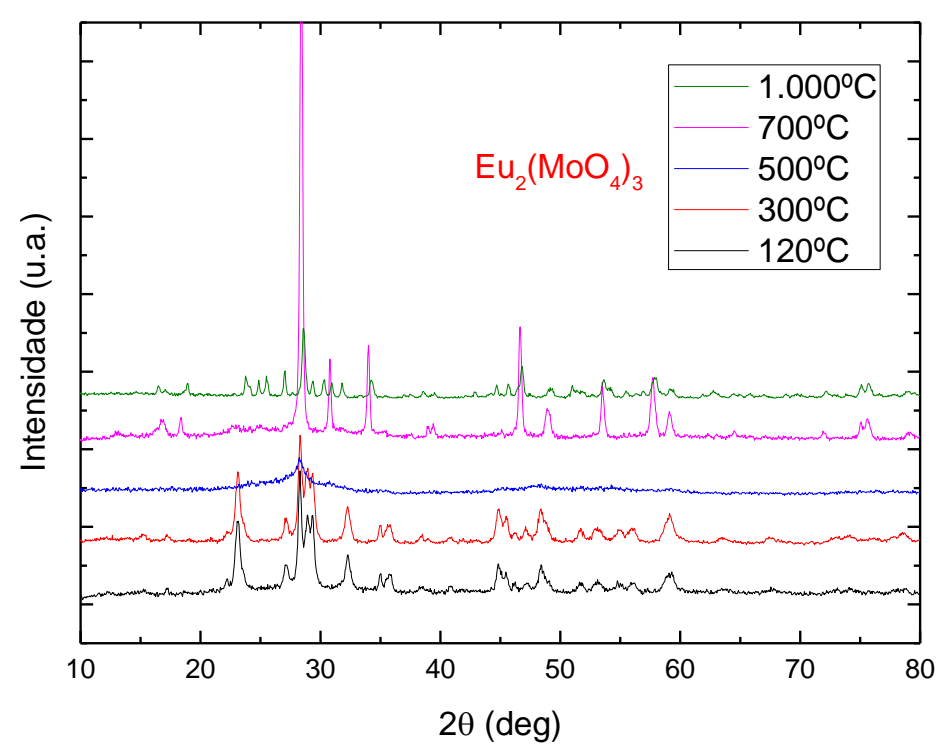

FIGURA 5.53. Difratogramas de raios $X$ do $\mathrm{Eu}_{2}\left(\mathrm{MoO}_{4}\right)_{3}$ submetidos ao tratamento térmico. 


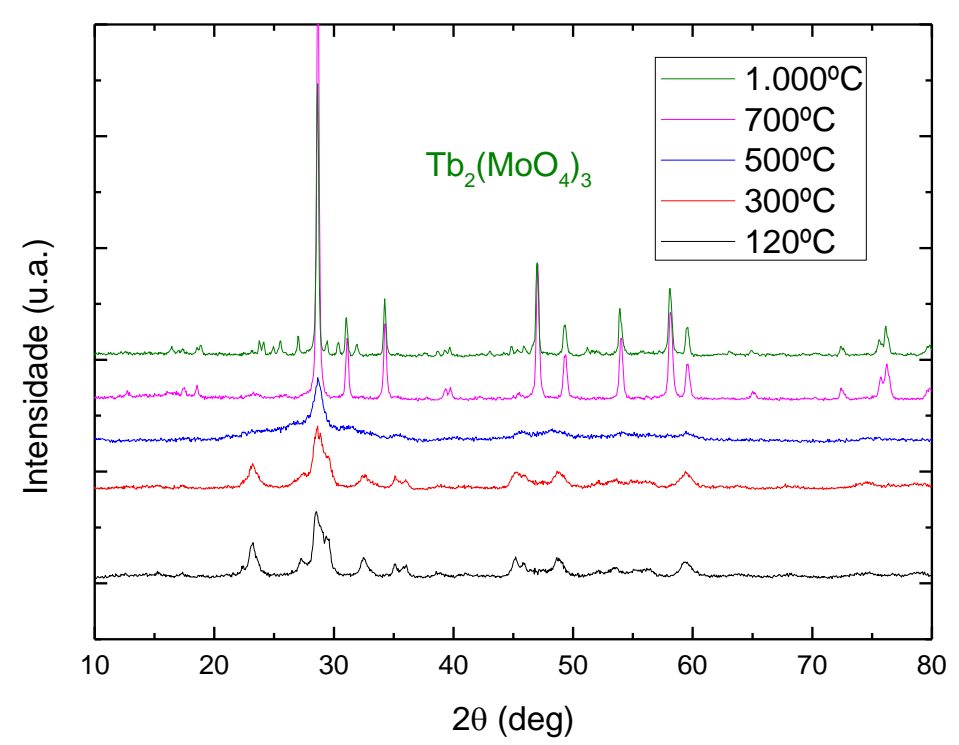

FIGURA 5.54 Difratogramas de raios $\mathrm{X}$ do $\mathrm{Tb}_{2}\left(\mathrm{MoO}_{4}\right)_{3}$ submetidos ao tratamento térmico.

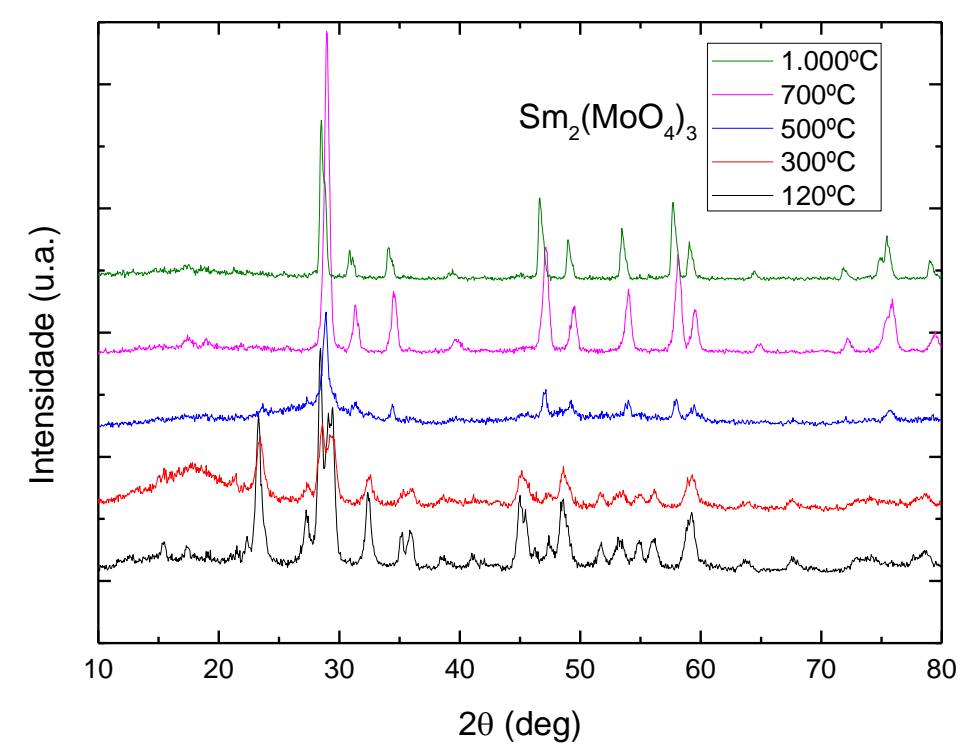

FIGURA 5.55. Difratogramas de raios $\mathrm{X}$ do $\mathrm{Sm}_{2}\left(\mathrm{MoO}_{4}\right)_{3}$ submetidos ao tratamento térmico. 


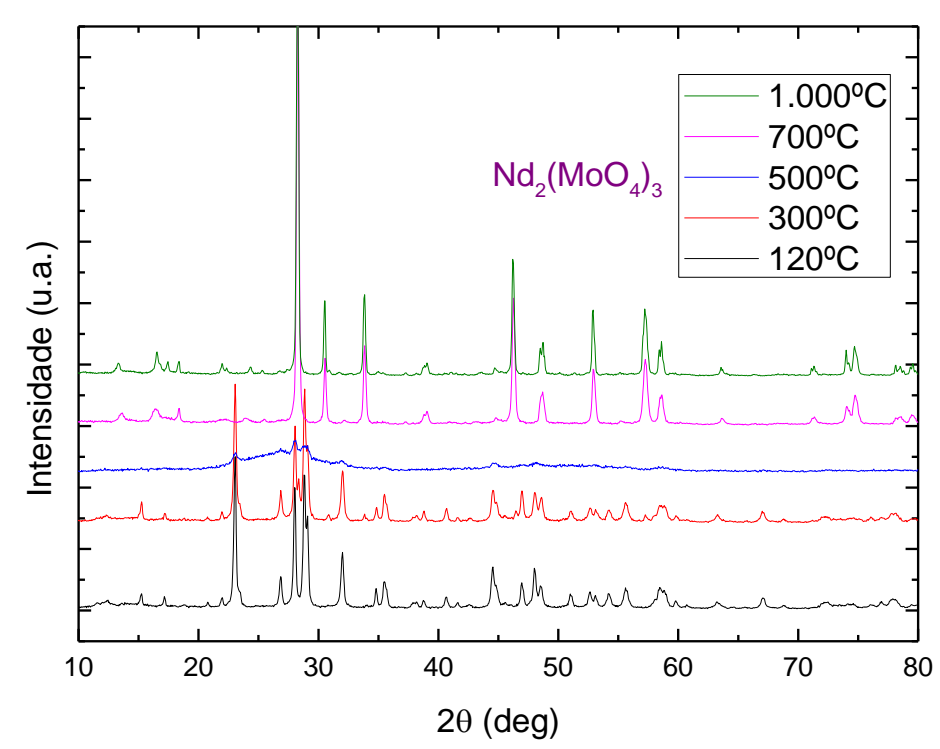

FIGURA 5.56. Difratogramas de raios $\mathrm{X}$ de $\mathrm{Nd}_{2}\left(\mathrm{MoO}_{4}\right)_{3}$ submetidas a tratamento térmico.

\subsubsection{Estudo do tamanho do cristalito em relação ao aumento da temperatura}

Com a finalidade de compreender o comportamento das amostras termicamente tratadas, foi determinado o tamanho de cristalito em cada etapa do tratamento térmico nas matrizes estudadas $\mathrm{Eu}_{2}\left(\mathrm{MoO}_{4}\right)_{3}, \mathrm{~Tb}_{2}\left(\mathrm{MoO}_{4}\right)_{3}, \mathrm{Sm}_{2}\left(\mathrm{MoO}_{4}\right)_{3}$ e $\mathrm{Nd}_{2}\left(\mathrm{MoO}_{4}\right)$. A partir dos dados adquiridos nos difratogramas de raio $\mathrm{X}$ gerou-se um gráfico que retrata o tamanho do cristalito em função da temperatura que a amostra foi submetida no tratamento térmico e que é apresentado na (FIG 5.57). Nesse gráfico, o tamanho do cristalito foi relacionado ao aumento da temperatura e pode-se observar (FIG 5.57) que para todas as amostras os perfis das curvas são iguais exceto para o $\mathrm{Sm}_{2}\left(\mathrm{MoO}_{4}\right)_{3}$ que não possui a fase de transição a $500^{\circ} \mathrm{C}$. Para o $\mathrm{Eu}_{2}\left(\mathrm{MoO}_{4}\right)_{3}, \mathrm{~Tb}_{2}\left(\mathrm{MoO}_{4}\right)_{3}$ e $\mathrm{Nd}_{2}\left(\mathrm{MoO}_{4}\right)_{3}$, a mudança ocorre em $500 \stackrel{\circ}{\circ}$, onde há a influência na diminuição do tamanho do cristalito e que volta a aumentar a partir dos $700 \stackrel{\circ}{\circ} \mathrm{C}$, conforme também observado por Tang et al., 
2009. ${ }^{74}$ Já no $\mathrm{Sm}_{2}\left(\mathrm{MoO}_{4}\right)_{3}$ apresenta um comportamento diferenciado e o aumento do tamanho do cristalito aumenta com o aumento da temperatura.

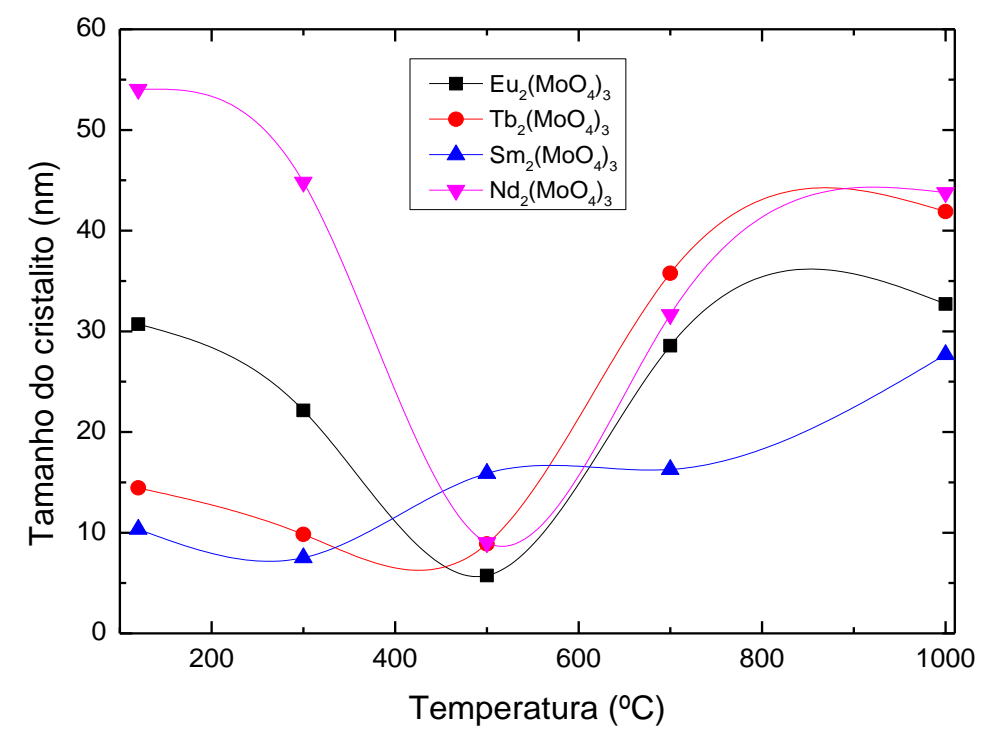

FIGURA 5.57. Difratograma de raio $X$ do estudo do tamanho do cristalito em relação ao aumento da temperatura para as amostras de $\mathrm{Eu}_{2}\left(\mathrm{MoO}_{4}\right)_{3}$, $\mathrm{Tb}_{2}\left(\mathrm{MoO}_{4}\right)_{3}, \mathrm{Sm}_{2}\left(\mathrm{MoO}_{4}\right)_{3} \mathrm{Nd}_{2}\left(\mathrm{MoO}_{4}\right)_{3}$.

\subsubsection{Microscopia eletrônica de varredura (MEV)}

Para avaliar a morfologia dos materiais tratados termicamente escolheu-se dois dos sistemas estudados $\mathrm{Nd}_{2}\left(\mathrm{MoO}_{4}\right)_{3}$ e $\mathrm{Eu}_{2}\left(\mathrm{MoO}_{4}\right)_{3}$ onde a escolha justifica-se por o molibdato de európio ser representativo dos demais íons terras raras e o neodímio por apresentar microestrutura na forma de nanorosas As Fig 5.58-59 apresentam as micrografias obtidas por MEV das amostras de $\mathrm{Nd}_{2}\left(\mathrm{MoO}_{4}\right)_{3}$ e Eu$\left(\mathrm{MoO}_{4}\right)_{3}$ submetidas ao tratamento térmico.

As imagens de $\mathrm{Nd}_{2}\left(\mathrm{MoO}_{4}\right)_{3}$ revelam microestruturas similares às de uma flor, composta por diversas lâminas nanoestruturadas. As microestruturas são muito porosas e a maioria das laminas nanométricas estão interligadas por 
conjunções lada-a-lado e lado-superfície, como também foi observado por Zhang et $a^{23}$ Com o aumento da temperatura do tratamento térmico estas rosas vão perdendo suas pétalas (lamínulas) até formar micro-aglomerados de nanopartículas.

As imagens de $\mathrm{Eu}_{2}\left(\mathrm{MoO}_{4}\right)_{3}$ revelam microestruturas similares ao de uma pitanga, composta por lâminas nanoestruturadas que se cruzam ao meio.

As imagens de $\mathrm{Nd}_{2}\left(\mathrm{MoO}_{4}\right)_{3}$ e $\mathrm{Eu}_{2}\left(\mathrm{MoO}_{4}\right)_{3}$ apresentam comportamentos semelhantes. Observam-se diferenças significativas na morfologia das microestruturas conforme há o aumento da temperatura no tratamento térmico. $\mathrm{Na}$ temperatura de $120{ }^{\circ} \mathrm{C}$ as estruturas estão grandes, uniformes e espaçadas. $\mathrm{Na}$ temperatura de $300{ }^{\circ} \mathrm{C}$ há uma diminuição no tamanho das partículas que compõem as microestruturas (que se apresentam em forma de flor, no molibdato de neodímio). Para as temperaturas de $500^{\circ} \mathrm{C}$ e $700^{\circ} \mathrm{C}$ as estruturas estão com formação de lâminas ainda menores e inicia-se a aparência de derretimento das camadas. Na temperatura de $1000^{\circ} \mathrm{C}$ há diferença aparente da morfologia das nanoparticulas, aparentando derretimento e agregação entre as extremidades. 
Resultados e discussões - Sínteses e Caracterizações
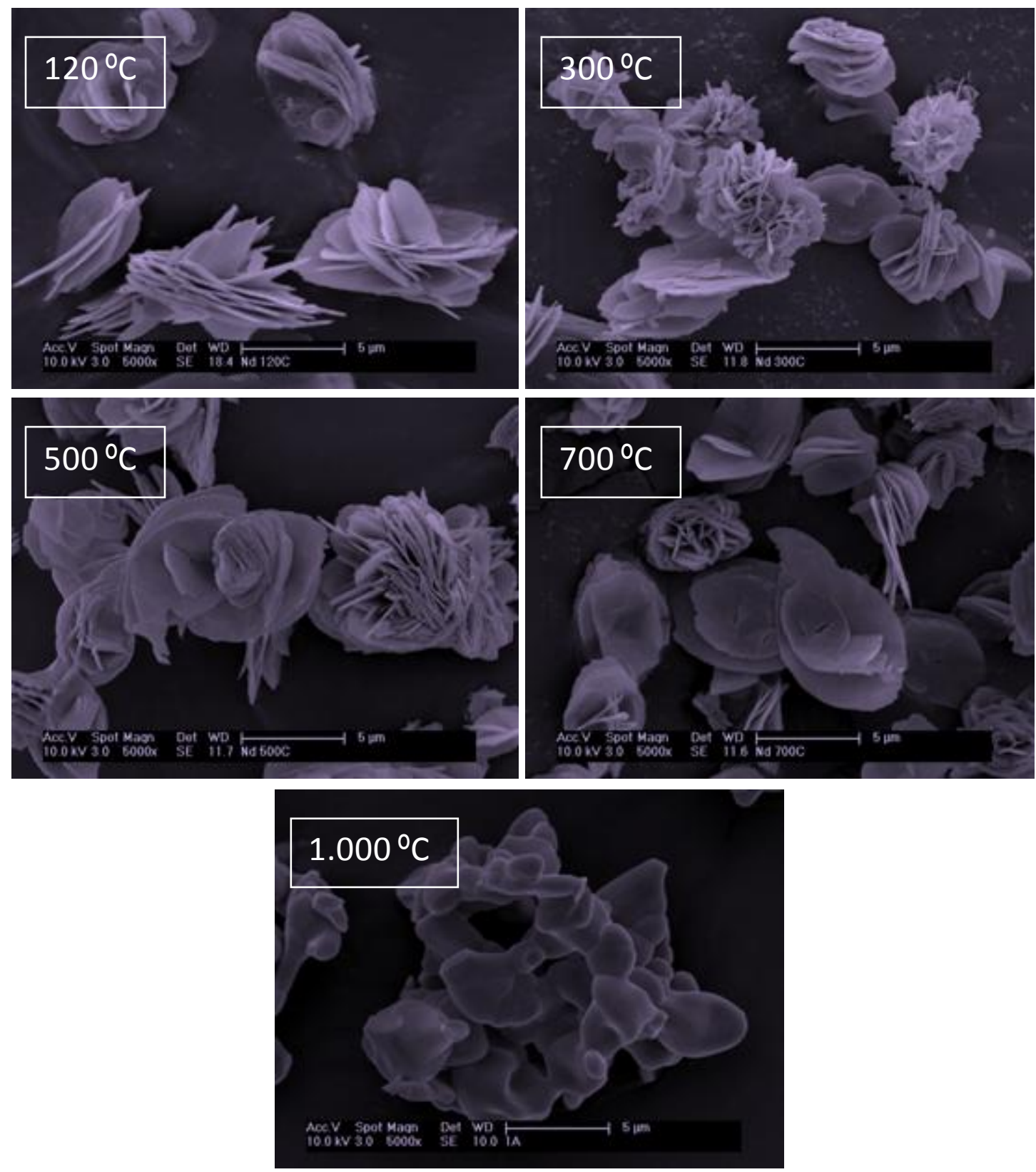

FIGURA 5.58. Micrografias de $\mathrm{Nd}_{2}\left(\mathrm{MoO}_{4}\right)_{3}$ submetidas ao tratamento térmico. 
Resultados e discussões - Sínteses e Caracterizações
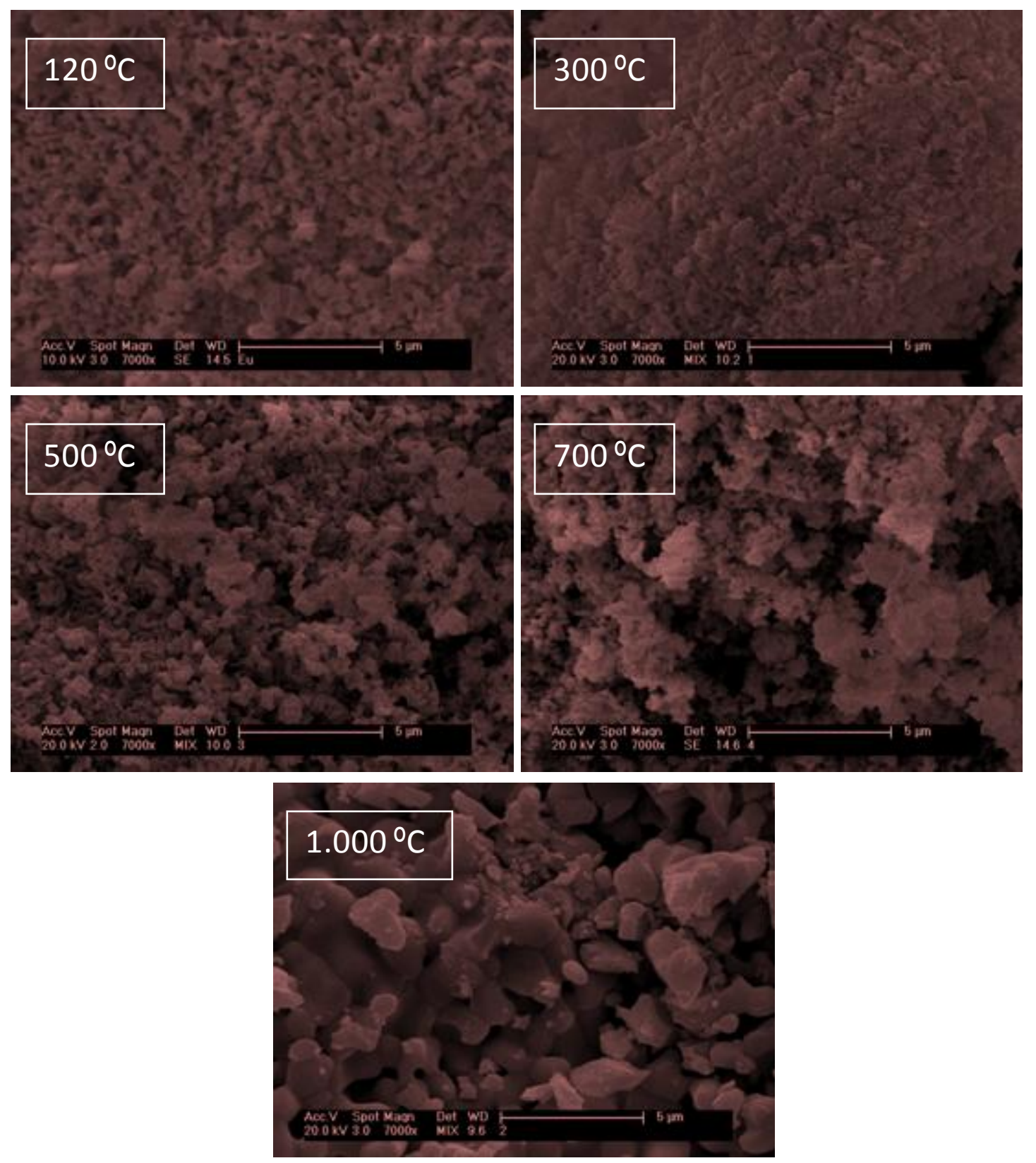

FIGURA 5.59. Micrografias de $\mathrm{Eu}_{2}\left(\mathrm{MoO}_{4}\right)_{3}$ submetidas ao tratamento térmico. 


\subsubsection{Estudo de luminescência das matrizes $\mathrm{Eu}_{2}\left(\mathrm{MoO}_{4}\right)_{3}$, $\mathrm{Tb}_{2}\left(\mathrm{MoO}_{4}\right)_{3}, \mathrm{Sm}_{2}\left(\mathrm{MoO}_{4}\right)_{3}$ e $\mathrm{Nd}_{2}\left(\mathrm{MoO}_{4}\right)_{3}$ termicamente tratadas}

\subsubsection{1 $\quad \mathrm{O} \mathrm{Eu}_{2}\left(\mathrm{MoO}_{4}\right)_{3}$ termicamente tratado}

$O$ estudo da fotoluminescência dosEu $2\left(\mathrm{MoO}_{4}\right)_{3}, \quad \mathrm{~Tb}_{2}\left(\mathrm{MoO}_{4}\right)_{3}$ , $\mathrm{Sm}_{2}\left(\mathrm{MoO}_{4}\right)_{3}$ e $\mathrm{Nd}_{2}\left(\mathrm{MoO}_{4}\right)_{3}$ foi realizado através dos espectros de excitação e emissão, registrados a temperatura ambiente ( 298 K). As FIG. 5.60-61 apresentam os espectros de excitação e emissão para o $\mathrm{Eu}_{2}\left(\mathrm{MoO}_{4}\right)_{3}$ calcinado em $120300,500,700$ e $1000{ }^{\circ} \mathrm{C}$, monitorandoa emissão em $615,2 \mathrm{~nm}$ na região de 200 a $590 \mathrm{~nm}$.

É importante ressaltar, que os perfis espectrais apresentaram mudanças significativas na região de 200 a $350 \mathrm{~nm}$ que é atriduida as transições de transferencia de carga O-M, para as diversas temperaturas de calcinação quando registrados a temperatura de $298 \mathrm{~K}$. Esta banda larga que inicialmente está centrada em $290 \mathrm{~nm}$ desloca-se para ao região do vermelho para o $\mathrm{Eu}_{2}\left(\mathrm{MoO}_{4}\right)_{3}$ calcinado em $500^{\circ} \mathrm{C}$ e $700^{\circ} \mathrm{C}$ (máximo em 325 e $311 \mathrm{~nm}$ respectivamente) e volta para região do azul no espectro da matriz tratada a 1000 ${ }^{\circ} \mathrm{C}$, com máximo em $286 \mathrm{~nm}$. Na região onde localizam-se as bandas intraconfiguracionais $4 f^{6}-4 f^{6}$ os espectros não apresentam modificações.

Estas bandas finas oriundas das transições intraconfiguracionais $4 f^{6}$ do íon $\mathrm{Eu}^{3+}$ presentes nos espectros de excitação foram atribuídas aos seguintes níveis de energia: ${ }^{7} \mathrm{~F}_{0} \rightarrow{ }^{5} \mathrm{D}_{4} \quad(363$ e $378 \mathrm{~nm}),{ }^{7} \mathrm{~F}_{0} \rightarrow{ }^{5} \mathrm{~L}_{7} \quad(378-383 \mathrm{~nm}){ }^{7} \mathrm{~F}_{0} \rightarrow{ }^{5} \mathrm{~L}_{6}$ $(396 \mathrm{~nm}),{ }^{7} \mathrm{~F}_{0} \rightarrow{ }^{5} \mathrm{D}_{3}(411-416 \mathrm{~nm}),{ }^{7} \mathrm{~F}_{0} \rightarrow{ }^{5} \mathrm{D}_{2}$ (448-465-488-474 nm), ${ }^{7} \mathrm{~F}_{0} \rightarrow{ }^{5} \mathrm{D}_{1}$ (527535-540-553 nm) e ${ }^{7} \mathrm{~F}_{0} \rightarrow{ }^{5} \mathrm{D}_{0}(579 \mathrm{~nm})$. Bandas convoluidas com a banda larga $\mathrm{M} \rightarrow \mathrm{O}$ não foram observadas. ${ }^{44,63}$ 


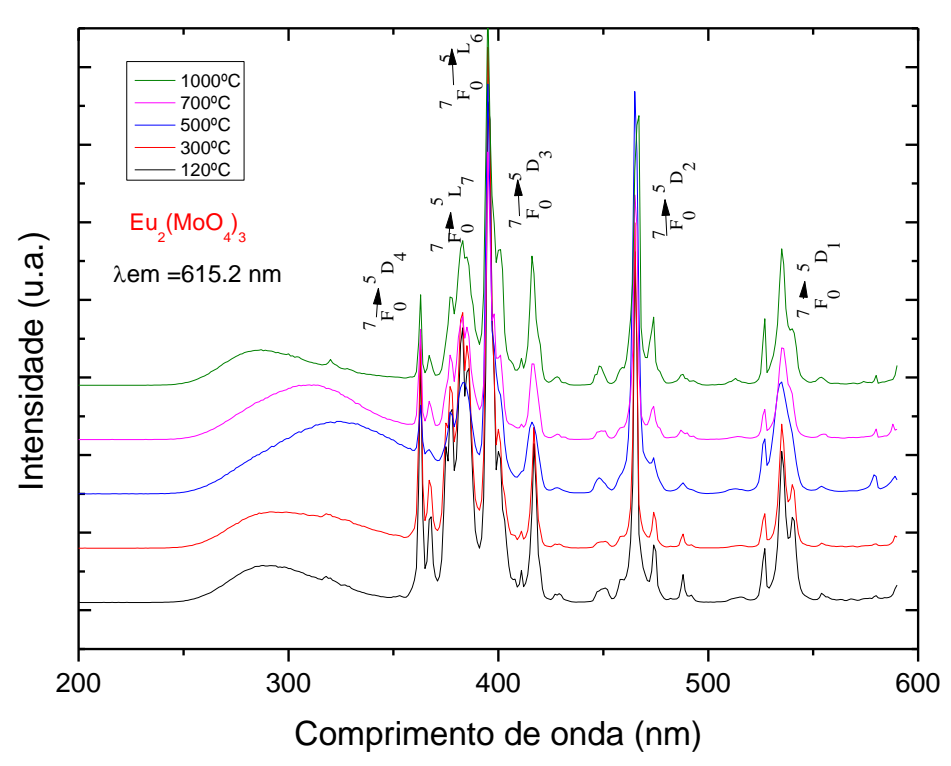

FIGURA 5.60. Espectros de excitação das nanopartículas de $\mathrm{Eu}_{2}\left(\mathrm{MoO}_{4}\right)_{3}$.

A FIG.5.61 Apresenta os espectros de emissão para o luminóforo $\mathrm{Eu}_{2}\left(\mathrm{MoO}_{4}\right)_{3}$ calcinadaa $120300,500,700$ e $1000^{\circ} \mathrm{C}$, com excitação monitorada em $394 \mathrm{~nm}$ e na temperatura ambiente 298K. Os espectros de emissão foram registrados na região de 500 a $800 \mathrm{~nm}$ a temperatura ambiente. Os espectros de emissão exibem bandas finas atribuídas às transições ${ }^{5} \mathrm{D}_{0} \rightarrow{ }^{7} \mathrm{~F}_{\mathrm{J}}$ (onde $\mathrm{J}=0-4$ ), nos quais apresentam a transição hipersensível ${ }^{5} \mathrm{D}_{0} \rightarrow{ }^{7} \mathrm{~F}_{2}$ como a banda mais proeminente. Nota-se também a ausência das bandas largas compreendidas entre 420 e $500 \mathrm{~nm}$, (parte do espectro não mostrada) referente à fosforescência da matriz, que indicam uma eficiente transferência de energia dos sistemas termicamente tratados. Um segundo fenômeno observado foi ao desdobramento da transição hipersensível ao ambiente químico ${ }^{5} \mathrm{D}_{0} \rightarrow{ }^{7} \mathrm{~F}_{2}$, passando de uma banda para cinco bandas, desdobramento máximo do subnível ${ }^{7} \mathrm{~F}_{2}$, corroborando com os dados de raio- $X$ e infravermelho. 


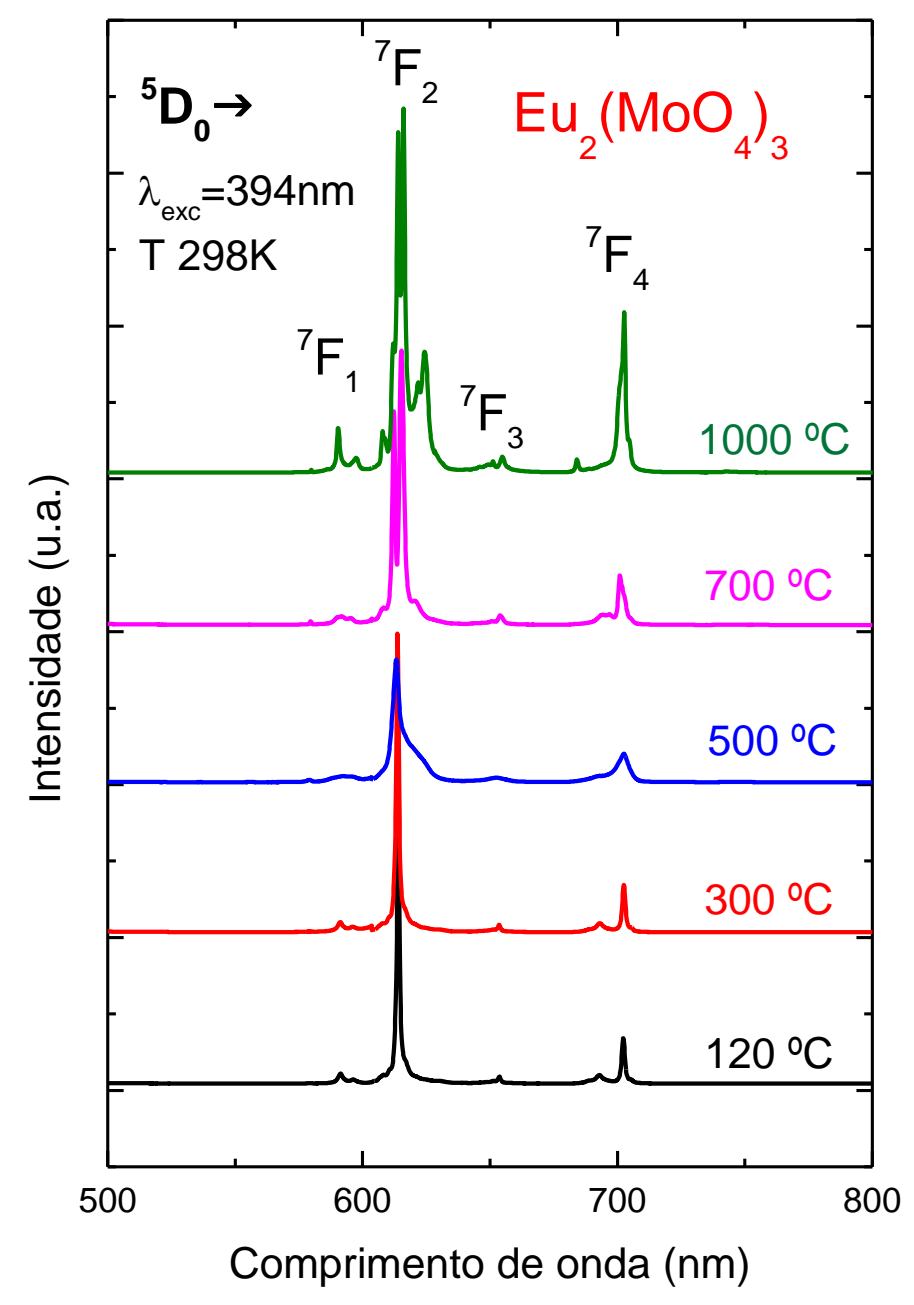

FIGURA 5.61. Espectro de emissão das nanopartículas de $\mathrm{Eu}_{2}\left(\mathrm{MoO}_{4}\right)_{3}$ submetidas ao tratamento térmico.

Os parâmetros de intensidade experimentais $\Omega_{\lambda}(\lambda=2$ e 4$)$ foram determinados para o compostos $\mathrm{Eu}_{2}\left(\mathrm{MoO}_{4}\right)_{3}$ nas várias temperaturas do tratamento térmico, tomando como base os espectros de emissão. Na TAB. 5.10 apresenta-se os dados calculados dos parâmetros de intensidade experimental. 
TABELA 5.10. Parâmetros de intensidade $\left(\Omega_{\lambda}\right)$, taxa radiativa $\left(A_{\text {rad }}\right)$, em $298 \mathrm{~K}$, determinado para o luminóforo $\mathrm{Eu}_{2}\left(\mathrm{MoO}_{4}\right)_{3}$ para diferentes temperaturas de annealing.

\begin{tabular}{c|cccc}
\hline $\begin{array}{c}\boldsymbol{T}_{\text {calcinação }} \\
\left({ }^{\circ} \mathrm{C}\right)\end{array}$ & $\begin{array}{c}\Omega_{2} \\
\left(10^{20} \mathrm{~cm}^{2}\right)\end{array}$ & $\begin{array}{c}\Omega_{4} \\
\left(10^{-20} \mathrm{~cm}^{2}\right)\end{array}$ & $\boldsymbol{R}_{02}$ & $\begin{array}{c}\boldsymbol{A}_{R A D} \\
\left(\mathrm{~s}^{-1}\right)\end{array}$ \\
\hline 120 & 8,13 & 8,4 & 0,019 & 418 \\
300 & 9,4 & 9,0 & 0,012 & 447 \\
500 & 12,9 & 12,9 & 0,024 & 630 \\
700 & 14,8 & 10,8 & 0,014 & 652 \\
1000 & 17,2 & 12,9 & 0,005 & 751 \\
\hline
\end{tabular}

Na TAB. 5.10 é verificado um acréscimo nos valores dos parâmetros $\Omega_{2}$ e $\Omega_{4}$ embora seja observado que o íon európio passa de um ambiente de simetria onde a polarizabilidade e os parâmetros cristalinos são equivalentes para uma simetria com maior polarizabilidade. Consequentemente, os íons $\mathrm{Eu}^{3+}$ nesta matriz estão em um ambiente químico mais polarizável sugerindo uma maior contribuição do mecanismo de acoplamento dinâmico.

\subsubsection{2 $\quad \mathrm{O} \mathrm{Tb}_{2}\left(\mathrm{MoO}_{4}\right)_{3}$ termicamente tratado}

Os espectros de excitação do $\mathrm{Tb}_{2}\left(\mathrm{MoO}_{4}\right)_{3}$ termicamente tratado foram registrados no intervalo de 200 a $450 \mathrm{~nm}$ (FIG.5.62), com emissão monitorada na transição ${ }^{5} \mathrm{D}_{4} \rightarrow{ }^{7} \mathrm{~F}_{5}$ ( $547 \mathrm{~nm}$ ). Não foram observadas diferenças significativas entre os espectros de excitação registrados a $298 \mathrm{~K}$ com diferentes temperaturas de tratamento térmico. Para estes espectros a $298 \mathrm{~K}$ verificou-se uma banda larga na região de 225 a $330 \mathrm{~nm}$ com máximo em 300 nm, atribuída à banda de transferência de carga L-M e cujo baricentro se deslocou para região de menor energia com o aumento da temperatura de annealing para $\circ \mathrm{Tb}^{3+}$ (FIG 5.62). 
Asbandas fixas em 320, 342; 355; 359; 366; 372 e 379nm aproximadamente, correspondem às transições ${ }^{7} \mathrm{~F}_{6} \rightarrow{ }^{5} \mathrm{G}_{\jmath},{ }^{5} \mathrm{~L}_{\jmath} \mathrm{e}{ }^{5} \mathrm{D}_{\jmath}$ do íon $\mathrm{Tb}^{3+}$.

Para os espectros de excitação além de se observar a banda referente à transição doL-M, aquelas oriundas das transições intraconfiguracionais $4 f^{8}-4 f^{8}$ foram convoluidas por estas. Observa-se também no espectro de excitação que a intensidade da banda LMCT é proporcional a concentração de $\mathrm{Tb}^{3+}$, corroborando com a ideia que a matriz transfere energia para o $\mathrm{Tb}^{3+}$ eficientemente.

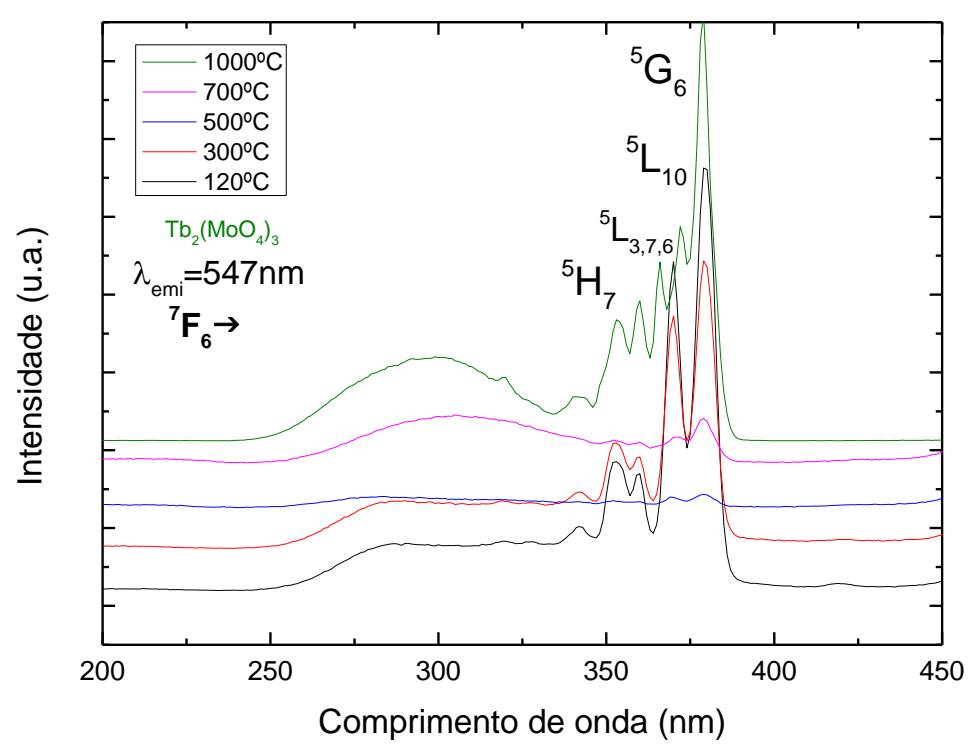

FIGURA 5.62. Espectro de excitação das nanopartículas de $\mathrm{Tb}_{2}\left(\mathrm{MoO}_{4}\right)_{3}$ submetidas ao tratamento térmico.

A FIG. 5.63 apresenta os espectros de emissão com excitação monitorada em $547 \mathrm{~nm}$, a $298 \mathrm{~K}$ do $\mathrm{Tb}\left(\mathrm{MoO}_{4}\right)_{3}$ termicamente tratado apresentando transições ${ }^{5} \mathrm{D}_{4} \rightarrow^{7} \mathrm{~F}_{\jmath^{\prime}}\left(\mathrm{J}^{\prime}=0-6\right)$ no intervalo entre 450 e $820 \mathrm{~nm}$.

A relaxação não-radiativa entre os estados eletrônicos dos íons $\mathrm{TR}^{3+}$ nos sólidos ocorre geralmente, por emissão multi-fóton ou por processo de 
relaxação cruzada, que envolve a interação entre um íon ativador excitado e um íon do estado fundamental vizinho, que tenha transições aproximadamente ressonantes com o intervalo pelo qual a relaxação poderia ocorrer.

O fenômeno de relaxação cruzada tem sido usado para explicar o "selfquenching" da emissão do íon $\mathrm{Tb}^{3+},{ }^{5} \mathrm{D}_{3} \rightarrow{ }^{7} \mathrm{~F}_{\mathrm{J}}$, em sistemas concentrados com íons térbio. A ocorrência de relaxação cruzada é explicada pelo fato de existir um grande número de transições entre os componentes do campo cristalino do estado fundamental ${ }^{7} F_{6}$ do íon $\mathrm{Tb}^{3+}$ e os estados ${ }^{7} F_{1}$ e ${ }^{7} F_{0}$, que são quase ressonantes com a transição ${ }^{5} \mathrm{D}_{3} \rightarrow{ }^{5} \mathrm{D}_{4}$.

As transições ${ }^{5} D_{3} \rightarrow{ }^{7} F_{J}$ são de intensidades bem menores e só aparecem quando se aumenta a escala na região de 400 a $480 \mathrm{~nm}$ nos espectros registrados a temperatura do nitrogênio líquido. Observa-se que estas se apresentam convoluidas com as bandas de fosforescência do luminóforo em questão. Neste trabalho elas aparecem apenas para os estados cristalinos intermediários 300,500 e $700{ }^{\circ} \mathrm{C}$.

Os espectros de emissão do $\mathrm{Tb}_{2}\left(\mathrm{MoO}_{4}\right)_{3}$ apresentaram aparente aumento na intensidade das bandas ${ }^{5} \mathrm{D}_{4} \rightarrow{ }^{7} \mathrm{~F}_{5}$ com o aumento da temperatura. $\mathrm{O}$ espectro de emissão da matriz tratada a $500{ }^{\circ} \mathrm{C}$ tem perfil diferente dos espectros nas outras temperaturas de annealing. 


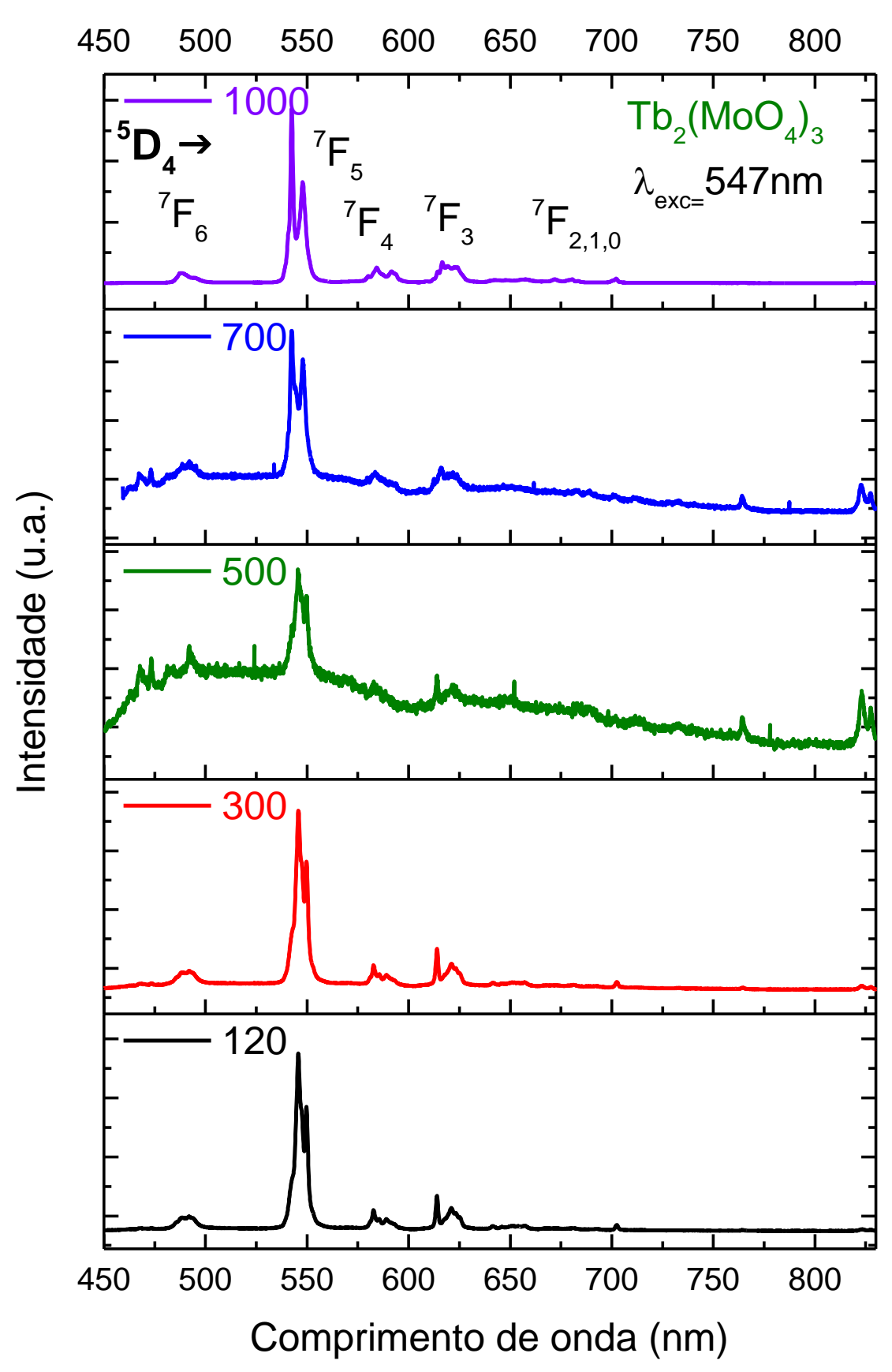

FIGURA 5.63. Espectro de emissão das nanopartículas de $\mathrm{Tb}_{2}\left(\mathrm{MoO}_{4}\right)_{3}$ submetidas ao tratamento térmico. 


\subsubsection{3 $\quad \mathrm{O} \mathrm{Sm}_{2}\left(\mathrm{MoO}_{4}\right)_{3}$ termicamente tratado}

O nível emissor ${ }^{4} G_{5 / 2}$ do íon $\mathrm{Sm}^{3+}\left(\sim 18021 \mathrm{~cm}^{-1}\right)$ é ressonante com um grande número de estados tripletos de vários ligantes $\beta$-dicetonatos e de matrizes inorgânicas como vem sendo observado pelo grupo ${ }^{41,50}$ permitindo desta maneira uma transferência de energia eficiente Ligante-Sm ${ }^{3+}\left(L \rightarrow{ }^{4} G_{5 / 2}\right)$.

As bandas estreitas dos complexos de samário são oriundas das transições eletrônicas do nível excitado ${ }^{4} G_{5 / 2}$ para os níveis do estado fundamental de menor energia ${ }^{6} H_{J}(J=5 / 2,7 / 2,9 / 2,11 / 2,13 / 2$ e 15/2). A transição ${ }^{4} \mathrm{G}_{5 / 2} \rightarrow{ }^{6} \mathrm{H}_{9 / 2}(\sim 642 \mathrm{~nm})$ tem comportamento hipersensível e o gap de energia entre o nível emissor ${ }^{4} G_{5 / 2}$ e o nível final ${ }^{6} \mathrm{H}_{9 / 2}$ encontra-se em torno de $7500 \mathrm{~cm}^{-1}$. Por causa da degenerescência de Kramer, o perfil dos espectros de emissão a baixa temperatura deveria consistir em 3, 4, 5, 6, 7 e 8 picos, para cada multipleto mencionado acima, quando os íons de $\mathrm{Sm}^{3+}$ ocupam um sítio de baixa simetria no campo ligante. ${ }^{77}$

Os espectros de excitação da matriz de samário $\mathrm{Sm}_{2}\left(\mathrm{MoO}_{4}\right)_{3}$ termicamente tratada com emissão monitorada na transição hipersensível ${ }^{4} \mathrm{G}_{5 / 2} \rightarrow{ }^{6} \mathrm{H}_{9 / 2}$ ( $\left.650 \mathrm{~nm}\right)$ foram registrados no intervalo de 250 a $550 \mathrm{~nm}$, a $298 \mathrm{~K}$ (Figura 5.64). Estes espectros apresentam bandas largas e intensas oriundas das transições ligante metal, devido a transferência de energia Ligante-Mo ${ }^{6+}$, Ligante$\mathrm{Sm}^{3+}$. Essas bandas estão sobrepostas às bandas finas oriundas das transições intraconfiguracionais $4 f^{5}$ envolvendo $\mathrm{o}$ estado fundamental ${ }^{6} \mathrm{H}_{5 / 2}$ e os estados excitados (em nm): ${ }^{4} \mathrm{H}_{9 / 2}$ ( 347), ${ }^{4} \mathrm{~F}_{9 / 2}$ ( 364), ${ }^{4} \mathrm{~L}_{17 / 2}(\sim 378),{ }^{4} \mathrm{H}_{11 / 2}(\sim 393),{ }^{4} \mathrm{~F}_{7 / 2}$ ( 405), ${ }^{4} \mathrm{M}_{19 / 2}$ ( 420), ${ }^{4} \mathrm{I}_{15 / 2}$ ( 442), ${ }^{4} \mathrm{I}_{13 / 2}(\sim 463),{ }^{4} \mathrm{I}_{11 / 2}(\sim 474),{ }^{4} \mathrm{G}_{7 / 2}(\sim 492)$. 


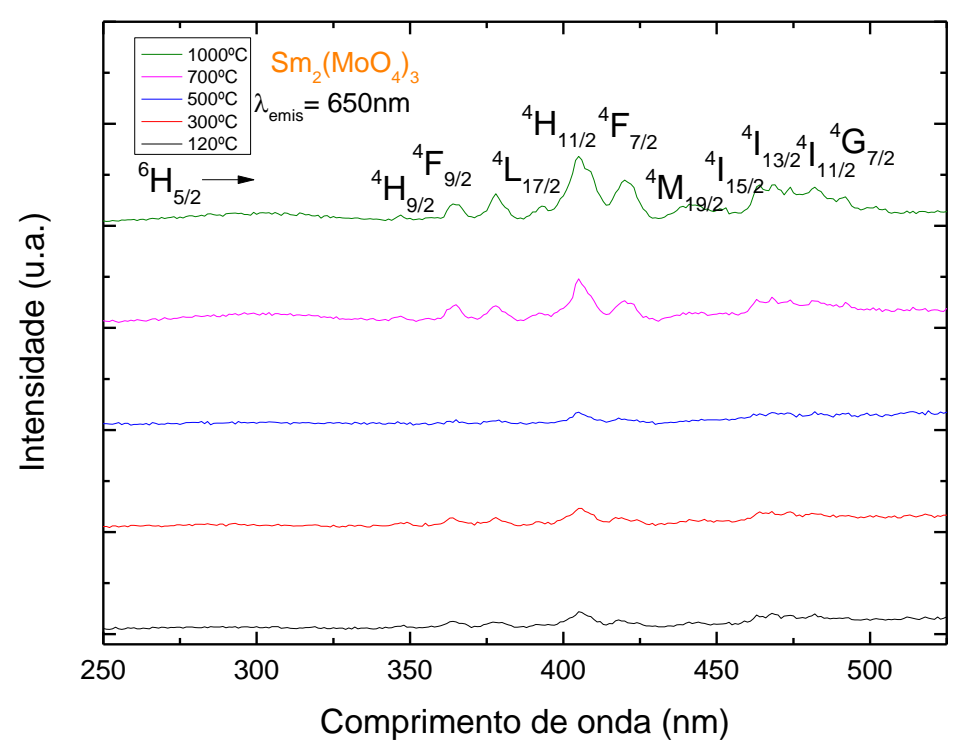

FIGURA 5.64. Espectro de excitação das nanopartículas de $\mathrm{Sm}_{2}\left(\mathrm{MoO}_{4}\right)_{3}$ submetidas ao tratamento térmico.

$\mathrm{Na}$ Figura 5.65 estão os espectros de emissão da matriz $\mathrm{Sm}_{2}\left(\mathrm{MoO}_{4}\right)_{3}$ de $\mathrm{Sm}^{3+}$ registrados no intervalo espectral de 500 a $750 \mathrm{~nm}$, a $298 \mathrm{~K}$ e monitorando a emissão em $405 \mathrm{~nm}$. Como pode ser observado, estes espectros consistem de bandas finas atribuídas às transições ${ }^{4} \mathrm{G}_{5 / 2} \rightarrow{ }^{6} \mathrm{H}_{J}$ (onde $\mathrm{J}=5 / 2,7 / 2$, 9/2 e 11/2) centradas no íon $\mathrm{Sm}^{3+}$, sendo a transição hipersensível a ${ }^{4} \mathrm{G}_{5 / 2} \rightarrow{ }^{6} \mathrm{H}_{9 / 2}$ ( 645 nm) por apresentar maior intensidade. A ausência de bandas largas oriundas da fosforescência da matriz evidencia a eficiência na transferência de energia Ligante- $\mathrm{Sm}^{3+}$, indicando que os molibdatos também são bons sensibilizadores de luminescência para o íon $\mathrm{Sm}^{3+}$. Os espectros de emissão mostram ainda que as bandas atribuídas transições ${ }^{4} \mathrm{G}_{5 / 2} \rightarrow{ }^{6} \mathrm{H}_{J}$ não estão desdobradas no número máximo de $(\mathrm{J}+1 / 2)$-componentes indicando que 0 íon $\mathrm{Sm}^{3+}$ ocupa um ambiente químico de simetria alta. Além disso, há uma diferença nos perfis dos espectros da matriz $\mathrm{Sm}_{2}\left(\mathrm{MoO}_{4}\right)_{3}$ em diferentes temperaturas de annealing evidenciando as mudanças no ambiente químico ao redor do íon $\mathrm{Sm}^{3+}$. 
A banda referente a transição ${ }^{4} \mathrm{G}_{5 / 2} \rightarrow{ }^{6} \mathrm{H}_{9 / 2}$ inverte a intensidade do pico máximo e a matriz tratada a $500^{\circ} \mathrm{C}$ penas um pico alargado.

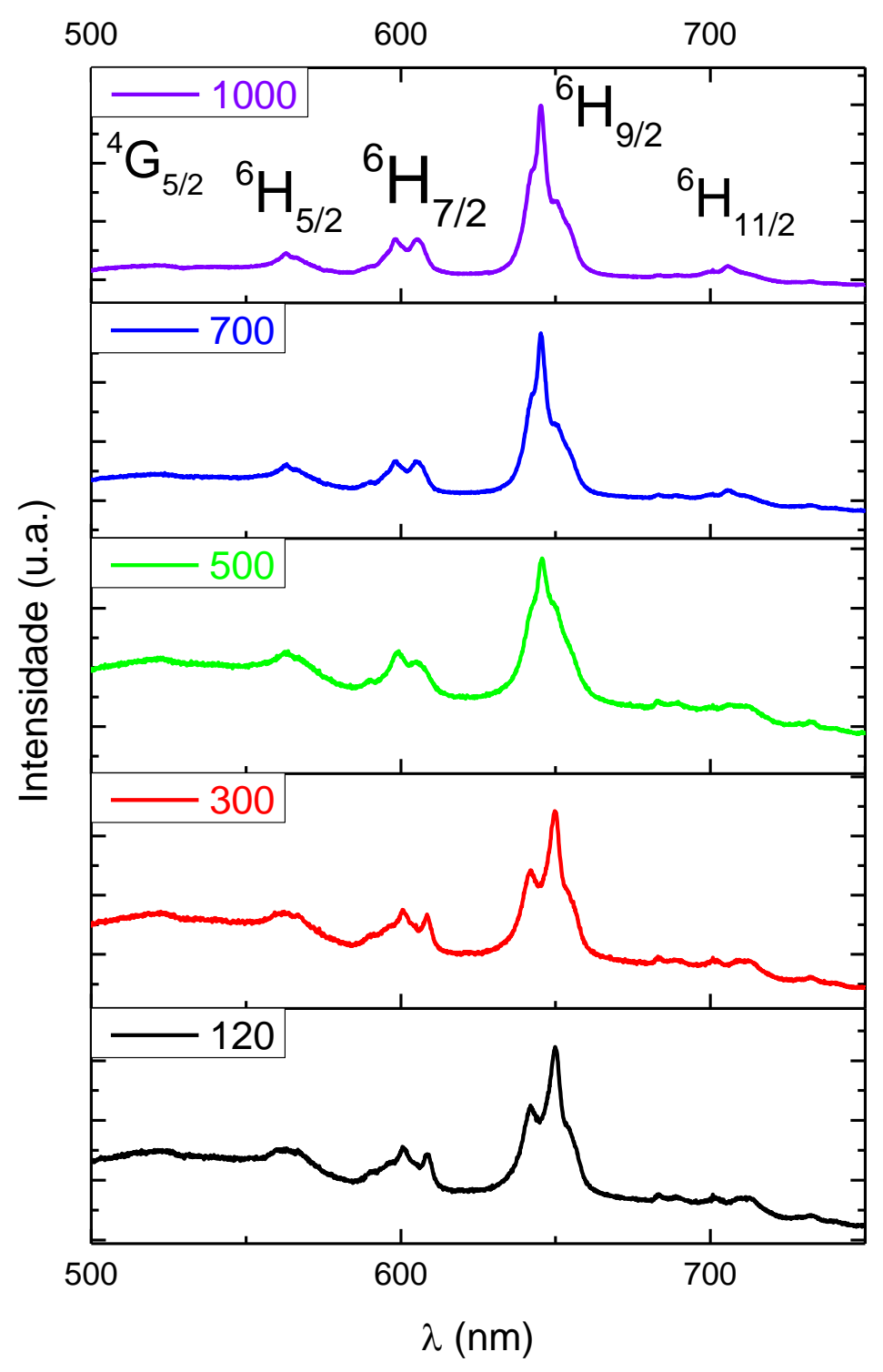

FIGURA 5.65. Espectro de emissão das nanopartículas de $\mathrm{Sm}_{2}\left(\mathrm{MoO}_{4}\right)_{3}$ submetidas ao tratamento térmico com $\lambda_{\text {exc }}=405 \mathrm{~nm}$ e temperatura ambiente. 
Com o intuito de se fazer um estudo comparativo entre o comportamento hipersensível dos íons $\mathrm{Sm}^{3+}$ e do $\mathrm{Eu}^{3+}$ foi determinado também o parâmetro $\eta_{E u}$ de $\mathrm{Eu}_{2}\left(\mathrm{MoO}_{4}\right)_{3}$ que foi calculado pela expressão:

$$
\eta_{\mathrm{Eu}}=\frac{\mathrm{S}\left({ }^{5} \mathrm{D}_{0} \rightarrow{ }^{7} \mathrm{~F}_{2}\right)}{\mathrm{S}\left({ }^{5} \mathrm{D}_{0} \rightarrow{ }^{7} \mathrm{~F}_{1}\right)}
$$

Os valores dos parâmetros experimentais $\eta_{\mathrm{Sm}}$ na matriz de $\mathrm{Sm}_{2}\left(\mathrm{MoO}_{4}\right)_{3}$ são menores do que na matriz de $\mathrm{Eu}_{2}\left(\mathrm{MoO}_{4}\right)_{3}$ evidenciando que a hipersensibilidade da transição ${ }^{4} \mathrm{G}_{5 / 2} \rightarrow{ }^{6} \mathrm{H}_{9 / 2}$ com a mudança no ambiente químico em torno do íon $\mathrm{Sm}^{3}+$ foi menos sensível do que a matriz deEu $\mathrm{U}_{2}\left(\mathrm{MoO}_{4}\right)_{3}$. Deve salientar que a existe uma correlação entre os parâmetros $\eta_{S m}$ e $\eta_{E u}$ indicando comportamento hipersensível semelhantes entre os complexos de samário e európio. ${ }^{50}$ No nosso caso essa correlação não foi observada.

TABELA 5.11. Parâmetros de intensidade experimentais $\eta_{\mathrm{Sm}}$ da matriz de $\mathrm{Sm}_{2}\left(\mathrm{MoO}_{4}\right)_{3}$ e $\eta_{\mathrm{Eu}}$ da matriz de $\mathrm{Sm}_{2}\left(\mathrm{MoO}_{4}\right)_{3}$.

\begin{tabular}{c|cc}
\hline $\boldsymbol{T}_{\text {calcinação }}\left({ }^{\circ} \mathrm{C}\right)$ & $\eta_{S m}$ & $\eta_{E u}$ \\
\hline 120 & 1,6 & 4,5 \\
300 & 1,6 & 5,4 \\
500 & 1,5 & 7,5 \\
700 & 1,6 & 8,5 \\
1000 & 1,4 & 9,7 \\
\hline
\end{tabular}




\subsubsection{4 $\quad \mathrm{O} \mathrm{Nd}_{2}\left(\mathrm{MoO}_{4}\right)_{3}$ termicamente tratado}

Os espectros de emissão no infravermelho próximo foram obtidos a $298 \mathrm{~K}$ no intervalo de $500-1300 \mathrm{~nm}$ com excitação em $250 \mathrm{~nm}$ e em $810 \mathrm{~nm}$ (FIGs. 5.66 e 5.67). Observa-se emissão do nível ${ }^{4} F_{3 / 2}$ para os níveis ${ }^{4} I_{9 / 2} e^{4} I_{11 / 2}$, 900, $1067 \mathrm{~nm}$ respectivamente, sendo que a transição ${ }^{4} \mathrm{~F}_{3 / 2} \rightarrow{ }^{4} \mathrm{I}_{/ 2}(900 \mathrm{~nm})$ é a mais intensa. Os espectros foram obtidos num Specfluorolog 3 que não tem a CCD de infravermelho, portanto são pouco intensos e resolvidos nesta região. Os espectros excitados em $250 \mathrm{~nm}$ apresentaram um conjunto de bandas convoluidas com a fosforescência da matriz na região de 600 a $850 \mathrm{~nm}$ que foi atribuída a transição ${ }^{4} \mathrm{~F}_{5 / 2} \rightarrow{ }^{4} \mathrm{I}_{9 / 2}$. A intensidade para excitação em $250 \mathrm{~nm}$ é decrescente com a temperatura do tratamento térmico.

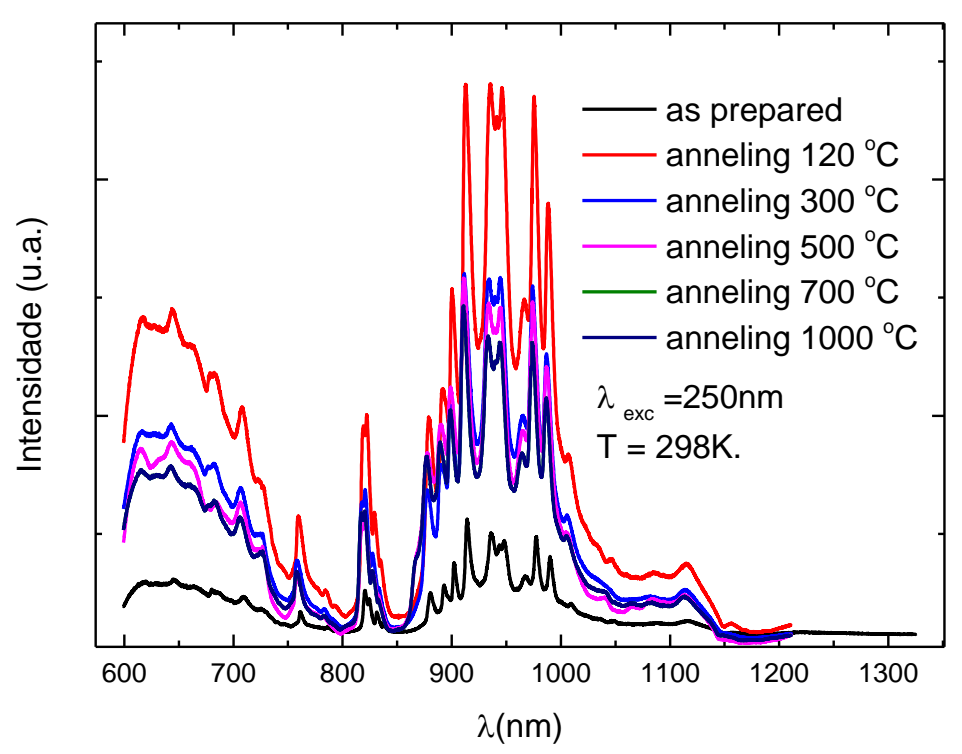

FIGURA 5.66. Espectro de emissão das nanopartículas de $\mathrm{Nd}_{2}\left(\mathrm{MoO}_{4}\right)_{3}$ submetidas ao tratamento térmico com excitação monitorada em $250 \mathrm{~nm}$. 


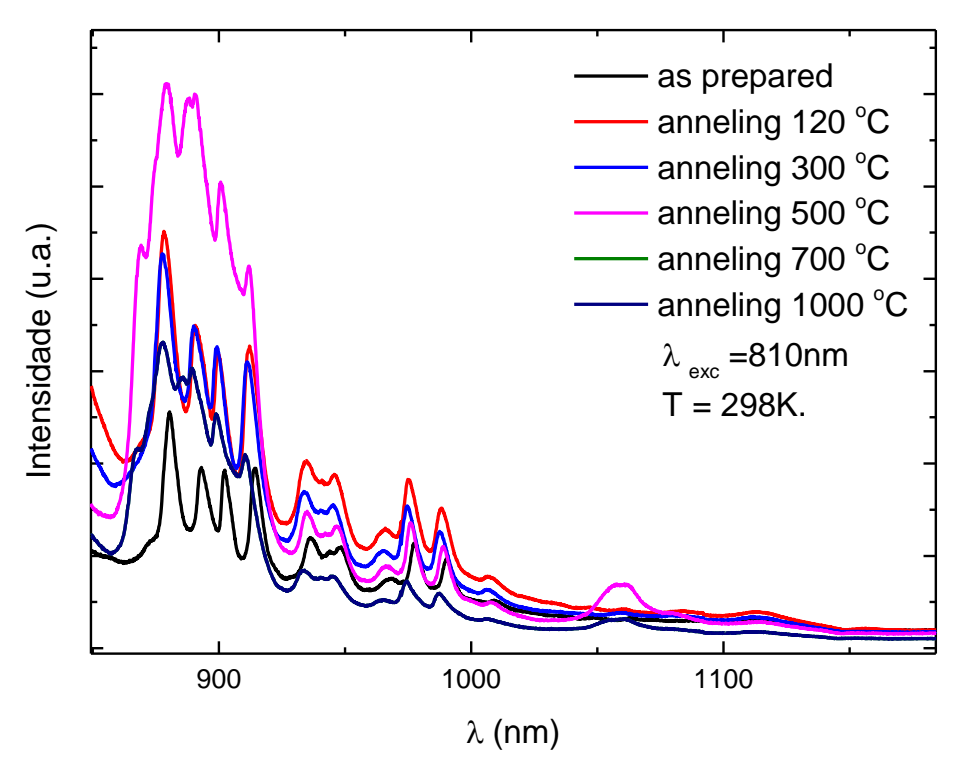

FIGURA 5.67 Espectro de emissão das nanopartículas de $\mathrm{Nd}_{2}\left(\mathrm{MoO}_{4}\right)_{3}$ submetidas ao tratamento térmico com excitação monitorada em $810 \mathrm{~nm}$.

\subsection{Funcionalização das nanopartículas dopadas com Terras Raras}

Os estudos sobre partículas esféricas de sílica começou com os trabalhos de Stöber et al. ${ }^{65}$ em 1968. Nos anos 70, técnicas para modificação de silanos atrelaram grupos funcionais na superfície da partícula de sílica. Deste modo, partículas de sílica modificadas passaram a ser utilizadas em todas as áreas de bioaplicações. ${ }^{78,79}$

Há dois métodos principais para a síntese de partículas de sílica. $\mathrm{O}$ primeiro é o método de Stöber, que consiste na hidrólise e condensação de um precursor alcóxido em etanol e amônia em meio aquoso. ${ }^{65,80}$ Outro método que vem sendo utilizado é a síntese por micro-ondas e que também foi abordada nesse trabalho.As partículas contendo na sua superfície um grupo funcional amina primária podem ser utilizadas em bioensaios, realizando imobilização por 
interação covalente. Vale ressaltar que aminas secundárias e terciárias não são reativas nestes sistemas.

As principais finalidades da modificação de superfícies são: a) introduzir grupos funcionais apropriados para conjugação com a parte biológica (- $\mathrm{NH}_{2},-\mathrm{COOH},-\mathrm{SH}$ etc.); b) fornecer estabilidade para as partículas de sílica em solução e aumentar a dispersão em água; c) preservar a estabilidade e atividade das biomoléculas (anticorpos, proteínas, enzimas etc.) quando imobilizadas na superfície das partículas; d) estabelecer um procedimento fácil e reprodutivo para a funcionalização das partículas. ${ }^{32,81}$

Neste trabalho a funcionalização foi realizada para os fósforos sintetizados pelo método de coprecipitação $\left(\mathrm{Eu}_{2}\left(\mathrm{MoO}_{4}\right)_{3}\right.$, $\mathrm{Y}\left(5 \% \mathrm{Eu}_{2}\left(\mathrm{MoO}_{4}\right)_{3}, \mathrm{~Tb}_{2}\left(\mathrm{MoO}_{4}\right)_{3}, \mathrm{Sm}_{2}\left(\mathrm{MoO}_{4}\right)_{3}, \mathrm{Nd}_{2}\left(\mathrm{MoO}_{4}\right)_{3}\right)$ utilizando-se o método de Stöber e de Micro-ondas.

As nanopartículas de molibdato de terras raras $\left(\mathrm{Eu}_{2}\left(\mathrm{MoO}_{4}\right)_{3}\right.$, $\mathrm{Y}\left(5 \% \mathrm{Eu}_{2}\left(\mathrm{MoO}_{4}\right)_{3}, \mathrm{~Tb}_{2}\left(\mathrm{MoO}_{4}\right)_{3}, \quad \mathrm{Sm}_{2}\left(\mathrm{MoO}_{4}\right)_{3}, \quad \mathrm{Nd}_{2}\left(\mathrm{MoO}_{4}\right)_{3}\right)$ amino-funcionalizadas pelas técnicas de Micro-ondas e Stöber foram então caracterizadas por espectroscopia de infravermelho, difração de raios X e Microscopia eletrônica de varredura, EDS, TEM, estudos de luminescência e pela determinação das aminas primárias.

5.6.1 Preparação das partículas contendo os fósforos $\left(\mathrm{Eu}_{2}\left(\mathrm{MoO}_{4}\right)_{3}\right.$, $\mathrm{Y}\left(5 \% \mathrm{Eu}_{2}\left(\mathrm{MoO}_{4}\right)_{3}, \mathrm{~Tb}_{2}\left(\mathrm{MoO}_{4}\right)_{3}, \mathrm{Sm}_{2}\left(\mathrm{MoO}_{4}\right)_{3}, \mathrm{Nd}_{2}\left(\mathrm{MoO}_{4}\right)_{3}\right)$ incorporados na sílica aminofuncionalizada: método micro-ondas

As partículas do composto de $\left(\mathrm{Eu}_{2}\left(\mathrm{MoO}_{4}\right)_{3}\right.$, $\mathrm{Y}\left(5 \% \mathrm{Eu}_{2}\left(\mathrm{MoO}_{4}\right)_{3}, \mathrm{~Tb}_{2}\left(\mathrm{MoO}_{4}\right)_{3}, \mathrm{Sm}_{2}\left(\mathrm{MoO}_{4}\right)_{3}, \mathrm{Nd}_{2}\left(\mathrm{MoO}_{4}\right)_{3}\right)$ foram funcionalizadas com o 3-aminopropiltrietoxisilano (APTES), utilizando-se a técnica de microondas. O APTES tem a função de revestir as partículas de $\left(\mathrm{TR}_{2}\left(\mathrm{MoO}_{4}\right)_{3}\right.$, de forma 
direta, oferecendo a melhor maneira de preservar as propriedades ópticas das nanopartículas dos fósforos e fornecer possibilidades de ligações à grupos biologicamente ativos ao mesmo tempo ${ }^{32,40}$. A FIG. 5.68 ilustra a representação esquemática de uma nanopartícula de $\mathrm{TR}_{2}\left(\mathrm{MoO}_{4}\right)_{3}$ funcionalizada.

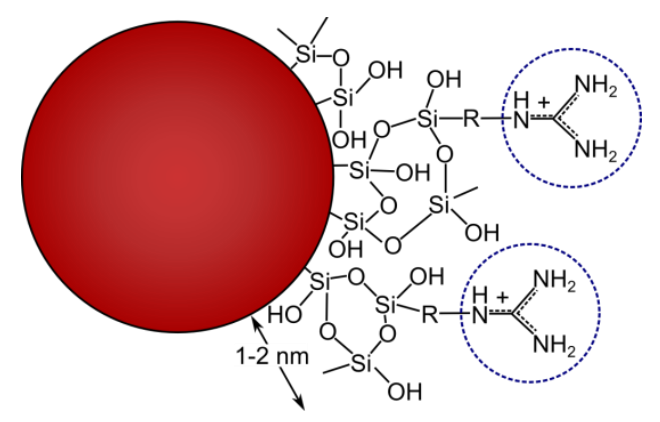

FIGURA 5.68. Representação esquemática de uma nanopartícula de $\mathrm{TR}_{2}\left(\mathrm{MoO}_{4}\right)_{3}$ funcionalizada (adaptação de Giaume et al. ${ }^{82}$ )

Trabalhos recentes ${ }^{83,84,40}$ têm reportado e demonstrado a eficiência da reação de polimerização utilizando irradiação de micro-ondas. Deste modo, o meio reacional que envolve o luminóforo no estado sólido e o aminosilano no estado líquido. A FIG. 5.69 ilustra a preparação das partículas de sílica aminofuncionalizadas incorporadas com o luminóforo pelo uso da reação microondas. 


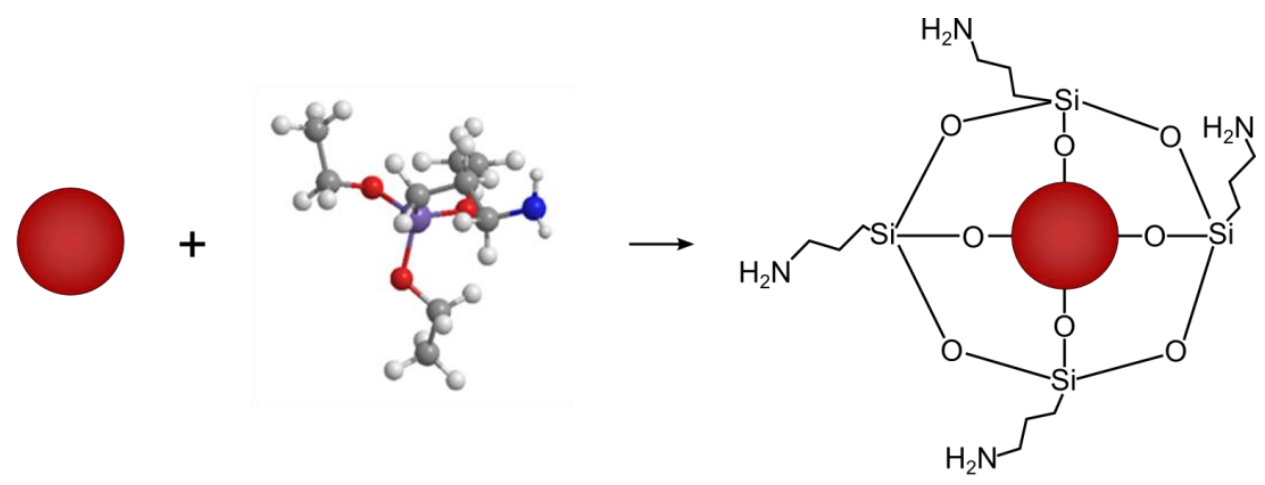

$\operatorname{TR}_{2}\left(\mathrm{MoO}_{4}\right)_{3} \mathrm{APTESTR}\left(\mathrm{MoO}_{4}\right)_{3} @ S i$

FIGURA 5.69. Representação esquemática do processo para a preparação de partículas de sílica aminofuncionalizadas incorporando o luminóforo $\mathrm{TR}_{2}\left(\mathrm{MoO}_{4}\right)_{3}$ utilizando o método por micro-ondas.

Dados da literatura ${ }^{86}$ indicam que o composto APTES não é suscetível à radiação de micro-ondas, portanto o complexo de TR absorve esta energia. A energia eletromagnética absorvida promove a reação de polimerização. $32,87,88,89,40$. A reação de polimerização do aminosilano ocorre na interface sólidolíquido, onde a camada de sílica liga-se covalentemente ao luminóforo de $\mathrm{TR}^{3+} .86$

5.6.2 Partículas de sílica contendo os fósforos $\left(\mathrm{Eu}_{2}\left(\mathrm{MoO}_{4}\right)_{3}\right.$, $\mathrm{Y}\left(5 \% \mathrm{Eu}_{2}\left(\mathrm{MoO}_{4}\right)_{3}, \mathrm{~Tb}_{2}\left(\mathrm{MoO}_{4}\right)_{3}, \mathrm{Sm}_{2}\left(\mathrm{MoO}_{4}\right)_{3}, \mathrm{Nd}_{2}\left(\mathrm{MoO}_{4}\right)_{3}\right)$ incorporado na sílica aminofuncionalizada: método Stöber

Utilizou-se de uma rota alternativa para as reações de hidrólise e condensação dos fósforos, reação pelo método de Stöber modificado ${ }^{32,65,40,90}$. A reação envolveu a hidrólise e a condensação do ortosilicato de tetraetila (TEOS) na presença dos fósforos $\mathrm{TR}_{2}\left(\mathrm{MoO}_{4}\right)_{3}$. A reação utiliza como catalisador o hidróxido de amônio, $\mathrm{NH}_{4} \mathrm{OH}$, em meio alcoólico e está esquematicamente representada na FIG. 5.70 . 


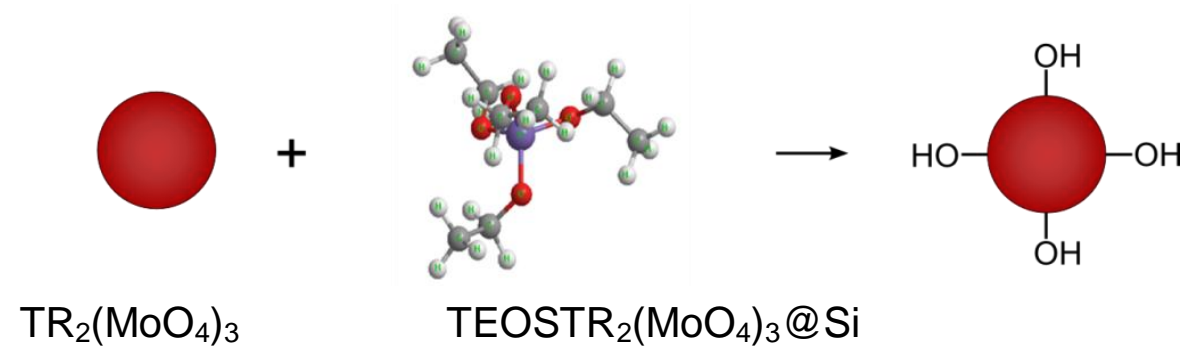

FIGURA 5.70. Representação esquemática do processo para a preparação de partículas de sílica incorporando os fósforos $\left(\mathrm{Eu}_{2}\left(\mathrm{MoO}_{4}\right)_{3}\right.$, pelo o método Stöber.

Em seguida, as partículas de sílica incorporadas com o luminóforo (na forma de pó) foram aminofuncionalizadas (FIG. 5.71) utilizando o APTES, através da reação de silanização ${ }^{90,91,92}$. Esta reação compreende a hidrólise do grupo Si$\mathrm{O}-\mathrm{C}_{2} \mathrm{H}_{5}$ do reagente APTES, seguida pela reação de condensação do grupoSi-OH da superfície com o grupo $\mathrm{Si}-\mathrm{OH}$ oriundo do APTES hidrolisado levando a formação do marcador luminescente.
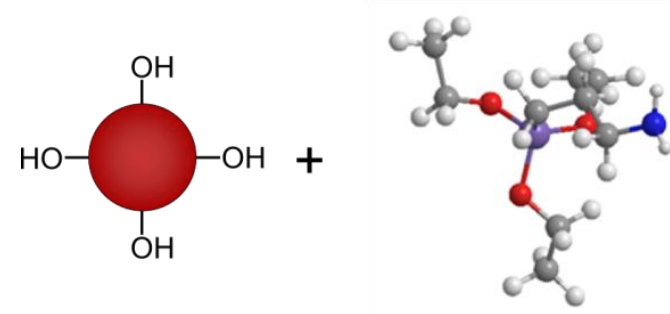

$\mathrm{TR}_{2}\left(\mathrm{MoO}_{4}\right)_{3} \mathrm{APTESTR} 2\left(\mathrm{MoO}_{4}\right)_{3} @ S i$

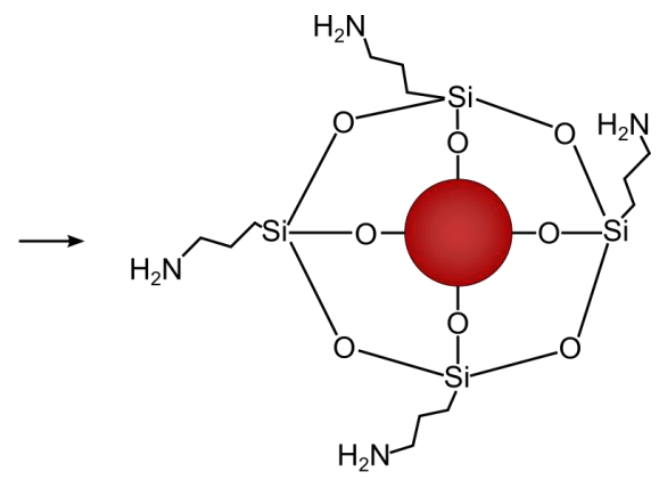

$\mathrm{SnO}_{2} / \mathrm{TiO}_{2}: \mathrm{TR}^{3+} @ \mathrm{Si}$

FIGURA 5.71. Representação esquemática da aminofuncionalização das partículas de sílica contendo os fósforosTR $\left(\mathrm{MoO}_{4}\right)_{3}$, utilizando o método Stöber. 
Nas reações de hidrólise há a formação de grupos silanóis a partir de grupos alcóxidos. Na condensação, ocorre o ataque nucleofílico do grupo silanol do alcoxissilano hidrolisado ao átomo de silício do alcoxissilano, tendo como resultado álcool ou o ataque do grupo silanol ao átomo de silício de outro grupo silanol, produzindo água. ${ }^{93,94}$ A reação de condensação produzindo água ou álcool forma uma rede de sílica tridimensional.

Neste trabalho a funcionalização foi realizada pelos métodos de microondas e Stöber para os fósforos $\mathrm{TR}_{2}\left(\mathrm{MoO}_{4}\right)_{3}$, visando a comparação destes dois métodos. A síntese inicialmente mostrou-se efetiva pelos dois métodos, porém, a comprovação da formação da capa de sílica nos fósforos para a obtenção dos marcadores foi alcançada com os dados da análise de determinação de amina.

\subsubsection{Caracterização das partículas aminofuncionalizadas}

Para a caracterização das nanoparticulas amino funcionalizadas o objetivo principal era identificar a superfície de sílica ligada ao marcador luminescente. Para tanto se utilizou as técnicas já citadas acima e que serão mostradas a seguir.

\subsubsection{Espectroscopia de absorção na região do infravermelho com transformada de Fourrier (FTIR) dos fósforos $\mathrm{TR}_{2}\left(\mathrm{MoO}_{4}\right)_{3}$}

Os dados impetrados através da espectroscopia de infravermelho foram obtidos com o objetivo de comprovar a presença da sílica através de da identificação de bandas de absorção oriundas da rede de sílica.

Os espectros de infravermelho apresentados nas FIG. $5.72-5.76$ fazem uma comparação entre os espectros de infravermelho das partículas de 
$\mathrm{TR}_{2}\left(\mathrm{MoO}_{4}\right)_{3} \quad(\mathrm{TR}=\mathrm{Eu}, \quad \mathrm{Sm}, \mathrm{Tb}, \mathrm{Y}(5 \% \mathrm{Eu})$ e $\mathrm{Nd})$ não funcionalizadas e funcionalizadas pelos métodos de Stöber e de micro-ondas.

Nestas figuras além das bandas do núcleo $\mathrm{TR}_{2}\left(\mathrm{MoO}_{4}\right)_{3}$ pode-se observar as bandas referentes aos grupos organosilanos.

A banda alargada na região $3500-3000 \mathrm{~cm}^{-1}$ com três ombros são atribuídos ao estiramento assimétrico da ligação $v \mathrm{Si}-\mathrm{O}-\mathrm{Si},-3200-3000 \mathrm{~cm}^{1}$ indicando a formação da rede de sílica e a banda localizada em $\sim 3750 \mathrm{~cm}^{-1}$ é atribuída ao estiramento $\mathrm{v} \mathrm{O}-\mathrm{H}$ da molécula de $\mathrm{H}_{2} \mathrm{O}$ livre ${ }^{21}$.

$\mathrm{Na}$ região de 1408-1512 foram observadas duas bandas pouco intensas e que não estão presentes no núcleo $\mathrm{TR}_{2}\left(\mathrm{MoO}_{4}\right)_{3}$ e estas foram atribuídas a vibração do grupo $\mathrm{N}-\mathrm{H}$. Estas bandas foram observadas também por Bahadur et al $(2011)^{20}$, em seu trabalho ele relata a presença de um pico em $1516 \mathrm{~cm}^{-1}$ que foi atribuído a vibração do grupo $\mathrm{N}-\mathrm{H}$ que ocorre pelo encapsulamento do núcleo por uma capa de sílica com grupos amina na superfície da sílica ${ }^{20}$

Na região de $\sim 1215$ a $1050 \mathrm{~cm}^{-1}$ um grupo de bandas com intensidade mediana foram observadas e estas foram relacionadas as transições de estiramento assimétrico da ligação $\mathrm{Si}$-O-Si. Estes dados corroboram com os dados de Bahadur et al..$^{95}$ que estão na literatura.

Pode-se observar também que nos espectros para as partículas obtidas pelo método do micro-ondas, a camada única de sílica leva à bandas menos proeminentes. 


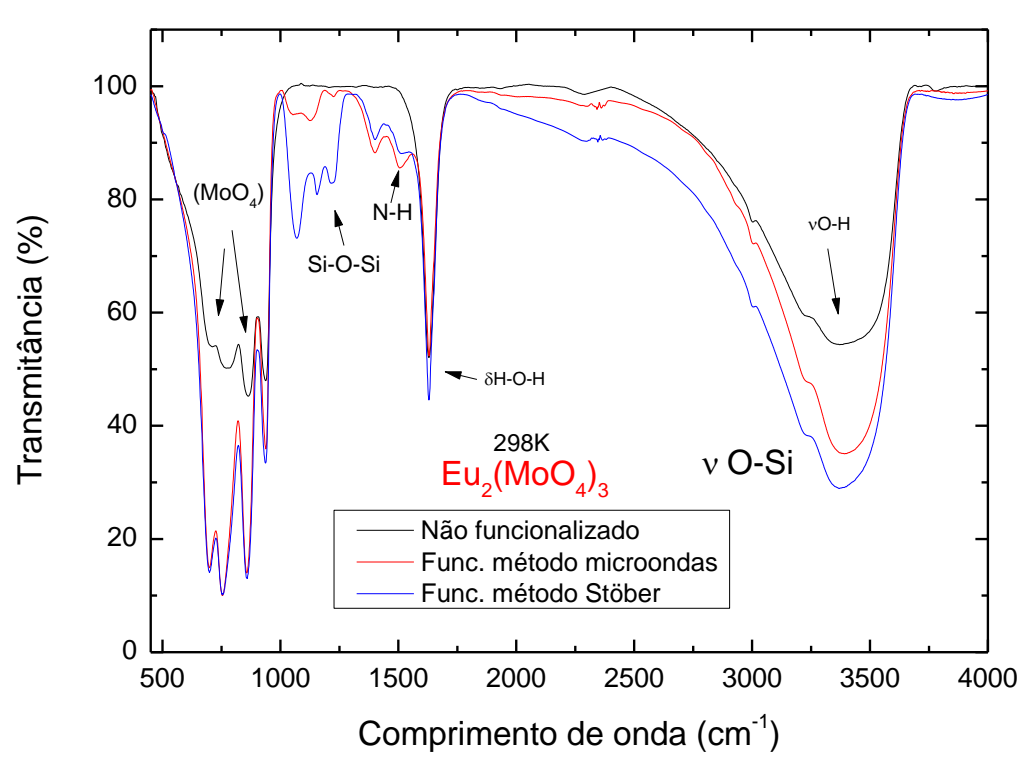

FIGURA 5.72. Espectro de infravermelho das partículas de $\mathrm{Eu}_{2}\left(\mathrm{MoO}_{4}\right)_{3}$ aminofuncionalizadas pelo método de Stöber e pelo método de micro-ondas.

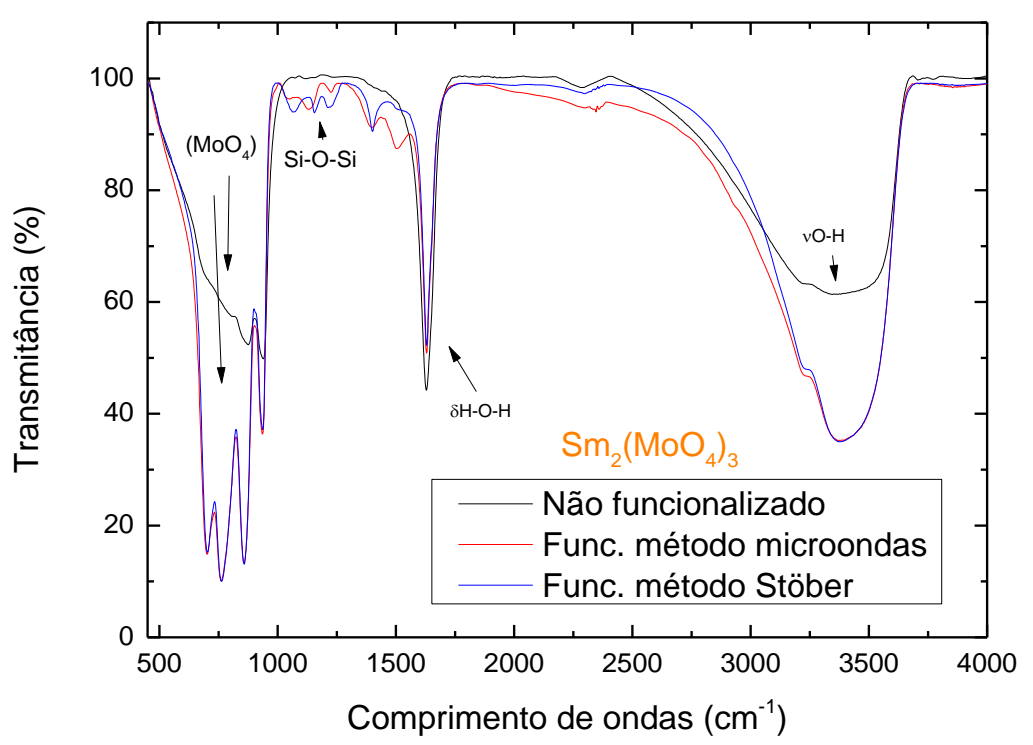

FIGURA 5.73.Espectro de infravermelho das partículas de $\mathrm{Sm}_{2}\left(\mathrm{MoO}_{4}\right)_{3}$ aminofuncionalizadas pelo método de Stöber e pelo método de micro-ondas. 


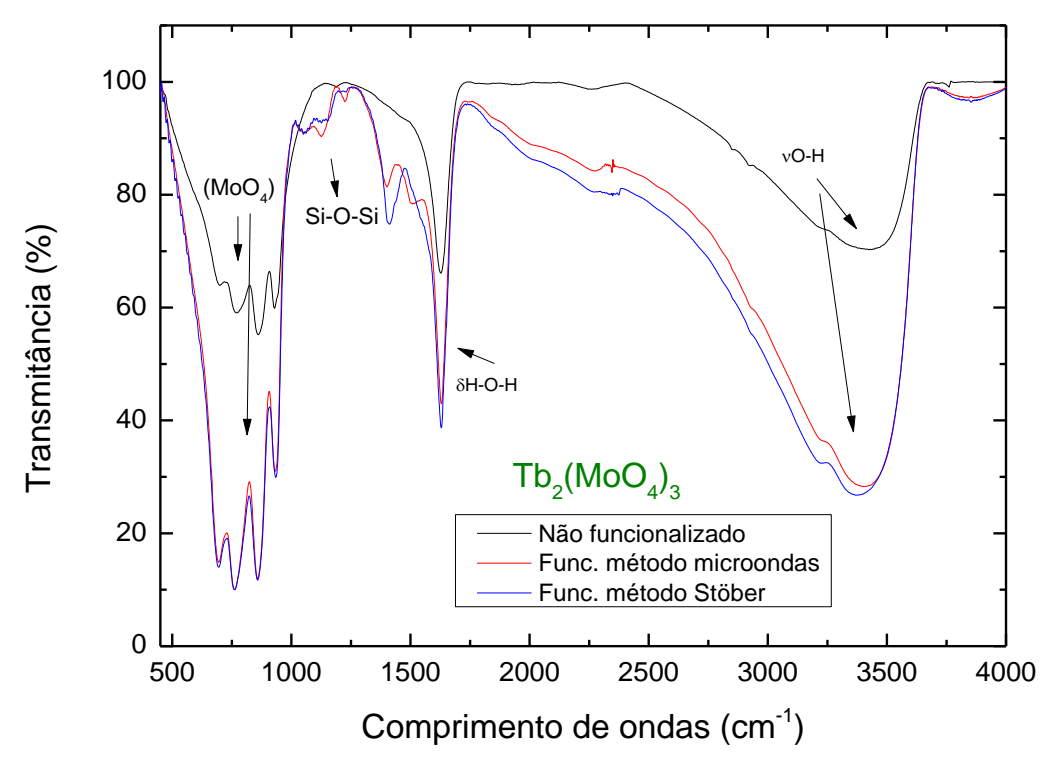

FIGURA 5.74. Espectro de infravermelho das partículas de $\mathrm{Tb}_{2}\left(\mathrm{MoO}_{4}\right)_{3}$ aminofuncionalizadas pelo método de Stöber e pelo método de micro-ondas.

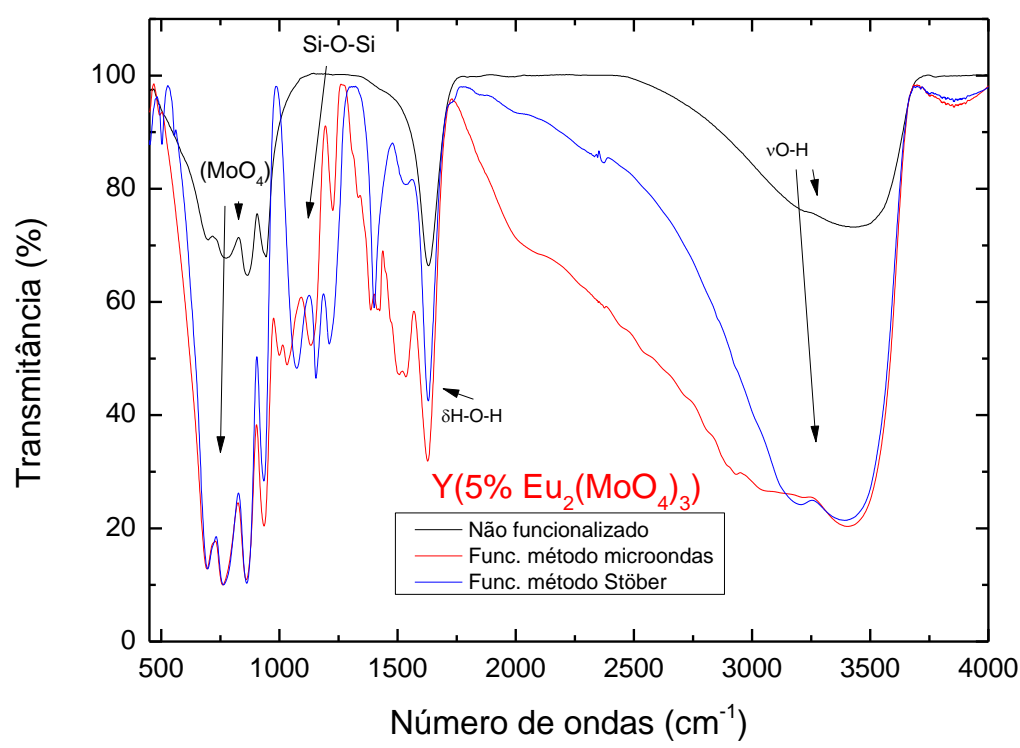

FIGURA 5.75. Espectro de infravermelho das partículas de $\mathrm{Y}\left(5 \% \mathrm{Eu}_{2}\left(\mathrm{MoO}_{4}\right)_{3}\right.$ amino-funcionalizadas pelo método de Stöber e pelo método de micro-ondas. 


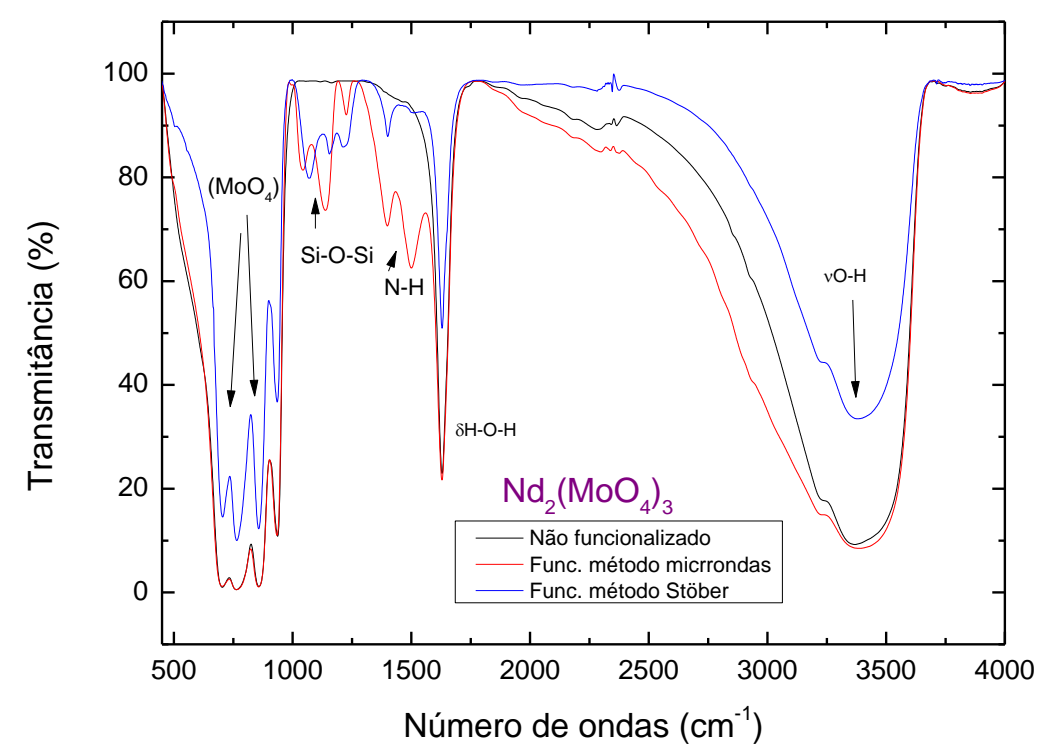

FIGURA 5.76. Espectro de infravermelho das partículas de $\mathrm{Nd}_{2}\left(\mathrm{MoO}_{4}\right)_{3}$ aminofuncionalizadas pelo método de Stöber e pelo método de micro-ondas.

5.6.3.2 Difração de raio $X$ (DRX) dos molibdatos de $\mathrm{TR}^{3+}$ (TR= $\mathrm{Eu}_{2}\left(\mathrm{MoO}_{4}\right)_{3}, \quad \mathrm{Y}\left(5 \% \mathrm{Eu}_{2}\left(\mathrm{MoO}_{4}\right)_{3}, \quad \mathrm{Sm}_{2}\left(\mathrm{MoO}_{4}\right)_{3}, \quad \mathrm{~Tb}_{2}\left(\mathrm{MoO}_{4}\right)_{3}\right.$ e $\left.\quad \mathrm{Nd}_{2}\left(\mathrm{MoO}_{4}\right)_{3}\right)$ funcionalizados.

As FIGs. 5.77 - 5.80 mostram os difratogramas dos fósforos $\mathrm{TR}_{2}\left(\mathrm{MoO}_{4}\right)_{3}$ (TR: Sm, $\mathrm{Eu}, \mathrm{Tb} \mathrm{Y}: 5 \% \mathrm{Eu}$ e $\mathrm{Nd}$ ) não funcionalizados e funcionalizados pelos métodos de Stöber (Sto) e Micro-ondas (Mic). É possível observar que os fósforos funcionalizados apresentam difratogramas semelhantes aos fósforos sem funcionalização. As amostras analisadas mostraram-se cristalinas, com fase marjoritaria tetragonal e pode-se observar que não há mudança no perfil estrutural das amostras funcionalizadas pelos dois métodos, quando comparadas as amostras não funcionalizadas 
É possível observar um alargamento dos picos na região de $2 \theta 10-$ $30^{\circ}$, devido a banda de difração da sílica amorfa ser nesta região ${ }^{32}$ para todas as nanopartículas funcionalizadas.

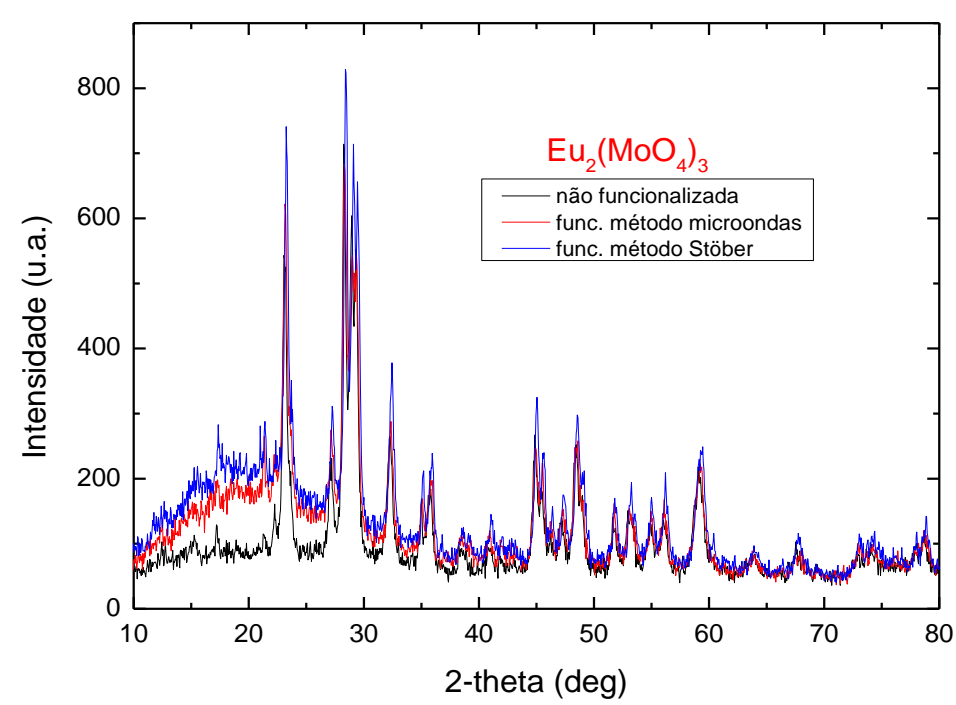

FIGURA 5.77.Difratogramas do $\mathrm{Eu}_{2}\left(\mathrm{MoO}_{4}\right)_{3}$ e $\mathrm{Eu}_{2}\left(\mathrm{MoO}_{4}\right)_{3} @ S$ funcionalizados pelo método de Stöber e micro-ondas.

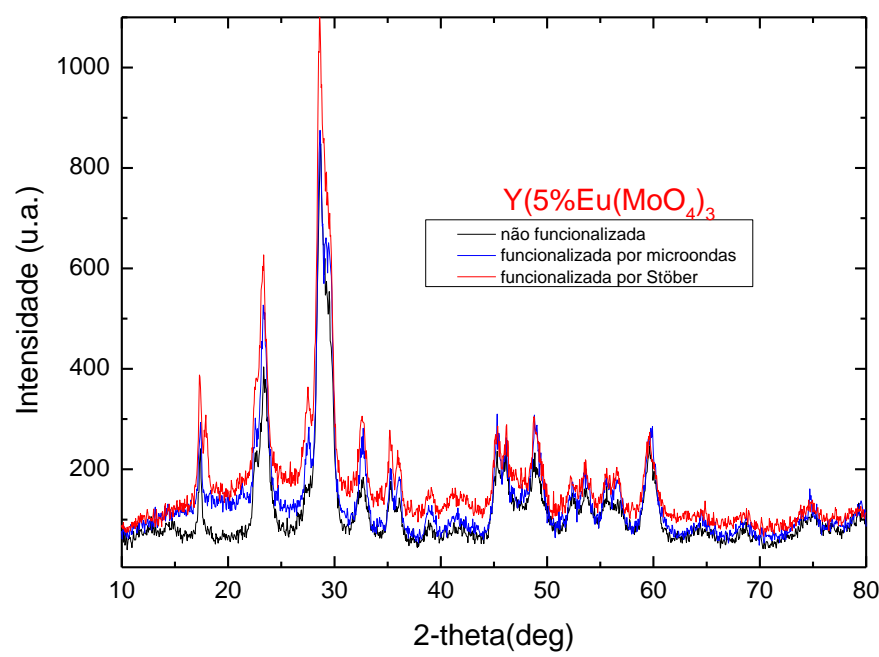

FIGURA 5.78. Difratogramas do $\mathrm{Y}\left(5 \% \mathrm{Eu}\left(\mathrm{MoO}_{4}\right)_{3}\right.$ funcionalizados pelo método de Stöber e micro-ondas. 


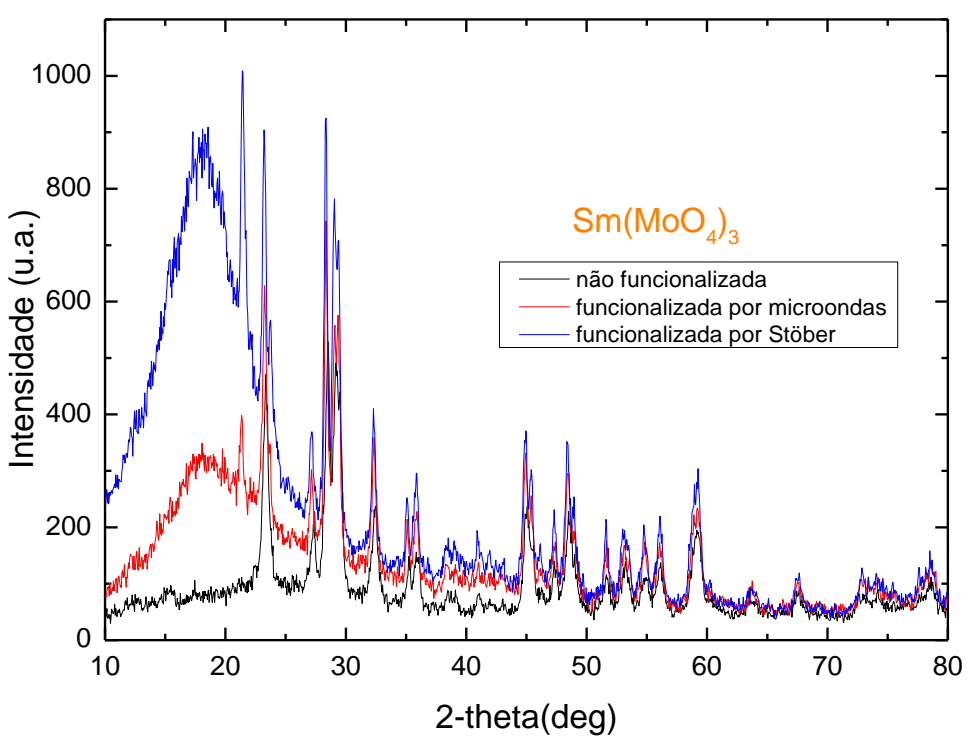

FIGURA 5.79. Difratogramas do $\mathrm{Sm}_{2}\left(\mathrm{MoO}_{4}\right)_{3}$ funcionalizados pelo método de Stöber e micro-ondas.

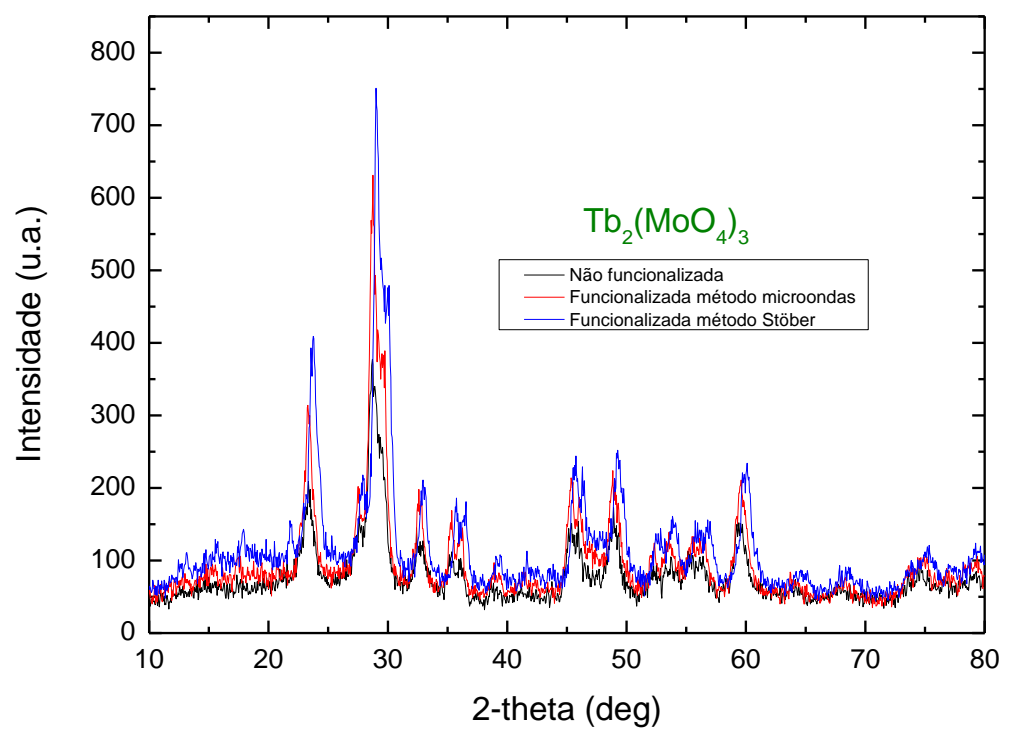

FIGURA 5.80. Difratogramas do $\mathrm{Tb}_{2}\left(\mathrm{MoO}_{4}\right)_{3}$ funcionalizados pelo método de Stöber e micro-ondas. 


\subsubsection{Microscopia eletrônica de varredura (MEV) das nanopartículas de neodímio aminofuncionalizadas $\left(\mathrm{Nd}_{2}\left(\mathrm{MoO}_{4}\right)_{3} @ \mathrm{Si}\right)$}

Na FIG. 5.81 estão dispostas as micrografias das nanopartículas de neodímio não funcionalizada (FIG. 5.81a), funcionalizada pelo método de Stöber (FIG. 5.81b) e micro-ondas (FIG. 5.81c) com aumento de 10000x.

É possível observar a diferença na morfologia das nanopartículas, pois quando as partículas não estão funcionalizadas apresentam-se com estruturas uniformes e com contornos similares ao de uma flor. Quando são recobertas pelo organosilano APTES e TEOS (método de Stöber) apresentam uma superfície rugosa e preenchida, o que comprova o recobrimento dos aglomerados com a dupla adição as sílica.

No método de funcionalização por micro-ondas, observar-se uma superfície de sílica mais fragmentada (quando comparada ao método de Stöber), provavelmente devido à única adição de APTES e à etapa do método de funcionalização por irradiação de micro-ondas. 

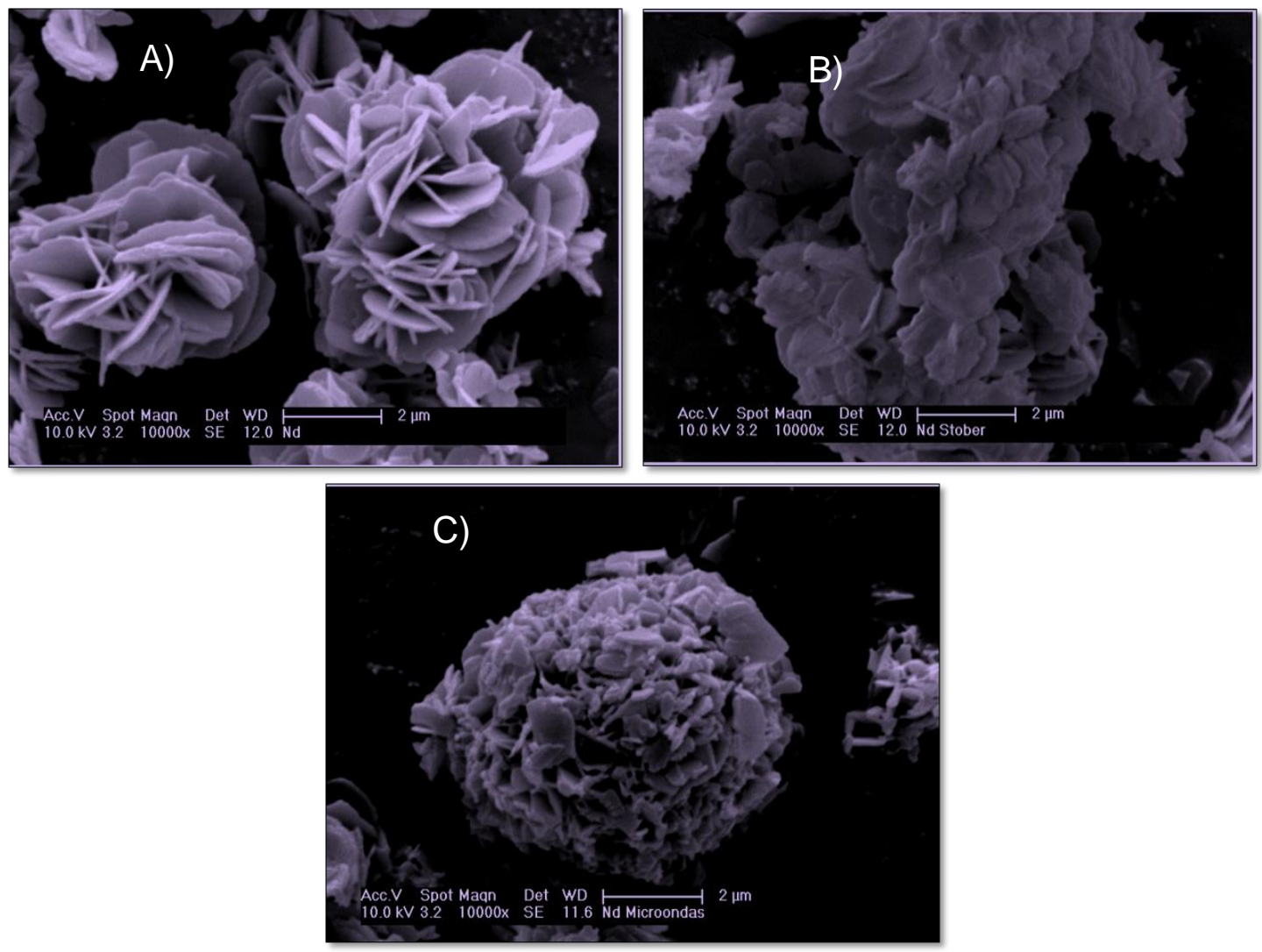

FIGURA 5.81.Micrografias de $\mathrm{Nd}_{2}\left(\mathrm{MoO}_{4}\right)_{3}$ a) não funcionalizada; b) funcionalizada pelo método de Stöber e c) funcionalizada pelo método de micro-ondas.

5.6.3.4 Espectroscopia por dispersão de energia (EDS) das nanopartículas de neodímio aminofuncionalizadas $\left(\mathrm{Nd}_{2}\left(\mathrm{MoO}_{4}\right)_{3} @ \mathrm{Si}\right)$

Com o objetivo de comprovar a presença da sílica nas partículas e realizar uma análise qualitativa das amostras, foi feita a caracterização por espectroscopia por dispersão de energia (EDS) da amostra de $\mathrm{Nd}_{2}\left(\mathrm{MoO}_{4}\right)_{3} @ S i$ pelo método de micro-ondas.

As FIG. 5.82 e 5.83 apresentam as fotos de EDS para as amostras de molibdato de neodímio funcionalizadas por micro-ondas. São apresentadas fotos com a distribuição dos elementos contidos no aglomerado da amostra, a) distribuição do oxigênio, b) distribuição do molibdato, c) distribuição do neodímio e 
d) distribuição do silício. Nota-se que há presença de todos os elementos citados por todo aglomerado, inclusive o recobrimento total pela sílica.

Para uma melhor comprovação qualitativa da funcionalização, caracterizou-se esses fósforos por EDS (Espectroscopia por dispersão de energia). Esta técnica permitiu a observação da distribuição dos elementos constituintes da matriz do luminóforo, bem como a presença do silício, comprovando a efetividade da funcionalização.Para cada luminóforo são apresentadas as fotos da distribuição de todos os elementos constituintes (a) e separadamente. É possível notar em todas as fotos de EDS, uma boa distribuição dos elementos que compõe a matriz, bem como do silício que forma a camada da funcionalização comprovando a eficácia do método de recobrimento.

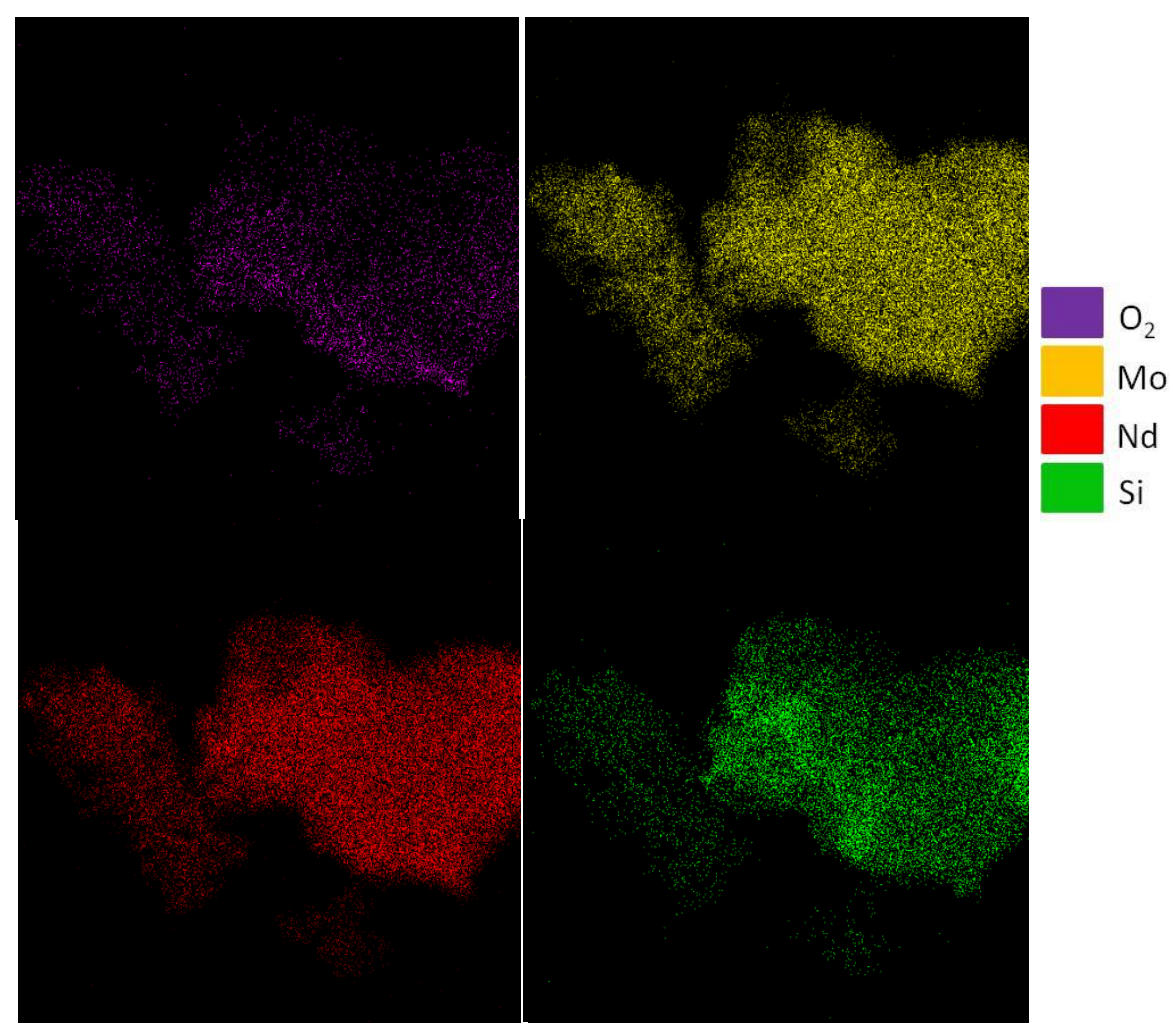

FIGURA 5.82. Imagens obtidas por EDS das amostras de $\mathrm{Nd}_{2}\left(\mathrm{MoO}_{4}\right)_{3}$ Stöber. 


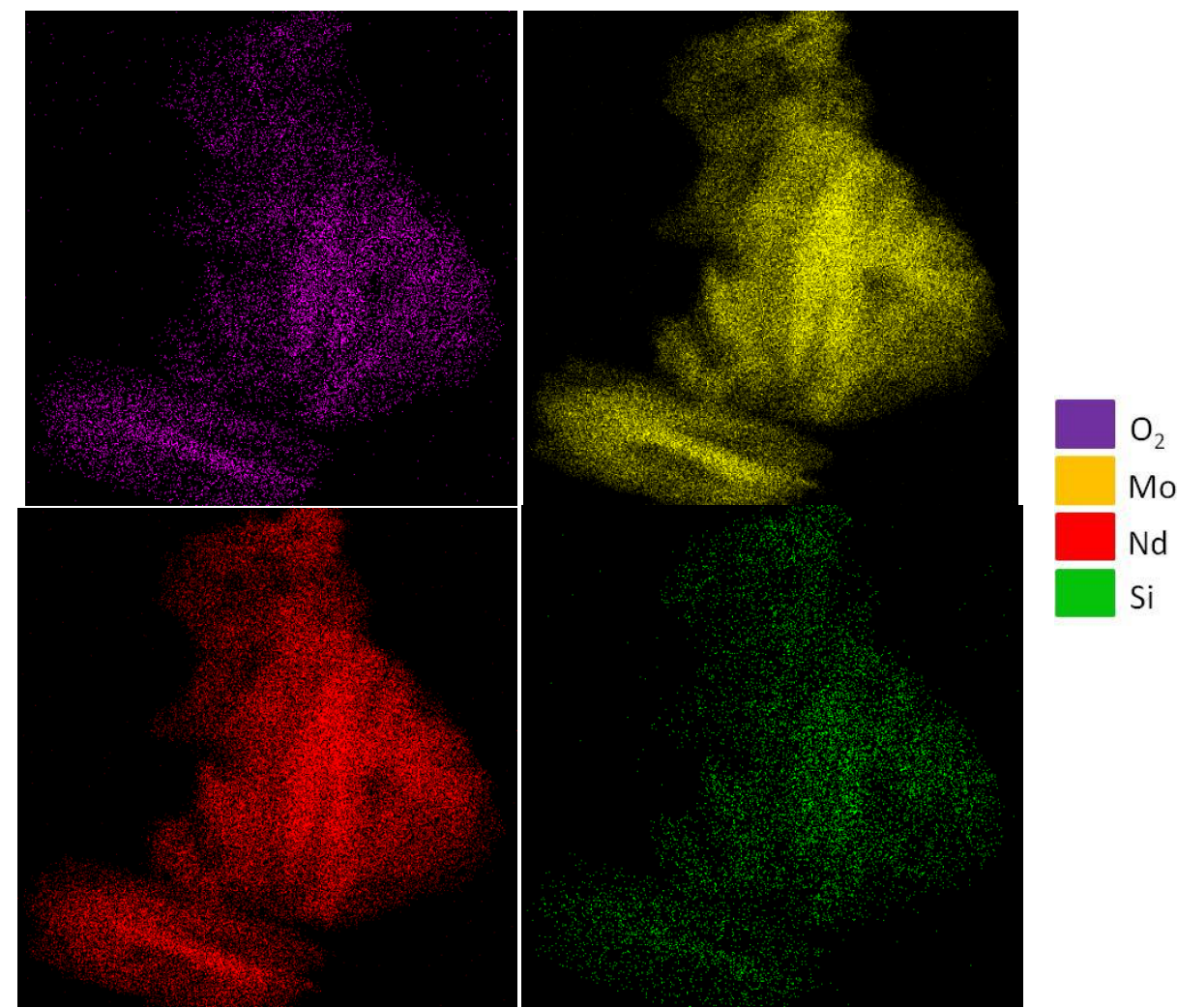

FIGURA 5.83. Imagens obtidas por EDS das amostras de $\mathrm{Nd}_{2}\left(\mathrm{MoO}_{4}\right)_{3}$ microondas.

\subsubsection{Microscopia eletrônica de transmissão (TEM) das nanopartículas de neodímio aminofuncionalizadas $\left(\mathrm{Nd}_{2}\left(\mathrm{MoO}_{4}\right)_{3} @ \mathrm{Si}\right)$}

As amostras de molibdato de neodímio foram caracterizadas por microscopia eletrônica de transmissão. A FIG. 5.84 apresenta os aglomerados de nanopartículas de a) molibdato de neodímio não funcionalizado, com contorno regular, b) molibdato de neodímio funcionalizado pelo método de micro-ondas, com contornos menos regulares e mais transparentes, sugerindo a presença e recobrimento pela sílica e c) molibdato de neodímio funcionalizado pelo método de Stöber, apresentando visualmente maior número de camadas sobrepostas de sílica quando comparado a partícula não funcionalizadas às funcionalizadas pelo método de micro-ondas e Stöber. Já quando se compara os dois métodos de funcionalização as partículas por micro-ondas tem uma camada menor de sílica 
do que as partículas revestidas pelo método de de Stöber o que se deve muito provavelmente à dupla camada de organosilano utilizadas no método de Stöber.
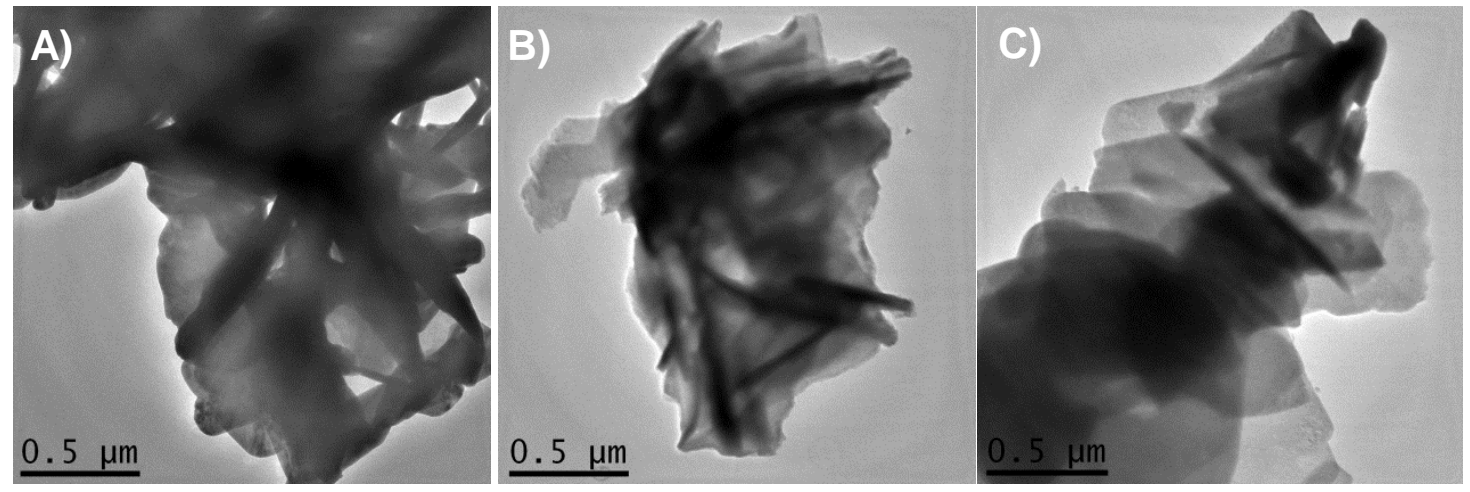

FIGURA 5.84. Micrografias de microscopia eletrônica de transmissão (TEM) das nanopartículas de A) $\left.\mathrm{Nd}_{2}\left(\mathrm{MoO}_{4}\right)_{3}, \mathrm{~B}\right) \mathrm{Nd}_{2}\left(\mathrm{MoO}_{4}\right)_{3} @ S i-m i c$ e $\mathrm{Nd}_{2}\left(\mathrm{MoO}_{4}\right)_{3} @ S i-$ Stöber

\subsubsection{Estudo das propriedades luminescentes das partículas de $\mathrm{TR}_{2}\left(\mathrm{MoO}_{4}\right)_{3} @ \mathrm{Si}$}

O estudo da fotoluminescência das partículas de sílica aminofuncionalizadas incorporando o luminóforo foi realizado através dos espectros de excitação e emissão, registrados à temperatura ambiente ( 298 K).

A FIG.5.85 mostra os espectros de excitação do luminóforo $\mathrm{Eu}_{2}\left(\mathrm{MoO}_{4}\right)_{3}$ e das partículas $\mathrm{Eu}_{2}\left(\mathrm{MoO}_{4}\right)_{3} @ \mathrm{Si}$ a temperatura ambiente registrados no intervalo de 200 a $590 \mathrm{~nm}$, com emissão monitorada na transição hipersensível ${ }^{5} \mathrm{D}_{0} \rightarrow{ }^{7} \mathrm{~F}_{2}$. Estes espectros a temperatura ambienteapresentam um mesmo perfil tanto do luminóforo, quanto das partículas funcionalizadas. A diferença é na intensidade destas transições que são menos intensas para as partículas revestidas. A banda de transferência de carga ligante metal desloca o seu máximo em $2 \mathrm{~nm}$ quando 0 material é revestido pelo APTES. 
A parte do espectro de $\mathrm{Eu}_{2}\left(\mathrm{MoO}_{4}\right)_{3} @ S i$ que se refere às transições 4f4 apresenta o mesmo comportamento que o luminóforo não silanizado, não há deslocamento das bandas, apenas diminuição da intensidade.

No estudo da fotoluminescência a partir dos dados de emissão do luminóforo $\mathrm{Eu}_{2}\left(\mathrm{MoO}_{4}\right)_{3} \mathrm{e}$ dos materiais $\mathrm{Eu}_{2}\left(\mathrm{MoO}_{4}\right)_{3} @ \mathrm{Si}-\mathrm{Mic}$ e Eu $\mathrm{Eu}_{2}\left(\mathrm{MoO}_{4}\right)_{3} @$ Si-Sto (FIG. 5.86), foram registrados os espectros na faixa de 550 a $750 \mathrm{~nm}$, sob excitação na transição ${ }^{7} \mathrm{~F}_{0} \rightarrow{ }^{5} \mathrm{~L}_{6}$ do íon $\mathrm{Eu}^{3+}$. Estes espectros de emissão exibem bandas atribuídas às transições ${ }^{5} \mathrm{D}_{0} \rightarrow{ }^{7} \mathrm{~F}_{\mathrm{J}}$ (onde $\mathrm{J}=0,1,2,3$ e 4), nos quais a transição hipersensível ${ }^{5} \mathrm{D}_{0} \rightarrow{ }^{7} \mathrm{~F}_{2}$ aparece como a banda mais proeminente. Nenhuma alteração foi a princípio observada nestes espectros.

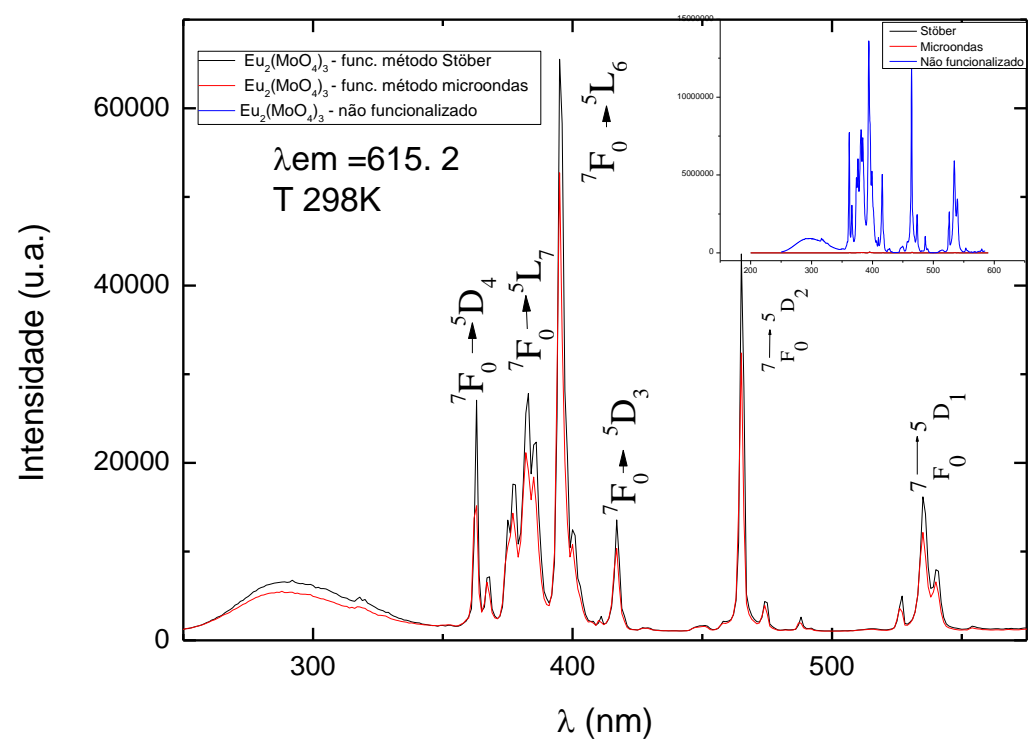

FIGURA 5.85. Espectro de excitação de $\mathrm{Eu}_{2}\left(\mathrm{MoO}_{4}\right)_{3}$ amino-funcionalizadas através do método de micro-ondas e Stöber. 


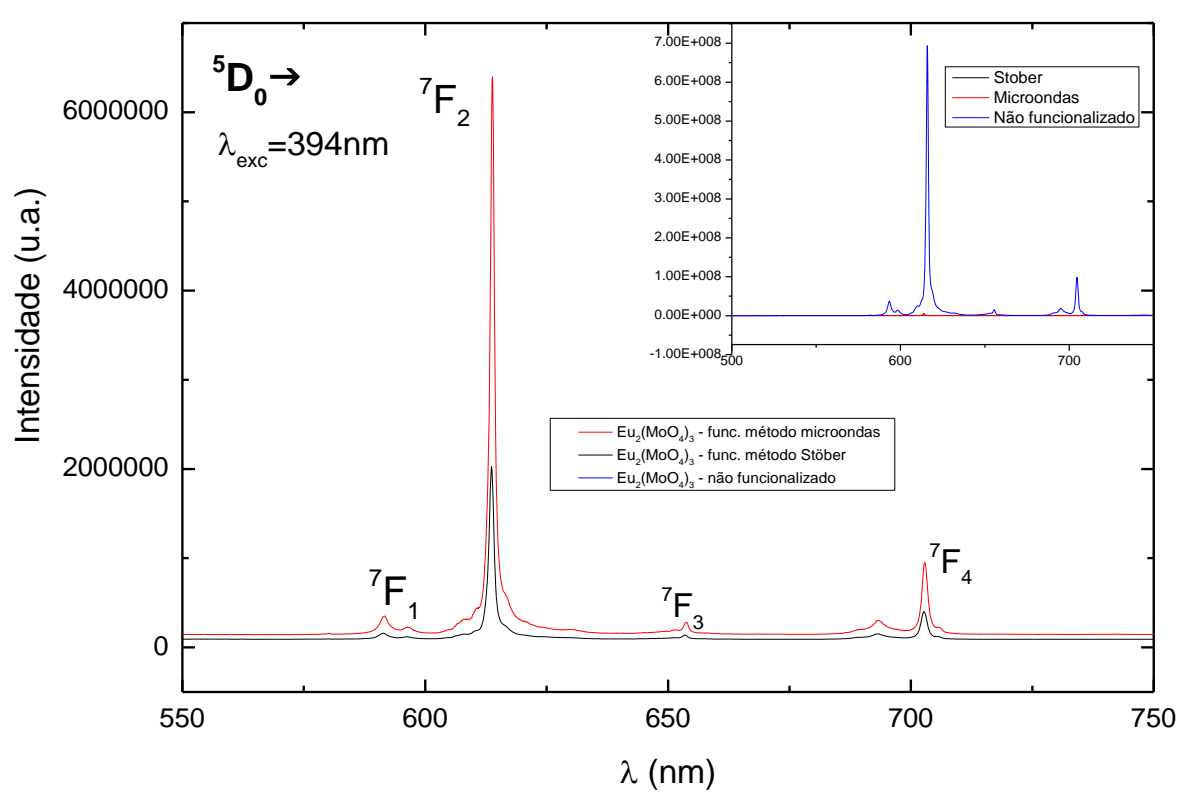

FIGURA 5.86. Espectro emissão das nanopartículas de $\mathrm{Eu}_{2}\left(\mathrm{MoO}_{4}\right)_{3}$ aminofuncionalizadas através do método de micro-ondas e Stöber.

Os parâmetros de intensidade experimental $\Omega_{\lambda}(\lambda=2$ e 4$)$, foram calculados e comparados aos dados da matriz sem funcionalização TAB. 5.12.

É verificado uma diminuição nos valores dos parâmetros $\Omega_{2}$ do material funcionalizado quando se compara com o do seu respectivo luminóforo, devido a diminuição da intensidade da transição ${ }^{5} \mathrm{D}_{0} \rightarrow{ }^{7} \mathrm{~F}_{2}$, indicando um aumento da distorção de simetria local do $\mathrm{Eu}^{3+}$ para um menor caráter centrossimétrico. Os altos valores dos parâmetros de intensidade $\Omega_{4}$ para os sistemas, quando comparados com os valores de $\Omega_{2}$, reflete a intensidade extremamente alta da transição ${ }^{5} \mathrm{D}_{0} \rightarrow{ }^{7} \mathrm{~F}_{4}$ observada nos espectros de emissão. 
TABELA 5.12. Parâmetros de intensidade $\left(\Omega_{\lambda}\right)$, taxa radiativa $\left(A_{\text {rad }}\right)$, do nível emissor ${ }^{5} \mathrm{D}_{0}$ determinado em $298 \mathrm{~K}$ para 0 luminóforo $\mathrm{Eu}_{2}\left(\mathrm{MoO}_{4}\right)_{3}$, funcionalizadopelo método micro-ondas (Mic) e Stöber (Sto).

\begin{tabular}{c|cccc}
\hline Método & $\begin{array}{c}\Omega_{2} \\
\left(10^{-20} \mathrm{~cm}^{2}\right)\end{array}$ & $\begin{array}{c}\Omega_{4} \\
\left(10^{20} \mathrm{~cm}^{2}\right)\end{array}$ & $\mathbf{R}_{02}$ & $\begin{array}{c}\mathbf{A}_{\mathrm{RAD}} \\
\left(\mathbf{s}^{-1}\right)\end{array}$ \\
\hline $\mathrm{Eu}_{2}\left(\mathrm{MoO}_{4}\right)_{3}$ & 14 & 10 & 0,021 & 622 \\
$\mathrm{Eu}_{2}\left(\mathrm{MoO}_{4}\right)_{3} \mathbf{M i c}$ & 8,9 & 10,3 & 0,030 & 469 \\
$\mathrm{Eu}_{2}\left(\mathrm{MoO}_{4}\right)_{3}$ Sto & 4,9 & 7,4 & 0,030 & 307 \\
\hline
\end{tabular}

A FIG. 5.87 mostra os espectros de excitação do molibdato de ítrio dopado com európio e esta matriz funcionalizada pelo método de Stöber e microondas. Os espectros são similares e diferem apenas na região entre 200 e 350 nm que é a região onde aparecem as transições de transferência de carga. No espectro do luminóforo sem funcionalização esta banda é deslocada para região de alta energia. Já para os materiais funcionalizados esta banda tem o máximo em 297nm. As bandas fixas em aproximadamente 361; 375, 393, 414, 464, 533, 525 e $578 \mathrm{~nm}$ correspondem às transições ${ }^{7} \mathrm{~F}_{0} \rightarrow{ }^{5} \mathrm{D}_{\mathrm{J}},{ }^{5} \mathrm{~L}$, do íon $\mathrm{Eu}^{3+}$. 


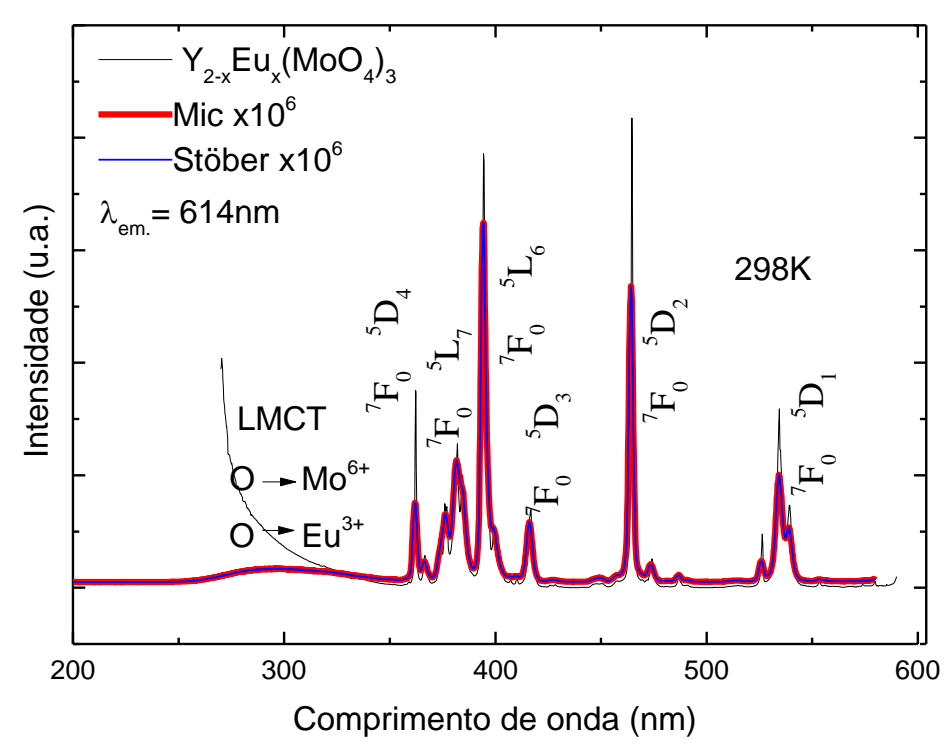

FIGURA 5.87. Espectro de excitação de $\mathrm{Y}_{2.995} \mathrm{Eu}_{0,005}\left(\mathrm{MoO}_{4}\right)_{3}$ aminofuncionalizadas através do método de micro-ondas e Stöber.

No estudo da fotoluminescência a partir dos dados de emissão do luminóforo $\mathrm{Y}_{2.995} \mathrm{Eu}_{0,005}\left(\mathrm{MoO}_{4}\right)_{3} \mathrm{e}$ dos materiais $\mathrm{Y}_{2.995} \mathrm{Eu}_{0,005}\left(\mathrm{MoO}_{4}\right)_{3} @$ Si-Mic e $\mathrm{Y}_{2.995} \mathrm{Eu}_{0,005}\left(\mathrm{MoO}_{4}\right)_{3} \mathrm{Si}$-Sto (FIG.5.88) foram registrados os espectros na faixa de 500 a $900 \mathrm{~nm}$, sob excitação na transição ${ }^{7} \mathrm{~F}_{0} \rightarrow{ }^{5} \mathrm{~L}_{6}$ do íon $\mathrm{Eu}^{3+}$. Estes espectros de emissão exibem bandas atribuídas às transições ${ }^{5} \mathrm{D}_{0} \rightarrow{ }^{7} \mathrm{~F}_{\mathrm{J}}$ (onde $\mathrm{J}=0,1,2$, $3 \mathrm{e}$ 4), nos quais a transição hipersensível ${ }^{5} D_{0} \rightarrow{ }^{7} F_{2}$ aparece como a banda mais proeminente. Os espectros dos materiais funcionalizados são de menor intensidade que o espectro do fluoróforo de partida. 


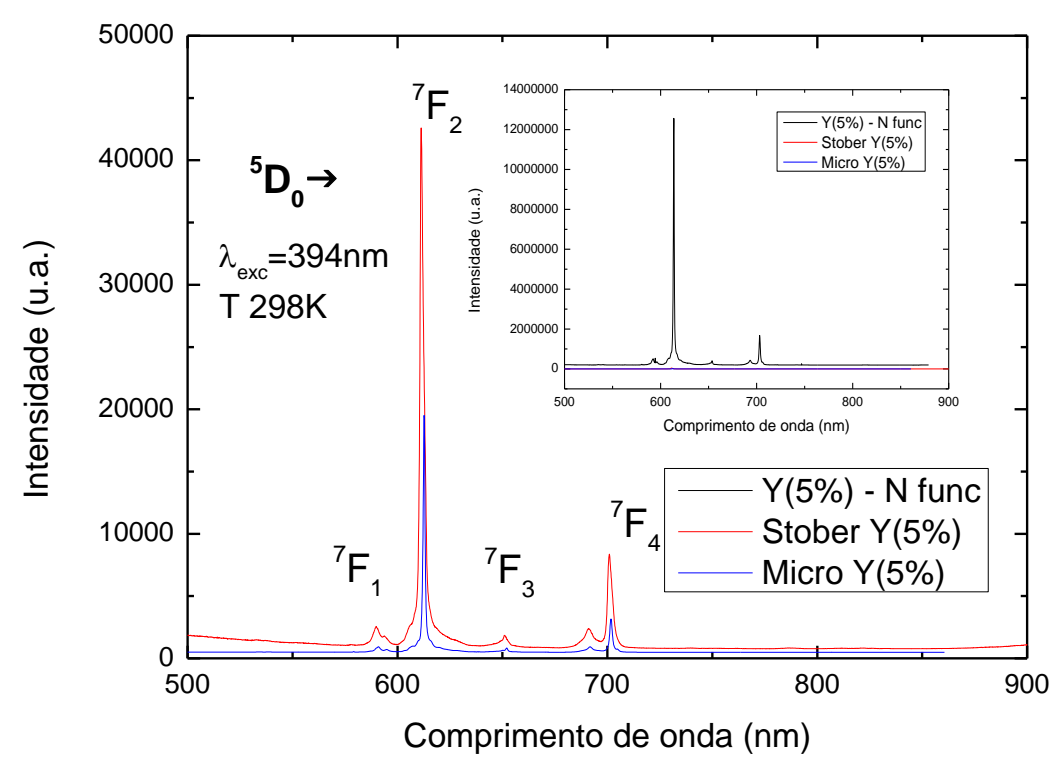

FIGURA 5.88. Espectros de emissão das nanopartículas de $\mathrm{Y}\left(5 \% \mathrm{Eu}_{2}\left(\mathrm{MoO}_{4}\right)_{3}\right.$ amino-funcionalizadas através do método de micro-ondas

Como mencionado anteriormente para compostos de térbio o intervalo

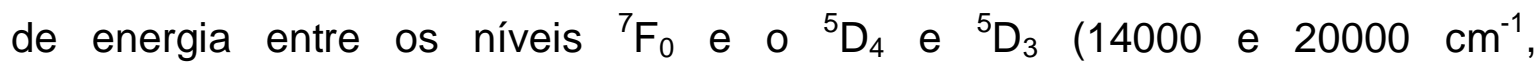
respectivamente) coloca quase todas as transições ${ }^{5} \mathrm{D}_{3,4} \rightarrow{ }^{7} \mathrm{~F}_{0-6}$ na região visível do espectro (com exceção da transição ${ }^{5} D_{3} \rightarrow{ }^{7} F_{6}$ situada na região do UV próximo). Todas as transições são relativamente fortes, em contraste com as transições ${ }^{5} \mathrm{D}_{\jmath} \rightarrow{ }^{7} \mathrm{~F}_{5-6}$ do íon $\mathrm{Eu}^{3+}$ que geralmente são muito fracas e situadas na região do infravermelho.

Os espectros de excitação foram registrados na faixa espectral de 250 a $500 \mathrm{~nm}$, a temperatura ambiente.

Os espectros de excitação do material $\mathrm{Tb}_{2}\left(\mathrm{MoO}_{4}\right)_{3} @ \mathrm{Si}$ (Figura 5.89) mostram os picos referentes às transições $4 \mathrm{f}-4 \mathrm{f}$ característicos do íon $\mathrm{Tb}^{3+}$, na faixa espectral entre $250-500 \mathrm{~nm}$. 
Nos espectros, verificou-se também uma banda larga na região de 250 a $344 \mathrm{~nm}$ com máximo em $\sim 281 \mathrm{~nm}$, atribuída à banda $\mathrm{O} \rightarrow$ Mo do $T b_{2}\left(\mathrm{MoO}_{4) 3}\right.$ Além disso, estes espectros mostram bandas finas correspondentes às transições oriundas da configuração $4 f^{8}-4 f^{8}$ do íon Tb $^{3+} 350,4 ; 357,8 ; 368,2 ; 376,4 ; 467,2$ e 484,6 , aproximadamente, correspondem às transições ${ }^{7} F_{6} \rightarrow{ }^{5} G_{\jmath},{ }^{5} L_{\jmath}$ e ${ }^{5} D_{\jmath}$ do íon $\mathrm{Tb}^{3+}{ }^{56}$

Os espectros a temperatura ambiente são praticamente idênticos excessão feita à banda atribuída ao $\mathrm{O} \rightarrow \mathrm{M}$, que aparece na região de 270 a $330 \mathrm{e}$ que intensifica as transições em 303, 317,5 e 326 nm quando comparados ao luminóforo sem funcionalização.

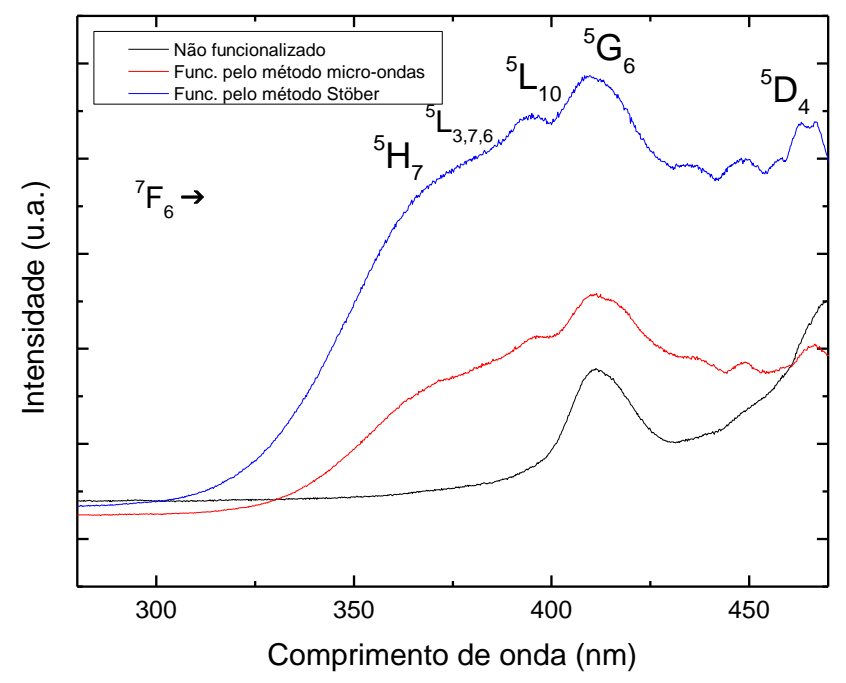

FIGURA 5.89. Espectros de excitação das nanopartículas de $\mathrm{Tb}_{2}\left(\mathrm{MoO}_{4}\right)_{3} \mathrm{e}$ $\mathrm{Tb}_{2}\left(\mathrm{MoO}_{4}\right)_{3}$ amino-funcionalizadas pelos métodos de micro-ondas e Stöber

A FIG. 5.90 mostra os espectros de emissão para o luminóforo $\mathrm{Tb}_{2}\left(\mathrm{MoO}_{4}\right)_{3}$ e as nanopartículas recobertas com sílica (298 K). Podem-se observar bandas de emissão finas características das transições ${ }^{5} D_{4} \rightarrow{ }^{7} F_{J}(J=6,5,4,3,2$, 1 e 0), atribuídas: ${ }^{5} \mathrm{D}_{4} \rightarrow{ }^{7} \mathrm{~F}_{6}(488,2 \mathrm{~nm}),{ }^{5} \mathrm{D}_{4} \rightarrow{ }^{7} \mathrm{~F}_{5}(542 \mathrm{~nm}),{ }^{5} \mathrm{D}_{4} \rightarrow{ }^{7} \mathrm{~F}_{4}(582 \mathrm{~nm})$, 
${ }^{5} \mathrm{D}_{4} \rightarrow{ }^{7} \mathrm{~F}_{3}(621,2 \mathrm{~nm}),{ }^{5} \mathrm{D}_{4} \rightarrow{ }^{7} \mathrm{~F}_{2}(650,6 \mathrm{~nm}),{ }^{5} \mathrm{D}_{4} \rightarrow{ }^{7} \mathrm{~F}_{1}(669 \mathrm{~nm}) \mathrm{e}^{5} \mathrm{D}_{4} \rightarrow{ }^{7} \mathrm{~F}_{0}(682 \mathrm{~nm})$. Vale ressaltar que os espectros apresentam perfis semelhantesa $298 \mathrm{~K}$.

A transição ${ }^{5} \mathrm{D}_{4} \rightarrow{ }^{7} \mathrm{~F}_{5}$ é predominante nos espectros de emissão, portanto, os materiais $\mathrm{Tb}_{2}\left(\mathrm{MoO}_{4}\right)_{3}, \mathrm{~Tb}_{2}\left(\mathrm{MoO}_{4}\right)_{3} @$ @i-Mic e Tb $2\left(\mathrm{MoO}_{4}\right)_{3} @$ Si-Sto exibem uma emissão monocromática da cor verde sob irradiação UV.

Ademais, observou-se que há um deslocamento dos baricentros das bandas ${ }^{5} \mathrm{D}_{4} \rightarrow{ }^{7} \mathrm{~F}$ J para menor comprimento de onda do material recoberto com sílica (efeito hipsocrômico).

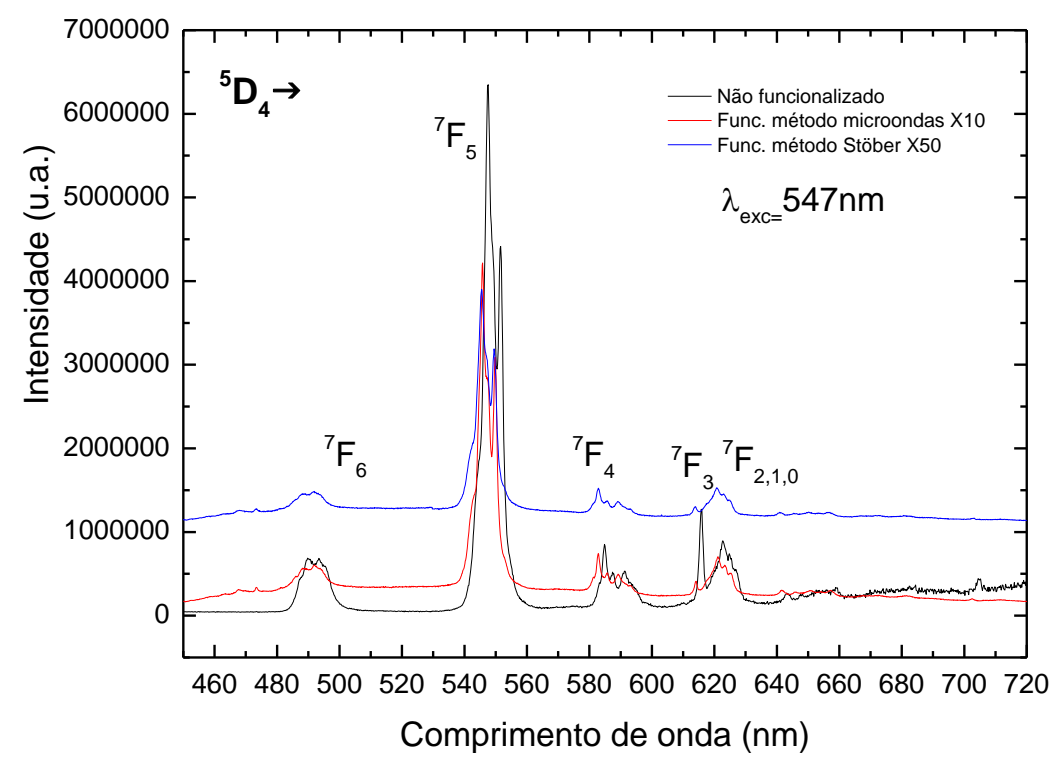

FIGURA 5.90. Espectros de emissão das nanopartículas de $\mathrm{Tb}_{2}\left(\mathrm{MoO}_{4}\right)_{3} \mathrm{e}$ $\mathrm{Tb}_{2}\left(\mathrm{MoO}_{4}\right)_{3}$ amino-funcionalizadas pelos métodos de micro-ondas e Stöber.

As propriedades luminescentes do $\mathrm{Sm}_{2}\left(\mathrm{MoO}_{4}\right)_{3}$ e $\mathrm{Sm}_{2}\left(\mathrm{MoO}_{4}\right)_{3} @ \mathrm{Si}$-mic e $\mathrm{Sm}_{2}\left(\mathrm{MoO}_{4}\right) 3 @$ Si-sto foram investigados e comparados nesse trabalho. Os espectros de excitação da matriz $\mathrm{Sm}_{2}\left(\mathrm{MoO}_{4) 3}\right.$ e $\mathrm{Sm}_{2}\left(\mathrm{MoO}_{4}\right)_{3}$ @Si-mic e $\mathrm{Sm}_{2}\left(\mathrm{MoO}_{4}\right) 3$ @Si-sto com emissão monitorada na transição hipersensível 
${ }^{4} \mathrm{G}_{5 / 2} \rightarrow{ }^{6} \mathrm{H}_{9 / 2}(\sim 645 \mathrm{~nm})$ foram registrados no intervalo de 200 a $550 \mathrm{~nm}$, a $298 \mathrm{~K} 7$ (Figura 5.91). Estes espectros apresentam bandas finas oriundas das transições intraconfiguracionais $4 f^{5}$ envolvendo o estado fundamental ${ }^{6} \mathrm{H}_{5 / 2}$ e os estados excitados (em nm): ${ }^{4} \mathrm{D}_{7 / 2}+{ }^{4} \mathrm{D}_{9 / 2}$ ( 350), ${ }^{4} \mathrm{~F}_{9 / 2}$ ( 362), ${ }^{4} \mathrm{~L}_{17 / 2},{ }^{5} \mathrm{D}_{1 / 2} \mathrm{P}_{7 / 2} \quad(\sim 376)$, ${ }^{4} \mathrm{H}_{11 / 2}{ }^{6} \mathrm{M}_{15 / 2} \quad(\sim 391), \quad{ }^{4} \mathrm{~F}_{7 / 2}{ }^{4} \mathrm{~L}_{13 / 2}{ }^{6} \mathrm{P}_{3 / 2} \quad(\sim 403), \quad{ }^{4} \mathrm{M}_{19 / 2}{ }^{6} \mathrm{P}_{5 / 2} \quad(\sim 417), \quad{ }^{4} \mathrm{I}_{15 / 2}{ }^{6} \mathrm{M}_{17 / 2}{ }^{4} \mathrm{G}_{9 / 2}$ ( 440), ${ }^{4} \mathrm{~F}_{3 / 2}(1)(\sim 450),{ }^{4} \mathrm{I}_{13 / 2}(\sim 463),{ }^{4} \mathrm{I}_{13 / 2}(\sim 463),{ }^{4} \mathrm{I}_{13 / 2}(\sim 467),{ }^{4} \mathrm{I}_{9 / 2}(\sim 471),{ }^{4} \mathrm{G}_{7 / 2}$ ( 499), ${ }^{4} \mathrm{~F}_{3 / 2}(2)(\sim 528)$ e ${ }^{4} \mathrm{G}_{5 / 2}(\sim 559)$, conforme Figura 5.91

Os espectros de emissão (FIGs. 5.91 e 5.92) do $\mathrm{Sm}_{2}\left(\mathrm{MoO}_{4}\right)_{3}$ e $\mathrm{Sm}_{2}\left(\mathrm{MoO}_{4}\right)_{3} @ \mathrm{Si}$-mic e Sm $\left(\mathrm{MoO}_{4}\right)_{3} @$ Si-sto foram registrados no intervalo espectral de 550 a $750 \mathrm{~nm}$, a $298 \mathrm{~K}$. Como pode ser observado, esses espectros consistem de bandas finas atribuídas às transições ${ }^{4} \mathrm{G}_{5 / 2} \rightarrow{ }^{6} \mathrm{H}_{\mathrm{J}}$ (onde $\mathrm{J}=5 / 2,7 / 2$, 9/2 e 11/2) centradas no íon $\mathrm{Sm}^{3+}$, sendo a transição hipersensível ${ }^{4} \mathrm{G}_{5 / 2} \rightarrow{ }^{6} \mathrm{H}_{9 / 2}$ ( 650 nm) apresentando maior intensidade. A presença de bandas largas oriundas da fosforescência da matriz foram observadas na região de $550 \mathrm{~nm}$ e evidenciam a ineficiente transferência de energia matriz- $\mathrm{Sm}^{3+}$ para todos os sistemas estudados. Os espectros de emissão mostram ainda que as bandas atribuídas às transições ${ }^{4} \mathrm{G}_{5 / 2} \rightarrow{ }^{6} \mathrm{H}_{\lrcorner}$estão alargadas devido ao caráter nanométrico das partículas. $O$ calculo do valor do parâmetro experimental $\eta_{S m}$ resultou em 5,0 para $\quad \circ \quad \mathrm{Sm}_{2}\left(\mathrm{MoO}_{4}\right)_{3}, \quad 1,36$ para $\quad$ o $\quad \mathrm{Sm}_{2}\left(\mathrm{MoO}_{4}\right)_{3} @$ Si-mic e $\quad 1,52$ para $\mathrm{Sm}_{2}\left(\mathrm{MoO}_{4}\right)_{3} @$ Si-sto. 


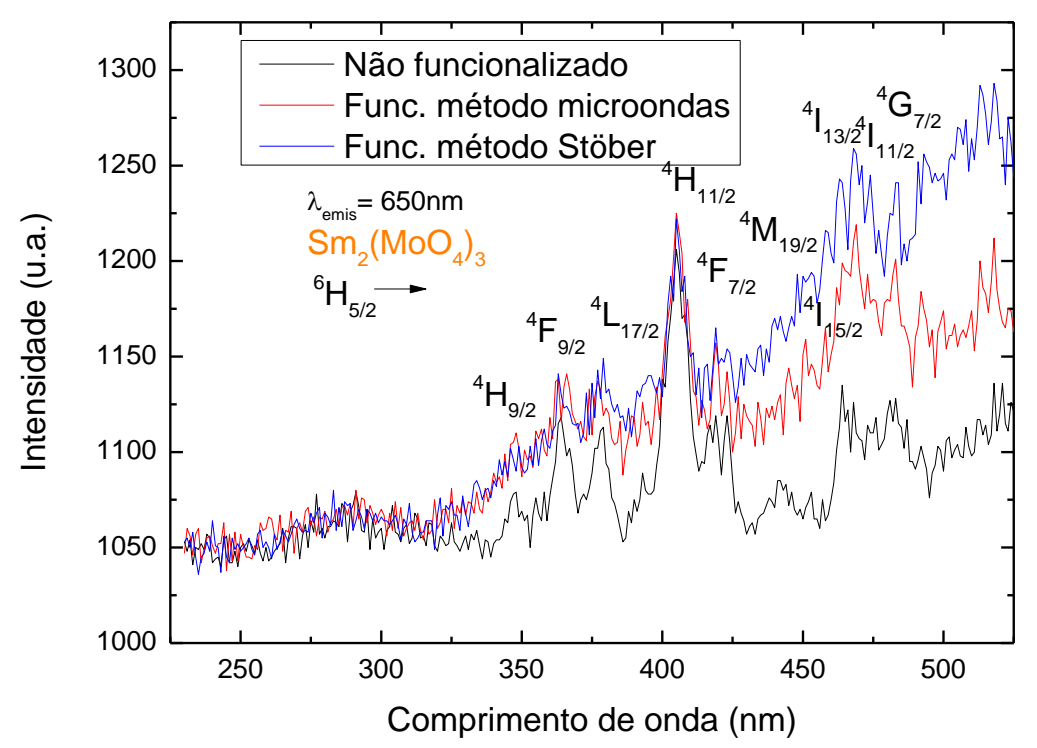

FIGURA 5.91. Espectros de excitação das nanopartículas de $\mathrm{Sm}_{2}\left(\mathrm{MoO}_{4}\right)_{3} \mathrm{e}$ $\mathrm{Sm}_{2}\left(\mathrm{MoO}_{4}\right)_{3}$ amino-funcionalizadas pelos métodos de micro-ondas e Stöber.

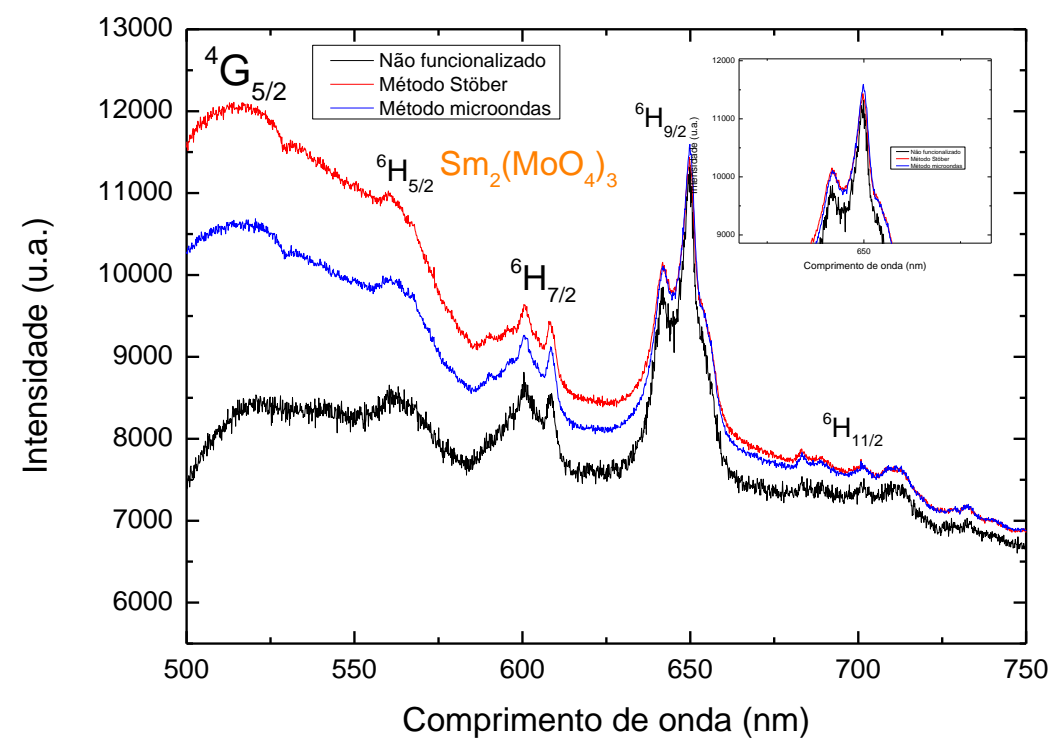

FIGURA 5.92. Espectros de emissão das nanopartículas de $\mathrm{Sm}_{2}\left(\mathrm{MoO}_{4}\right)_{3}$ aminofuncionalizadas pelo método de micro-ondas. 
Não foi possível registrar no SpecFluorolog 3 os espectros dos molibdatos de neodímio funcionalizados.

\subsubsection{Determinação das aminas primárias}

Para a quantificação das aminas primárias na amostras funcionalizadas, aplicou-se o método espectrofotométrico da ninidrina.

\subsubsection{Curva de calibração}

Inicialmente foi montada a curva padrão de concentração utilizando-se a glicina como material de referência. O espectro de absorção molecular da glicina é apresentado na FIG. 5.93, o qual possui absorção máxima em 570nm.

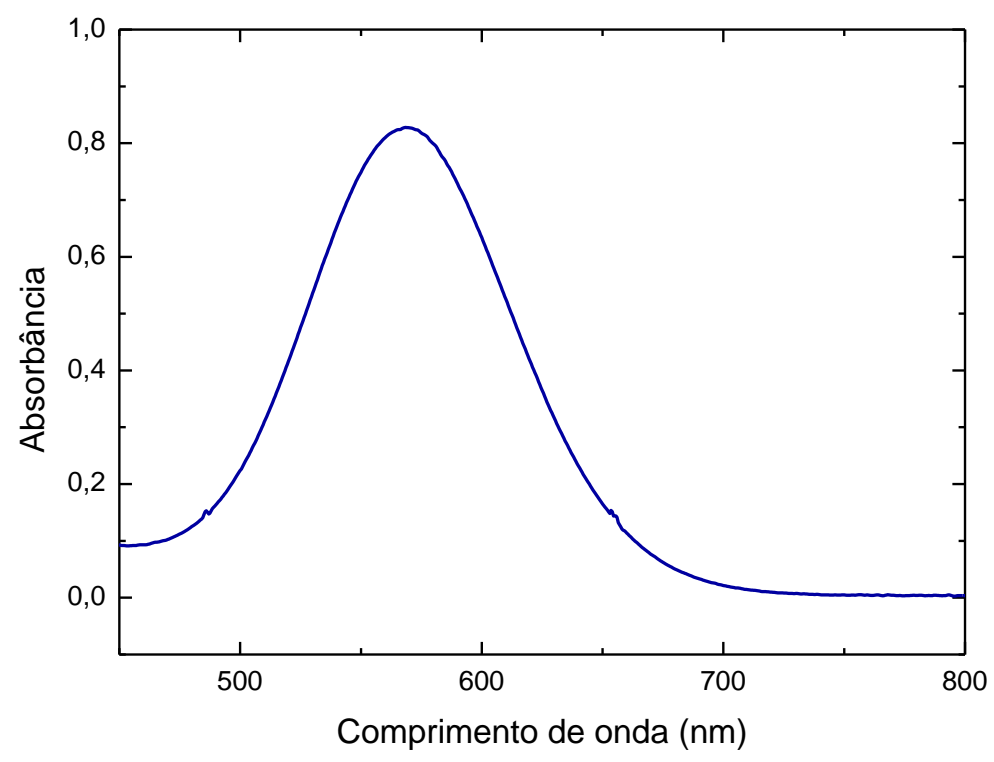

FIGURA 5.93. Espectro de absorção da glicina. 
O intervalo de concentrações da glicina para construir a curva de calibração para a análise espectrofotométrica foi de $1,0.10^{-05} \mathrm{gL}^{-1} \mathrm{a} 2,0.10^{-04} \mathrm{~g} \mathrm{~L}^{-1}$. Obteve-se então a equação da reta $y=4107 x+0,000295$ (FIG. 5.94).

$\mathrm{Na}$ análise dos fósforos funcionalizados, estes reagiram com a ninidrina, apresentando cor violeta indicando a presença de aminas primárias, portanto, pode-se afirmar que a funcionalização foi efetiva e que a rede de sílica do revestimento contém grupamentos de aminas primárias na superfície, possibilitando a aplicação destes fósforos como marcadores luminescentes para espécies biológicas

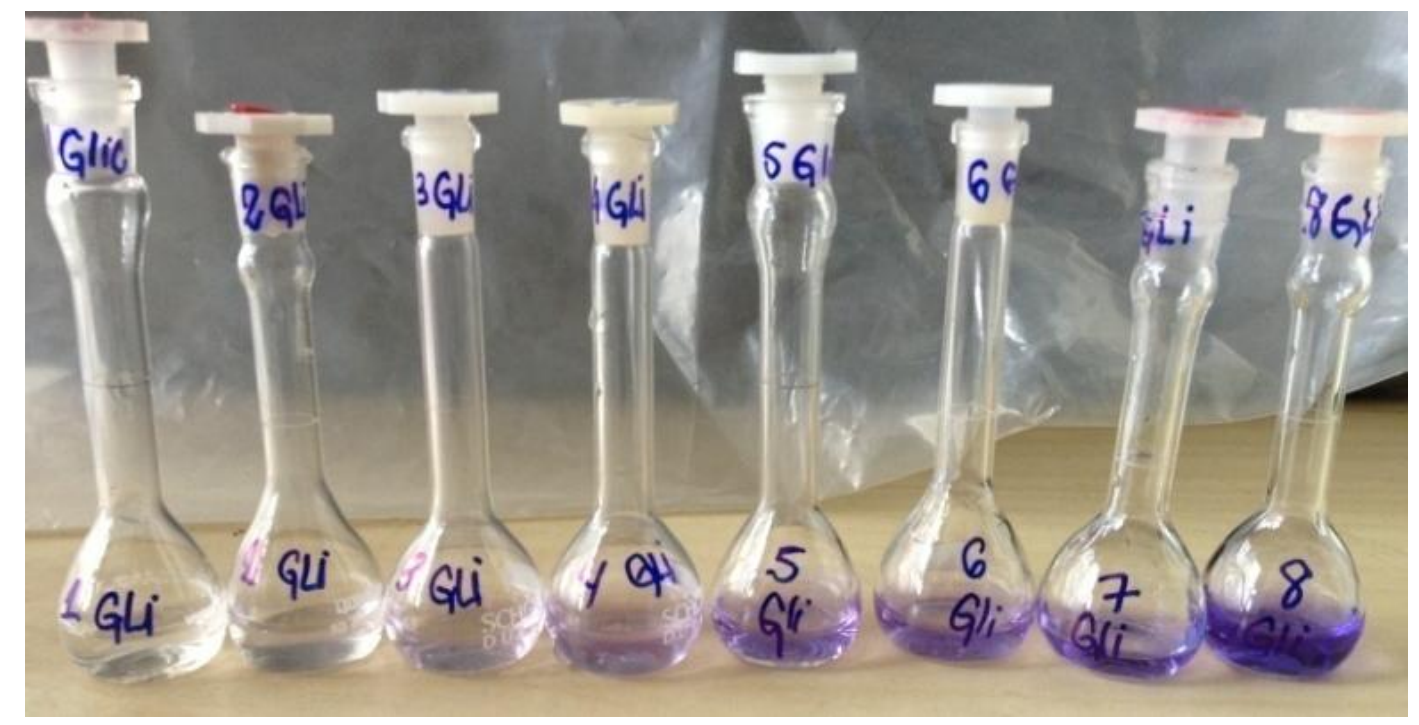

FIGURA 5.94. Foto das diluições de glicina usadas para construir a curva de calibração 


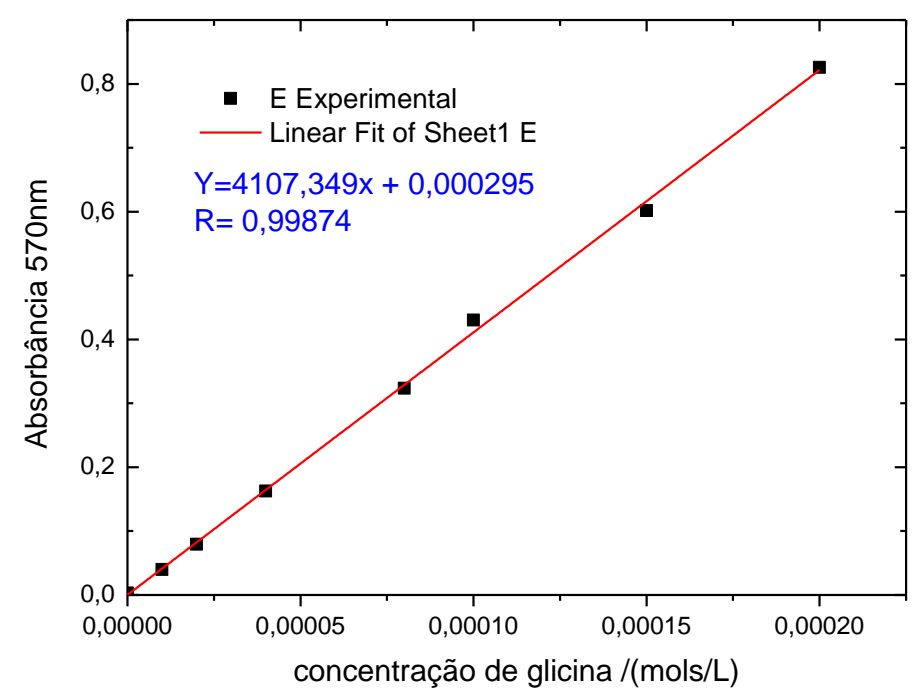

FIGURA 5.95. Curva de calibração da glicina para determinação de grupos aminas primárias.

\subsubsection{Quantificação de aminas nas partículas silanizadas}

A TAB. 5.13 apresenta a quantidade de amina em $\mu$ mol por massa de luminóforo. Observa-se que a funcionalização foi efetiva para os dois métodos, porém, o método de recobrimento usando a técnica de micro-ondas apresentou maior quantidade de amina por miligrama de luminóforo em sua superfície quando comparado com o método de recobrimento Stöber. Em relação aos diferentes fósforos funcionalizados por micro-ondas, o método apresentou em média 114 $\mu$ mol $_{\mathrm{NH}_{2}} \mathrm{mg}^{-1}$, sendo que o luminóforo $\mathrm{Nd}_{2}\left(\mathrm{MoO}_{4}\right)_{3}$ apresentou maior quantidade de amina por miligrama de luminóforo. 
Resultados e discussões - Sínteses e Caracterizações

TABELA 5.13. Quantificação de aminas por luminóforo $\left(\mu \mathrm{molmg}^{-1}\right)$.

\begin{tabular}{l|ll}
\hline $\begin{array}{l}\text { Luminóforo } \\
\text { (dopante/método) }\end{array}$ & $\mu \mathrm{mol}_{\mathrm{NH} 2} \cdot \mathrm{mg}^{-1}$ & $\begin{array}{l}\text { Desvio } \\
\text { padrão }\end{array}$ \\
\hline $\mathrm{Y}(5 \% \mathrm{Eu})$ Micro-ondas & 114,64 & 4,83 \\
$\mathrm{Y}(5 \% \mathrm{Eu})$ Stöber & 18,67 & 0,60 \\
$\mathrm{Nd}_{2}\left(\mathrm{MoO}_{4}\right)_{3}$ Micro-ondas & 119,88 & 5,97 \\
$\mathbf{N d}_{2}\left(\mathrm{MoO}_{4}\right)_{3}$ Stöber & 24,43 & 5,84 \\
\hline
\end{tabular}




\section{REFERÊNCIAS BIBLIOGRÁFICAS}

1. XU, L.; YANG, X.; ZHAI, Z.; GU, D.; Pang, H.; HOU, W. Cryst Eng Comm, v.14, p.7330, 2012.

2. YI, G.; SUN, B.; YANG, F.; CHEN, D., ZHOU, Y; CHENG, J., Chem. Mater. v. 14, p. 2910, 2002.

3. LIU, J.; XU, B.; SONG, C; LUO, H; ZOU, X.; HAN, L.; YU, X. Cryst. Eng Comm, v.14, p.2936, 2012.

4. BILECKA; I. NIEDERBERGER, M.Nanoscale, v. 2, p. 1358, 2010.

5. ZHANG, J.; WANG, X.; ZHANG, X; ZHAO, X.; LIU, X.; PENG, L. Inorg. Chem. Commun., v. 14, p. 1723, 2011.

6. TIAN, Y.; CHEN, B.; HUA, R; YU, N; LIU, B.; SUN, J.; CHENG, L.; ZHONG, H.; LI, X.; ZHANG, J.; TIAN, B; ZHONG, H. CrystEngComm, v. 14,p. 1760, 2012.

7. LEI, F.; YAN, B. J. Am. Ceram. Soc., v.92, p.1262, 2009.

8. LEI , F.; YAN, B; CHEN, H.H. J. Solid State Chem.,v.181, p.2845, 2008.

9. PAN, Y.; ZHANG, Q.; ZHAO, C.; JIANG, Z. Solid State Commun., v.142, p. 24, 2007.

10. PramaniK, S.; Bhattacharya, S. C. Mater. Chem. Phys., v. 121, p. 125, 2010.

11. HE, X.; ZHOU, J.; LIAN, N.; SUN, J.; GUAN, M. J. Lumin., v.130,p. 743, 2010.

12. BECK, H.P.; EISER, W.; HABERKORN, R. Pitfalls in the synthesis of nanoscaled perovskite type compounds. Part II: Influence of different sol-gel preparation methods and characterization of nanoscaled mixed crystals of the type Ba1-xSrxTiO3 $(0<=x<=1)$. J. European Ceramic Soc., v. 21(13), p. 2319-2323, 2001.

13. CULLITY, B. D. Elements of X-rays diffraction. Addison Wesley Publishing Company, 1972.

14. TEOTÔNIO, E.E.S. Síntese e investigação das propriedades fotoluminescentes de dispositivos moleculares conversores de luz (DMCL) de complexos dicetonatos de terras raras com ligantes amidas. 2004.p.216. Tese (Doutorado) - Instituto de Química - Universidade de São Paulo, São Paulo. 
15. OLIVEIRA, G.F.B. Fonons em arsenatos e molibdatos de Terras Raras. 2012. Dissertação (mestrado) - Universidade do Ceará - Ceará.

16. BAZHENOV, A. V.; FURSOVA, T. N.; KISELEV, A. P.; SHMURAK, S. Z; KHASANOV, S. S.; RED'KIN B. S.; SINITSYN, V. V. Structural Ordering upon Annealing of Europium Molybdate, Subjected to Pressure Treatment Physics of the Solid State, v.. 53, No. 4, p. 815-823, 2011.

17. MORA, N. D. Apostila de materiais Elétricos. Disponível em: http://www.foz.unioeste.br/ lamat/downmateriais em 11/10/2013.

18. DINNEBIER, R E.; BILLINGE, S J L Powder Diffraction RSC, 2008.

19. VITALIJ, P.; ZAVALIJ, P. Fundamentals of Powder Diffraction and Structural Characterization of Materials, Second Edition Springer 2009, 741p.

20. HUANG, Q; XU, J.Z.; LI, W. Preparation of tetragonal defect scheelite-type $\mathrm{RE}(\mathrm{MoO}) 3$ ( $\mathrm{RE}=\mathrm{La}$ to $\mathrm{Ho}$ ) by precipitation method. Solid State Ionics, v.32/33, p.244-9, 1989.

21. NASSAU, K.; LEVINSTEIN, H.J.; LOIACONO, G.M. A comprehensive study of trivalent tungstates and molybdates of the type L2(MoO4)3. Journal Phys. Chem. Solids, v. 26, p.1805-16, 1965.

22. WANG, Q.M.; YAN, B. Hydrotermal mild synthesis of microrod crystalline $\mathrm{Y}_{\mathrm{x}} \mathrm{Gd}_{2-\mathrm{x}}\left(\mathrm{MoO}_{4}\right)_{3}: \mathrm{Eu}^{3+}$ phosphors derived from facile co-precipitation precursors. Mater. Chem. Phys, v. 94, p.241-4, 2005.

23. ZHANG, N.; BU, W.; XU, Y.; JIANG, D.; SHI, J. Self assembled flowerlike europium doped lanthanide molybdate microarchtectures and their photoluminescence properties. J. Phys. Chem. C, v. 111, p.5014-9, 2007.

24. WANG, S.F.; RAO, K.K.;WANG, Y.R.;HSU,Y.F.;CHEN, S. H.; LU, Y.C. Structural characterization and luminescent properties of a red phosphor series: $Y_{2}$ ${ }_{x} \mathrm{Eu}_{x}\left(\mathrm{MoO}_{4}\right)_{3}(\mathrm{x}=0,4-2.0)$. J. Am. Ceram. Sec, v. 92, p.1732-1738, 2009.

25. GUO, C.; CHEN, T.; LUAN, L.; ZHANG, W.; HUANG, D. Luminescent properties of R2(MoO4)3:Eu3+(R=La, $\mathrm{Y}, \mathrm{Gd})$ phosphors prepared by sol-gel process. J. Phys. Chem. Solids, v. 69, p.1905-11, 2008.

26. BRITO, H.F.; LIU, G.K.; Crystal field influence on the $8 S 7 / 2$ ground state splitting of Bk4+ in CeF4. Journal of Chemical Physics, v.112, n.9, p. 4334$4341,2000$. 
27. LI, C.; LIN, C., LIU, X.; LIN, J.; Nanostructured CaWO4, CaWO4:Eu3+ and CaWO4:Tb3+ particles: sonochemical synthesis and luminescent properties, Journal of Nanoscience and Nanotechnology, v. 8, n. 3. p. 1183-1190, 2008.

28. RYU, J.H.; YOON, J.-W.; SHIM, K.B., Blue luminescence of nanocrystalline PbWO4 phosphor synthesized via a citrate complex route assisted by microwave irradiation, Solid State Communications, v. 133, n. 10, p. 657-661, 2005.

29. KANO, T.; SEKI, S.; CHIOU, S.Z.. J. luminescence, v. 29, p.163-176, 1984.

30. MALTA, O.L.; BRITO, H.F.; MENEZES, J.F.S.; GOLÇALVES E SILVA, F.R.; ALVES JR.,S.; FARIAS JR., F.S.; ANDRADE, A.V.M. Spectroscopic properties od a new light-converting device Eu(thenoyltrifluorocetonatos) a theorical analysis based on structural data obtained from a sparkle model. Jornal of luminescence, v.75, p.255,1997.

31. JIA, G. Spectroscopy and energy transfer in doped complexes. 2009. PhD tesis, p.231. Hong Kong University, Hong Kong.

32. LOURENÇO, A.V.S. Partículas de sílica funcionalizadas contendo complexos de TR3+ para aplicação como marcadores em ensaios biológicos. 2010. Tese (Doutorado) - Universidade de São Paulo, São Paulo.

33. BONDIOLI, F.; MANFREDINI, T.; OLIVEIRA, A.P.N. Pigmentos Inorgânicos: Projeto, produção e Aplicação Industrial. Ceram. Industrial, v. 3, p. 13-17, 1998.

34. BANERJEE, A.N. The design, fabrication, and photocatalytic utility of nanostructured semiconductors: focus on $\mathrm{TiO}^{-}$- based nanostructures. Nanotechnol Sci Appl., v. 4, p. 35-65, 2011.

35. OREL, Z.C.; OREL, B.; HODOSCEK, M.; KAUCIC, V. Conductive SnO2/Sb powder: preparation and optical properties. J. Mater. Sci., v. 27, p. 313-318, 1992.

36. YANG, H.Y.; YU, S.F.; LAU, S.P.; TSANG, S.H.; XING, G.Z.; WU, T. Ultraviolet coherent random lasing in randomly assembled $\mathrm{SnO} 2$ nanowires. Appl. Phys. Lett., v. 94, n. 241121, p. 1-3, 2009.

37. DE SÁ, G.F.; MALTA, O.L.; MELLO DONEGÁ, C.; SIMAS, A.M.; LONGO, R.L.; SANTA-CRUZ, P.A.; DA SILVA JR, E.F. Spectroscopic properties and 
design of highly luminescent lanthanide coordination complexes. Coord. Chem. Rev., v.196, p.165-195, 2000.

38. CARNALL, W.T.; CROSSWITHE, H.; CROSSWITHE, H.M. Energy Level Structure and transition probabilities of the Trivalent Lanthanide in LaF3. Argone National Lab. Argonne Illinos, p. 4493, 1977.

39. JUDD, B.R. Ionic transitions hypersensitive to environment. J. Chem. Phys. v. 70 , n. 11 , p. $4830-4833,1979$.

40. PAGANINI, P.P. Síntese e caracterização de trocadores iônicos inorgânicos a base de óxidos mistos estanho-titânio para utilização na recuperação de cádmio e níquel e estudos fotoluminescentes. 2007. Dissertação (Mestrado) - Instituto de Pesquisas Energéticas e Nucleares, IPEN/CNEN-SP, São Paulo.

41. KODAIRA, C.A.; BRITO, H.F.; MALTA, O.L.; SERRA, O.A. Luminescence and energy transfer of the europium (III) tungstate obtained via the Pechini method. J. Lumin., v. 101, p. 11-21, 2003.

42. SILVA, H.R.M. Complexos luminescentes de európio trivalente imobilizados em vermiculitas modificadas com 1-metil-imidazol. 2012. Dissertação (Mestrado) - Universidade Federal da Paraíba, João Pessoa.

43. ZHAO, D.; QIAO, X.; FAN, X.; WANG, M. Local vibration around rare earth in $\mathrm{SiO} 2-\mathrm{PbF} 2$ glass and glass ceramics using Eu3+ probe. Physica B, v. 395, p. 10-15, 2007.

44. BLASSE, G. The Eu3+ luminescence as a measure for chemical bond differences in solids. Chem. Phys. Lett. v. 20, n. 6, p. 573-574, 1973.

45. SÁ FERREIRA, R.A.; NOBRE, S.S.; GRANADEIRO, C.M.; NOGUEIRA, H.I.S.; CARLOS, L.D.; MALTA, O.L. A theoretical interpretation of the abnormal $5 \mathrm{D} 0 \rightarrow 7 \mathrm{~F} 4$ intensity based on the Eu3+ local coordination in the Na9[EuW10O36]-14H2O polyoxometalate. J. Lumin., v. 121, p. 561-567, 2006.

46. MALTA O.L.; AZEVEDO, W.M.; ARAÚJO, E.G.; SÁ, G.F. On the 5D0 $\rightarrow 7 F 0$ transition of the Eu3+ ion in the $\{(\mathrm{C} 4 \mathrm{H} 9) 4 \mathrm{~N}\} 3 \mathrm{Y}(\mathrm{NCS}) 6$ host. Journal of Luminescence, v. 26, n. 3, p. 337-343, 1982. 
47. LUNSTROOT, K.; NOCKEMANN,P.; HECKE, K.V.;MEERVELT, L.V.;GORLLER-WALRAND,C.;BINNEMANS, K.;DRIESEN, K.. Visible and near infrared emission by Sm(III) containing ionic liquid mixtures, Inorg. Chem. v.48, 3018-3026, 2009.

48. KLIMESZ, B.;DOMINIAK-DZIK, G.;SOLARZ, P.ZELECHOWER,M.; RYBAROMANOWSKI, W. Optical study of $\mathrm{GeO}_{2}-\mathrm{PbO}-\mathrm{PbF} 2$ oxyfluoride glass singly doped with $\mathrm{Pr} 3+, \mathrm{Nd} 3+, \mathrm{Sm} 3+$ e Eu3+. Journal of Alloys and Compounds, v.403, p. 76, 2005.

49. CHEPCANOFF, V. Desenvolvimento de uma metodologia para a separação de samário e európio a partir de mistura de óxidos de terras raras por redução eletroquímica/precipitação. 2006. Tese (doutorado) - Instituto de Pesquisas Energéticas e Nucleares - Universidade de São Paulo.

50. BRITO, H.F.; MALTA, O.L.; FELINTO, M.C.F.C.; TEOTONIO, E.E.S.; MENEZES, J.F.S.; SILVA, C.F.B.; TOMIYAMA, C.S.; CARVALHO, C.A.A.; Luminescence investigation of the $S \mathrm{~m}$ (III)- $\beta$-diketonates with sulfoxides, phosphine oxides and amides ligands J. Alloys Compd., v.344, p.293, 2002.

51. KAI, J. Desenvolvimento de sistemas luminescentes à base dos polímeros PHB e PMMA dopados com complexos de terras raras. 2009. Tese (Doutorado) - Universidade de São Paulo, São Paulo.

52. BIJU, S.; REDDY, M.L.P.; FREIRE, R.O. 3-phenyl-4-aroyl-5isoxazolonate complexes of $\mathrm{Tb} 3+$ as promising light-conversion molecular devices. Inorg. Chem. Commun., v. 10, p. 393-396, 2007.

53. BÜNZLI, J.-C.G.; CHOPPIN, G.R. Lanthanide probes in life, chemical and earth sciences -theory and practice, Amsterdam: Elsevier, 1989.

54. RICHARDSON, F.S. Terbium(III) and europium(III) ions as luminescent probes and stains for biomolecular systems. Chem. Rev., v. 82, n. 5, p. 541-552, 1982.

55. SU, Y.; LI, L.; LI, G. Synthesis and optimum luminescence of CaWO4based red phosphors with codoping of Eu3+ and $\mathrm{Na}+$. Chemistry of Materials, v. 20, n. 19, p. 6060-6067, 2008.

56. NIU, N.; YANG, P.; WANG, W.; HE, F.; GAI, S.; WANG, D.; LIN, J. Solvothermal synthesis of SrMoO4:Ln ( $\mathrm{Ln}=\mathrm{Eu} 3+, \mathrm{Tb3}+, \mathrm{Dy} 3+)$ nanoparticles and 
its photoluminescence properties at room temperature. Materials Research Bulletin, v. 46, n. 3, p. 333-339, 2011.

57. HÖLSÄ, J.; LAMMINMÄKI, R.J. Analysis of the $4 \mathrm{fN}$ energy-level structure of the RE3+ ions in REOCl. Journal of Luminescence, v.69, n.5/6, p.311-317, 1996.

58. BERDOWSKI, P.A.M.; LAMMERS, M.J.J.; BLASSE, G. 5D3-5D4 crossrelaxation of Tb3+ in a-GdOF, Chemical Physics Letters, v. 113, n. 4, p. 387390, 1985.

59. KIM, G.C.; PARK, H.L.; KIM, T.W. Emission color tuning from blue to green through cross-relaxation in heavily Tb3+-doped YAIO3, Materials Research Bulletin, v. 36, n. 9, p. 1603-1608, 2001.

60. KIM, G.C.; PARK, H.L.; KIM, T.W. Emission color tuning from blue to green through cross-relaxation in heavily Tb3+-doped YAIO3, Materials Research Bulletin, v. 36, n. 9, p. 1603-1608, 2001

61. CRISTOVAN, F.H.; EIRAS, S.P.;CRUZ, W.O. Preparação e caracterização óptica de filmes de poli(estireno sulfonados) dopados com neodímio. Química Nova, v.28, p.964-967, 2005.

62. SINHA, S.P. Spectroscopic investigations of some Nd complexes. Acta Physicochim, v.22, p.57-62, 1984.

63. CAMARGO, A. S.S. Caracterização espectroscópica de possíveis meios ativos para lasers de Nd3+e Tm3+, Tese de doutorado USP-,2003.

64. CARNALL, W.T.; GOODMAN, G.L.; RAJNAK, K.; RANA, R.S. A systematic analysis of the spectra of the lanthanides doped into single crystal LaF3. J. Chem. Phys., v. 90, p, 3443-3457, 1989.

65. GRIFFITH, J.S.; The theory of transition-metal ions. Londres: Cambridge at the University Press, 1961.

66. ULLMAN, F. G.; HOLDENTF, J.; GANGULY, B. N.; HARDY, J. R. raman spectrum of gadolinium molybdate above and below the ferroelectric transition Physical Review B, v.8, n.6 2991-2998, 1973. 
67. BROWN R G, DENNING J, HALLETT A, ROSS S D. Forbidden transitions in the infrared spectra of tetrahedral anions-VIII. Spectra and structures of molybdates, tungstates and periodates of the formula MXO4. Spectrochim. Acta A, v.26, p.963, 1970.

68. HANUZA J, MCZKA M, VAN DER MAAS $\mathrm{J} \mathrm{H}$. Polarized IR and Raman spectra of tetragonal $\mathrm{NaBi}(\mathrm{WO} 4) 2, \mathrm{NaBi}(\mathrm{MoO} 4) 2$ and $\mathrm{LiBi}(\mathrm{MoO} 4) 2$ single crystals with scheelite structure. J. Mol. Struct., v.348:p. 349, 1995.

69. VEGARD, L. Die konstitution der mischkristalle und die raumfüllung der atome. zeitschrift für physik, v.5, n.1, p. 17-26, 1921.

70. KO, S.W.; MOAREY, D.A.; CLARK, T.; MEKINSTRY, S.T. Synthesis, characterization, and dielectric properties of $\mathrm{B}-\mathrm{Gd}_{2}(\mathrm{MoO} 4) 3$ thin films prepared by chemical solution deposition. J. Sol-gel Sci Technol, v. 54, p.269-275, 2010.

71. TKACHENKO, E. A, FEDOROV, P. P. Lower rare-earth molybdates. Inorganic Materials, v. 39, p. S25-S45, 2003.

72. KISELEV,

A. P.; SHMURAK,

S.Z.;RED'KIN, B.S.;SINITSYN,V.V.;SHMUT'KO, E.A.;KUDRENKO, E.A.;PONYATOVSKII, E.G.. Evolution of the spectral response of amorphous europium molybdate under annealing. Physics of the Solid State, v.48, p.1544-1552, 2006.

73. TANG, Z., ZHOU, L., WHANG, F., ZHOU, L. Synthesis, characterization and luminescence study of $\mathrm{Eu}(\mathrm{III})$ tungstates and molybdates nanotubes using carbon nanotubes as templates. Spectrochimica Acta, Part A v.72, p.348-355, 2009.

74. nassau, K.; LeVInStein, H.J.; LOIACONO, G.M. J. Phys. Chem. Solids, v. 26, p.1805, 1965.

75. NASSAU, K.; Jamieson, P.B.; ShIEVeR, J.W. J. Phys. Chem. Solids, v.30, p.1225, 1969.

76. CHEN, X.Y.; JENSEN, M.P.; LIU, G.K. Analysis of energy level structure and excited-state dynamics in a Sm3+ complex with soft-donor ligands: Sm(Et(2)Dtc)(3)(bipy). J. Phys. Chem. B,v.109, p.13991-13999, 2005. 
77. STÖBER, W.; FINK, A. Controlled growth of monodisperse silica spheres in the micron size range. Journal of colloid and interface science, v.26, p. 62-69, 1968.

78. SCHIEL, J.E.; MALLIK, R.; SOMAN, S.; JOSEPH, K.S.; HAGE, D.S. Applications of silica supports in affinity chromatography. J. Sep. Sci., v. 29, n. 6, p. 719-737, 2006.

79. HERMANSON, G.T. Bioconjugate Techniques. 2.ed. Amsterdam: Elsevier, 2008, 1202p.

80. ENRICHI, F.; RICCÒ, R.; SCOPECE, P.; PARMA, A.; MAZAHERI, A.R.; RIELLO, P.; BENEDETTI, A. Comparison of Eu(NO3)3 and Eu(acac)3 precursors for doping luminescent silica nanoparticles. J. Nanopart. Res., v. 12, p.19251931, 2010.

81. DOSEV, D.; NICHKOVA, M.; KENNEDY, I.M. Inorganic lanthanide nanophosphors in biotechnology. J. Nanosci. Nanotech., v.8, p.1052-1067, 2008.

82. GIAUME,D.; BUISSETTE, V.; LAHLIL, K.; GACOIN, T.; BOILOT, J.-P.; CASANOVA, D.; BEAUREPAIRE, E.; SAUVIAT, M.-P.; MERCURI, A.; ALEXANDROU, A. New biological labels based on functionalized $\mathrm{YVO}_{4}$ : Eu nanoparticles. Mater. Res.Soc. Proc., v. 845, AA6.2, p. 131-136, 2004.

83. BACCILE, N.; BABONNEAU, F.; THOMAS, B.; CORADIN, T. Introducing ecodesign in silica sol-gel materials.J. Mater. Chem., v. 19, p. 8537-8559, 2009.

84. XU, Z.-S.; DENG, Z.-W.;HU, X.-X.; LI, L.; YI, C.-F. Monodisperse polystyrene microspheres prepared by dispersion polymerization with microwave irradiation.J. Polym. Sci. Part A: Polym. Chem., v. 43, n. 11, p. 2368-2376, 2005.

85. GALEMA, S. A. Microwave chemistry.Chem. Soc. Rev., v. 26, n. 3, p. 233238, 1997.

86. FENG, J.; SHAN, G.; MAQUIEIRA, A.; KOIVUNEN, M.E.; GUO, B.; HAMMOCK, B.D.; KENNEDY, I.M. Functionalized europium oxide nanoparticles used as a fluorescent label in an immunoassay for atrazine. Anal. Chem., v. 75, n. 19, p. 5282-5286, 2003. 
87. LIDSTRÖM, P.; TIERNEY, J.; WATHEY, B.; WETSMAN, J. Microwave assisted organic synthesis - a review.Tetrahedron, v. 57, n. 45, p. 9225-9283, 2001.

88. CADDICK, S.; FITZMAURICE, R. Microwave enhanced synthesis. Tetrahedron, v. 65, n. 17, p. 3325-3355, 2009.

89. GABRIEL, C.; GABRIEL, S.; GRANT, E.H.; HALSTEAD, B.S.J.; MINGOS, D.M.P. Dielectric parameters relevant to microwave dielectric heating. Chem. Soc. Rev., v. 27, n. 3, p. 213-223, 1998.

90. JIN, Y.; LI, A.; HAZELTON, S.G.; LIANG, S.; JOHN, C.L.; SELID, P.D.; PIERCE, D.T.; ZHAO, J.X. Amorphous silica nanohybrids: Synthesis, properties and applications. Coord. Chem. Rev., v. 253, n. 23/24, p. 2998-3014, 2009.

91. AN, Y.; CHEN, M.; XUE, Q.; LIU, W. Preparation and self-assembly of carboxylic acid-functionalized silica. J. Colloid Interface Sci., v. 311, n. 2, p. 507513, 2007.

92. KNOPP, D.; TANG, D.; NIESSNER, R. Bioanalytical applications of biomolecule-functionalized nanometer-sized doped silica particles. Anal. Chim. Acta, v. 647, n. 1, p. 14-30, 2009.

93. COLTRAIN, B.K.; KELTS, L.W. Colloidal sílica: fundamentals and applications. Boca Raton, FL: CRC, 2006. cap. 48, the chemistry of hydrolysis and condensation of silica sol-gel precursors p. 637-644.

94. BAGWE, R.P.; HILLIARD, L.R.; TAN, W. Surface modification of silica nanoparticles to reduce aggregation and nonspecific binding. Langmuir, v. 22, $\mathrm{n}$. 9, p. 4357-4362, 2006.

95. BAHADUR, N. M.;FURUSAWA, T.; SATO, M.; KURAYAMA, F.; SIDDIQUEY, I. A.; SUZUKI, N. Fast and facile synthesis of silica coated silver nanoparticles by microwave irradiation. Journal of colloid and interface science, v.355, p.312-20, 2011. 


\section{RESULTADOS E DISCUSSÕES - CONJUGAÇÃO BIOLÓGICA}

\subsection{Quantificação e eletroforese dos anticorpos}

\subsubsection{Quantificação dos anticorpos monoclonais}

Para quantificar os anticorpos de PSA utilizou-se o método de Bradford descrito no item 4.5.4 onde se fez uma curva de calibração para proteínas, neste caso utilizando-se a albumina bovina sérica (BSA) como padrão e após obtenção da curva de calibração (FIG.6.1), procedeu-se a quantificação dos anticorpos.

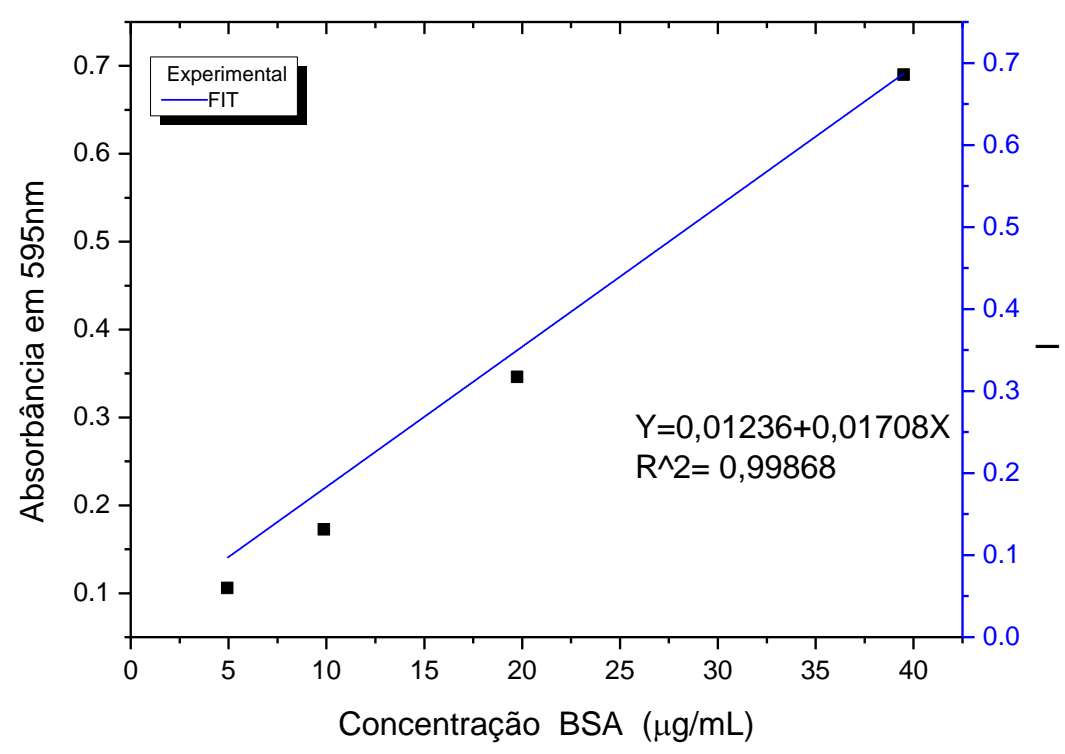

FIGURA 6.1.Curva de calibração da albumina bovina sérica utilizada para quantificação dos anticorpos monoclonais (método de Bradford).

A partir da leitura das absorbâncias para os anticorpos monoclonais purificados aqui estudados (H2P8 e H11P8), utilizou-se a equação $Y=0,01236+$ 
0,01708x. Desta forma, obteve-se a concentração de $1,30 \mu g \mu \mathrm{L}^{-1}$ para amostra H2P8 (anticorpos monoclonais de captura) e de $0,26 \mu \mathrm{gL}^{-1}$ para amostra H11P8 (anticorpo monoclonal de marcação).

\subsubsection{Eletroforese das proteínas}

Para se ter resultados sobre a eficácia do processo de purificação dos anticorpos, utilizou-se resultados de eletroforese realizados previamente por Tomyama, $C{ }^{1}$ para obterdados da composição do sistema protéico. Através do gel obtido na análise de eletroforese pode ser comprovada a eficácia do processo de purificação das ascites. A FIG.6.2 ilustra o gel da eletroforese da proteína revelado após todas as etapas de tratamento, onde se verificam 5 colunas. A primeira coluna refere-se ao padrão de proteína utilizado para a corrida de eletroforese, a segunda e a terceira colunas são referentes ao anticorpo H2P8 e as duas últimas colunas são referentes à amostra da anticorpo H11P8.

Como observado na foto, todas as colunas referentes às amostras apresentam somente uma banda (linha) em $\sim 34 \mathrm{kDa}$, o que indica que o processo que se utilizou para purificar os ascites foi eficaz e os anticorpos encontram-se adequados para sensibilização das placas e para a conjugação com o marcador. 


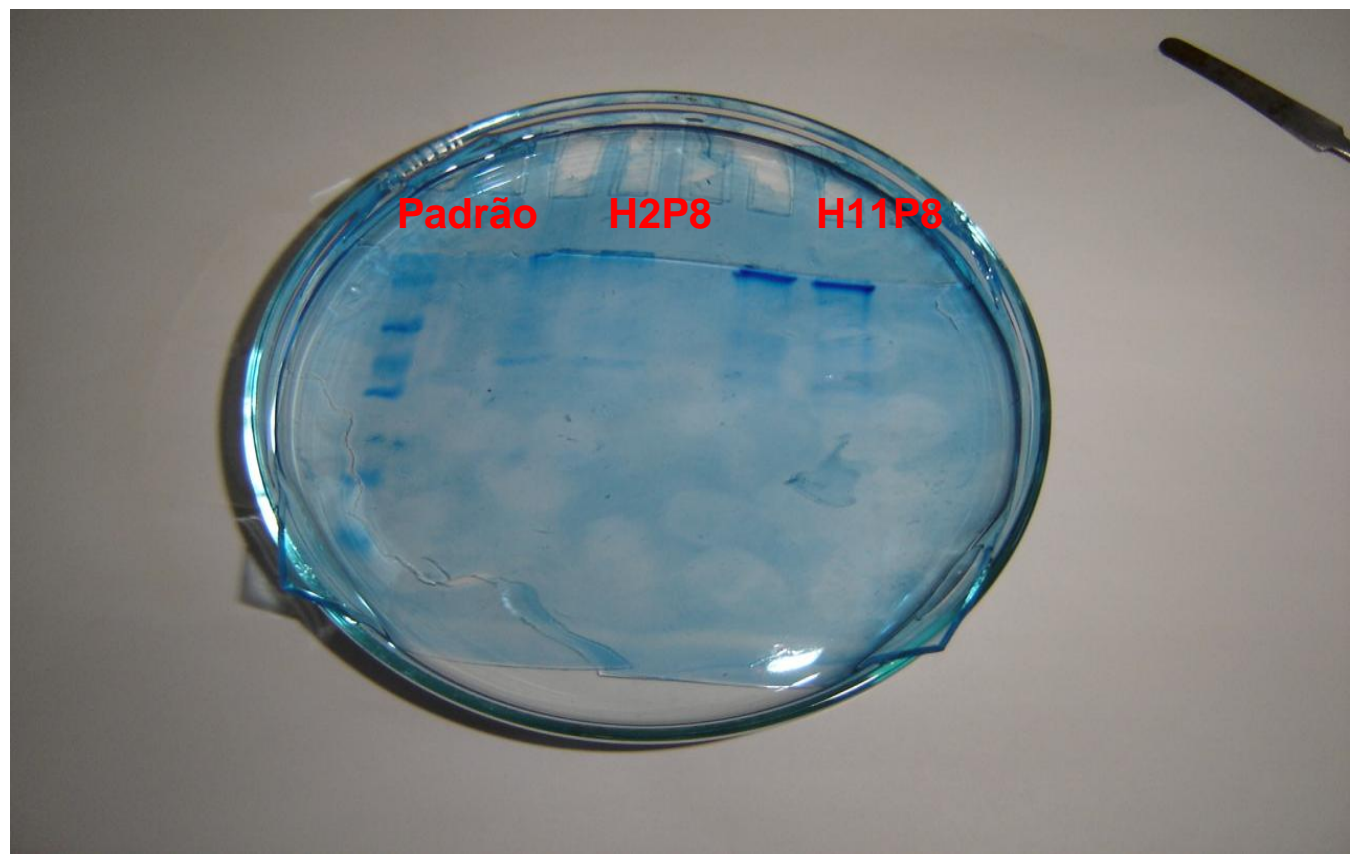

FIGURA 6.2. Foto do gel de eletroforese após todas as etapas de tratamento.

\subsection{Conjugação das nanopartículas de $\mathrm{TR}_{2}\left(\mathrm{MoO}_{4}\right)_{3}$ com a parte biológica}

Nesse trabalho foram testados dois materiais biológicos para fazer a conjugação com as partículas funcionalizadas com sílica, BSA e PSA.

\subsubsection{Detecção de BSA conjugada com a partícula luminescente $\mathrm{TR}_{2}\left(\mathrm{MoO}_{4}\right)_{3} @ \mathrm{Si}\left(\mathrm{TR}=\mathrm{Nd}^{3+}\right)$ utilizando o método de Bradford}

A proteína albumina de soro bovino (FIG.6.3) é largamente empregada na área de bioquímica, devido à relativa facilidade com que pode ser isolada e purificada em grande escala além de ser estruturalmente homológa ao HSA (albumina de soro humano - humanserumalbumin). ${ }^{2,3}$ A BSA é a proteína mais abundante no plasma sanguíneo bovino e atua como depósito, assim como veículo para transporte intracelular. É a principal proteína que contribui para a pressão coloidal osmótica do sangue e também para o transporte de proteínas 
para numerosos compostos endógenos e exógenos. ${ }^{4,5}$ Com massa molecular de $66 \mathrm{kDa}$, consiste em uma única cadeia polipeptídica, contendo cerca de 583 aminoácidos. $^{6}$

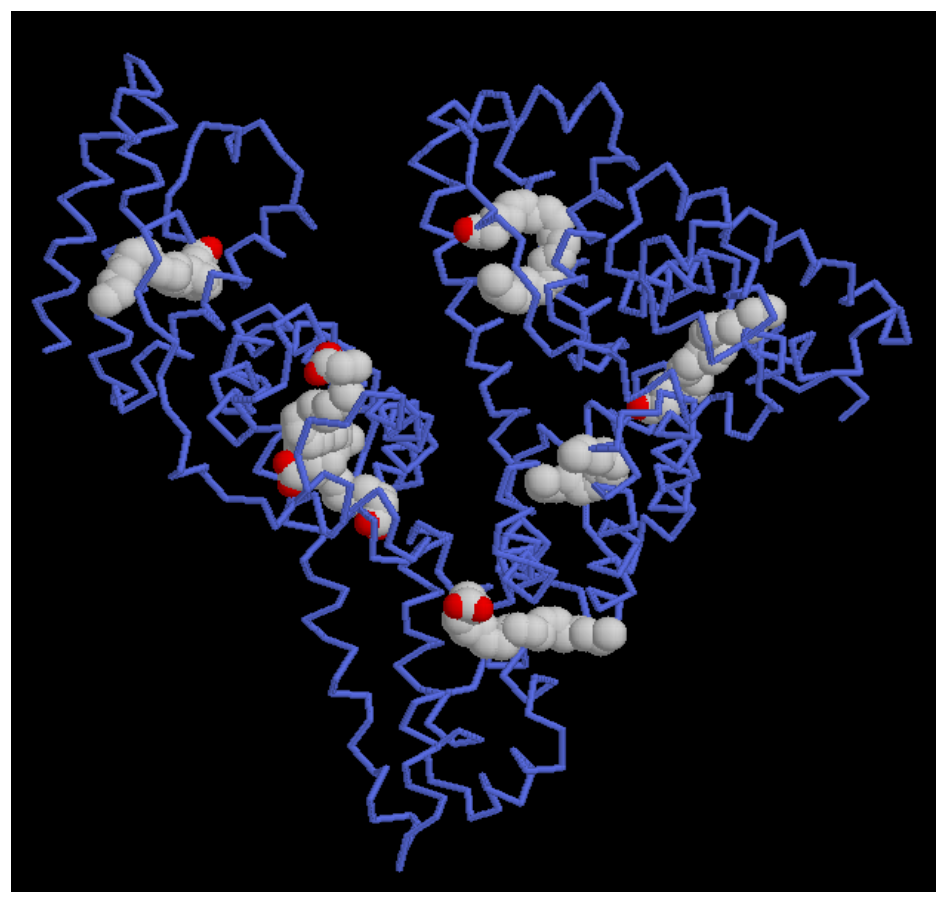

FIGURA 6.3. Estrutura da albumina sérica bovina (BSA).

A capacidade da partícula $\mathrm{TR}_{2}\left(\mathrm{MoO}_{4}\right)_{3} @ S i-g l u$ de interagir com a espécie biológica (proteína BSA) foi avaliada e identificada pelo método de dosagem de proteínas conhecido como método de Bradford. ${ }^{7} \mathrm{~A}$ reação de imobilização da partícula aminofuncionalizada (FIG.6.4), contendo o espaçador glutaraldeído com a proteína BSA $\left(\mathrm{TR}_{2}\left(\mathrm{MoO}_{4}\right)_{3} @ \mathrm{Si}\right.$-glu-BSA), foi realizada em meio de PBS (tampão fosfato salino - phosphatebuffered saline $-0,05 \mathrm{molL}^{-1}$ $\mathrm{pH} 7,4)$. Para a identificação da presença de BSA no sistema foi analisado o sobrenadante do meio reacional da conjugação juntamente com as quatro águas de lavagem da partícula e, também, a dispersão em PBS da partícula. Os ensaios biológicos foram realizados em triplicatas. A maioria dos métodos de ensaio de proteína colorimétricos podem ser divididos em dois grupos de acordo com o tipo de química envolvida: os que envolvem agentes quelantes de proteína (como o 
cobre com detecção secundária do cobre reduzido) e os métodos baseados em ligação com a detecção direta da alteração de cor associada com a proteína (corante ligado A maioria dos reagentes comerciais de ensaio para detecção de proteína são bem caracterizados e eficazes, pois oferecem resultados consistentes e confiáveis. No entanto, cada reagente de ensaio tem as suas limitações, ter uma compreensão básica da química envolvida em cada tipo de ensaio é essencial para a escolha de um método adequado para uma determinada amostra e para avaliar corretamente os resultados.

Neste caso escolheu-se o método de Bradford que usa o corante de Coomassie (FIG 6.5). Em solução ácida do reagente, a proteína liga-se ao corante Coomassie. Isto resulta num desvio espectral do avermelhado/castanho forma do corante (máximo de absorbância em $465 \mathrm{~nm}$ ) para a forma de corante azul (máximo de absorção a $610 \mathrm{~nm}$ ). A diferença entre as duas formas do corante é maior em $595 \mathrm{~nm}$, de modo que é o comprimento de onda ideal para medir a cor azul a partir do complexo de proteína. O desenvolvimento da cor nos ensaios de proteína de Bradford está associada com a presença de determinados aminoácidos básicos (principalmente arginina, lisina e histidina) na proteína. As interações de Van der Waals e interações hidrofóbicas são as principais interações no método. O número de moléculas do corante de Coomassie ligadas a cada molécula de proteína é aproximadamente proporcional ao número de cargas positivas que se encontram na proteína. Aminoácidos livres, peptídeos e proteínas de baixo peso molecular não produzem cores com Coomassie. Em geral, a massa de um péptido ou proteína deve ser de pelo menos 3000 Daltons para ser detectável com este reagente. Em algumas aplicações isto pode ser uma vantagem. Neste trabalho detectou-se proteinas nas águas de lavagem das particulas que posteriormente foram usadas nos imunoensaios. Este método tem sensibilidade entre 0,3 a $1000 \mu \mathrm{gmL}^{-1}$. 

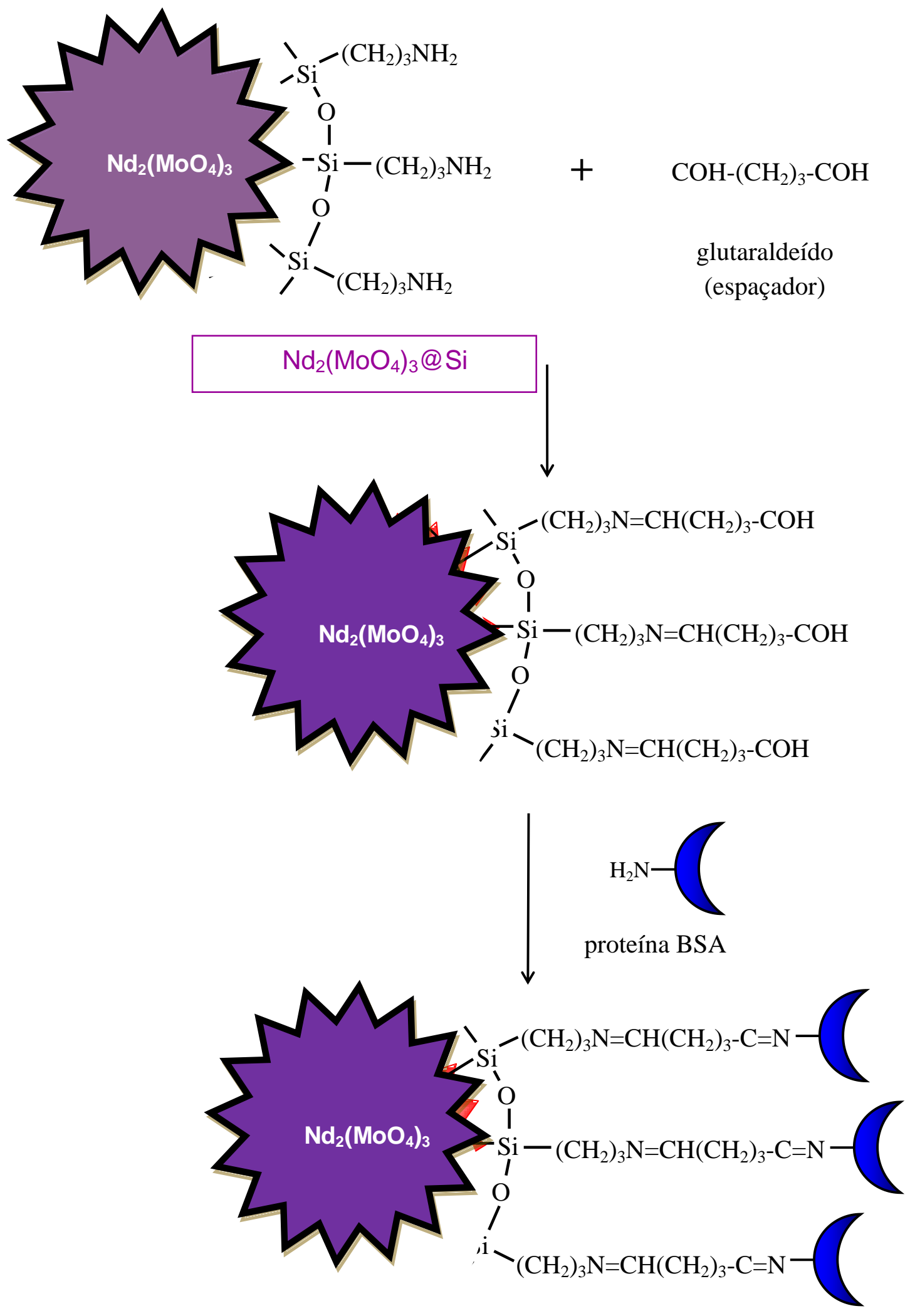
FIGURA 6.4.Esquema representativo da imobilização da proteína BSA na partícula $\mathrm{Nd}_{2}\left(\mathrm{MoO}_{4) 3} @ S i\right.$ utilizando glutaraldeído como espaçador. ${ }^{8}$
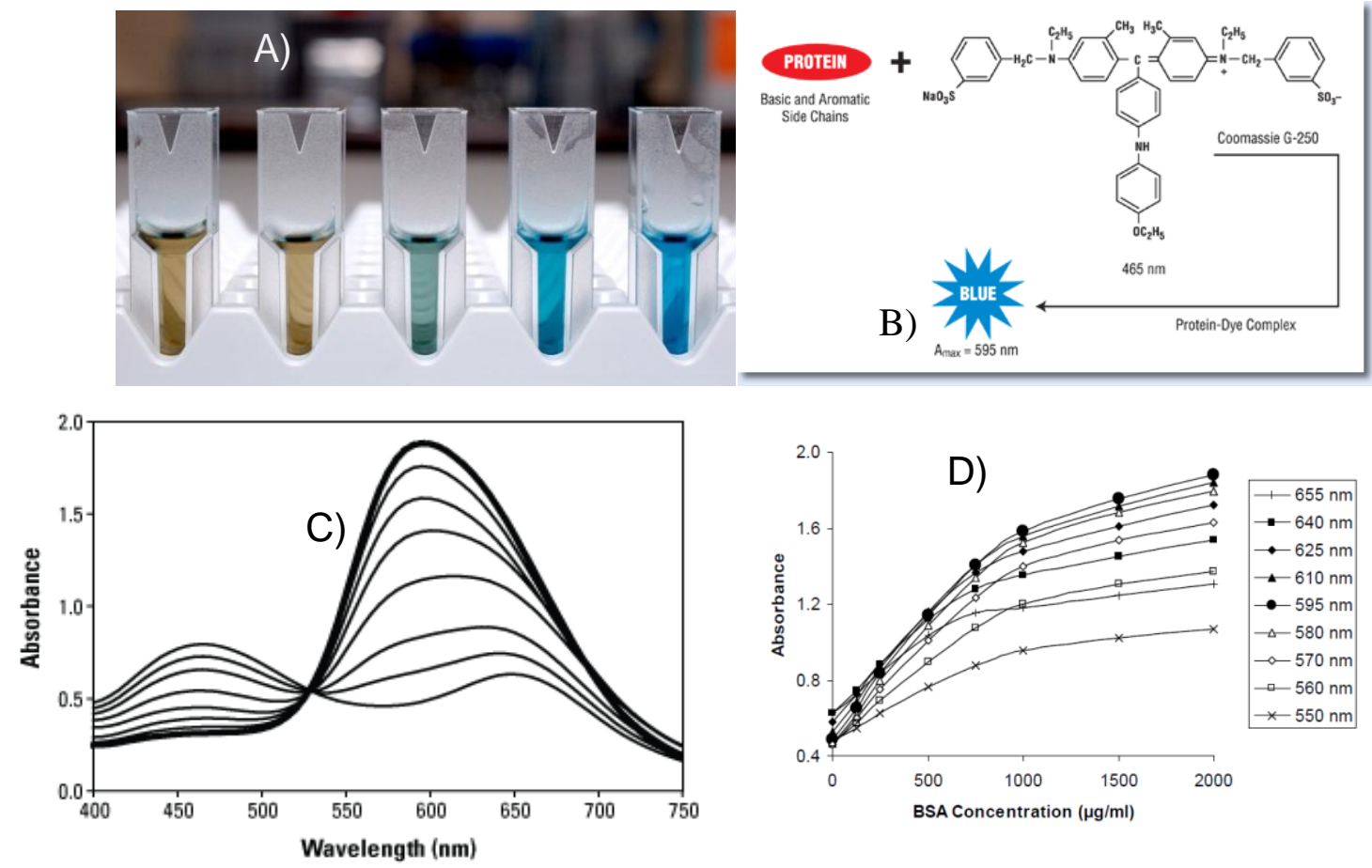

FIGURA 6.5. Esquema da reação para a identificação de proteínas, com a formação do complexo Proteína - corante de coloração azul. a) cubetas com material para análise no espectrofotômetro; b) reação da proteína com o reagente de Coomassie; c) Espectros de absorção da proteína-corante; e d)perfil as curvas absorbância versus concentração da proteína em vários comprimentos de onda. ${ }^{7}$

Neste trabalho foram testadas alíquotas tanto do sobrenadante quanto das águas de lavagem e os resultados indicaram que somente havia proteína na partícula dispersa como mostrado na TAB. 6.1.

Além do mais, a dispersão das partícula $\mathrm{TR}_{2}\left(\mathrm{MoO}_{4}\right)_{3} @ S i-G l u t-B S A$ em PBS também exibiu cor azul. No entanto, esta cor apresentou-se localizada nas partículas, indicando que a proteína está conjugada na partícula e não livre em solução (FIG.6.6). Ressalta-se que as amostras na TAB. 6.1 referem-se as amostras do ensaio realizado em triplicata. 
TABELA 6.1. Ensaio de identificação da presença de proteína BSA método de Bradford. A presença de BSA foi confirmada pelo desenvolvimento da cor azul nas amostras.

\begin{tabular}{|c|c|c|c|}
\hline Amostra & Descrição & Presença de BSA & Poços \\
\hline \multirow[t]{4}{*}{1} & Sobrenadante & Não & $1 \mathrm{~A}$ \\
\hline & $1^{\mathrm{a}}$ água de lavagem & Não & $1 \mathrm{~B}$ \\
\hline & $4^{\mathrm{a}}$ água de lavagem & Não & $1 \mathrm{C}$ \\
\hline & Partícula dispersa & Sim & $1 \mathrm{E}$ \\
\hline \multirow[t]{4}{*}{2} & Sobrenadante & Não & $2 A$ \\
\hline & $1^{\mathrm{a} a}$ água de lavagem & Não & $2 \mathrm{~B}$ \\
\hline & $4^{\mathrm{a}}$ água de lavagem & Não & $2 \mathrm{C}$ \\
\hline & Partícula dispersa & Sim & $2 \mathrm{E}$ \\
\hline \multirow[t]{4}{*}{3} & Sobrenadante & Não & $3 A$ \\
\hline & $1^{\mathrm{a}}$ água de lavagem & Não & 3B \\
\hline & $4^{\mathrm{a}}$ água de lavagem & Não & $3 C$ \\
\hline & Partícula dispersa & Sim & $3 E$ \\
\hline \multirow[t]{4}{*}{4} & Sobrenadante & Não & $4 \mathrm{~A}$ \\
\hline & $1^{\mathrm{a}}$ água de lavagem & Não & $4 \mathrm{~B}$ \\
\hline & $4^{\mathrm{a}}$ água de lavagem & Não & $4 \mathrm{C}$ \\
\hline & Partícula dispersa & Sim & $4 \mathrm{E}$ \\
\hline \multirow[t]{4}{*}{5} & Sobrenadante & Não & $5 A$ \\
\hline & $1^{a}$ água de lavagem & Não & $5 \mathrm{~B}$ \\
\hline & $4^{\mathrm{a}}$ água de lavagem & Não & $5 \mathrm{C}$ \\
\hline & Partícula dispersa & Sim & $5 \mathrm{E}$ \\
\hline \multirow[t]{4}{*}{6} & Sobrenadante & Não & $6 \mathrm{~A}$ \\
\hline & $1^{\mathrm{a}}$ água de lavagem & Não & $6 \mathrm{~B}$ \\
\hline & $4^{\mathrm{a}}$ água de lavagem & Não & $6 \mathrm{C}$ \\
\hline & Partícula dispersa & Sim & $6 \mathrm{E}$ \\
\hline
\end{tabular}

Os resultados obtidos neste ensaio confirmaram que a partícula $\mathrm{TR}_{2}\left(\mathrm{MoO}_{4}\right)_{3} @ S i-G l u t$ é capaz de conjugar com a proteína $\mathrm{BSA}$, devido à presença do grupamento $\mathrm{C}=\mathrm{O}$ disponível na superfície da partícula de sílica funcionalizadas com glutaraldeído. Já a ausência de proteína (identificada pela cor azul) no 
sobrenadante sugere que não há BSA em excesso na reação de conjugação com a partícula $\mathrm{TR}_{2}\left(\mathrm{MoO}_{4}\right)_{3} @ S i-G l u t$.

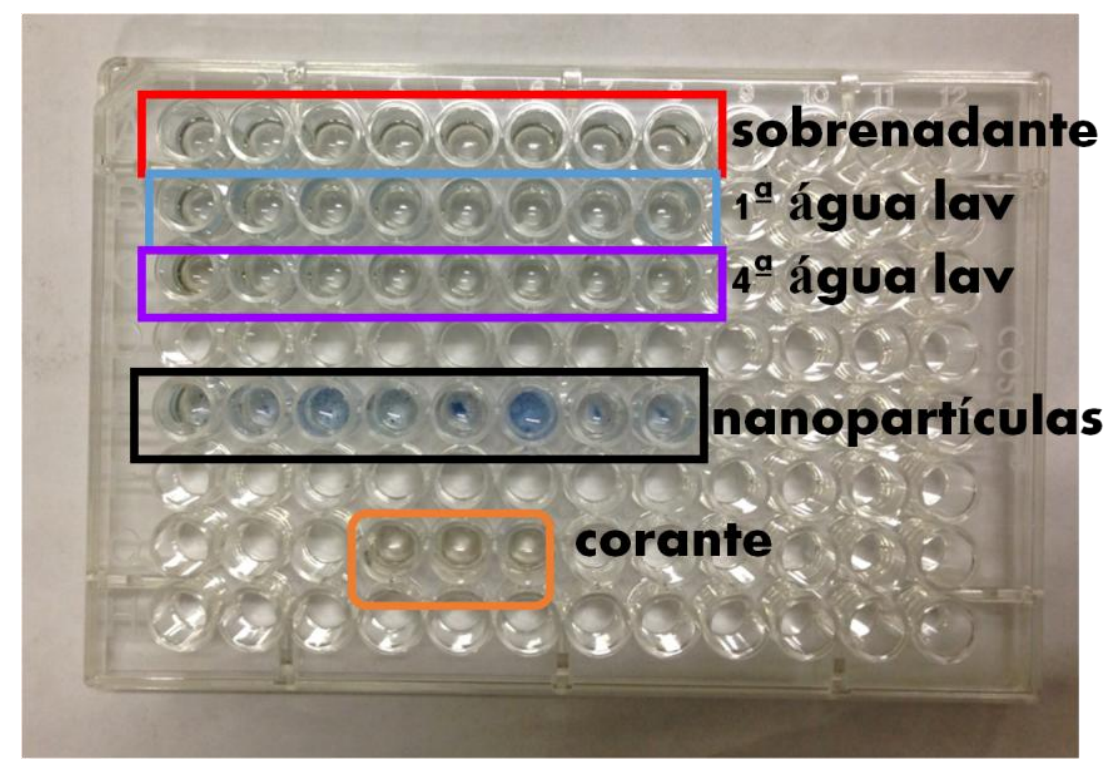

FIGURA 6.6. Fotografia da placa de poliestireno de 96 poços do ensaio para identificação da proteína BSA. Os sobrenadantes são identificados em vermelho, as $1^{\text {a }}$ águas de lavagem são identificadas em azul, as quartas águas de lavagem são identificadas em lilás, as dispersões de partículas são identificados em preto e o em laranja é o reagente colorimétrico.

Também se obteve os espectros de emissão das nanopartículas de neodímio conjugadas com $\mathrm{BSA} \quad \mathrm{Nd}_{2}\left(\mathrm{MoO}_{4}\right)_{3} @ S i-G l u t-B S A$ em várias concentrações da proteína. As nanopartículas foram excitadas por um laser de $\mathrm{Ti}$ Safira e na figura 6.7 apresentam-se os espectros destes materiais. Os resultados concordam com um melhor sinal para marcação quando a concentração da BSA é $0,1 \mu \mathrm{gmL}^{-1}$. Além disso, pode-se observar que ocorreu perda de intensidade, especialmente na banda de transição ${ }^{4} \mathrm{~F}_{3 / 2} \rightarrow{ }^{4} \mathrm{I}_{1 / 2 / 2}$ das nanopartículas conjugadas com BSA em comparação com a nanopartícula padrão. Esse fato já era esperado pois a camada de proteína conjugada, que envolve a partícula, faz com que o sinal do laser seja suprimido. 


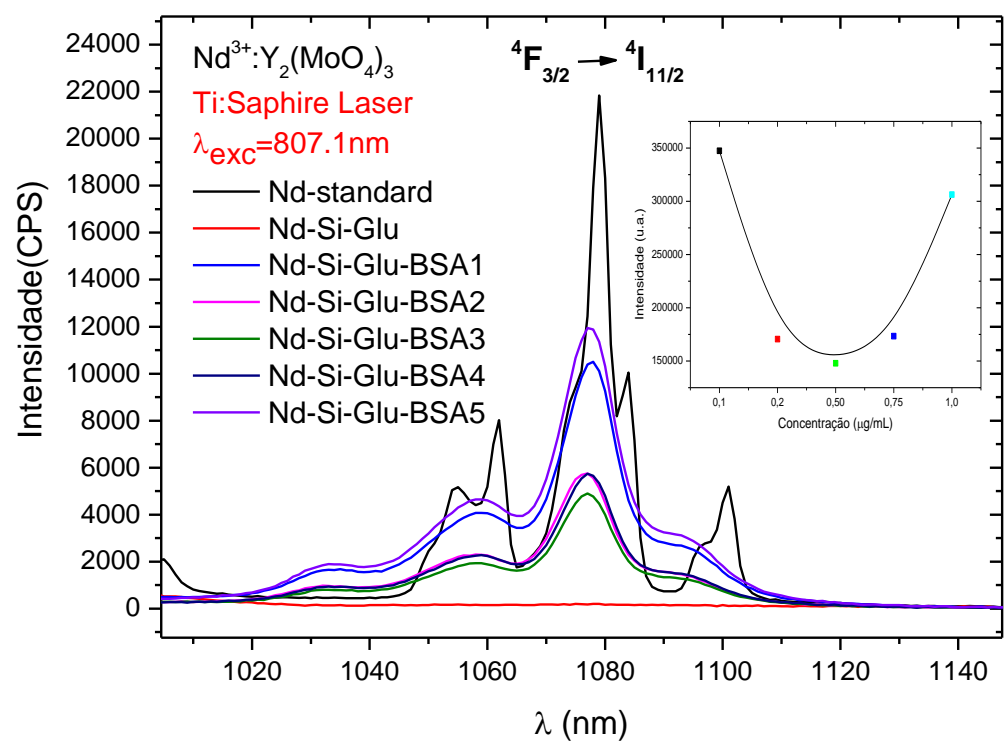

FIGURA 6.7. Espectros de emissão obtidos da nanopartículas de $\mathrm{Nd}_{2}\left(\mathrm{MoO}_{4}\right)_{3} @ S i$ ligadas ao BSA

\subsubsection{Detecção de PSA conjugada com a partícula luminescente $\mathrm{TR}_{2}\left(\mathrm{MoO}_{4}\right)_{3} @ \mathrm{Si}\left(\mathrm{TR}=\mathrm{Nd}^{3+}\right.$ e Eu $\left.{ }^{3+}\right)$ utilizando o método de Bradford}

As partículas de $\mathrm{TR}_{2}\left(\mathrm{MoO}_{4}\right)_{3} @ \mathrm{Si}\left(\mathrm{TR}=\mathrm{Nd}^{3+}\right.$ e Eu$\left.{ }^{3+}\right)$ conjugadas com o anticorpo de marcação, H11P8, também foram avaliadas quanto a sua capacidade de conjugação. Na FIG.6.8apresenta-se o diagrama ilustrativo destas reações. 

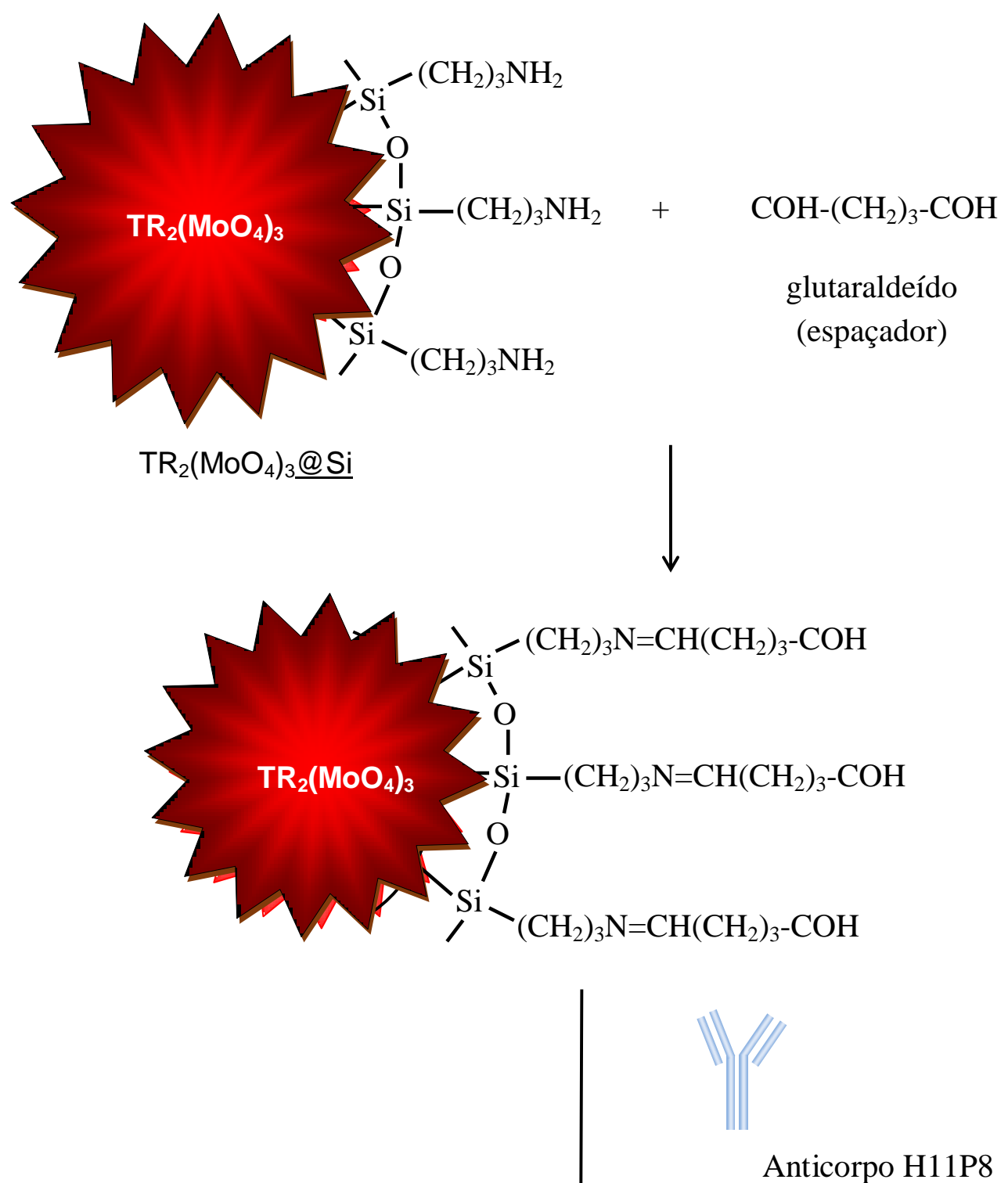

Anticorpo H11P8

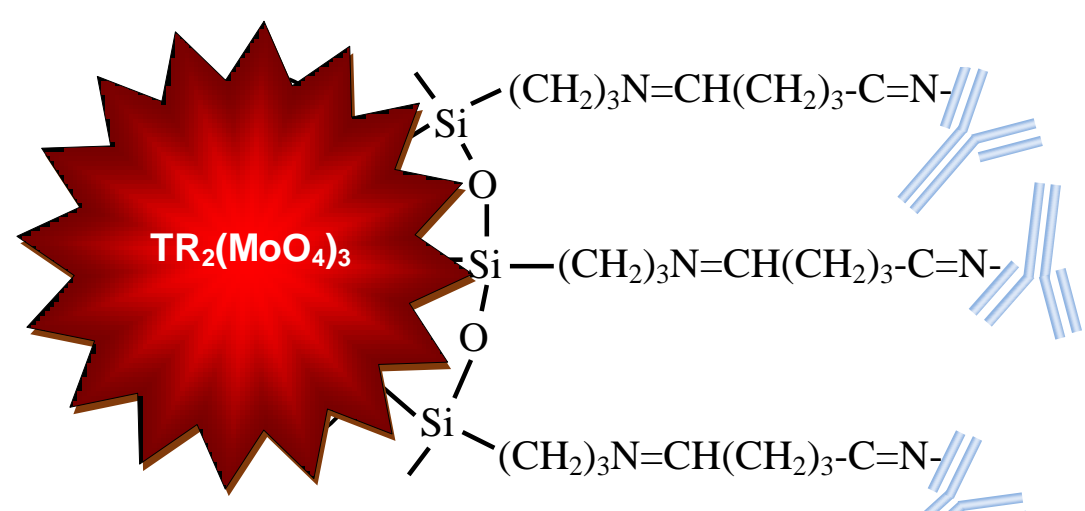

FIGURA 6.8. Esquema representativo da imobilização do anticorpo anti-PSA H11P8 na partícula TR $\left(\mathrm{MoO}_{4}\right)_{3} @ S i$ utilizando glutaraldeído como espaçador. ${ }^{8}$ 
Após reação com H11P8, o sobrenadante e as lavagens foram analisados quantitativamente pelo método de Bradford chegando-se aos seguintes dados: foram analisadas 9 amostras de partículas de $\mathrm{Eu}$ e $\mathrm{Nd}$ conjugadas com o PSA, variando a concentração do luminóforo e do anticorpo. A retenção média do anticorpo H11P8 na partícula foi de $16,387 \mu \mathrm{gmL}^{-1}$; a melhor condição de reação foi para amostra 3 e a pior retenção foi paraamostra $9 . \mathrm{Na}$ TAB.6.2 têm-se as condições de cada reação para os sistemas estudados e a quantificação de retenção de proteínas. A partir destes resultados, verifica-se que as nanopartículas em questão são capazes de atuar como marcador biológico. 
TABELA 6.2. Relação da quantidade de proteína encontrada na solução sobrenadante e ligadas ao anticorpo H11P8 nas diversas condições de reações estudadas. Concentração da proteína PSA $26 \mu \mathrm{gmL}^{-1}$.

\begin{tabular}{|c|c|c|c|}
\hline AMOSTRAS & Condições de reação & $\begin{array}{c}\text { Quantidade de } \\
\text { proteína no } \\
\text { sobrenadante } \\
\mu \mathrm{gmL}^{-1}\end{array}$ & $\begin{array}{c}\text { Proteína ligada } \\
\text { a nanopartícula } \\
\qquad \%) .\end{array}$ \\
\hline 1 & $\begin{array}{c}\text { Nanopartícula de Eu=2mg } \\
\qquad P S A=0,100 \mu \mathrm{L}\end{array}$ & 6,50 & 72,90 \\
\hline 2 & $\begin{array}{c}\text { Nanopartícula de } \mathrm{Eu}=2 \mathrm{mg} \\
\mathrm{PSA}=0,200 \mu \mathrm{L}\end{array}$ & 7,70 & 67,81 \\
\hline 3 & $\begin{array}{c}\text { Nanopartícula de } E u=2 \mathrm{mg} \\
\qquad \mathrm{PSA}=0,500 \mu \mathrm{L}\end{array}$ & 6,30 & 73,83 \\
\hline 4 & $\begin{array}{c}\text { Nanopartícula de } \mathrm{Eu}=2 \mathrm{mg} \\
\mathrm{PSA}=0,750 \mu \mathrm{L}\end{array}$ & 6,98 & 70,91 \\
\hline 5 & $\begin{array}{c}\text { Nanopartícula de } \mathrm{Eu}=2 \mathrm{mg} \\
\text { PSA }=1,000 \mu \mathrm{L}\end{array}$ & 7,27 & 69,70 \\
\hline 6 & $\begin{array}{c}\text { Nanopartícula de Eu= 1mg } \\
\qquad P S A=0,100 \mu \mathrm{L}\end{array}$ & 8,17 & 65,94 \\
\hline 7 & $\begin{array}{c}\text { Nanopartícula de } \mathrm{Eu}=2 \mathrm{mg} \\
\qquad \mathrm{PSA}=0,100 \mu \mathrm{L}\end{array}$ & 8,34 & 65,24 \\
\hline 8 & $\begin{array}{c}\text { Nanopartícula de Eu=3mg } \\
\text { PSA }=0,100 \mu \mathrm{L}\end{array}$ & 7,98 & 66,73 \\
\hline 9 & $\begin{array}{c}\text { Nanopartícula de } \mathrm{Nd}=2 \mathrm{mg} \\
\text { PSA }=0,100 \mu \mathrm{L}\end{array}$ & 7,34 & 58,81 \\
\hline
\end{tabular}




\subsubsection{Estudo da conjugação entre os sistemas $\mathrm{Y}_{2}-\mathrm{xEu_{0,05 }}\left(\mathrm{MoO}_{4}\right)_{3} @ S i-G l u t-$ H11P8 e antígeno em função da concentração dos anticorpos do PSA.}

Para demonstrar a eficácia dos marcadores luminescentes à base do íon $\mathrm{Eu}^{3+}$ para detecção e quantificação de espécies biológicas, realizou-se experimento para a conjugação do antígeno PSA com os anticorpos anti-PSA, H11P8 e H2P8. Vale ressaltar, que para a obtenção destes resultados foramrealizados uma série de experimentos para otimizar as condições reacionais. O imunoensaio é baseado na reação entre um anticorpo e antígeno formando um conjugado Ac-Ag. Este conjugado pode ser identificado utilizandose um marcador óptico, por exemplo, à base de íons terras raras. $O$ experimento foi fundamentado na conjugação do anticorpo ligado a partícula luminescente com o antígeno, utilizando o glutaraldeído como espaçador.

Para as reações de conjugação utilizou-se a partícula $Y_{2^{-}}$ ${ }_{x} \mathrm{Eu}_{1.95}\left(\mathrm{MoO}_{4}\right)_{3} @$ Si-Glut-H11P8 em diferentes concentrações de anticorpo H11P8 e sem variar a concentração do antígeno.

Para o desenvolvimento do experimento de detecção e quantificação de espécies biológicas conjulgadas ao íon de TR foram preparadas cinco diferentes concentrações de anticorpo H2P8 $=13.10^{-3}, 26.10^{-3}, 65.10^{-3}, 97,5.10^{-3} \mathrm{e}$ $13.10^{-2} \mathrm{mg} \mathrm{mL}^{-1}$ ). A placa de poliestireno de 96 poços, foi sensibilizada com o anticorpo de captura (H11P8) onde foram adicionadas $100 \mu \mathrm{L}$ de uma solução do anticorpo em quatro diferentes concentrações: $0,008 \mu \mathrm{gmL}^{-1}, 0,016 \mu \mathrm{gmL}^{-1}$, $0,033 \mu \mathrm{gmL}^{-1}$ e $0,066 \mu \mathrm{gmL}^{-1}$ do anticorpo H2P8. A metodologia seguiu o protocolo descrito abaixo: 


\section{Protocolo:}

1) Sensibilização da placa com $100 \mu \mathrm{l}$ de Anticorpo Monoclonal (diluído em PBS pH 7.2) em uma concentração de $0,008 \mu \mathrm{gmL}^{-1}, 0,016 \mu \mathrm{gmL}^{-1}, 0,033 \mu \mathrm{gmL}^{-1}$ e $0,066 \mu \mathrm{gmL}^{-1}$ nos poços e deixar overnight a $4^{\circ} \mathrm{C}$;

2) Lavar a placa 4 vezes com PBS - Tween 20 (0,05\%), colocando $200 \mu \mathrm{L}$ em cada poço e na última lavagem secar a placa;

3) Bloquear a placa com uma solução de proteínas para bloqueio a $5 \%$ diluída em PBS pH 7.2, adicionar $200 \mu \mathrm{L}$ em cada poço, deixar $1 \mathrm{~h}$ e 30 minutos a temperatura ambiente;

4) Lavar a placa 4 vezes com PBS -Tween $20(0,05 \%)$, colocando $200 \mu \mathrm{L}$ em cada poço e na última lavagem secar a placa;

5) Adicionar $100 \mu \mathrm{L}$ do soro de pacientes(antígeno) com PSA diluído 1:100 em cada poço, incubar por $1 \mathrm{~h}$ sob agitação lenta, deixar a temperatura ambiente;

6) Lavar a placa 4 vezes com PBS - Tween $20(0,05 \%)$, colocando $200 \mu \mathrm{L}$ em cada poço, na última lavagem secar a placa;

7) Adicionar o $\mathrm{Y}_{2^{-} \mathrm{x}} \mathrm{Eu}_{\mathrm{x}+0,05}\left(\mathrm{MoO}_{4}\right)_{3} @$ Si-Glut-H11P8, colocando $100 \mu \mathrm{L}$ em cada poço, incubar por 2 horas sob agitação lenta;

8) Lavar a placa 1 vez com PBS - Tween 20 (0,05\%), colocando $200 \mu \mathrm{L}$ em cada poço, secar a placa;

9) Fazer a leitura no espectrofotômetro Victor $^{2} \mathrm{D}$ com filtro de corte em $340 \mathrm{~nm}$;

10) Lavar a placa com PBS - Tween $20(0,05 \%)$, colocando $200 \mu \mathrm{L}$ em cada poço, secar a placa; 
11) Fazer a leitura no espectrofotômetro Victor $^{2} D$ com filtro de corte em $340 \mathrm{~nm}$. E assim sucessivamente até a quarta lavagem.

A placa de 96 poços do experimento utilizando o marcador luminescente $\mathrm{Y}_{2^{-} \times} \mathrm{Eu}_{1,95}\left(\mathrm{MoO}_{4}\right)_{3} @$ Si-Glut-H11P8que sofreu interação Ac-Ag foi lida no contador Victor ${ }^{2}$ D (FIG.6.9) por fluorescência resolvida no tempo. Para o registro da contagem de fótons foi utilizado um protocolo para leitura de európio existente no instrumento, usando os filtros de $340 \mathrm{~nm}$ na excitação e $615 \mathrm{~nm}$ na emissão.

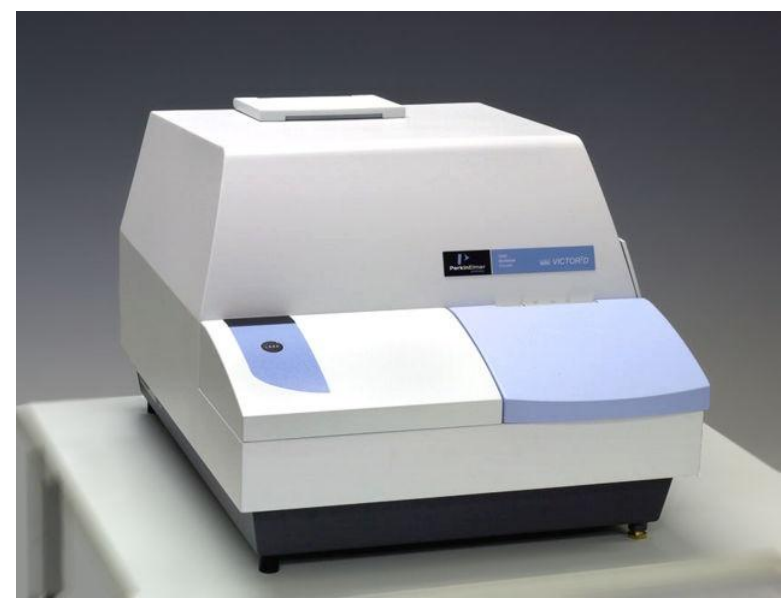

FIGURA 6.9. Fotografia do fluorímetro Victor ${ }^{2} D$ da Perkin Elmer.

A utilização do marcador biológico $\mathrm{Y}_{2^{-} x} \mathrm{Eu}_{1,95}\left(\mathrm{MoO}_{4}\right)_{3} @ S i$ preparado pelo método micro-ondas indica a ocorrência da interação partícula-anticorpoantígeno, devido a leitura de sinal luminescente oriundo do íon európio na placa. Assim, a partícula luminescente é capaz de atuar como marcador biológico.

As curvas que descrevem o perfil da variação da concentração dos anticorpos H11P8 e H2P8 estão representadas nas FIG.6.10 e 6.11. Elas mostram que o processo de conjugação Ac-Ag-Ac apresenta melhores resultados 
para as concentrações de $\mathrm{H} 2 \mathrm{P} 8$ e $\mathrm{H} 11 \mathrm{P} 8$ iguais a $0,016 \mu \mathrm{gmL}^{-1}$ e $65.10^{-4} \mathrm{mgmL}^{-1}$. A concentração das partículas de luminóloros para marcação foi estudada também em função da intensidade do sinal luminescente FIG.6.12. Observa-se que o perfil do gráfico é semelhante para as várias concentrações de partículas e que a concentração de $2 \mathrm{mgmL}^{-1}$ apresenta melhor resposta de intensidade no imunoensaio.

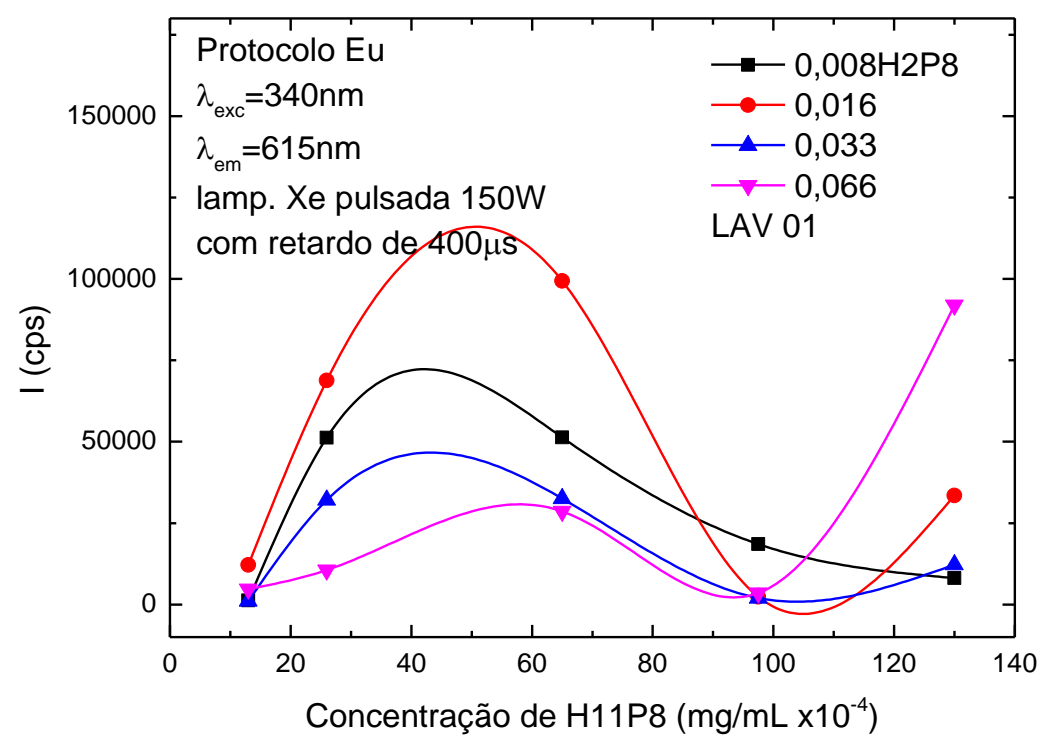

FIGURA 6.10. Perfil da variação da concentração de H11P8 (anticorpo de marcação) em função da densidade de contagens em várias concentrações de H2P8 (anticorpo de captura). 


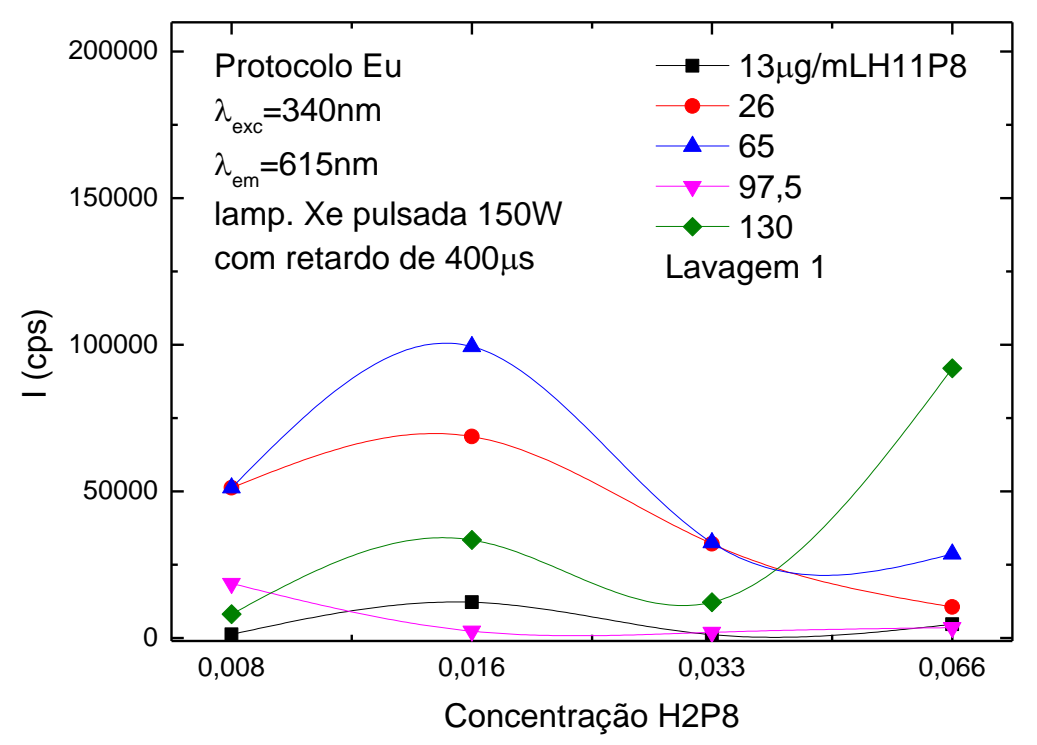

FIGURA 6.11. Perfil da variação da concentração de H2P8 (anticorpo de captura) em função da densidade de contagens, em várias concentrações de H11P8 (anticorpo de marcação).

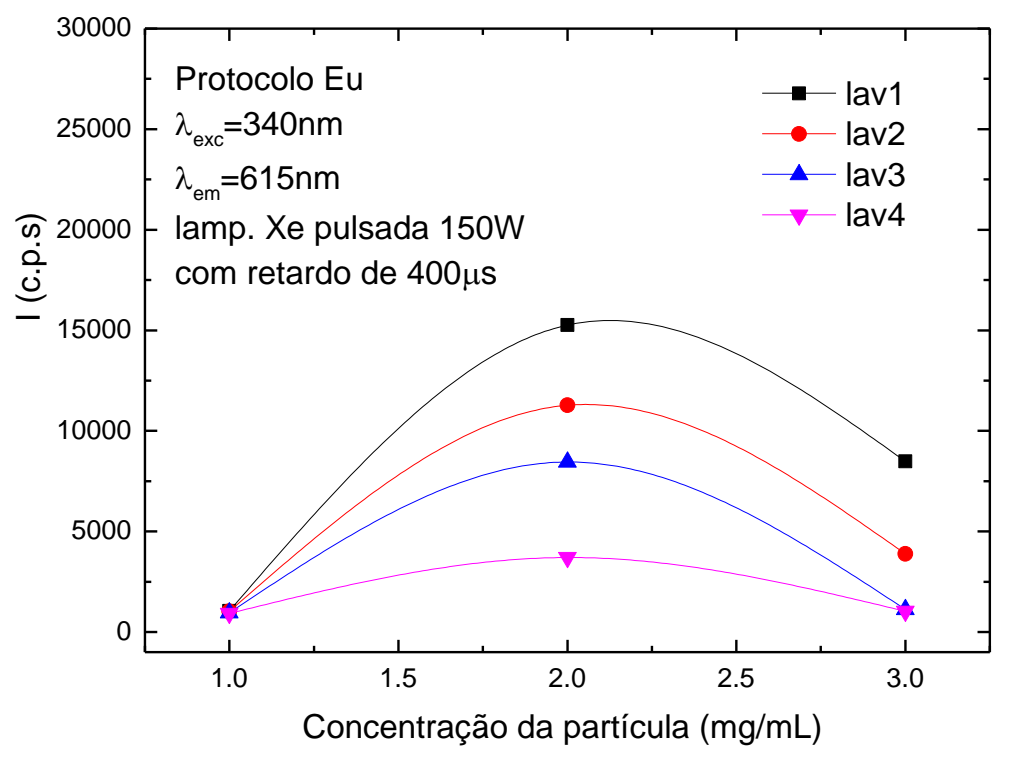

FIGURA 6.12. Intensidade do sinal luminescente com a concentração da partícula de $\mathrm{Eu}_{0,05}{ }^{3+} \mathrm{Y}_{0,95}\left(\mathrm{MoO}_{4}\right)_{3}$. 


\subsection{Teste de Hemocompatibilidade}

A hemocompatibilidade, ou seja, o teste de compatibilidade com o sangue é estudado quando há interação direta de um material ou dispositivo com células sanguíneas. O teste tem como objetivo identificar e quantificar possíveis alterações e/ou lise celular no sangue quando em contato com o material em questão ${ }^{9}$, no presente trabalho realiza-se o ensaio para diagnóstico do PSA em contato com o plasma do sangue de um doador.

Dentre os vários eventos que ocorrem na interação do material com as células sanguíneas, os mais importantes são a adesão plaquetária e a coagulação sanguínea. Quando as plaquetas são ativadas, ou seja, sofrem adesão celular à superfície do material, provoca a formação de trombos sanguíneos.Assim que o material em questão entra em contato com o sangue, o primeiro evento que ocorre é a adsorção de proteínas do sangue na superfície do material. Como consequência, a superfície do material é alterada e eventos subsequentes serão determinados por tal modificação.

Existem diversas formas de se realizar o teste de hemocompatibilidade, por contagem de plaquetas aderidas, hemólise e formação de trombos.O presente trabalho analisou a hemocompatibilidade das nanopartículas de molibdato de terras raras pela contagem das plaquetas aderidas. Nesse método, quanto menor o número de células aderidas na superfície, maior a hemocompatibilidade do material testado. ${ }^{10}$ Todos estes filmes foram submetidos ao contato com sangue de acordo com a norma ISO $10.993 .^{9}$

A partir das imagens de microscopia eletrônica de varredura, observase a quantidade de plaquetas aderidas ao filme de quitosana contendo as partículas de $\mathrm{Eu}_{2}\left(\mathrm{MoO}_{4}\right)_{3}$.

$\mathrm{Na}$ FIG.6.13, observa-se uma pequena agregação plaquetária na superfície do filme de quitosana contendo nanopartículas de $\mathrm{Eu}_{2}\left(\mathrm{MoO}_{4}\right)_{3}$ quando comparado ao filme de quitosana que não contêm nanopartículas. $O$ filme de 
Resultados e discussões - Sínteses e Caracterizações

quitosana sem nanopartículas atua como controle e com o objetivo de se comprovar que o filme é biocompatível e que não desempenha função trombogênica. $O$ filme sem nanopartículas apresenta adesão plaquetária, mas sem formações de trombos (grandes agregados plequetários). Já no filme que contém nanopartículas de $\mathrm{Eu}_{2}\left(\mathrm{MoO}_{4}\right)_{3}$ observa-se aglomerados que sugerem formações de trombos com tamanhos de até $160 \mu \mathrm{m}$.

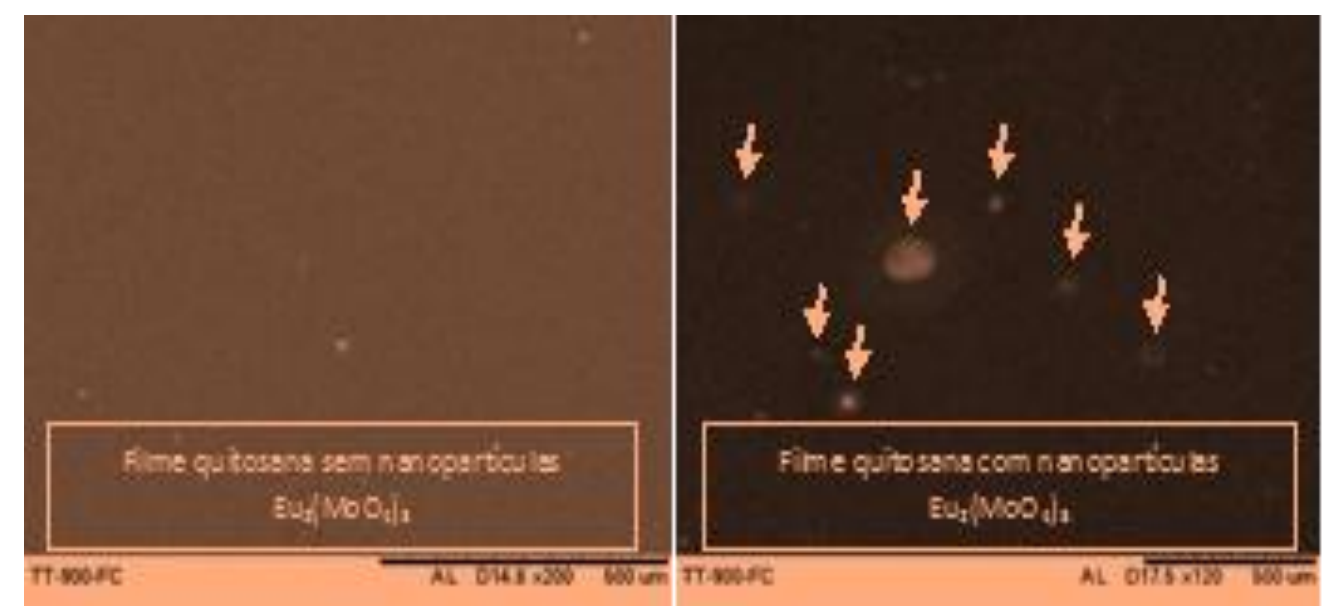

FIGURA 6.13. Micrografias dos filmes de quitosana contendo nanopartículas de

$$
\mathrm{Eu}_{2}\left(\mathrm{MoO}_{4}\right)_{3} \text {. }
$$




\section{REFERÊNCIAS BIBLIOGRÁFICAS}

1. TOMYAMA, C. Utilização de supermoléculas de b-dicetonatos de európio e samário como agentes de fluoroimunoensaiopara detecção do antígeno específico da próstata (PSA). 2007. Dissertação (Mestrado) - Instituto de Pesquisas Energéticas e Nucleares - Universidade de São Paulo.

2. KRAGH-HANSEN, U. Molecular aspects of ligand binding to serum albumin. Pharmacologycal Review, v.33, p.17-53, 1981.

3. YANG, Q.; LIANG, J.; HAN, H. Probing the interaction of magnetic iron oxide nanoparticles with bovine serum albumin by spectroscopic techniques. The Journal Physical Chemistry B, v.113, p.10454-10458, 2009.

4. YU, C. H.; AL-SAADI, A.; SHIH, S.-J.; QIU, L.; TAM, K. Y.; TSANG, S. C. Immobilization of BSA on silica-coated magnetic iron oxide nanoparticle. The Journal Physical Chemistry C, v.113, p.537-543, 2009.

5. RAN, D.; WU, X.; ZHENG, J.; YANG, J.; ZHOU, H.; ZHANG, M.; TANG, Y. Study on the interaction between florasulam and bovine serum albumin. Journal of Fluorescence, v.17, p.721-726, 2007.

6. MISRA, T. K.; HUANG, K.-P.;LIU, C.-Y. Bioconjugation of 32-macrocyclic polyammoniumcations-functionalized gold nanoparticles with BSA. Journal of Colloid and Interface Science, v.344, p.137-143, 2010.

7. ROE, S. Protein Purification Techniques, Oxford University Press, p.262, 2006.

8. LOURENÇO, A.V.S.;Partículas de sílica funcionalizadas contendo complexos de $T R^{3+}$ para aplicação como marcadores em ensaios biológicos. 2010. Tese (Doutorado). Instituto de Química. Universidade de São Paulo.

9. PEREIRA, K. R.Avaliação da biocompatibilidade "in vivo" e "in vitro" de ligas metálicas de titânio para aplicação odontológica. 2008 - Dissertação (Mestrado) - Universidade de São Paulo, São Paulo.

10. ALMEIDA, A. T.Obtenção de superfícies hemocompatíveis por meio da modificação de materiais poliméricos pela radiação ionizante. 2000 Dissertação (mestrado) - Universidade de São Paulo, São Paulo. 


\section{CONCLUSÃO}

O presente trabalho foi desenvolvido em três grandes partes principais: a síntese de nanopartículas de $\mathrm{TR}^{3+}\left(\mathrm{MoO}_{4}\right)_{3} \mathrm{TR}=\mathrm{Eu}, \mathrm{Sm}, \mathrm{Tb}, \mathrm{Gd}, \mathrm{Nd}$ e $\mathrm{Y}$, assim como o desenvolvimento de estudos para avaliar a influência de fatores como: a velocidade de dispersão no momento da precipitação, o tratamento térmico dos produtos finais e a influência de diferentes concentrações do dopante; na segunda parte deste trabalho estudou-se a funcionalização destas nanopartículas de TR3+ através de dois métodos: micro-ondas e Stöber; e como terceira parte estabeleceu-se protocolo para conjugação dessas partículas funcionalizadas com materiais biológicos, com o objetivo de diagnosticar o PSA.

Após as sínteses e caracterizações dos luminóforos padrões (Eu, Tb, Sm, $\mathrm{Gd}, \mathrm{Nd}, \mathrm{Y})$, escolheu-se o luminóforo de $\mathrm{Eu}_{2}\left(\mathrm{MoO}_{4}\right)_{3}$ e estudou-se a influência da velocidade do dispersor na precipitação onde foram avaliadas diferentes velocidades $(2.500,8.000,16.000$ e $24.000 \mathrm{rpm})$. Este estudo demonstrou que houve diminuição da intensidade da luminescência com o aumento da velocidade do dispersor na precipitação. $O$ infravermelho mostrou as bandas características da estrutura tetragonal do $\mathrm{MoO}_{4}{ }^{2-}, v 1$ e $v 3$. Os resultados de difração de raios-X mostraram que as nanopartículas são cristalinas, com formação das fases tetragonal e monoclínica onde não apresentam diferenças significativas na cristalinidade, conforme houve a variação da velocidade do dispersor na reação de precipitação. Já as imagens de MEV mostraram que há aparente diminuição da formação lamelar dos aglomerados conforme a velocidade de dispersão aumenta. Os estudos das propriedades luminescentes realizados em temperatura ambiente e do nitrogênio demonstrou a transição ${ }^{5} \mathrm{D}_{0} \rightarrow{ }^{7} \mathrm{~F}_{2}$, como sendo a mais proeminente, que está relacionada com o ambiente local do ín Eu3+ e que a velocidade de 16.000rpm apresentou maior intensidade luminescente. Os parâmetros de intensidade $\Omega_{\lambda}$, tem valores de mesma magnitude mostrando que 


\section{Conclusão}

a polarizabilidade e a simetria são importantes na obtenção destes parâmetros.A eficiência quântica é baixa quando comparados a complexos de európio mas é alta quando comparados a valores de outras matrizes inorgânicas $(\eta=24 \%$ para $2500 \mathrm{rpm})$.

Os resultados do estudo da influência das dopagens $\mathrm{Y}_{2-x}(\mathrm{MoO} 4)_{3} \% \mathrm{Eu}$ $(x=0,01, \quad 0,03,0,05$ e 0,1$)$ e $Y_{2-x}\left(M_{0} O_{4}\right)_{3} \% T b \quad(x=0,01,0,03,0,05$ e 0,1$)$ apresentaram um mesmo perfil dos $\mathrm{TR}_{2}\left(\mathrm{MoO}_{4}\right)_{3}$ nas matrizes anteriormente estudadas, tanto para a matriz dopada com térbio quanto a dopada com európio. $O$ padrão de difração de raios $X$ para as quatro dopagens foi o mesmo, apresentando estrutura isomorfa. $\mathrm{O}$ tamanho do cristalito diminuiu com o aumento da dopagem do material exceção feita para a dopagem $1 \%$ nos dois casos. As imagens de MEV para as matrizes dopadas com $\mathrm{Eu}^{3+}$ e $\mathrm{Tb}^{3+}$ mostram aglomerados de superfície homogênea, com distribuição de tamanho de grão heterogêneo e os estudos luminescentes demonstram aumento na intensidade de emissão conforme a porcentagem do dopante aumenta. Os valores dos parâmetros de intensidade, $\Omega_{\lambda}$, aumentaram demonstrando o efeito de supressão de luminescência com a concentração do dopante. Fato também notado na eficiência quântica que aumenta de um fator de $\sim 3$.

No estudo do tratamento térmico das nanopartículas $\mathrm{Eu}_{2}\left(\mathrm{MoO}_{4}\right)_{3}$, $\mathrm{Sm}_{2}\left(\mathrm{MoO}_{4}\right)_{3}$, $\mathrm{Tb}_{2}\left(\mathrm{MoO}_{4}\right)_{3}$ e $\mathrm{Nd}_{2}\left(\mathrm{MoO}_{4}\right)_{3}$, os dados de espectroscopia de infravermelho indicam uma mudança significativa das amostras de $700{ }^{\circ} \mathrm{C}$ e 1000 으 nas bandas na região do $\mathrm{H}-\mathrm{O}-\mathrm{H}(\sim 1630 \mathrm{~cm}-1)$ e O-H ( 3385) . Na temperatura de $500 \stackrel{\circ}{\circ} \mathrm{C}$ estes materiais têm suas estruturas cristalinas completamente modificadas. A partir de $700{ }^{\circ} \mathrm{C}$, há uma aparente mudança na posição dos planos cristalográficos e aumento da intensidade dos picos em todo o difratograma e uma visível modificação da estrutura pelo aumento na intensidade dos picos devido aos seus estreitamentos. As imagens de $\mathrm{MEV}$ de $\mathrm{Nd}_{2}\left(\mathrm{MoO}_{4}\right)_{3}$ e $\mathrm{Eu}_{2}\left(\mathrm{MoO}_{4}\right)_{3}$ corroboram com os dados de raio-X e mostram variação morfológica quando se compara os MEVs em todas as temperaturas, com diferenças significativas na morfologia das microestruturas conforme houve o aumento da temperatura no tratamento térmico. 


\section{Conclusão}

Fica bem claro a partir dos dados de luminescência que houve uma mudança de sítios de simetria com o tratamento térmico dos fósforos. Esta mudança é demonstrada pelos valores de parâmetros $\Omega_{\lambda}$ que vão de valores de $\Omega_{2}$ e $\Omega_{4}$ da mesma magnitude até valores de $\Omega_{2}$ maiores do que $\Omega_{4}$.

Para a obtenção das nanopartículas para conjugação biológica, fez-se o processo de funcionalização das partículas. Após o processo de aminofuncionalização das nanopartículas de $\mathrm{Eu}_{2}\left(\mathrm{MoO}_{4}\right)_{3}, \quad \mathrm{Y}\left(5 \% \mathrm{Eu}_{2}\left(\mathrm{MoO}_{4}\right)_{3}\right.$, $\mathrm{Tb}_{2}\left(\mathrm{MoO}_{4}\right)_{3}, \mathrm{Sm}_{2}\left(\mathrm{MoO}_{4}\right)_{3}, \mathrm{Nd}_{2}\left(\mathrm{MoO}_{4}\right)_{3}$ pelos métodos de microondas e Stöber, comprovou-se a eficácia do processo de funcionalização pelos dados de absorção na região do infravermelho, com o aparecimento das bandas relativas aos estiramentos $v \mathrm{Si}-\mathrm{O}, v \mathrm{Si}-\mathrm{O}-\mathrm{Si}$ e $v \mathrm{~N}-\mathrm{H}$ da capa de sílica e no raio-X com a presença do halo de amorficidade da sílica nos difratogramas dos matérias funcionalizados. As imagens MEV e TEM apresentaram diferenças na superfície entre os materiais aminofuncionalizados e os compostos precursores, demonstrando que ocorreu a incorporação da rede de sílica nestes compostos. Estes dados corroboram com os dados de quantificações de aminas primárias disponíveis em suas superfícies. Os estudos de luminescência demonstraram que os luminóforos funcionalizados pelos dois métodos tem emissão de luminescência menos intensa quando comparados aos luminóforos não funcionalizados, esse fato pode ser explicado devido a perda de luminescência por dissipação da luminescência na matriz de silício e por diminuição da concentração do fluoróforo na matriz. Este fato também corrobora com os dados obtidos dos parâmetros de intensidade, $\Omega_{\lambda}$, antes e após a funcionalização.

A funcionalização dos luminóforos $\mathrm{Eu}_{2}\left(\mathrm{MoO}_{4}\right)_{3}, \quad \mathrm{Y}\left(5 \% \mathrm{Eu}_{2}\left(\mathrm{MoO}_{4}\right)_{3}\right.$, $\mathrm{Tb}_{2}\left(\mathrm{MoO}_{4}\right)_{3}, \mathrm{Sm}_{2}\left(\mathrm{MoO}_{4}\right)_{3}, \mathrm{Nd}_{2}\left(\mathrm{MoO}_{4}\right)_{3}$ foi efetiva para os dois métodos utilizados (micro-ondas e Stöber). Embora, a análise de determinação de amina tenha comprovado que o método de micro-ondas apresenta maior quantidade de $\mathrm{NH}_{2}$ por mg de luminóforo do que o método de Stöber, não se descarta a possibilidade do uso deste método. 
A conjugação dos marcadores luminescentes com a parte biológica foi efetiva onde pode-se testar e demonstrar a capacidade de interação de dois tipos de material biológico para PSA e BSA.

Os luminóforos incorporados com a rede de sílica aminofuncionalizada e conjugados a parte biológica foram aplicados como marcadores luminescentes em sistema biológico para diagnótico do PSA.

Foi desenvolvido e testado um protocolo utilizando estes marcadores luminescentes à base de terras raras para a detecção e quantificação do antígeno específico da próstata (PSA), responsável pelo desenvolvimento câncer da próstata.

De forma geral pode-se concluir que devido às suas propriedades luminescentes, o luminóforos de molibdatos de terras raras podem ser aplicados em várias áreas, como marcadores biológicos. $O$ controle de diversos parâmetros de síntese é muito importante para o produto final, e pode-se observar com os resultados apresentados nesse trabalho que fatores como: o controle da velocidade de dispersão na precipitação; a concentração de dopagem, o aumento da temperatura após a síntese (tratamento térmico) e os diferentes métodos de funcionalização apresentam ter um papel importante na eficiência desses materiais luminescentes como marcador. 


\section{PERSPECTIVAS FUTURAS}

- Estudar mais detalhadamente a aplicação dos fósforos desenvolvidos neste trabalho como marcadores ópticos para aplicações diversas, inclusive marcadores luminescentes biológicos

- Preparar novos fósforos com novos íons dopantes e co-dopantes em diferentes proporções e outras matrizes de molibdatos para estudar a emissão luminescente destes materiais.

- Estudar a dopagem simultânea de $\mathrm{Eu}^{3+} \mathrm{ou} \mathrm{Tb}^{3+} \mathrm{e} \mathrm{Nd}^{3+}$ em diferentes proporções a fim de preparar fósforos multicolor para atuarem como marcadores na região do UV-Vis e Infravermelho.

- Realizar o estudo dos fósforos calcinados em outras temperaturas para estudar os estados de oxidação com XANES dos íons TR e fazer os cálculos de EXAFS Estrutura fina de absorção de raios $\mathrm{X}$ estendida (Extended $X$-ray Absorption Fine Structure).

- Utilizar estes materiais para detecção por imagem e marcação de células.

- A partir das propriedades químicas e dos estudos ópticos dos materiais aminofuncionalizados contendo complexos luminescentes, pode-se sugerir as seguintes etapas para trabalhos futuros:

- Investigar a interação dos complexos com a rede de sílica, obtidas pelo método de preparação Stöber. Além de variar as relações $\mathrm{TEOS} / \mathrm{NH}_{3}$, para a obtenção de partículas menores e esféricas.

- Efetuar um estudo da interação partícula-espécie biológica em meio aquoso, registrando os espectros de emissão e excitação. Este estudo é de particular importância, haja vista que estes materiais apresentaram-se como candidatos para aplicações em ensaios clínicos.

- Incrementar os estudos de interação dos marcadores luminescentes com as espécies biológicas. Espera-se com isso a obtenção de dados da relação espécie biológica por massa de partícula. 